MARIO ALVES DOS SANTOS JUNIOR

\title{
AVALIAÇÃO DE DESEMPENHO DE CÂMARAS EXCITADAS VIA LINHAS DE TRANSMISSÃO APLICÁVEIS À COMPATIBILIDADE ELETROMAGNÉTICA
}

Tese apresentada à Escola Politécnica da Universidade de São Paulo para obtenção do título de Doutor em Engenharia.

São Paulo 2009 
MARIO ALVES DOS SANTOS JUNIOR

\title{
AVALIAÇÃO DE DESEMPENHO DE CÂMARAS EXCITADAS VIA LINHAS DE TRANSMISSÃO APLICÁVEIS À COMPATIBILIDADE ELETROMAGNÉTICA
}

\author{
Tese apresentada à Escola Politécnica da \\ Universidade de São Paulo para obtenção \\ do título de Doutor em Engenharia. \\ Área de Concentração: \\ Sistemas de Potência \\ Orientador: \\ Prof. Dr. Carlos Antonio França Sartori
}

São Paulo

2009 
Este exemplar foi revisado e alterado em relação à versão original, sob responsabilidade única do autor e com a anuência de seu orientador.

São Paulo, de dezembro de 2009.

Assinatura do autor

Assinatura do orientador

FICHA CATALOGRÁFICA

Santos Junior, Mario Alves dos

Avaliação de desempenho de câmaras excitadas via linhas de transmissão aplicáveis à compatibilidade eletromagnética / M.A. dos Santos Junior. -- ed.rev. -- São Paulo, 2009.

$196 \mathrm{p}$.

Tese (Doutorado) - Escola Politécnica da Universidade de São Paulo. Departamento de Engenharia de Energia e Automação Elétricas.

1. Compatibilidade eletromagnética 2. Instrumentação e medidas elétricas 3. Eletromagnetismo I. Universidade de São Paulo. Escola Politécnica. Departamento de Engenharia de Energia e Automação Elétricas II. t. 
À minha esposa Aparecida e minhas filhas Gabriela e Mariana 


\section{AGRADECIMENTOS}

Agradeço ao CTMSP/MB e aqueles que apoiaram incondicionalmente este trabalho CA(EN) Bezerril, CA(EN) Artur Campos, CMG(EN) Luciano, CMG(EN) F. Marques, CMG(EN-Rrm) Luis Antonio, e especialmente, minha orientadora técnica $\mathrm{CF}(\mathrm{EN})$ Ana Maria.

Ainda agradeço ao LMAG/ EPUSP na pessoa do Coordenador Prof. Dr. J. R. Cardoso, que me acolheu neste Laboratório, aos professores: Prof. Dr. S. Nabeta, Profa. Dra. Viviane e aos companheiros de todos os dias Dr. M. Salles, L. Blattner e Dr. Cassiano. Em especial ao Prof. Dr. L. Lebensztajn pelas discussões e trabalho conjunto.

Je remercie au Laboratoire Ampère de l'Ecole Centrale de Lyon, dans la personne de son Directeur Dr. L. Nicolas, et aussi les copains de tous les jours Dr. R. Perrussel, Dr. D. Voyer, Dr. C. Vollaire, pour m'avoirent reçu tellement bien à Lyon et me avoirent donné son temps et aussi des extraordinaires coups de main.

Agradeço, com o meu profundo reconhecimento de suas qualidades humanas e técnicas, ao meu orientador na EPUSP, Prof. Dr. Carlos A. F. Sartori, et a mon directeur de recherche à l'EC-Lyon Dr. Laurent Krähenbühl.

Aos grandes colaboradores deste trabalho Prof. Dr. D. Weinzerl, Prof. Dr. S. Avila e Prof. Dr. M. Perotoni, sem a ajuda dos quais o progresso seria muito mais lento e penoso, têm minha gratidão profunda.

Aos especialistas dos laboratórios envolvidos nas medidas e cuja experiência ajudou a fechar com chave de ouro este trabalho. Do IEE/USP: Dr. K. Soleto e Eng. Guido; do LM/USP: Prof. Dr. J. Kléber; e do INPE/LIT: Eng. Leandro.

Ao Prof. J. Perini (in memoriam), que dispendeu seu valioso tempo para nos passar este legado de trabalho e que infelizmente nos deixou tão inesperadamente.

Agradeço ainda à FAPESP e à CAPES/COFECUB pelo aporte financeiro parcial das pesquisas. 


\section{RESUMO}

Este trabalho propõe uma configuração de câmaras excitadas por linhas de transmissão, considerada como potencial solução para as restrições das câmaras reverberantes atuais. Dentre estas restrições menciona-se, por exemplo, as relativas à operação das câmaras em baixas frequências, cujas dimensões poderão representar uma restrição física à sua implementação em ambientes de teste. Outras características físicas podem ser consideradas também restritivas, ao se considerar o volume útil de trabalho e o modo de excitação das câmaras canônicas.

Visando satisfazer os índices de mérito aplicáveis, as diversas configurações propostas são avaliadas, onde, além dos arranjos das linhas de transmissão, também são considerados os detalhes relativos às variações da excitação e da carga via controle eletrônico.

A metodologia de análise de desempenho da câmara proposta utiliza, basicamente, métodos analíticos, numéricos e avaliações experimentais. A aplicação de algoritmos e métodos de otimização recomendados pela literatura atual e alguns procedimentos desenvolvidos e adaptados pelos autores, foram utilizados na busca de configurações que melhor satisfaçam os índices de mérito adotados.

Diversos resultados, obtidos através de simulações numéricas e de avaliações experimentais realizadas em um protótipo são apresentados e comparados, visando uma análise das potencialidades e da aplicabilidade deste tipo de câmara às necessidades dos ensaios de compatibilidade eletromagnética de equipamentos e sistemas elétricos e eletrônicos. 


\begin{abstract}
This Thesis presents the proposition of a Transmission Line Excited Chamber configuration. This configuration is considered to be a potential solution for the constraints of reverberation chambers of nowadays. Among this constraints, e.g. the ones related to chamber operation at some $\mathrm{MHz}$, is a physical restriction to implement in tests environments. Moreover the work volume and the canonical chamber excitation ways are also considered restrictions.

In order to satisfy the chamber evaluation indexes of merit applicability, several transmission line sets are evaluated, including the details concerned to electronic exciting variation and load variation.

The chamber performance analysis methodology is proposed in this work is based on analytical and numerical methods, and also experimental evaluations. Not only optimization algorithms and methods recommended by literature were used in order to reach the adopted indexes of merit but also procedures developed and adapted by the authors.

To analyze the chamber capacity to reach all the electromagnetic compatibility test requirements applied to equipments and electric and electronic systems, several tests, were performed over one Transmission Line Excited Chamber prototype. The results obtained by numerical simulations and experimental evaluations are presented and compared.
\end{abstract}




\section{LISTA DE ILUSTRAÇÕES}

FIGURA 1 - CAVIDADE RETANGULAR, COM PERFIL DAS COMPONENTES DE CAMPO EXE EY, ESTACIONÁRIAS EM UMA CAVIDADE VAZIA, SEM FONTES DE CORRENTE, MODO TE ${ }_{110}$.......

FIGURA 2 - MODELO DE CIRCUITO EQUIVALENTE PARA LINHAS DE TRANSMISSÃO CURTA SEM PERDAS...........31

FIGURA 3 - CIRCUITO EQUIVALENTE PARA CÁLCULO DO COEFICIENTE DE REFLEXÃO....................................33

FIGURA 4 - LINHA DE TRANSMISSÃO COM TRÊS CONDUTORES, EXCITAÇÃO INDEPENDENTE DOS CONDUTORES CENTRAIS E CONDUTOR EXTERNO COMO REFERÊNCIA.

Figura 5 - CAMPOS EX, Ey E EZ, COM AS RESPECTIVAS PROJEÇÕES NOS EIXOS REAL E IMAGINÁRIO E O CAMPO RESULTANTE $\mathrm{E}_{\text {TOT }}$ 38

FIGURA 6 - REPRESENTAÇÃO ESQUEMÁTICA DE REDE COM N PORTAS, UTILIZADA NA DEFINIÇÃO DE [S]........39

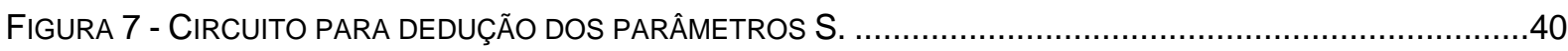

FIGURA 8 - MÉTODOS DE OTIMIZAÇÃO

FIGURA 9 - ILUSTRAÇÃO DO COMPROMETIMENTO DE DUAS FUNÇÕES OBJETIVO E FRONTEIRA PARETO PARA MAXIMIZAÇÃO DE AMBOS.

FIGURA 10 - FLUXOGRAMA METODOLÓGICO DAS FERRAMENTAS DE OTIMIZAÇÃO DE ALGORITMOS GENÉTICOS.

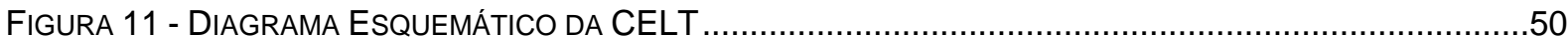

FIGURA 12 - CONECTOR TIPO N - (A) IMPLEMENTADO NA SIMULAÇÃO (B) DADOS DE CATÁLOGO. .................53

FIGURA 13 - DiagRAMA ESQUEMÁtICO DA CELT - PONTOS DE MEDIÇÃO, NO PLANO CORRESPONDENTE A ALTURA $\mathrm{H}$. .56

FIGURA 14 - CONFIGURAÇÃO DE MEDIDAS DE PARÂMETROS S NA CELT, COM INDICAÇÃO DAS PORTAS MEDIDAS.

FIGURA 15 - DESENHO ESQUEMÁTICO DA CELT COM 4 LINHAS DE TRANSMISSÃO E LOCAIS DE AVALIAÇÃO Área de Trabalho e Volume de Trabalho.

FIGURA 16 - DEFINIÇÃO DA ELIPSÓIDE INTERNA AO PARALELEPÍPEDO (A) ELIPSÓIDE (B) PONTOS QUE DEFINEM A ELIPSÓIDE 64

FIGURA 17 - MÚLTIPLOS PARETOS, CONSIDERANDO VÁRIAS POSIÇÕES DOS CONDUTORES.........................66

FIGURA 18 - FLUXOGRAMA DE APLICAÇÃO DO AGMO NA OTIMIZAÇÃO DA CELT ........................................70

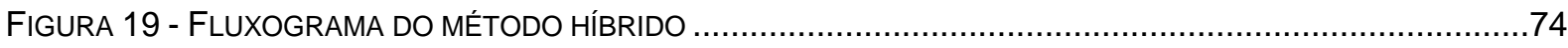

FIGURA 20 - PROTÓTIPO DE CELT COM LINHAS DE TRANSMISSÃO LMAG/CTMSP...................................76

FIGURA 21 - FREQUÊNCIAS DE RESSONÂNCIA (RESULTADO ANALÍTICO) PARA O PROTÓTIPO LMAG/CTMSP,

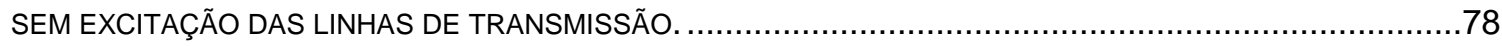

FIGURA 22 - VISTA SUPERIOR MODO TM 405 - ANALÍTICO PARA O PROTÓTIPO LMAG/CTMSP, SEM A INSERÇÃO DAS LINHAS DE TRANSMISSÃO. 
FIGURA 23 - EFEITO DA CARGA PURAMENTE REAL (RESISTIVA) NA ONDA RESULTANTE PARA IMPEDÂNCIA CARACTERÍSTICA $=270 \Omega$ E CARGAS $0 \Omega, 25 \Omega, 50 \Omega, 100 \Omega, 200 \Omega, 270 \Omega, 500 \Omega, 1 \mathrm{~K} \Omega, 10 \mathrm{~K} \Omega-50$ $\mathrm{MHz}$

FIGURA 24 - EFEITO DA CARGA IMAGINÁRIA SOBRE A DISTRIBUIÇÃO ESPACIAL DE CAMPO E GERADA POR UMA LINHA DE TRANSMISSÃO.

FIGURA 25 - EFEITO DA CARGA COMPLEXA SOBRE A DISTRIBUIÇÃO ESPACIAL DE TENSÃO GERADO SOBRE UMA LINHA DE TRANSMISSÃO COM IMPEDÂNCIA CARACTERÍSTICA $270 \Omega$. VALORES DE ONDA RESULTANTES, PARA EXCITAÇÃO COM MÓDULO 1 E VÁRIAS CARGAS COMPLEXAS.

FIGURA 26 - CAVIDADE PREENCHIDA COM DIELÉTRICO PERFEITO (VÁCUO) EXCITADA COM ANTENA PEQUENA NA FREQUÊNCIA $80 \mathrm{MHZ}$ (A) EX, (B) EY, (C) EZ.

FIGURA 27 - CAVIDADE PREENCHIDA COM DIELÉTRICO PERFEITO (VÁCUO) EXCITADA COM ANTENA PEQUENA

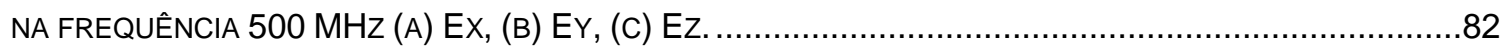

FIGURA 28 - VALOR ABSOLUTO PARA CAMPO E, PLANO 0,3 M, FASE 210 GRAUS, $100 \mathrm{MHZ}$, PEC...............83

FIGURA 29 - VALOR ABSOLUTO PARA CAMPO E, PLANO 0,3 M, FASE 210 GRAUS, 500 MHZ, PEC................83

FIGURA 30 -POSIÇÃO DOS SENSORES VIRTUAIS $X$, Y E Z NO CENTRO DA CÂMARA $(0,3 \mathrm{M}, 0,3 \mathrm{M}, 0,6 \mathrm{M}) \ldots \ldots \ldots . . .85$

FIGURA 31 - CAMPO E NO CENTRO DA CELT, MODELO COM PORTA DISCRETA E PORTA GUIA DE ONDA (A)COMPONENTES EX, EY E EZ (B) DIFERENÇA DE VALORES ENTRE OS MODELOS.

FIGURA 32 - (A) CAMPO EABS SIMULADO SOBRE LINHAS PARALELAS AO EIXO X, NO PLANO Y=0,3M, MODELOS PAREDES COM PERDAS E SEM PERDAS. (B) VALORES DA DIFERENÇA ENTRE OS MODELOS, PONTO A PONTO.

FIGURA 33 - CAMPOS EABS RESULTANTES DA EXCITAÇÃO DA LT1 (VERDE), LT2 (VERMELHO) SEM DEFASAGEM. CAMPO E (LT1+LT2) COM DIVERSAS DEFASAGENS DA LT2 - $0^{\circ} \sim 360^{\circ}$ PASSO $20^{\circ}$ (AZUL), NA CELT PARA UMA CARGA $50 \Omega$.

FIGURA 34 - EFEITO NA FREQUÊNCIA QUANDO SE VARIA A DEFASAGEM ENTRE A EXCITAÇÃO DOS CONDUTORES NA ENTRADA DA CELT - CARGA $50 \Omega$, CENTRO DA CÂMARA PROTÓTIPO.(A) ABS(EX); (B)ABS(EY)

FIGURA 35 - VALORES de CAMPO E ABS EM Y = 0,3 M, $100 \mathrm{MHZ}$, COM APLICAÇÃO DE DEFASAGENS NA EXCITAÇÃO (0 360). (A) POSIÇÃO DOS CONDUTORES X1 $=0,1 \mathrm{M}, \mathrm{Y} 1=0,45 \mathrm{M}, \mathrm{X} 2=0,5 \mathrm{M}, \mathrm{Y} 2=0,5 \mathrm{M}$;

(B) PERFIL DE CAMPO E.

FiguRA 36 - VALORES DE CAMPO E ABS EM Y = 0,3 M, $100 \mathrm{MHz}$, COM APLICAÇÃO DE DEFASAGENS A EXCITAÇÃO (0 360). (A) POSIÇÃO DOS CONDUTORES X1 = 0,3 M, Y1 = 0,45 M, X2 = 0,5 M, Y2=0,5 M; (B) PERFIL DE CAMPO E.

FiguRA 37 - VALORES dE CAMPO E ABS EM Y =0,3 M, $100 \mathrm{MHz}$, COM APLICAÇÃO DE DEFASAGENS A EXCITAÇÃO (0 360) (A) POSIÇÃO DOS CONDUTORES X1 =0,1 M, Y1 =0,1 M, X2 = 0,5 M, Y2 =0,5 M; (B) PERFIL DE CAMPO EABS.

FIGURA 38 - VALORES DE CAMPO E ABS EM Y = 0,3 M, $100 \mathrm{MHZ}$, COM APLICAÇÃO DE DEFASAGENS A EXCITAÇÃO (0 360). (A) POSIÇÃO DOS CONDUTORES X1 $=0,5 \mathrm{M}, \mathrm{Y} 1=0,1 \mathrm{M}, \mathrm{X} 2=0,5 \mathrm{M}, \mathrm{Y} 2=0,5 \mathrm{M}$ (B) PERFIL DE CAMPO EABS. 
FIGURA 39 - ARRANJO DA CELT PARA ANÁLISE DE EFEITOS DE CARGA. .93

FIGURA 40 - PERFIS DE CAMPO EABS NO PLANO Y=0,3M, FREQUÊNCIA IGUAL A $100 \mathrm{MHZ}$, (A) CARGA $50 \Omega$

(B) CARGA $255 \Omega$ (C) $500 \Omega$. 94

FIGURA 41 - COMPONENTES DO CAMPO E, RESULTANTES DA CELT COM DUAS LINHAS DE TRANSMISSÃO, COM CARGAS REAIS (A) EX; (B) EY......

FIGURA 42 - COMPONENTES DO CAMPO E, RESULTANTES DA CELT COM DUAS LINHAS DE TRANSMISSÃO, COM CARGAS INDUTIVAS (A) EX; (B) EY.

FIGURA 43 - CAMPO EXY MÉDIO NA ÁREA DE TRABALHO DEVIDO À EXCITAÇÃO DE SOMENTE UMA LINHA DE TRANSMISSÃO.

FIGURA 44 - CAMPO EXY MÉDIO NA ÁREA DE TRABALHO DEVIDO À EXCITAÇÃO DE DUAS LINHAS DE TRANSMISSÃO.

FIGURA 45 - CAMPOS E MÉDIOS NA ÁREA DE TRABALHO DEVIDO À EXCITAÇÃO DE DUAS LINHAS DE TRANSMISSÃO EM POSIÇÕES OPOSTAS E EXCITAÇÃO FIXA (I1=12). 100

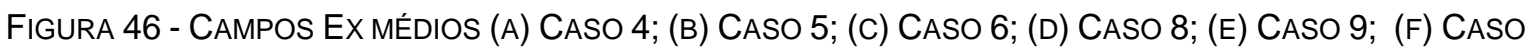
10.

FIGURA 47 - CAMPOS E MÉDIOS NA ÁREA DE TRABALHO PARA ARRANJO DE 4 LINHAS DE TRANSMISSÃO, ....103 FIGURA 48 - . (A) VARIAÇÃO DE AMPLITUDE DE EXCITAÇÃO - ALEATÓRIA UNIFORME DURANTE 50\% DO TEMPO (B) DEFASAGEM DA EXCITAÇÃO UNIFORMEMENTE VARIADA. 103

FIGURA 49 - CAMPOS E MEDIDOS COM EXCITAÇÃO INDIVIDUAL 5 W E CARGAS $50 \Omega$ E CIRCUITO-ABERTO (A) LT1 E (B) LT2. 104

FIGURA 50 - COMPONENTES DE CAMPO E GERADOS PELA EXCITAÇÃO DA LINHA DE TRANSMISSÃO 1, NO CENTRO dA CELT. VAlores MEdidos E Simulados. (A) CARGa $50 \Omega$ (B) CARGa ABertA. 105

FIGURA 51 - COMPONENTES DE CAMPO E GERADOS PELA EXCITAÇÃO DA LINHA DE TRANSMISSÃO 2, NO CENTRO dA CELT. VALORES MEdidos E Simulados. (A) CARGA $50 \Omega$ (B) CARGA ABERTA. 105

FIGURA 52 - CAMPOS E (DBV/M) PARAMETRIZADOS PELOS VALORES MÁXIMOS, GERADOS PELA EXCITAÇÃO DA LINHA DE TRANSMISSÃO 1. VALORES MEDIDOS E SIMULAdOS. (A) CARGA $50 \Omega$ (B) CARGA ABERTA....106 FIGURA 53 - CAMPOS E (DBV/M) PARAMETRIZADOS PELOS MÁXIMOS, GERADOS PELA EXCITAÇÃO DA LINHA DE TRANSMISSÃO 2 . VALORES MEDIDOS E SIMULADOS. (A) CARGA $50 \Omega$ (B) CARGA ABERTA. 106

Figura 54 - CAMPo E MEdido E Simulado NA CELT COM CARGA $50 \Omega$ (A) P1 $(0,3 ; 0,3 ; 0,6)$ M; (B) P2 $(0,4 ; 0,3 ; 0,8)$ M; (C) P3 $(0,2 ; 0,3 ; 0,8)$ M; (D) P4 $(0,2 ; 0,3 ; 0,4)$ M; E (E) P5 $(0,4 ; 0,3 ; 0,4)$ M. 108

Figura 55 - CAmpo E VAloRes medidos e simulados. CARGa AberTA (A) PONTO $1(0,3 ; 0,3 ; 0,6)$ M; (B) PONTO $2(0,4 ; 0,3 ; 0,8)$ M; (C) PONTO $3(0,2 ; 0,3 ; 0,8)$ M; (D) PONTO $4(0,2 ; 0,3 ; 0,4)$ M; E (E) PONTO 5 $(0,4 ; 0,3 ; 0,4) \mathrm{M}$. 110

FIGURA 56 - MEDIDAS dE CAMPO ABS(EX), EM VÁRIAS POSIÇÕES DA CÂMARA, E VÁRIAS FREQUÊNCIAS COM CARGA ABERTA.

FIGURA 57 -MEDIDAS DE CAMPO ABS(EY), EM VÁRIAS POSIÇÕES DA CÂMARA E VÁRIAS FREQUÊNCIAS COM CARGA ABERTA 
FIGURA 58 - MEDIDAS DE CAMPO E RESULTANTE [ABS(EXYZ]) EM VÁRIAS POSIÇÕES DA CÂMARA E VÁRIAS FREQUÊNCIAS COM CARGA ABERTA.

FIGURA 59 - CARACTERIZAÇÃO DA CÂMARA - RESULTADOS DIRETO DO VNA - LINHA DE TRANSMISSÃO 1 COM CARGA $50 \Omega$.(A) CARTA DE SMith (B)TOE (C)AMPLITUde S11 dB (D) ÂNGULO DE S11 EM GRAuS. .114 FIGURA 60 - CARACTERIZAÇÃO DA CÂMARA - RESULTADOS DIRETO DO VNA - LINHA DE TRANSMISSÃO 2 COM CARGa $50 \Omega$.(A) CARTA E SMITH (B) TOE (C) AMPLITUdE S22 dB (D) ÂNGULO DE S22 EM GRAuS...115 FIGURA 61 - CARACTERIZAÇÃO dA CÂMARA COM CARGA $50 \Omega$. COMPARAÇÃO DOS VALORES EM DB, MEDIDOS E SIMULADOS.(A) S11; (B) S13; (C)S12. 116

FIGURA 62 - LINHA DE TRANSMISSÃO 1 COM CARGA INFINITA (A) CARTA E SMITH (B)TOE (C)AMPLITUDE S11 DB (D) ÂNGULO DE S11 EM GRAUS. 117

FIGURA 63 - PARÂMETROS S11 E S22 DA CELT COM CARGA ABERTA. 118

FIGURA 64 - LT1 COM CARGA CURTO-CIRCUITO (DO KIT DE CALIBRAÇÃO DO VNA)(A) CARTA DE SMITH (B)TOE (C)AMPLITUdE S11 DB (D) ÂNGULO DE S11 EM GRAUS. .119

FIGURA 65 - S11 E S22 DA CELT COM CARGA EM CURTO-CIRCUITO.................................................120

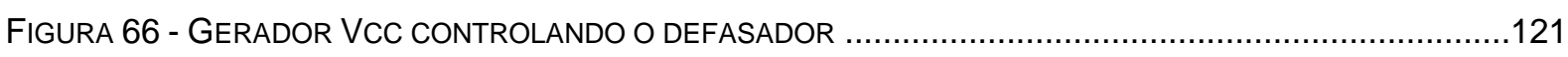

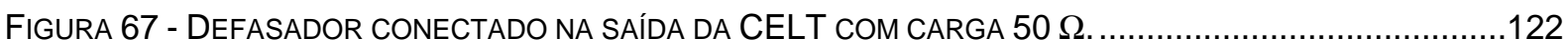

FIGURA 68 - CARACTERIZAÇÃO DA CÂMARA COM DEFASADOR SO-01 NA SAÍDA E CARGA $50 \Omega(10-20 \mathrm{MHZ})$

(A) CARTA DE SMith (B) S11 MódULO E ANGULO 123

FIGURA 69 - CARACTERIZAÇÃO DA CÂMARA COM DEFASADOR SO-02 NA SAÍDA E CARGA $50 \Omega$ (20 MHZ - 40

MHZ) (A) CARTA DE SMITH (B) S11 MÓDULO E ANGULO. 124

FIGURA 70 - CARACTERIZAÇÃO DA CÂMARA COM DEFASADOR SO-05 NA SAÍDA E CARGA $50 \Omega$ (100 MHZ -

$190 \mathrm{MHZ}$ ) (A) CARTA DE SMITH (B) S11 MÓDULO E ANGULO. 125

FIGURA 71 - CARACTERIZAÇÃO DA CÂMARA COM DEFASADOR SO-06 NA SAÍDA E CARGA $50 \Omega$ (150 MHz -

$250 \mathrm{MHz}$ ) (A) CARTA DE SMITH (B) S11 Módulo E ANGulo. 126

FIGURA 72 - CARACTERIZAÇÃO DA CÂMARA CARGA DEFASADOR 1 COM SAÍDA ABERTA (10 MHz - $20 \mathrm{MHz}$ ) (A)

CARTA DE SMITH (B) S11 MÓdULO E ANGULO. 128

FIGURA 73 - CARACTERIZAÇÃO DA CÂMARA CARGA DEFASADOR 2 COM SAÍDA ABERTA (20 MHz - 40 MHz) (A)

CARTA DE SMITH (B) S11 MÓdULO E ANGULO. 129

FIGURA 74 - CARACTERIZAÇÃo DA CÂMARA CARGA DEFASADOR 5 COM SAÍDA ABERTA (100 MHz - $190 \mathrm{MHz}$ )

(A) CARTA DE SMITH (B) Z11 REAL VERSus IMAGinÁRIO (C) S11 Módulo E ANGULO. 130

FIGURA 75 - CARACTERIZAÇÃO DA CÂMARA CARGA DEFASADOR 6 COM SAÍDA ABERTA (150 MHz - 250 MHz)

(A) CARTA DE SMITH (B) S11. 131

FIGURA 76 - CONFIGURAÇÃO DA CÂMARA COM TRÊS CONDUTORES. 133

FIGURA 77 - CELT COM POSIÇÃO DOS EIXOS DO ELIPSÓIDE QUE ATENDE ÀS CONDIÇÕES MONO-OBJETIVO.

FIGURA 78 - CARACTERIZAÇÃo dA CÂMARA ATRAVÉS DA FRONTEIRA PARETO.......................................136

FIGURA 79 - COMPROMISSO ENTRE VOLUME DE TRABALHO E CAMPO E. 137 
FIGURA 80 - DIAGRAMA GENÉRICO DA CELT COM POSIÇÕES PERMITIDAS PARA AS LINHAS DE TRANSMISSÃO.

FIGURA 81 - OtIMIZAÇÃO HÍBRIDA dA CÂMARA "PADRÃO"(A) FRONTEIRAS PARETO (B )ARRANJO dE

CONDUTORES COM MELHOR ÍNDICE LA 140

FIGURA 82 - OTIMIZAÇÃO HÍBRIDA DA CELT PROTÓTIPO (A) FRONTEIRAS PARETO (B) MELHOR CONFIGURAÇÃO DE LINHAS DE TRANSMISSÃO.

FIGURA 83 - ASPECTOS CONSTRUTIVOS DO PROTÓTIPO 165

FIGURA 84 - (A) CONECTOR DE FIBRA ÓTICA; (B) CABO DE CONEXÃO TIPO N -MACHO/MACHO; (C)

ADAPTADOR TIPO N (3 X FÊMEA).

FIGURA 85 - Diagrama ESQUEMÁtICO: MONTAGEM DE TESTE LIT/INPE (LISTA DE MATERIAL - TABELA 7).

FIGURA 86 - Foto COM EQUIPAMENTOS DE TESTE INPE/LIT - (A)GERADOR, AMPLIFICADOR, MEDIDOR DE

POTÊNCIA, COMPUTADOR. (B)GERADOR R\&S (2

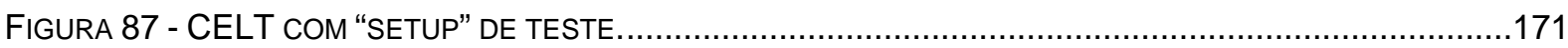

FIGURA 88 - SENSOR DE CAMPO E HOLADAY POSICIONADO DENTRO DA CELT, VISTA EXTERNA. ................171

FIGURA 89 - CARGAS APLICADAS NA CELT (A) TIPO TERMINAL $50 \Omega$; (B) TIPO COAXIAL RESISTIVA $50 \Omega$; (C)

CARGA ABERTA.

172

FIGURA 90 - ACOPLADOR DIRECIONAL AR, COM TRANSDUTOR DE POTÊNCIA, SAÍDA PARA OS DOIS CABOS DE

ALIMENTAÇÃO DAS LINHAS DE TRANSMISSÃO. 172

FIGURA 91 - ANALISADOR VetORIAL DE REDE - RoHDE \& SCHWARTZ, MODELO ZVRE............................174

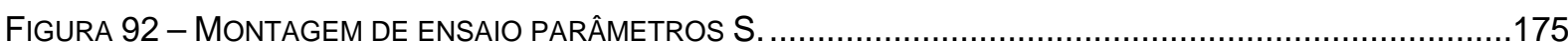

FiguRA 93 - (A) GERADOR DE POTÊNCIA DE CORRENTE CONTÍNUA TEKTRONIX MOD. PS280 (B) DEFASADOR

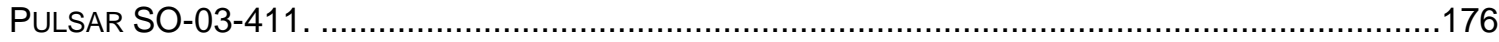

FIGURA 94 - KIT DE CARGAS DE CALIBRAÇÃO ROHDE \& SCHWARTZ.

FIGURA 95 - DiagRAMA ESQUEMÁTICO DA CELT - PONTOS DE MEDIÇÃO, NO PLANO CORRESPONDENTE A ALTURA H.....

FIGURA 96 - CARACTERIZAÇÃO dO DEFASADOR 1 - 10MHZ A 30MHZ (A) Z REAL VERSUS IMAGINÁRIO (B)

FASE (S21) (C) ABS (S21).

FIGURA 97 - CARACTERIZAÇÃO do DEFASADOR 2 - 20MHZ A 40 MHZ (A) Z REAL VERSUS IMAGINÁRIO (B)

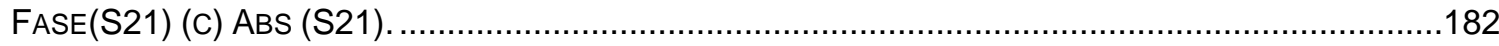

FIGURA 98 - CARACTERIZAÇÃo dO DEFASADOR 5 - 100MHZ A 190MHZ.(A) Z REAL VERSUS IMAGINÁRIO (B)

FASE (S21) (C) ABS (S21). 182

FIGURA 99 - CARACTERIZAÇÃO DO DEFASADOR 6 - 150MHZ A 250MHZ (A) Z REAL VERSUS IMAGINÁRIO (B)

FASE(S21) (C) ABS (S21). 182

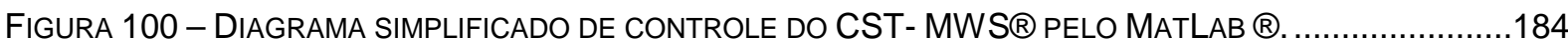

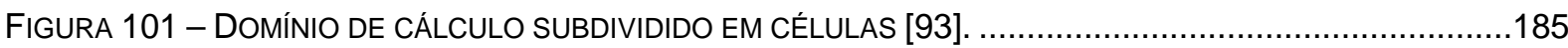

FIGURA 102 - EXEMPLO DA FORMULAÇÃO FIT APLICADA A UMA ÚNICA CÉLULA, AQUI APLICADA À LEI DE

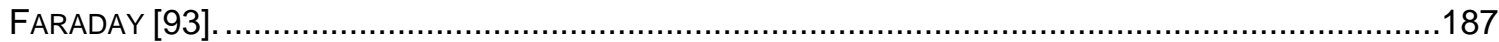

FIGURA 103 - GEOMETRIA NO PLANO XY CONSIDERADA PELO MÉTODO ANALÍTICO......................................188 


\section{LISTA DE TABELAS}

TABELA 1 - Modelos DetalHAdo E SimplificAdo - SUMÁRIO COMPARATIVO .53

TABELA 2 - MOdOS E FREQUÊNCIAS DE RESSONÂNCIA PARA O PROTÓTIPO LMAG/CTMSP. .77

TABELA 3 - RESULTADOS DE DESVIOS PADRÃO COM MÉTODO NUMÉRICO - MODELO SIMPLIFICADO CARGA $50 \Omega$. .97

TABELA 4 - VARIÁVEIS DE OTIMIZAÇÃO. 134

TABELA 5 - CARACTERÍSTICAS DO VOLUME DE TRABALHO RESULTANTE MONO-OBJETIVO. 135

TABELA 6 - LISTA DE MATERIAIS UTILIZADOS PARA A CONSTRUÇÃO DA CÂMARA ANALISADA. 167

TABELA 7 - RELAÇÃO DOS EQUIPAMENTOS: TESTES - LIT/INPE. 173

TABELA 8 - RELAÇÃO DOS EQUIPAMENTOS: TESTE - IEE/USP. 175

TABELA 9 - POSIÇÕES DE MEDIDA 178

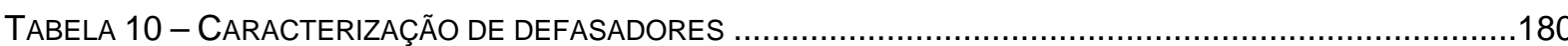

TABELA 11 - RESULTADOS DE DESVIOS PADRÃO PARA MÉTODO SEMI-ANALÍTICO. 196 


\section{LISTA DE ABREVIATURAS E SIGLAS}

AG - Algoritmo Genético

AGM - Algoritmo Genético Mono-objetivo

AGMO - Algoritmo Genético Multi-Objetivo

ASCII - Formato padronizado internacional de arquivos computacionais

BTU - Universidade Técnica de Brandenburgo (Brandenburgische Technische Universität)

CELT - Câmara Excitada por Linhas de Transmissão

CEM - Compatibilidade Eletromagnética

CR - Coeficiente de Reflexão

CST-MWS - Computer Simulation Tecnologies - MicroWave Studio ${ }^{\circledR}$

CTMSP - Centro Tecnológico da Marinha em São Paulo

EAbs - Valor Absoluto do Campo Elétrico

EST - Equipamento Sob Teste

EUA - Estados Unidos da América

EV - Extreme Values

FDTD - Finite Derivative in Time Domain

FE - Finite Elements

FIT - Finite Integration Technique

GEV - Generalized Extreme Values 
IEC - International Electrotecnique Commission

IEE/USP - Instituto de Eletrotécnica e Energia da Universidade de São Paulo

IEM - Interferência Eletromagnética

IL - Perdas por inserção "Insertion Loss"

INPE/LIT - Instituto de Pesquisas Espaciais / Laboratório Integrado de Testes

IUN - Istituto Universitário Navale

LA - Lebensztajn \& Ávila

LMAG - Laboratório de Magnetismo Aplicado

LT - Linha de Transmissão

MFU - Mínima Frequência de Utilização

MIL-STD - Military Standard

MoM - Method of Moments

NASA - National Aeronautics and Space Administration

NIST - National Institute of Standardization

$\mathrm{NRL}$ - National Research Laboratory

PEC - Condutor Perfeito (do inglês "Perfect Electric Conductor")

PVC - Polivinil Cloreto

RL - Perdas por Retorno ("Return Loss")

TE - Transversal Elétrico

TEM - Transversal EletroMagnético 
TLM - Transmission Line Matrix

TM - Transversal Magnético

TOE - Taxa de Onda Estacionária

VNA - Analisador de Rede Vetorial (do inglês - "Vectorial Network Analyzer") 


\section{LISTA DE SÍMBOLOS}

$\omega-$ Frequência angular [rad/s]

$\nabla$ - Operador Nabla

$c$ - Velocidade da luz $[\mathrm{m} / \mathrm{s}]$

Abs $(\vec{r})$ - Valor Absoluto do vetor $(\vec{r})$

D - Vetor densidade de fluxo elétrico [C/m2]

B - Vetor densidade de fluxo magnético [ $\mathrm{Wb} / \mathrm{m} 2]$

E - Vetor campo elétrico $[\mathrm{V} / \mathrm{m}]$

$\rho$ - Densidade volumétrica de carga $\left[\mathrm{C} / \mathrm{m}^{3}\right]$

H - Vetor campo magnético $[\mathrm{A} / \mathrm{m}]$

$\mathbf{J}$ - Vetor densidade superficial de corrente $[\mathrm{A} / \mathrm{m} 2]$

$\alpha$ - Constante de atenuação $[\mathrm{Np} / \mathrm{m}]$

$\beta$ - Constante de fase $[\mathrm{rad} / \mathrm{m}]$

$\lambda$ - Comprimento de onda [m]

$\gamma$ - Constante de propagação $\left[\mathrm{m}^{-1}\right]$

$\delta$ - profundidade pelicular [m]

$\Gamma$ - coeficiente de reflexão

$\sigma-$ (elétrica) Condutividade elétrica [S/m]

$\sigma-$ (estatística) desvio padrão 
$\hat{\sigma}-$ (estatística) desvio padrão normalizado [dB]

$\pi$ - Constante pi

$x$ - Operação de produto vetorial

$\mu$ - Permeabilidade magnética $[\mathrm{H} / \mathrm{m}]$

$\varepsilon$ - Permissividade elétrica $[\mathrm{F} / \mathrm{m}]$

$\mu_{0}$ - Permeabilidade magnética do espaço livre $[\mathrm{H} / \mathrm{m}]$

$\varepsilon_{0}$ - Permissividade elétrica do espaço livre $[\mathrm{F} / \mathrm{m}]$

$\mu_{r}$ - Permeabilidade magnética relativa

$\varepsilon_{r}$ - Permissividade elétrica relativa (constante dielétrica)

$\theta$ - Ângulo da onda de tensão

$E$ - Intensidade de campo elétrico [V/m]

$E_{0}$-Amplitude máxima do campo elétrico [V/m]

$E x, E y, E z$ - Componentes do campo elétrico nas direções $x, y$ e $z$ respectivamente $[\mathrm{V} / \mathrm{m}]$

$f$ - Frequência [Hz]

$H$ - Intensidade de campo magnético $[\mathrm{A} / \mathrm{m}]$

$H x, H y, H z$ - Componentes do campo magnético nas direções $x, y$ e $z$, respectivamente

i- Corrente $[\mathrm{A}]$

$t$ - Tempo $[\mathrm{s}]$ 
$v$ - Velocidade de propagação da onda $[\mathrm{m} / \mathrm{s}]$

$\operatorname{Re}($ ) - Parte real do número complexo

Im( ) - Parte imaginária do número complexo

$R, R_{L}, R_{S}$ - Resistência, resistência de carga, resistência superficial das paredes $[\Omega]$

$S-$ Área $\left[\mathrm{m}^{2}\right]$

$V$ - Tensão [V]

$x, y, z-$ Coordenadas espaciais cartesianas [m]

$Z_{0}$ - Impedância característica do espaço livre [ $[$ ]

$Z_{L}$ - Impedância da carga $[\Omega]$

$Q$ - fator de qualidade da câmara reverberante

$\mathrm{N}$ - quantidade de indivíduos em uma população

$\bar{V}$ - média do tensão

cte - constante

$h$ - auto-valores modais

$k$ - número de onda do dielétrico

$f$ - frequência [Hz]

$f_{c}$ - frequência de corte modal [Hz]

$P$ - Potência [W]

$P_{\text {in }}$ - Potência injetada [W] 


$$
\begin{aligned}
& P_{\text {refletida }} \text { - Potência refletida [W] } \\
& C \text { - capacitância [F] } \\
& L \text { - indutância [H] } \\
& \phi \text { - defasagem de onda [rad] } \\
& f(\text { ) - função genérica } \\
& \text { [S] - matriz espalhamento }
\end{aligned}
$$




\section{ÍNDICE}

$1 \quad$ INTRODUÇÃO

2 REVISÃO DA LITERATURA

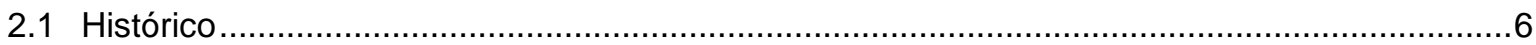

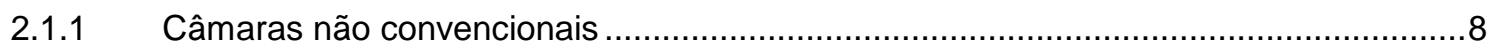

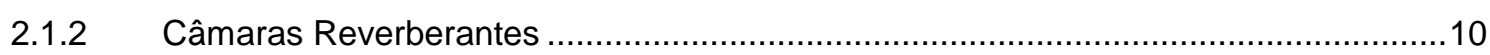

2.1.3 Aplicação de Métodos Numéricos na Avaliação de Câmaras......................................11

2.1.4 Tópicos Gerais relativos aos Métodos Estatísticos....................................................12

2.1.5 Métodos de Otimização Aplicados às Câmaras Reverberantes ...................................14

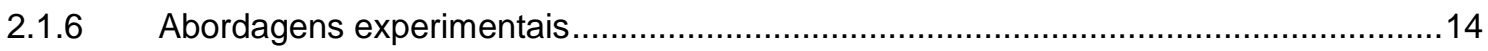

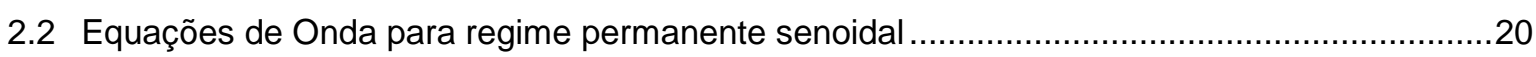

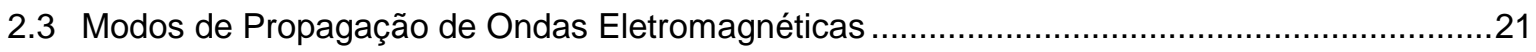

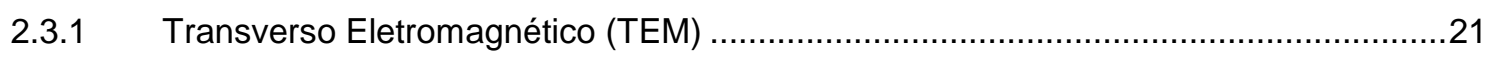

2.3.2 Modos de Propagação Transverso Elétrico e Transverso Magnético ..........................22

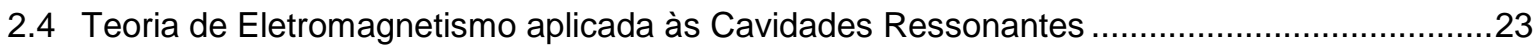

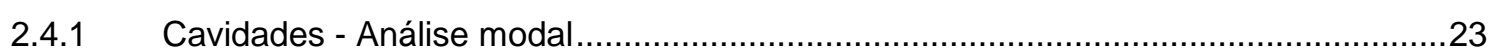

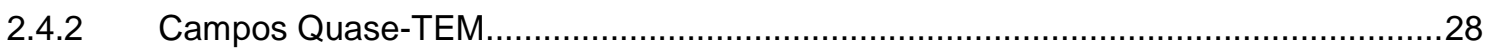

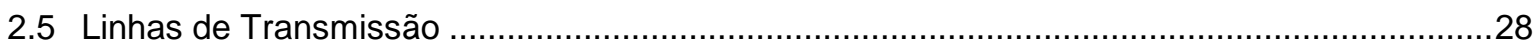

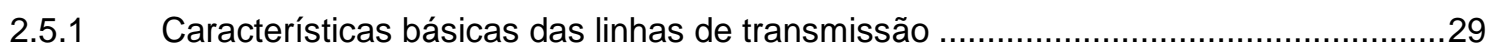

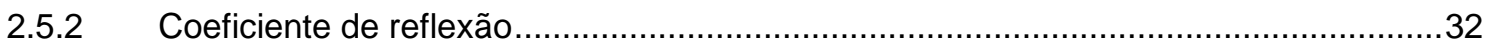

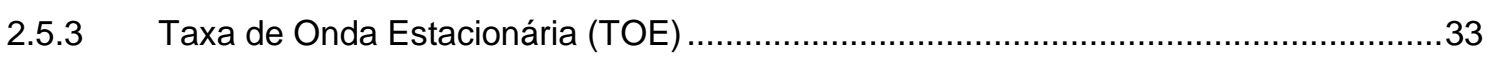

2.5.4 Campo elétrico resultante na consideração da carga .................................................33

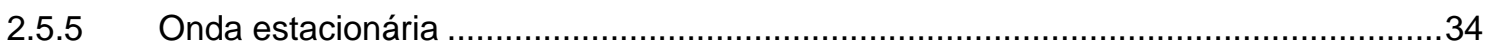

2.5.6 Independência de campos gerados dentro de envoltórias metálicas ............................36

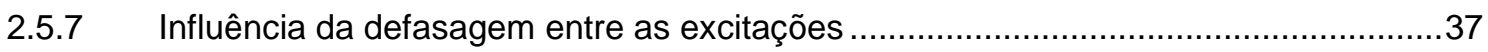

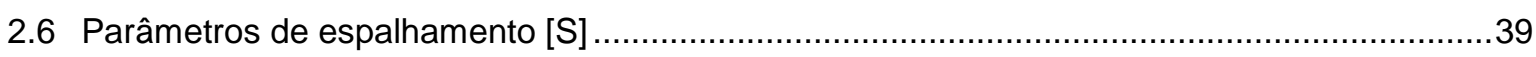

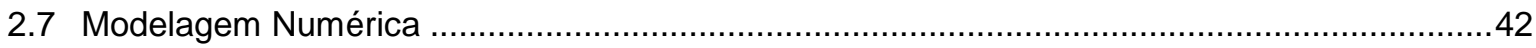

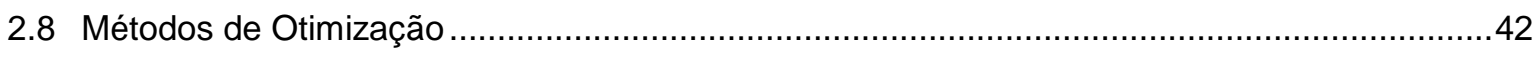

3 CÂMARAS EXCITADAS POR LINHAS DE TRANSMISSÃO (CELT) ...................................50

3.1 Operação da CELT abaixo da frequência de corte (modo único) ……...................................51

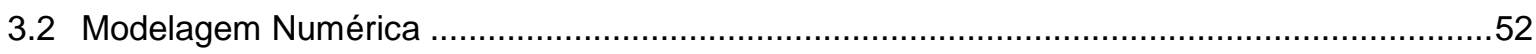

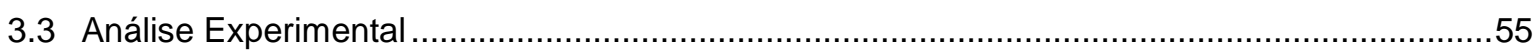

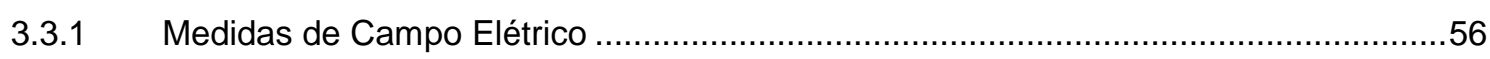

3.3.2 Medidas de parâmetros com o Analisador Vetorial de Redes (VNA). .........................57

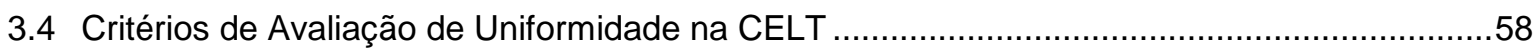




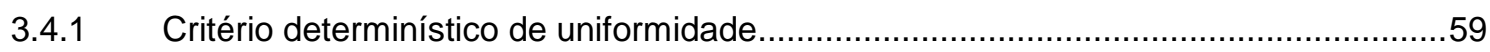

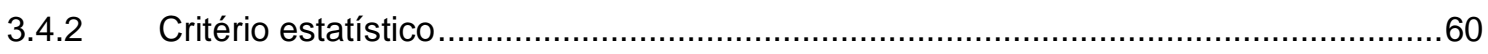

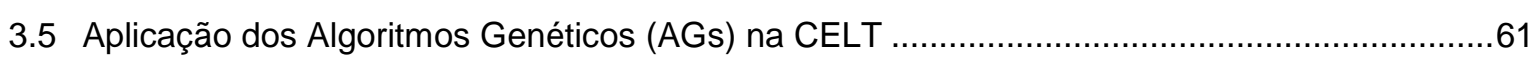

3.5.1 Compromisso Volume de Trabalho versus Campo Elétrico .......................................62

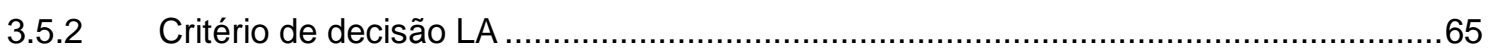

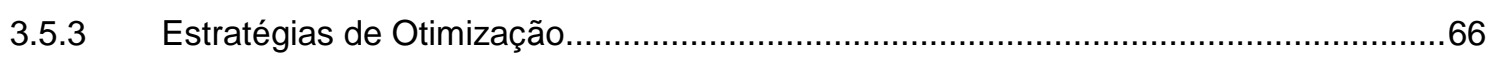

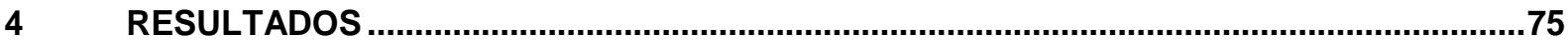

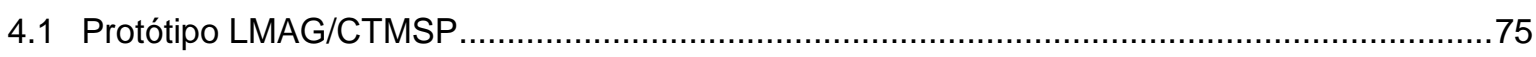

4.1.1 Modelo de cálculo do campo elétrico resultante na consideração da carga.................79

4.1.2 Formas de onda na câmara - operação "no-moded", "single-moded" e "over-moded"-

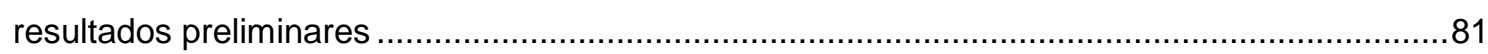

4.2 Análise das simulações numéricas do protótipo LMAG/CTMSP ............................................ 83

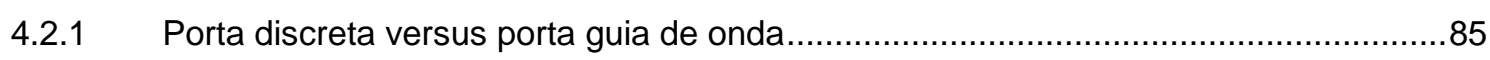

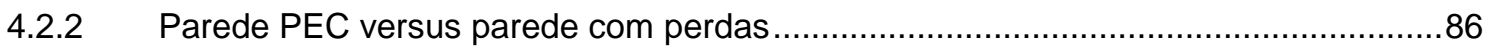

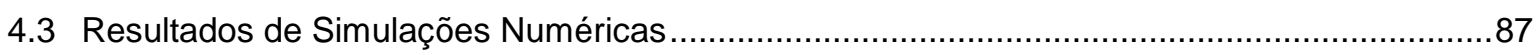

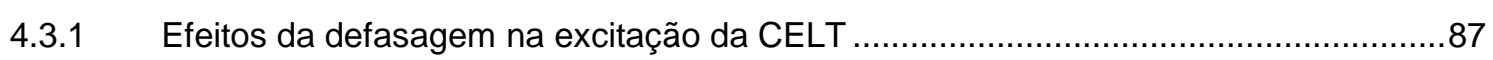

4.3.2 Efeito da variação das posições das Linhas de Transmissão na CELT ......................89

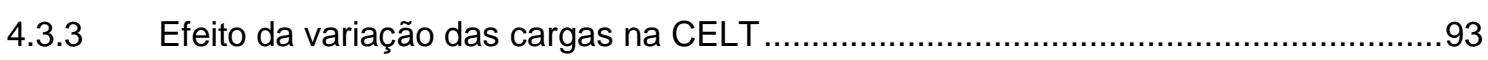

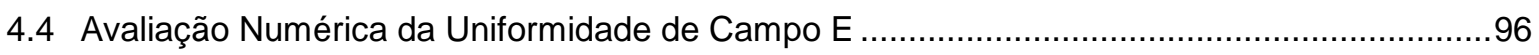

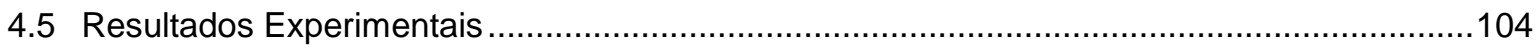

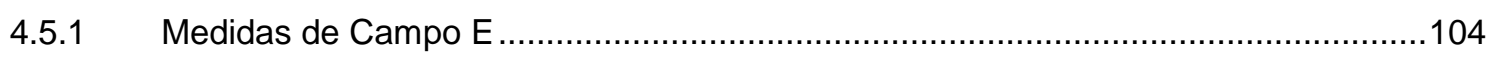

4.5.2 Medidas de parâmetros com o Analisador Vetorial de Redes ...................................112

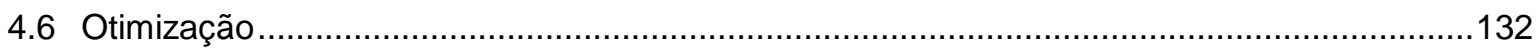

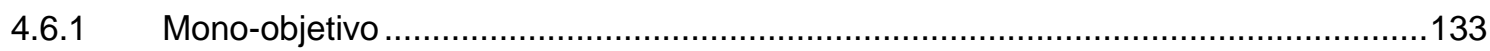

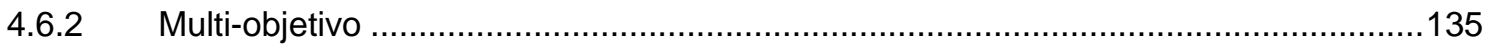

4.6.3 Otimização do arranjo de condutores (LT) - método híbrido .................................137

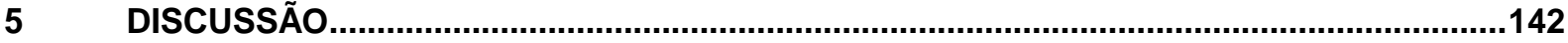

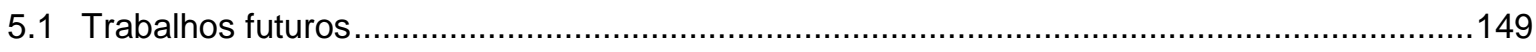

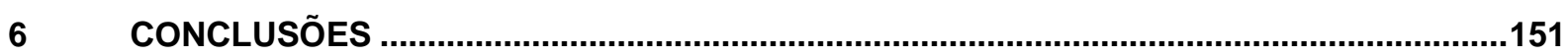

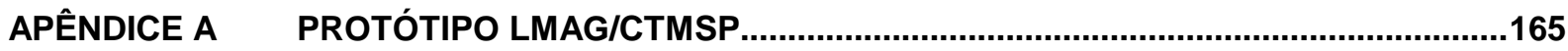

APÊNDICE B CONFIGURAÇÃO E METODOLOGIA DE TESTES..........................................168

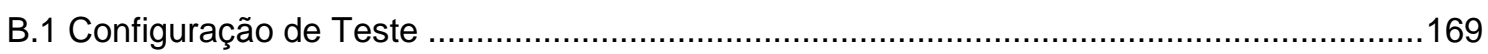

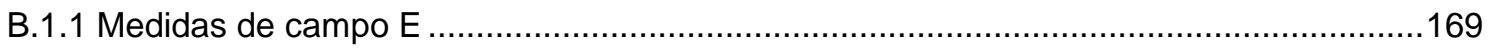

B.1.2 Caracterização de componentes utilizando parâmetros S .........................................174

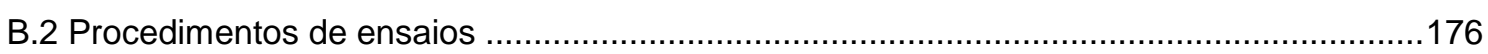

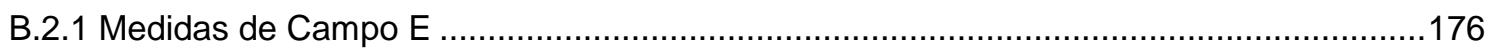

B.2.2 Medidas de parâmetros S, Taxa de Onda Estacionária (TOE) e carta de Smith..............178

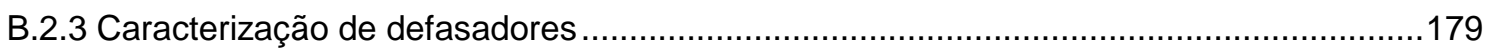




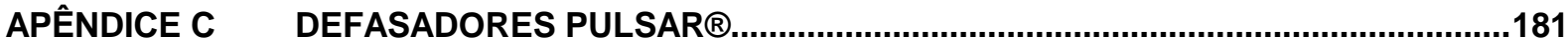

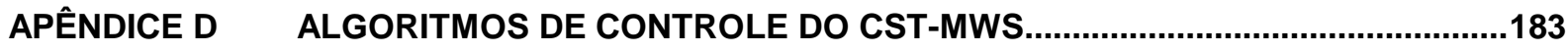

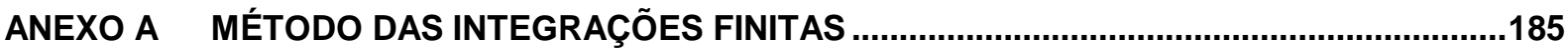

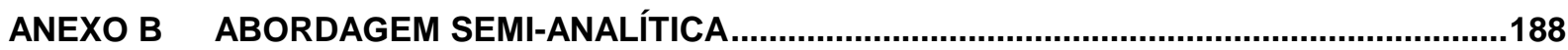

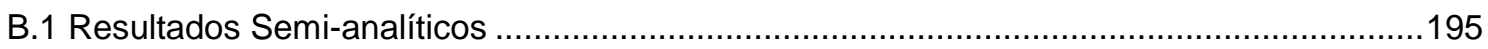




\section{INTRODUÇÃO}

Atualmente destaca-se a importância do desenvolvimento de metodologias científicas de avaliação dos fenômenos eletromagnéticos, além do estabelecimento de regras, normas, critérios e recomendações com o objetivo de assegurar 0 perfeito funcionamento de equipamentos e sistemas eletro-eletrônicos e a segurança dos seres vivos nos diversos ambientes eletromagnéticos a que estarão sujeitos. Este campo de pesquisas é chamado de Compatibilidade Eletromagnética (CEM).

As atividades relacionadas à área de CEM tais como o controle do ambiente eletromagnético e, consequentemente, de ocorrências de interferências eletromagnéticas (IEM), fazem parte das diversas etapas de projeto de equipamentos e sistemas, tais como os sistemas embarcados, os sistemas industriais etc.

Menciona-se que eventos relacionados à IEM podem estar presentes nestes sistemas, devido à baixa imunidade dos equipamentos e à presença frequente de fenômenos eletromagnéticos de elevadas intensidades [1]. Entre esses fenômenos, considerados como fontes severas de IEM, estão os pulsos decorrentes de chaveamentos de circuitos, harmônicos resultantes dos sistemas de alimentação de energia elétrica, IEM resultantes da utilização de rádios de comunicação, falhas elétricas, além da própria "assinatura eletromagnética resultante" ou energia radiada dos equipamentos elétricos. Menciona-se que contribuem também para amplificação desses problemas, a crescente miniaturização dos circuitos e a compactação dos equipamentos em estruturas fechadas, com pequenas distâncias entre equipamentos emissores de ruídos e equipamentos com baixa imunidade a esses ruídos.

Por outro lado, com o uso crescente de sistemas analógicos avançados ou de tecnologia digital nos sistemas relacionados à segurança, a consideração dos aspectos de CEM passam a assumir grande importância, existindo uma 
preocupação crescente com relação a estes tópicos, sendo amplamente descritos na literatura atual [2]-[6].

Nota-se, também, a preocupação sobre IEM na área nuclear, existindo a recomendação (com força de norma) em que a Agência Internacional de Energia Atômica (AIEA), através de Boletim Técnico de Instrumentação e sistemas de controle importantes para a segurança em Usinas Nucleares [2], que indica que os sistemas de instrumentação e controle devem ser projetados e instalados de forma a funcionar perfeitamente nos ambientes eletromagnéticos das instalações nucleares.

A Comissão Regulatória Nuclear dos Estados Unidos (USNRC - United States Nuclear Regulatory Commission), no seu guia 1.180 [3], apresenta as recomendações relativas ao controle de IEM e os testes, onde se percebe uma influência das normas militares e comerciais [4]-[5]. Nota-se, também, a elaboração de relatórios onde se mencionam os fenômenos relacionados à migração de sistemas analógicos para digitais em usinas nucleares [6].

Ressalta-se, porém, que os testes de certificação em CEM apresentam dificuldades devido aos altos investimentos associados à implantação de ambientes de teste, citando-se, por exemplo, aqueles decorrentes dos requisitos de utilização de câmaras anecóicas (absorvedores, geradores com grande potência, etc.). Desta forma, as câmaras reverberantes apresentam-se financeiramente atrativas, e como uma alternativa para a execução de testes de imunidade radiada e emissão (devido à prescindirem da utilização dos absorvedores e poderem ser utilizados com geradores de menor potência).

Dentre as normas que preveem a aplicação de câmaras reverberantes, destacase a IEC61000-4-21 da IEC (International Electrotechnical Commission). As câmaras reverberantes excitadas por pás misturadoras são tipicamente operadas acima de $200 \mathrm{MHz}$, observando-se que a operação abaixo desse valor exige câmaras com dimensões superiores às salas blindadas típicas [4]. 
Menciona-se, também, as normas MIL-STD e a série ISO 11452 (International Organization for Standardization) que preveem testes em equipamentos elétricos e eletrônicos embarcados utilizando câmaras reverberantes [5], [7].

Pode-se ainda citar outros tipos de câmara previstas em normas internacionais, como a Stripline, ou a TEM. A utilização destas compreende as frequências abaixo de $200 \mathrm{MHz}$, e apresentam como característica limitante a uniformidade na área de trabalho paralela ao septum, sendo que nas outras direções ou no volume como um todo, este requisito não é atendido [8].

No Brasil existe a tendência em adotar as normas da IEC e ISO, na forma de versões traduzidas. Por outro lado, estimulada-se ainda, via diversas instituições (INMETRO, SENAI, Forças Armadas, Universidades) a criação e complementação de centros de testes de CEM, a instalação de onerosas câmaras, tais como as anecóicas, semi-anecóicas, GTEM.

Desta forma observa-se que, apesar da preocupação com a imunidade dos sistemas, os métodos de medida dos campos eletromagnéticos apresentam as restrições anteriormente mencionadas, em particular com relação aos aspectos referentes à avaliação de imunidade em baixas frequências. A proposta de utilização de câmaras excitadas por linhas de transmissão apresenta-se como uma alternativa às configurações atuais.

O objetivo geral deste trabalho é analisar a viabilidade da aplicação de Câmaras Excitadas por Linhas de Transmissão (CELT) como ambiente padronizado de testes de CEM, especialmente os de imunidade irradiada.

A descrição e análise desta câmara, são realizadas através de diversas ferramentas numéricas e experimentais.

Como objetivos específicos são destacados os mais importantes, que são:

- Pesquisar na literatura os modelos analíticos que podem ser aplicados na CELT;

- Gerar modelo numérico da CELT; 
- Definir método de avaliação da uniformidade da CELT;

- Analisar os efeitos da defasagem do sinal de excitação na uniformidade dos campos E na CELT;

- Analisar os efeitos das posições das LTs na uniformidade dos campos E na CELT;

- Analisar os efeitos das cargas das LTs na uniformidade dos campos E na CELT;

- Promover ensaios para medidas de campo E na CELT;

- Promover ensaios para medidas de parâmetros [S] da CELT;

- Procurar configurações ótimas da CELT, através da aplicação de ferramentas de otimização;

- Desenvolver índices de avaliação das configurações aplicáveis à CELT.

Basicamente, apresentam-se neste documento a análise teórica; a modelagem numérica; os ensaios de um protótipo construído; e as técnicas de otimização aplicáveis. A metodologia proposta e as ferramentas utilizadas no desenvolvimento deste trabalho, evidenciam quais os efeitos físicos predominantes na CELT e como utilizá-los de forma a se atingir os índices de uniformidade de campos eletromagnéticos recomendados [4], [5]. Note-se que estes índices de uniformidade foram assumidos como os mesmos para o caso da CELT, devido à inexistência de normas específicas para esta câmara. A metodologia de análise, de um modo geral, está calcada na avaliação de desempenho através dos índices estatísticos e índices de mérito já recomendados e por aqueles desenvolvidos e propostos pelos autores deste trabalho.

No desenvolvimento da CELT, dois modelos numéricos são apresentados, descritos e comparados: estes modelos são utilizados para mapeamento do campo e dos efeitos devido aos vários parâmetros envolvidos na operação da CELT. Dentre eles pode-se citar: a excitação, incluindo ou não defasagens; as cargas; e as 
posições das linhas de transmissão. Assim, estes modelos numéricos são utilizados no cálculo dos campos eletromagnéticos gerados pelas diversas configurações que são propostas ao longo do trabalho, visando a obtenção valores de índices de uniformidade e de campos elétricos médios que satisfaçam os requisitos préestabelecidos.

Após o desenvolvimento analítico e os modelos numéricos, uma análise experimental preliminar tem início, a fim de consolidar e refinar os resultados conseguidos nesta primeira etapa. Uma série de ensaios foi realizada obtendo-se o perfil de campo $E$ em vários pontos da câmara, em função da frequência, para uma dada potência de excitação. Além disso, dadas as características do protótipo, das antenas utilizadas, e das frequências em questão, optou-se pela caracterização da CELT através da medida dos parâmetros de espalhamento (S) com uma reprodutibilidade em altas frequências bastante satisfatória. Inclui-se nesta fase a aplicação de defasadores controlados por tensão como carga variável.

Um estudo de otimização da CELT relativo às configurações e arranjos de condutores, que melhor satisfaçam os índices de mérito propostos, também foi desenvolvido. A estratégia de otimização consistiu de simulações com base nos modelos numéricos desenvolvidos, e na aplicação de algoritmos e métodos distintos. 


\section{REVISÃO DA LITERATURA}

Neste capítulo apresenta-se uma revisão de trabalhos aplicáveis às câmaras de testes de compatibilidade eletromagnética.

Inicialmente são apresentados os aspectos históricos do desenvolvimento de câmaras reverberantes, e alguns trabalhos sobre câmaras não-convencionais.

Em seguida abordam-se alguns trabalhos que tratam dos aspectos de desenvolvimento teórico, onde se consideram a modelagem por métodos numéricos e aspectos estatísticos dos campos eletromagnéticos resultantes na câmara.

Alguns trabalhos sobre métodos de otimização aplicáveis à melhoria de desempenho das câmaras, e sobre procedimentos experimentais, também são comentados.

Finalmente, as tendências e trabalhos atuais relacionados à câmaras de testes de imunidade são analisados.

\subsection{Histórico}

A literatura reporta que a primeira utilização de uma cavidade para reverberação de ondas eletromagnéticas está relacionada com o aquecimento de alimentos, cuja patente data de 1947, sendo atribuída à Raytheon Co., e intitulada "Heating Apparatus". Nota-se que nesta aplicação alguns requisitos previstos para as câmaras de teste atuais são mencionados: uniformidade de campo, volume de trabalho, alto valor de campo com pequena injeção de potência e eficiência do misturador.

Em 1968, Mendes propôs a utilização de grandes cavidades para testes de CEM em equipamentos [9].

A partir dos anos 70, artigos relacionados às câmaras com aplicações em CEM começaram a ser publicados com maior frequência. 
Inicialmente duas equipes se destacaram no desenvolvimento de câmaras reverberantes: a do National Bureau of Standards (NIST), que contava com a participação de Crawford, Ladbury, Kanda, Ma, Hill e Koepke [10]-[16]; e o grupo de Corona, Latmiral, Primiani, Migliaccio e Ferrari [17]-[22].

A primeira equipe (NIST) defendia a operação da câmara reverberante em modos sintonizados ("mode-tuned") e a segunda defendia a operação em modos misturados ("mode-stirred").

$\mathrm{Na}$ operação em modos sintonizados as pás misturadoras são acionadas por um motor de passo, que provê o movimento das pás em pequenos deslocamentos angulares. Cerca de duzentos passos em uma volta das pás são recomendados, conforme descrito por Ladbury, Hill, Holloway e Koepke, entre outros [10]-[16].

$\mathrm{Na}$ operação de modos misturados as pás misturadoras giram com uma velocidade constante, de forma a "distorcer" o campo. Detalhes desta concepção são apresentados por Corona, Latmiral, Migliaccio, Ferrara [17]-[22]. Estes trabalhos apresentam o desenvolvimento teórico com base na termodinâmica, e o tratamento dos dados experimentais, modelando-se, inclusive, o surgimento de modos não misturados, através de métodos estatísticos.

A partir de 2003 essas duas vertentes foram harmonizadas, sendo consolidadas na norma IEC61000-4-21 [4].

Com o passar do tempo, vários outros grupos de pesquisa passaram a tratar do tema e outros trabalhos foram desenvolvidos, com abordagens do problema relacionadas à diferentes configurações físicas de câmaras, formas de operação, e comparações de desempenho entre as câmaras reverberantes e anecóicas, utilizando-se modelagem numérica [36]-[91].

Devido às restrições à operação em baixas frequências, e às necessidades atreladas à dimensão física das câmaras reverberantes, diferentes polos de pesquisa desenvolveram-se, destacando-se aqueles oriundos da proposta de Perini e Cohen. Menciona-se que o trabalho aqui desenvolvido tem como ponto de partida 
a configuração básica proposta por estes pesquisadores, cuja cooperação científica se estabeleceu na década de 90 e que, no princípio de 2000 , gerou alguns trabalhos científicos sobre a CELT [24], [25].

Nos itens seguintes apresenta-se um panorama dos trabalhos sobre câmaras reverberantes e câmaras não convencionais, ressaltando os aspectos teóricos, numéricos, estatísticos, de otimização e experimentais desenvolvidos no mundo.

\subsubsection{Câmaras não convencionais}

\subsubsection{Câmara Excitada por Linhas de Transmissão}

Em 2000, Perini e Cohen apresentam uma configuração de câmara reverberante com excitação através de 2 linhas de transmissão paralelas e posicionadas no sentido do maior eixo da câmara [23]. Este trabalho apresenta curvas de intensidade de campo $E$ em uma linha central na câmara, sendo empregada função densidade de probabilidade para descrição estatística da amplitude dos campos elétricos. Os resultados foram analisados e concluiu-se que, para a câmara avaliada, os campos apresentavam-se uniformemente distribuídos, para a faixa de frequência até 500 MHz. Em 2002 resultados adicionais, relacionados à configuração de 3 linhas, sendo estas paralelas aos eixos coordenados, são apresentados [24]. Ainda em 2002, Perini et al apresentam resultados de simulações para duas e três linhas de transmissão, além de medições que acenam com a possibilidade de utilização da configuração proposta, em baixas frequências [25].

É interessante notar que a câmara proposta por Perini e Cohen foi concebida a partir do conceito desenvolvido por Rahman e Perini [26]-[29], o qual formula uma metodologia de cálculo com base em funções de Green, para o caso de condutores que penetram em cavidades retangulares. Cabe ainda ressaltar que esta abordagem, de modelagem de cavidades retangulares via funções de Green, foi precedida pelo trabalhos de Tai e Rozenfeld [30], seguida de Seidel [31] e Wang [32]. 
Em [34] e [35] Weinzierl et al, apresentam os resultados aplicados a uma câmara de mesmas dimensões que a de Perini [22], cujos resultados teóricos foram obtidos aplicando-se os métodos numéricos da Matriz de Linhas de Transmissão (TLM) e Técnica das Integrações Finitas (FIT), e índices estatísticos.

\subsubsection{Câmara Intrínseca}

Esta configuração particular é apresentada, por exemplo, por Kouveliotis, Trakadas e Capsalis, apresentando como característica a utilização de paredes móveis, constituídas de tecido condutor [36].

\subsubsection{Câmara "Stadium".}

Em [37], Arnault descreve a câmara "stadium", construída como uma esfera oca, contendo diversas semi-esferas convexas difratoras, de forma a tornar o campo injetado na forma de uma distribuição aleatória de campos EM. Apresenta-se uma câmara de pequenas dimensões (raio interno médio $35 \mathrm{~cm}$ ) e analisa-se a aplicação em frequências acima de $2,5 \mathrm{GHz}$. A influência da proximidade das paredes e dos sensores são analisadas, tanto com relação aos efeitos eletromagnéticos propriamente ditos, quanto às perturbações nos sensores de campo.

\subsubsection{Câmara de paredes não-paralelas}

Em [38], Chung apresenta um estudo relacionado às câmaras de paredes não paralelas, com difusores, cujos resultados são obtidos através de simulações numéricas aplicando-se o método FDTD e considerando paredes com perdas. Esta configuração visa eliminar a necessidade de pás giratórias, utilizando somente estruturas fixas. Os resultados simulados entre a câmara proposta e a câmara padrão retangular, para a faixa de $400 \mathrm{MHz}$ a 2,2 GHz, são comparados.

\subsubsection{Câmara Transverso-Eletromagnética tridimensional}

Em 2001, Klingler et al [39] propuseram a utilização de linhas de transmissão, nos mesmos moldes de uma célula TEM, em câmaras, de forma a diminuir a potência injetada, e obter um volume de trabalho com uniformidade adequada. Um protótipo 
com placas paralelas aos eixos x, y e z (uma em cada direção) foi construído e medições foram executadas, resultando todas em valores de desvio padrão acima dos recomendados para câmaras reverberantes (< 4dB em $80 \mathrm{MHz}$, decrescendo linearmente para $3 \mathrm{~dB}$ em $400 \mathrm{MHz},<3 \mathrm{~dB}$ acima de $400 \mathrm{MHz}$ ). Um modelo numérico foi implementado utilizando MoM e com duas placas paralelas em cada eixo, com valores de desvio padrão abaixo dos recomendados, quando se considera a uniformidade e valores de campo EM.

\subsubsection{Câmaras Reverberantes}

\subsubsection{Aplicação de métodos analíticos na avaliação de câmaras}

Em 1994, Hill [70] apresenta um desenvolvimento teórico aplicável em estudos de câmaras reverberantes de modos eletronicamente misturados. Apresentam-se resultados com desvio padrão menores que $1 \mathrm{~dB}$, considerando-se a largura de banda de $10 \mathrm{MHz}$ com frequência central de $4 \mathrm{GHz}$ e uma fonte unidimensional de excitação aplicável em uma linha de transmissão. Também foi apresentada a configuração de excitação através de duas fontes em frequência única, o que não melhora os resultados já conseguidos com somente uma linha de transmissão. Em 1996, Hill [8] apresenta um desenvolvimento teórico para o cálculo do fator de qualidade $Q$ de uma cavidade arbitrária, considerando materiais com alta condutividade, e uma formulação de cálculo do tempo de decaimento da energia armazenada na cavidade.

Prosseguindo o trabalho de desenvolvimento teórico do fator de qualidade $Q$ da câmara em 2003 Hill et al [15] apresentam estudo sobre o carregamento teórico de uma câmara com material absorvedor com formato esférico. Desta são determinadas funções através das quais calculam-se os valores máximos de carregamento da câmara, para dado $Q$ intrínseco. As dimensões do volume utilizável da câmara, também, são calculadas.

Em 2005, Hill et al [10] derivam um equacionamento a partir da representação de onda plana integral para campos misturados em câmaras reverberantes para 
posições próximas às paredes da câmara. Concluem que os campos tornam-se não distorcidos a partir da distância das paredes $d>\lambda / 2$.

No artigo de Arnaut 2003 [71] são tecidas considerações sobre o fator teórico $Q$ da câmara reverberante para os diversos modos, propondo a utilização do valor médio e do desvio padrão aplicados ao fator $Q$. Desta forma estima-se o $Q$ total da câmara em todos os modos. Simulações numéricas são utilizadas para corroborar os resultados teóricos. Uma análise do fator $Q$ para uma câmara com paredes móveis também é apresentada.

\subsubsection{Aplicação de Métodos Numéricos na Avaliação de Câmaras}

Diversos trabalhos podem ser mencionados, no que tange à aplicação de métodos numéricos na avaliação de câmaras reverberantes:

Em 1998, Bunting iniciou a publicação de uma série de artigos, utilizando uma ferramenta numérica bidimensional de Elementos Finitos (FE) [40]. Neste trabalho foi modelada uma câmara retangular com paredes sem perdas. Nos artigos seguintes, publicados entre 1999 e 2003, Bunting prossegue com o refinamento da modelagem através de novas funções para o cálculo numérico, insere fontes livres, modela fendas dentro da câmara, pás, além da inserção de equipamentos para teste de blindagem dentro da câmara [41]-[48]. Durante o desenvolvimento fez a comparação com dados experimentais, em câmaras reverberantes da NASA. Observa-se que toda sua modelagem considera paredes e materiais perfeitamente condutores (PEC).

Em 2002, menciona-se o trabalho de Kouveliotis [36], que utiliza o método FDTD para cálculo de câmaras reverberantes intrínsecas.

EM 2005, Bruns e Vahldieck [49] apresentam simulações utilizando o Método dos Momentos (MoM - Method of Moments), incluindo os detalhes geométricos, e verificam a influência desses detalhes nos resultados das simulações. Consideram insuficiente o tratamento estatístico dos dados simulados, que são, então, complementando com valores experimentais. 
Também em 2005, Weinzierl et al [34] apresentam simulações de uma câmara excitada por linhas de transmissão, utilizando o método TLM, com resultados comparáveis aos anteriores de Perini [24], que utilizou o método numérico MoM. Em 2008, Weinzierl et al [35] analisaram diferentes configurações de câmaras reverberantes excitadas por linhas de transmissão, através dos métodos TLM e FIT. As configurações foram comparadas através de métodos estatísticos.

\subsubsection{Tópicos Gerais relativos aos Métodos Estatísticos}

Em 1976, Corona [17] apresenta um trabalho considerado precursor da análise estatística considerando-se o desenvolvimento de câmaras reverberantes de modos misturados (ainda não designada como tal). Neste trabalho apresenta resultados experimentais, sugerindo que os campos medidos dentro de uma câmara podem ser tratados estatisticamente. Apresenta gráficos da densidade de probabilidade do campo $\mathrm{E}^{2}$ e da probabilidade cumulativa, que apresentam características semelhantes à função densidade de probabilidade chi-quadrada $\left(\chi^{2}\right)$. Em [18], Corona apresenta um capítulo dentro de um livro dedicado à técnicas estatísticas, que prossegue apresentando os resultados de medidas experimentais e sua descrição estatística. Em 1996, Corona [19] analisa o comportamento das medidas dentro da câmara reverberante de modos misturados, utilizando a função Rayleigh e os testes de ajuste de curvas $\chi^{2}$ e Kolmogorov-Smirnov. Em 2000, em outro artigo [20], apresenta as funções probabilística Rice e Rayleigh, que permitem a inclusão de componentes não misturados, para o caso de câmaras mal operadas, bem como comparações com dados experimentais. Em 2002 [21], faz uma revisão do desenvolvimento de câmaras reverberantes, junto com Ladbury e Latmiral, com base no texto clássico de 1976. Em 2004 descreve a utilização da distribuição generalizada $\mathrm{K}$, que modela os vários casos especiais (mistura perfeita, presença de componente não misturada etc.) [22].

Em 1991 [50] Kostas apresenta a descrição dos campos eletromagnéticos (EM) acoplados em uma antena dentro de uma câmara reverberante, em termos de funções estatísticas tipo Rayleigh (chi-quadrada com 2 graus de liberdade), para cada componente do campo EM. Os campos EM resultantes são descritos por uma 
função densidade de probabilidade chi-quadrada com 6 graus de liberdade. É efetuada a análise de dados experimentais.

Em 1993, Lehman [51] apresentou um estudo técnico à força aérea dos EUA/NIST, com base na estatística Bayesiana, que modela o comportamento dos campos EM dentro de cavidades complexas. A partir de funções analíticas, deriva expressões para o fator de qualidade $Q$, funções densidade de probabilidade (campos EM componentes e total), além de apresentar testes de ajuste de curvas.

Também em 1993, Price, Davis e Wenaas [52] descrevem uma técnica analítica para previsão da distribuição estatística das amplitudes de campo em cavidades complexas, resultante da excitação de milhares de modos dentro dessas cavidades. Propõem que a distribuição possa ser representada por uma função de densidade de probabilidade gama tornando-se, para cavidades com $Q$ de moderado a baixo, uma distribuição chi-quadrada com dois (componentes) ou seis (total) graus de liberdade. Apresentam-se também medidas em diferentes sistemas, com características diversas (avião, lata de refrigerante), para corroborar a teoria.

Durante "workshop" do IEEE 2000 [53], Perini tratou das incertezas de medição, através de estatística descrevendo os campos em termos de função densidade de probabilidade normal e de sua probabilidade acumulada. Apresenta a consideração de vários equipamentos sob teste ou apenas um equipamento de um lote com incertezas fixadas.

Em artigo de 2003, Carobbi, Cati e Millanta [54] tratam da modelagem de funções estatísticas para descrever o comportamento dos campos eletromagnéticos em testes de EMC, tendo em vista grandes dispersões dos dados medidos. Além disso, introduzem funções densidade de probabilidade mais gerais, como a Rice, para modelagem do ambiente EM dentro da câmara reverberante.

Outra abordagem foi apresentada em 2006 por Hallbjörner [55], que apresenta um método para estimativa do número de amostras independentes necessárias para avaliar a uniformidade de campos EM de câmaras reverberantes. De forma diferente do método convencional, em que se calcula a função de correlação das 
amostras, é proposto um método que compara as amostras medidas na vizinhança do ponto desejado. Utiliza resultados de simulações numéricas e de medições para validar o método.

Em 2007, Orjubin [56], [57] apresenta a representação estatística do campo E através de uma distribuição tipo Weibull e demonstra que ela pode ser usada para modelar o comportamento da câmara reverberante excitada por pás. Notam-se resultados acima das médias, o que é caracterizado pela função densidade de probabilidade com "cauda pesada", ou seja, valores extremos. Caracteriza-se, assim, a modelagem EV (“Extreme Values"). O método de elementos finitos e a análise modal são utilizados para calcular os campos eletromagnéticos na câmara. O efeito de carga dentro da câmara é avaliado através do fator de qualidade $Q$ e a uniformidade do campo é estudada aplicando-se o método de Monte Carlo. No mesmo ano de 2007 [58], uma extensão deste trabalho é apresentada, utilizando-se teoria estatística, e propondo a aplicação da distribuição GEV ("Generalized Extreme Value"), que engloba as funções densidade de probabilidade Gumbel, Weibull e Fréchet.

\subsubsection{Métodos de Otimização Aplicados às Câmaras Reverberantes}

Em 2005, Clegg [59] adota uma metodologia de otimização de câmaras, através da variação de parâmetros, tais como dimensões da câmara e do misturador e formato do misturador (quantidade de pás, ângulos entre elas), utilizando algoritmos genéticos. Uma verificação experimental foi realizada, através de medidas na câmara reverberante da Universidade de York. Como resultado comenta-se que o misturador com melhor desempenho apresenta formas e dimensões que inviabilizam a fabricação, devido ao seu volume e a utilização deste quando comparado com o volume total da câmara.

\subsubsection{Abordagens experimentais}

Conforme já mencionado anteriormente, o precursor no desenvolvimento de análises estatísticas na avaliação de câmaras foi Corona, em 1976 [17]. Utilizou dos resultados experimentais obtidos através de ensaios em câmaras reverberantes, 
operadas em modos misturados. A descrição dos ensaios efetuados por Corona são apresentados em [17]-[22].

Em 1997, Ladbury, Koepke e Camell [11] apresentam um estudo de refinamento de medidas para avaliação em câmaras reverberantes, operadas em modos misturados, ressaltando-se os aspectos relativos à utilização de equipamentos apropriados e a consequente diminuição das incertezas de medição. Em 1999, Ladbury e Koepke [12] apresentam várias considerações sobre os valores medidos e as análises de média e desvio padrão, correspondentes à análise de uma câmara utilizando os procedimentos errôneos e os corretos são apresentados. Desta forma, demonstram que resultados incorretos, em diversas etapas, podem se sobrepor entre si, compensando-se, de forma a gerar resultados próximos aos corretos (casualmente).

Em 2001, Freyer e Bäckstrom [60] publicam uma comparação das tendências de erros observados nas medidas executadas em uma câmara reverberante, operada em modos sintonizados, com 12 posições de pás misturadoras, e em uma câmara anecóica, em condições equivalentes de campo elétrico. Chegaram à conclusão que na câmara reverberante o erro pode ser minimizado, se a câmara for operada com maior quantidade de passos no giro das pás, apresentando resultados mais satisfatórios que o das anecóicas.

Harima e Yamanaka [61] apresentam a avaliação experimental de uma câmara operada em modos sintonizados, com a verificação das variações dos erros quando se varia o número de posições das pás do misturador, quantidade de misturadores dentro da câmara e de pontos de coleta de dados, para frequências entre $200 \mathrm{MHz}$ e $30 \mathrm{GHz}$. Através da comparação entre os resultados, concluem que são suficientes dois misturadores, 100 posições dos misturadores e que poucos locais de coleta de dados aumentam a variação dos erros de medida. Nota-se que entre 27 e 125 pontos de coleta os resultados de variação de erros não foi expressiva, porém entre 08 e 27 pontos a houve uma deterioração na linearidade dos resultados. Da mesma forma, em 2005 Harima [62] comparou as curvas resultantes das funções de densidade de probabilidade teóricas tipo Rayleigh (que é outra 
denominação dada à chi-quadrada com dois graus de liberdade) com os dados obtidos. Verificou então, que quanto mais modos existem dentro da câmara (frequências de operação maiores), melhor é o ajuste das curvas teóricas e experimentais.

Wellander, Lundén e Bäckstrom apresentam a caracterização experimental da câmara da Agência de Pesquisa de Defesa da Suécia (FOI), comparando a distribuição cumulativa do valor máximo sobre o valor médio com a distribuição chiquadrada. Em artigo posterior [64], os autores apresentam uma investigação sobre o projeto de várias pás misturadoras na câmara da FOI. Foi detectado que existiam componentes não misturadas, para determinadas configurações de misturadores, e que a câmara poderia ser operada em frequências inferiores, após a adequação dos misturadores.

De Leo e Primiani [65], em artigo de 2005, utilizam duas linhas de transmissão, que representam o equipamento sob teste (EST), e fazem ensaios comparativos entre uma câmara reverberante, operada cerca de 10 vezes acima da frequência de corte e uma câmara anecóica. Foi verificado, em concordância com a teoria, que a câmara reverberante tem ganho de tempo de teste, pois nas câmaras anecóicas o ajuste desejado da direção e magnitude pode ser encontrado somente após várias repetições dos testes, ao passo que devido às características de campo omnidirecional das câmaras reverberantes esse resultado é obtido mais rapidamente.

Cerri, De Leo e Primiani [66] apresentam um teste experimental utilizando uma antena dipolo como emissor, com posicionamento aleatório, de forma a substituir as pás girantes. Desta forma giram a antena, montada sobre um cavalete móvel. Indicam, desta forma, a possibilidade de utilização de um arranjo de dipolos para a mistura dos campos EM dentro da câmara reverberante. Os resultados experimentais adaptam-se bem à previsão de distribuição de probabilidades chiquadrada com dois graus de liberdade.

Piette, Moesen e Montezuma [67] apresentam o "setup" de testes, resultados de medições e análise estatística da câmara reverberante da Royal Military Academy, que tem configuração cúbica. Os resultados obtidos experimentalmente indicaram 
que a câmara preenche os requisitos de uniformidade das normas, habilitando-a para ensaios em frequências entre $800 \mathrm{MHz}$ e $2,5 \mathrm{GHz}$.

Em 2006, Holloway, Hill et al [68] apresentam as medidas de campo E sob diferentes condições de carga dentro de uma câmara reverberante. Os resultados experimentais são mostrados para diversas frequências. Faz-se uma análise de limite de carregamento calculado através de funções densidade de probabilidade. Trata-se de trabalho complementar ao de Hill [15] que havia apresentado métricas para a verificação de carregamento de câmaras reverberantes, com base no fator de qualidade $Q$ da câmara.

Em artigo de 2007 Pouhè [69] utiliza um método experimental para avaliar a uniformidade em câmaras TEM. O método consiste de medições por toda a área de interesse da câmara TEM, e com essas medições gerou fórmulas métricas para avaliar se os desvios padrão nestas áreas atendem à norma [9]. Como resultado a ser destacado, menciona-se que as exigências de tamanho da área de uniformidade das normas (de câmaras TEM) geram áreas muito menores que as áreas em que efetivamente a uniformidade de $6 \mathrm{~dB}$ é alcançada.

\subsubsection{Tendências atuais relacionadas às câmaras de testes em CEM}

Lallechère [72] aborda simulações com códigos híbridos no domínio do tempo, utilizando Finite Diference Time Domain (FDTD) em conjunto com Finite Volumes Time Domain (FVTD). A zona onde é aplicada o FDTD é toda a câmara, exceto a zona dos misturadores, onde é aplicada a FVTD. A FVTD tem a característica de considerar de forma natural as malhas conformes, não estruturadas e fortemente não homogêneas, mas por outro lado as perdas numéricas são superiores às perdas reais. Aplica-se a áreas de grande complexidade geométrica, como as pás misturadoras, deixando o restante da área de propagação para cálculo com a FDTD. Ainda Lallechère [73] faz uma comparação dos valores obtidos através de simulação numérica e de medidas experimentais, introduzindo um critério de relação entre as grandezas de calibração. Mostra a importância da obtenção de modelos que 
incluam as perdas reais, além da modelagem correta de antenas e outros objetos que estejam dentro da câmara, para a calibração desta.

Lemoine [74] propõe uma evolução na metodologia de avaliação das câmaras reverberantes, aplicando-se intervalos de confiança ao invés do limite de $3 \mathrm{~dB}$, atualmente estabelecidos pelas normas. Baseia-se em medidas e em distribuições probabilísticas, como a de Rayleigh, e leva em consideração o número de posições independentes das pás. Em particular, ressalta-se que a CR avaliada, embora não satisfaça à condição proposta, satisfaz a condição das normas.

Zhang [75] avalia uma câmara durante a sua calibração, considerando a uniformidade dos campos em função da posição e altura da antena de excitação, além das dimensões do volume de trabalho. Entre os resultados obtidos destaca-se aquele referente ao volume de trabalho, cujos limites poderiam ir além dos atuais 1 $\mathrm{m}$ das paredes. Mesmo para 0,5 $\mathrm{m}$ de distância das paredes, os requisitos de uniformidade seriam atendidos.

Moebhurrun [77] utiliza uma pequena câmara reverberante para avaliação da potência total irradiada por uma placa de "WiFi".

Cerri [78] propõe uma configuração que poderá possuir um vetor de monopolos acoplados, de forma que se possa controlar eletronicamente a emissão dentro da câmara.

Finalmente, vários trabalhos escritos por Anderson [79], Conway [80] e suas equipes, tratam sobre a medição de campos radiados por dispositivos tais como antenas de redes sem fio e telefones celulares, entre outros, utilizando um tipo comercial de câmara reverberante com linhas de transmissão, na qual as linhas de transmissão funcionam como antenas de recepção. O ensaios de validação apresentam resultados com baixa diferença (cerca de 0,5 dB) entre a câmara anecóica e a "BlueTest". Destaca-se que esta configuração de câmara apresenta dimensões reduzidas em comparação às câmaras reverberantes com pás misturadoras, quando se consideram as mesmas frequências de operação. 
Menciona-se, assim, que a presente Tese apresenta similaridades com [79] e [80] relativas ao seu objetivo e metodologia, propondo-se uma configuração alternativa de forma a acelerar o processo de medição através de dispositivos eletrônicos e suprir as deficiências encontradas nas câmaras já consagradas. Com relação às técnicas utilizadas mencionam-se a utilização de métodos de otimização em conjunto com os modelos numéricos. Destacam-se, no entanto, as medidas experimentais realizadas e a análise da aplicação de defasagens na excitação, além do efeito da carga na CELT, a fim de prover a uniformidade de campos eletromagnéticos. 


\section{Metodologia}

Neste capítulo é apresentado o desenvolvimento teórico referente aos conceitos envolvidos na análise de câmaras excitadas por linhas de transmissão. Desta forma, partindo das equações de Maxwell, foi efetuado um desenvolvimento sumário dos tipos de ondas que podem ocorrer em guias de ondas e cavidades ressonantes, além do próprio conceito de cavidade ressonante e campos gerados dentro destas cavidades. Em seguida relaciona-se as ondas eletromagnéticas geradas por linhas de transmissão, os coeficientes de reflexão relacionados às linhas de transmissão, a Taxa de Onda Estacionária, além da própria onda estacionária e os efeitos de linhas de transmissão inseridas dentro de invólucros metálicos. Na seção posterior é efetuada uma introdução aos parâmetros $\mathrm{S}$. Na seção subsequente, discute-se sumariamente o método que foi aplicado no desenvolvimento dos modelos numéricos da CELT. Finalmente, alguns aspectos dos métodos de otimização, em especial dos algoritmos genéticos são abordados.

A seguinte notação é adotada neste capítulo:

- Caracteres em negrito denotam vetores: $\mathbf{E , H , B , J , D ; ~ e ~}$

- caracteres com ponto $\dot{\mathbf{E}}, \dot{\mathbf{H}}, \dot{\mathbf{B}}, \dot{\mathbf{J}}, \dot{\mathbf{D}}$ denotam fasores.

\subsection{Equações de Onda para regime permanente senoidal}

Considerando-se meio homogêneo, isotrópico e linear, isento de fontes de correntes de condução ( $\mathbf{J}=0$ ) e de cargas elétricas, e regime permanente senoidal, as equações de Helmholtz podem ser escritas por:

$$
\begin{gathered}
\nabla^{2} \dot{\mathrm{E}}+\omega^{2} \mu \varepsilon \dot{\mathrm{E}}=0 \\
\nabla^{2} \dot{\mathbf{H}}+\omega^{2} \mu \varepsilon \dot{\mathbf{H}}=0
\end{gathered}
$$

Nota-se que o número de onda, se o meio não tiver perdas, é dado por: 


$$
k=\frac{2 \pi}{\lambda}
$$

Logo, substituindo (3) em (1) e (2), as equações de onda podem ser reescritas, resultando em (4) e (5).

$$
\begin{aligned}
& \nabla^{2} \dot{\mathbf{E}}+k^{2} \dot{\mathbf{E}}=0 \\
& \nabla^{2} \dot{\mathbf{H}}+k^{2} \dot{\mathbf{H}}=0
\end{aligned}
$$

\subsection{Modos de Propagação de Ondas Eletromagnéticas}

Nas seções seguintes são conceituados os modos de propagação de ondas eletromagnéticas, iniciando-se pelo modo Transverso EletroMagnético (TEM), em seguida descrevendo os modos Transverso Elétrico e Transverso Magnético.

O desenvolvimento abaixo considera o eixo z como sendo paralelo à direção de propagação da onda e o plano xy ortogonal a esta direção.

\subsubsection{Transverso Eletromagnético (TEM)}

Os campos TEM são assim designados quando os campos $\mathbf{E}$ e $\mathbf{H}$ são perpendiculares à direção de propagação. Um campo com tais propriedades é dito um modo transverso eletromagnético, que é classicamente a forma das onda planas e como se apresentam em linhas de transmissão. Estas se propagam em qualquer faixa de frequência.

Assim, os campos elétrico e magnético não apresentam componentes na direção de propagação da onda, ou seja, as componentes são existentes apenas no plano transversal à direção de propagação.

Estas ondas podem propagar-se ao longo de um ou mais condutores, mas não podem propagar-se dentro de um guia oco [85]. 
Tomando z como a direção Normal aos campos e a fase de $\dot{E}_{x 0}^{+}$como referência, obtém-se para a propagação na direção z [84], considerando meio isotrópico e de condutividade nula, em função do tempo.

$$
\begin{gathered}
\dot{E}_{x}=\dot{E}_{x 0}^{+} e^{-j k z} \\
\mathbf{E}(t, z)=\operatorname{Re}\left[\mathrm{E}_{x 0}^{+} \mathrm{e}^{-j k z} \mathrm{e}^{j \omega t}\right] \hat{a}_{x} \\
\mathbf{H}(t, z)=\operatorname{Re}\left[H_{y} \mathrm{e}^{j \omega t}\right] \hat{a}_{y}
\end{gathered}
$$

onde:

$\frac{\partial \mathbf{H}_{y}}{\partial z}=\varepsilon \frac{\partial \mathbf{E}_{x}}{\partial t}$.

\subsubsection{Modos de Propagação Transverso Elétrico e Transverso Magnético}

Os modos de propagação são determinados a partir das equações de Maxwell, aplicando-se as condições de contorno impostas pelo tipo de guia de onda. Representam o conjunto de ondas eletromagnéticas que são guiadas de maneira estável pelo guia. Ressalta-se que os guias de onda admitem somente números discretos de modos propagando-se ao longo de seu comprimento.

Uma característica fundamental das ondas guiadas em cavidades é que apresentam frequência de corte inferior $\left(f_{c}\right)$, só havendo propagação acima desta frequência. Esta característica está intrinsecamente ligada às dimensões geométricas da cavidade. Assim, os modos propagados são dados por números inteiros subscritos, por exemplo, $\mathrm{TE}_{10}$ e $\mathrm{TM}_{01}$ (serão apresentados nas seções seguintes).

\subsubsection{Transverso Elétrico (TE)}

A onda é chamada de transversa elétrica quando o campo $\mathbf{E}$ não apresenta componentes na direção de propagação da onda. Em outras palavras, o campo $\mathbf{E}$ 
está totalmente em um plano (xy) que é transversal à direção de propagação (a direção z), descrito na equação (9). Neste modo, existe propagação do campo H na direção de propagação da onda:

$$
\left\{\begin{array}{c}
\dot{E}_{z}=0 \\
\dot{H}_{Z} \neq 0
\end{array}\right.
$$

\subsubsection{Transverso Magnético (TM)}

A onda é chamada de transversa magnética quando o campo H não apresenta componentes na direção de propagação da onda. Em outras palavras, o campo $\mathbf{H}$ está totalmente em um plano (xy) que é transversal à direção de propagação (a direção z). Neste modo, existe uma componente de campo $\mathbf{E}$ ao longo da direção z de propagação da onda:

$$
\left\{\begin{array}{l}
\dot{E}_{z} \neq 0 \\
\dot{H}_{Z}=0
\end{array}\right.
$$

\subsection{Teoria de Eletromagnetismo aplicada às Cavidades Ressonantes}

\subsubsection{Cavidades - Análise modal}

Uma cavidade retangular é formada tomando uma seção de guia de onda (por exemplo, um tubo metálico quadrado preenchido com dielétrico perfeito) e fechando-se suas faces frontal e traseira, com placas condutoras. O acoplamento para dentro ou para fora das cavidades pode ser efetuado através do acoplamento de pequenas antenas ou de orifícios.

As cavidades retangulares, como a representada na Figura 1, podem comportar os modos $\mathrm{TE}_{\mathrm{mnp}}$ ou $\mathrm{TM}_{\mathrm{mnp}}$, nas faixas de frequência, nas quais as ondas se propagam. Os modos propagantes comportam-se de maneira similar àquela dos guias de onda, a menos que sejam geradas ondas estacionária decorrentes das condições de contorno adicionais ao longo das paredes frontal e traseira. As formas dos campos ao longo das direções $x$ e $y$, e as condições de contorno na paredes laterais, superior e inferior são idênticas àquelas dos guias de onda. 
Note-se que os modos de propagação TEM dentro de uma cavidade retangular, preenchida com dielétrico perfeito, não serão produzidos.

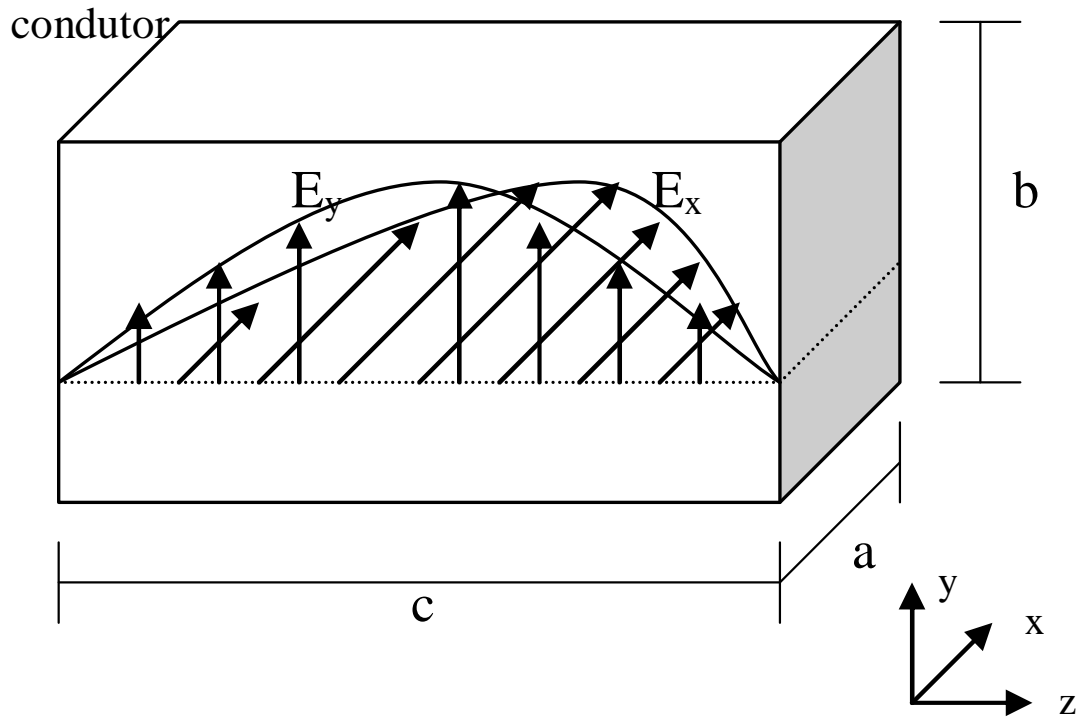

Figura 1 - Cavidade retangular, com perfil das componentes de campo Ex e Ey, estacionárias em uma cavidade vazia, sem fontes de corrente, modo $T E_{110}$.

Os modos dentro de uma cavidade de forma simples, totalmente preenchida com dielétrico perfeito (vácuo) e sem fontes de corrente, podem ser calculados de forma analítica, como uma abordagem simplificada. Levando-se em conta as condições de contorno nas paredes, e a definição dos vetores potencial elétrico e potencial magnético, deriva-se equações para cálculo dos valores dos campos $\mathbf{E}$ e $\mathbf{H}$ em cada ponto da câmara. Um equacionamento detalhado é apresentado em [81], e outras abordagens similares podem ser encontradas em [85], [88], [90].

Definindo-se os vetores auxiliares potencial elétrico $(\dot{\mathbf{F}})$ e potencial magnético $(\dot{\mathrm{A}})$, tem-se:

$$
\begin{gathered}
\dot{\mathbf{E}}=-\frac{1}{\varepsilon} \nabla \times \dot{\mathbf{F}} ; \quad \nabla(-\nabla \times \dot{\mathbf{F}})=0 \\
\dot{\mathbf{B}}=\nabla \times \dot{\mathbf{A}} ; \quad \nabla^{2} \dot{\mathbf{A}}=0
\end{gathered}
$$

As condições de contorno nas pareces frontal e traseira da cavidade são dadas pelas equações (13) e (14). 


$$
\begin{aligned}
& \dot{E}_{x}(0 \leq x \leq a, 0 \leq y \leq b, z=0)=\dot{E}_{x}(0 \leq x \leq a, 0 \leq y \leq b, z=c)=0 \\
& \dot{E}_{y}(0 \leq x \leq a, 0 \leq y \leq b, z=0)=\dot{E}_{y}(0 \leq x \leq a, 0 \leq y \leq b, z=c)=0
\end{aligned}
$$

As condições de contorno, nas paredes superior e inferior são análogas e dadas por:

$$
\begin{aligned}
& \dot{E}_{x}(0 \leq x \leq a, y=0, z)=\dot{E}_{x}(0 \leq x \leq a, y=b, z)=0 \\
& \dot{E}_{z}(0 \leq x \leq a, y=0, z)=\dot{E}_{z}(0 \leq x \leq a, y=b, z)=0
\end{aligned}
$$

Ainda, as condições de contorno das paredes lateral direita e esquerda, são:

$$
\begin{aligned}
& \dot{E}_{y}(x=a, 0 \leq y \leq b, z)=\dot{E}_{y}(x=a, 0 \leq y \leq b, z)=0 \\
& \dot{E}_{z}(x=a, 0 \leq y \leq b, z)=\dot{E}_{z}(x=a, 0 \leq y \leq b, z)=0
\end{aligned}
$$

- Modo transverso E

Considerando-se todas estas condições de contorno (13)-(18), a função $F_{z}(x, y, z)$ para cavidade retangular pode ser escrita como equações (19) e (20).

$$
\begin{gathered}
\dot{F}_{z}(x, y, z)=A_{m n p} \cos \left(\frac{m \pi}{a} x\right) \cos \left(\frac{n \pi}{b} y\right) \operatorname{sen}\left(\frac{p \pi}{c} z\right) \mathrm{e}^{(j \omega t-\beta z)} \\
\left.\begin{array}{c}
m=0,1,2 \ldots \\
n=0,1,2 \ldots \\
p=0,1,2 \ldots
\end{array}\right\}
\end{gathered}
$$

$A_{m n p}=$ Amplitude complexa da onda

que são similares às equações aplicadas aos guias de onda, exceto pelas funções de onda estacionária representando as variações em $z$.

Assim, pode-se escrever a componente $\dot{E}_{x}$, aplicando-se a equação (11) à (19): 


$$
\dot{E}_{x}(x, y, z)=-\frac{1}{\varepsilon} \frac{\partial F_{z}}{\partial y}
$$

Os demais componentes de $\dot{\mathrm{E}}$ e $\dot{\mathbf{H}}$ para os modos $T E_{m n p}$ são calculados de forma equivalente.

Então, os modos TE mnp podem ser calculados através das equações (22) a (27).

$$
\begin{gathered}
\dot{E}_{x}=\frac{1}{\varepsilon} \frac{n \pi}{b} A_{m n p} \cos \left(\frac{m \pi}{a} x\right) \operatorname{sen}\left(\frac{n \pi}{b} y\right) \operatorname{sen}\left(\frac{p \pi}{c} z\right) \mathrm{e}^{(j \omega t-\beta z)} \\
\dot{E}_{y}=-\frac{1}{\varepsilon} \frac{m \pi}{a} A_{m n p} \operatorname{sen}\left(\frac{m \pi}{a} x\right) \cos \left(\frac{n \pi}{b} y\right) \operatorname{sen}\left(\frac{p \pi}{c} z\right) \mathrm{e}^{(j \omega t-\beta z)} \\
\dot{E}_{z}=0 \\
\dot{H}_{x}=j \frac{1}{\omega \mu \varepsilon} \frac{m \pi}{a} \frac{p \pi}{c} A_{m n p} \operatorname{sen}\left(\frac{m \pi}{a} x\right) \cos \left(\frac{n \pi}{b} y\right) \cos \left(\frac{p \pi}{c} z\right) \mathrm{e}^{(j \omega t-\beta z)} \\
\dot{H}_{y}=j \frac{1}{\omega \mu \varepsilon} \frac{n \pi}{b} \frac{p \pi}{c} A_{m n p} \cos \left(\frac{m \pi}{a} x\right) \operatorname{sen}\left(\frac{n \pi}{b} y\right) \cos \left(\frac{p \pi}{c} z\right) \mathrm{e}^{(j \omega t-\beta z)} \\
\dot{H}_{z}=-j \frac{1}{\omega \mu \varepsilon} A_{m n p}\left[\left(\frac{m \pi}{a}\right)^{2}+\left(\frac{n \pi}{b}\right)^{2}\right] \cos \left(\frac{m \pi}{a} x\right) \cos \left(\frac{n \pi}{b} y\right) \operatorname{sen}\left(\frac{p \pi}{c} z\right) \mathrm{e}^{(j \omega t-\beta z)}
\end{gathered}
$$

- Modo transverso magnético

Tomando-se o vetor potencial $\mathbf{A}$, que atende às condições de contorno conforme as equações (13)-(18), resulta em:

$$
\begin{gathered}
\dot{\mathbf{A}}_{z}(x, y, z)=B_{m n p} \operatorname{sen}\left(\frac{m \pi}{a} x\right) \operatorname{sen}\left(\frac{n \pi}{b} y\right) \cos \left(\frac{p \pi}{c} z\right) \mathrm{e}^{(j \omega t-\beta z)} \\
\text { onde: } \left.\begin{array}{r}
m=0,1,2 \ldots \\
n=0,1,2 \ldots \\
p=0,1,2 \ldots
\end{array}\right\} \\
\mathrm{B}_{m n p}=\text { Amplitude complexa da onda. }
\end{gathered}
$$


Aplicando-se (12) à equação (28), os modos $\mathrm{TM}_{\mathrm{mnp}}$ podem ser calculados através das equações (30) a (35).

$$
\begin{gathered}
\dot{E}_{x}=-B_{m n p} \frac{m \pi}{a}\left(-\frac{p \pi}{c}\right) \cos \left(\frac{m \pi}{a} x\right) \operatorname{sen}\left(\frac{n \pi}{b} y\right) \operatorname{sen}\left(\frac{p \pi}{c} z\right) \mathrm{e}^{(j \omega t-\beta z)} \\
\dot{E}_{y}=-B_{m n p} \frac{n \pi}{b}\left(-\frac{p \pi}{c}\right) \operatorname{sen}\left(\frac{m \pi}{a} x\right) \cos \left(\frac{n \pi}{b} y\right) \operatorname{sen}\left(\frac{p \pi}{c} z\right) \mathrm{e}^{(j \omega t-\beta z)} \\
\dot{E}_{z}=B_{m n p}\left(\left(\frac{m \pi}{a}\right)^{2}+\left(\frac{n \pi}{b}\right)^{2}\right) \operatorname{sen}\left(\frac{m \pi}{a} x\right) \operatorname{sen}\left(\frac{n \pi}{b} y\right) \cos \left(\frac{p \pi}{c} z\right) \mathrm{e}^{(j \omega t-\beta z)} \\
\dot{H}_{x}=B_{m n p} \frac{n \pi}{b} \operatorname{sen}\left(\frac{m \pi}{a} x\right) \cos \left(\frac{n \pi}{b} y\right) \cos \left(\frac{p \pi}{c} z\right) \mathrm{e}^{(j \omega t-\beta z)} \\
\dot{H}_{y}=-B_{m n p} \frac{m \pi}{a} \cos \left(\frac{m \pi}{a} x\right) \operatorname{sen}\left(\frac{n \pi}{b} y\right) \cos \left(\frac{p \pi}{c} z\right) \mathrm{e}^{(j \omega t-\beta z)} \\
\dot{H}_{z}=0
\end{gathered}
$$

Uma característica das cavidades retangulares, preenchidas com um dielétrico perfeito, é a de atenuar todos os modos de propagação que se encontram abaixo de determinada frequência, denominada frequência de corte $\left(f_{c}\right)$.

Então, não há propagação na faixa de frequência de $0<f<f_{c}$ e quando $f \geq f_{c}$ o modo referido é propagado.

A frequência de corte de uma cavidade retangular pode ser calculada por:

$$
f_{m n p}=\frac{1}{2} \sqrt{\frac{1}{\mu_{0} \varepsilon_{0}}} \sqrt{\left(\frac{m}{a}\right)^{2}+\left(\frac{n}{b}\right)^{2}+\left(\frac{p}{c}\right)^{2}}
$$

onde $a, b$ e c são as dimensões da cavidade e $m, n$ e p são números inteiros e definem os modos que são propagados.

Uma abordagem detalhada pode ser encontrada em [81]. 


\subsubsection{Campos Quase-TEM}

Os campos são chamados quase-TEM quando ocorre a distorção dos campos elétrico e magnético devido à presença de paredes condutoras. Um breve comentário sobre os campos quase-TEM é efetuado nesta seção. Maiores detalhes são dados em [84].

Considerando que as superfícies condutoras metálicas são usadas para guiar as ondas eletromagnéticas que se deslocam no espaço, e a análise dos campos eletromagnéticos é, usualmente, feita sob a premissa de que as superfícies dos condutores possuem condutividade infinita, conclui-se, através da aplicação das equações de Maxwell, que o campo E tangencial a essas superfícies seria zero.

Mas, na realidade o campo terá uma componente tangencial, com valor próximo a zero. Este efeito é devido aos campos dentro de um guia de onda (ou cavidade com paredes metálicas), que induzem correntes superficiais nas paredes da câmara, gerando, por sua vez, outras componentes de campos magnéticos, que se sobrepõem aos campos já existentes, gerando uma polarização elíptica.

Devido à componente longitudinal do campo $\mathrm{E}$, os componentes dos campos elétrico e magnético não são confinadas aos planos transversos à direção de propagação. A diferença da onda plana padrão verdadeira é pequena e, uma vez que a onda plana é uma configuração do modo TEM mais geral, este modo com perdas poderia ser chamado de modo quase-TEM.

\subsection{Linhas de Transmissão}

Referências: Weisshaar [83], Magnusson [84], Collin [85],

As linhas de transmissão apresentam-se como uma parte essencial da CELT, funcionando como elementos de excitação das ondas TEM dentro da cavidade. Desta forma, os principais conceitos de linhas de transmissão são analisados e também suas equações são aqui apresentadas. 
Uma linha de transmissão é um sistema de guia eletromagnética para transmissão de sinais elétricos e potência. Geralmente consiste de dois ou mais condutores imersos em um meio dielétrico. Ainda, circuitos de linhas de transmissão podem ser utilizados em várias configurações para casamento de impedâncias.

No desenvolvimento abaixo, considera-se que a direção z é a direção paralela à linha de transmissão, e que o plano xy é ortogonal à mesma linha de transmissão.

\subsubsection{Características básicas das linhas de transmissão}

Para uma linha de transmissão ideal, consistindo de dois condutores paralelos perfeitamente condutores, imersos em um meio dielétrico homogêneo, o modo de transmissão fundamental é uma onda Transverso-Eletromagnética (TEM), que é similar à onda plana [83], [84].

Considerando-se linhas de transmissão sem perdas e excitação permanente senoidal, a formulação eletromagnética para as ondas TEM em uma linha de transmissão pode ser relacionada às quantidades correspondentes de corrente e tensão.

Por outro lado, ao integrar-se o campo elétrico entre os condutores e o campo magnético à volta do condutor em um dado plano transverso à direção da propagação de onda, poder-se-à obter, conforme equações (37)-(38), a indutância e a capacitância de linha de transmissão.

$$
\begin{aligned}
& L=\frac{\mu}{|\dot{V}|^{2}} \int_{S} \dot{\mathbf{H}} \cdot \dot{\mathbf{H}}^{*} d s \\
& C=\frac{\varepsilon}{|\dot{V}|^{2}} \int_{S} \dot{\mathbf{E}} \cdot \dot{\mathbf{E}}^{*} d s
\end{aligned}
$$

Após a obtenção dos parâmetros L e C, pode-se, então, escrever as equações de tensão e corrente, em função do tempo $t$ e da posição $z$, conforme equações (39)(40). 


$$
\begin{gathered}
v(t, z)=v_{0}^{+} \mathbf{c o s}(\omega t-\beta z)+v_{0}^{-} \mathbf{c o s}(\omega t+\beta z) \\
i(z, t)=\frac{v^{+}\left(t-\frac{z}{v}\right)}{Z_{0}}-\frac{v^{-}\left(t+\frac{z}{v}\right)}{Z_{0}}
\end{gathered}
$$

onde:

- $Z_{0}$ é a impedância característica da linha de transmissão, calculada por:

$$
Z_{0}=\sqrt{\frac{L}{C}}
$$

- $\quad v_{o}^{+}$onda de tensão positiva na direção z (progressiva);

- $\quad v_{0}^{-}$onda de tensão negativa na direção z (regressiva);

- $\quad z$ posição sobre o eixo z;

- $\quad v$ velocidade de propagação da onda;

- $\quad \beta$ é a constante de fase.

Outros parâmetros importantes quando se trata de linhas de transmissão são listados abaixo:

O comprimento de onda na linha de transmissão é calculado pela equação (42):

$$
\lambda=v / f
$$

A constante de fase é calculada pela equação (43):

$$
\beta=\omega / v=2 \pi / \lambda
$$

E a velocidade de propagação da onda em uma linha de transmissão é dada pela equação (44): 


$$
v=c / \sqrt{\varepsilon \mu}
$$

Onde:

- $\quad c$ é a velocidade da luz no vácuo $c=\frac{1}{\sqrt{\mu_{0} \varepsilon_{0}}}$;

- $\varepsilon$ é a permissividade do meio;

- $\quad \mu$ é a permeabilidade do meio;

Uma outra forma usual de expressar as equações de linhas de transmissão é descrita a seguir, considerando-se que a linha é curta, sem perdas e deixando-se implícita a dependência com a frequência.

$$
\begin{gathered}
\dot{V}(z)=\dot{V}^{+} e^{-j \beta z}+\dot{V}^{-} e^{j \beta z} \\
\dot{I}(z)=\frac{1}{z_{0}}\left[\dot{V}^{+} e^{-j \beta z}-\dot{V}^{-} e^{j \beta z}\right]
\end{gathered}
$$

Uma representação de linha de transmissão sem perdas através de um modelo de linhas curtas, é mostrado na Figura 2.

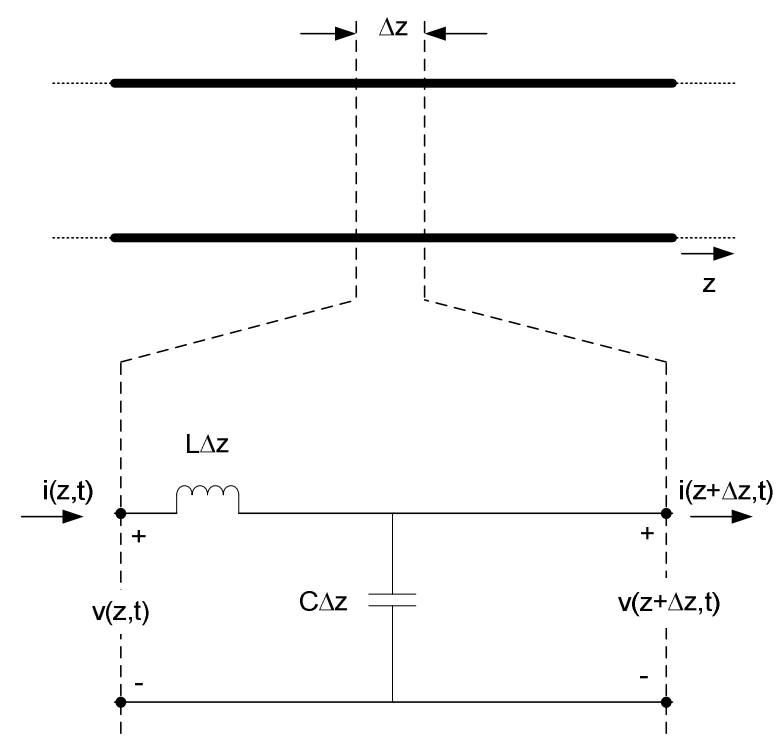

Figura 2 - Modelo de circuito equivalente para linhas de transmissão curta sem perdas. 


\subsubsection{Coeficiente de reflexão}

Conforme já observado no item 2.5.1, uma linha de transmissão é completamente especificada pelos parâmetros $L, C$ e seu comprimento $\ell$, ou equivalente, pela sua impedância característica $Z_{0}=\sqrt{L / C}$ e um tempo de percurso $: t_{d}=\frac{1}{v_{p}}=\ell \sqrt{L C}$.

A terminação das LTs impõe as condições de contorno de tensão e de corrente.

Assim, quando uma onda viajante encontra o final da linha de transmissão, uma onda refletida é gerada, a menos que as terminações apresentem condições de carga que sejam iguais às impedâncias características da linha. A razão da tensão refletida pela tensão incidente na terminação é definida como o coeficiente de reflexão de tensão $\Gamma=|\Gamma| e^{j \theta}$.

Para o circuito da Figura 3, o coeficiente de reflexão de tensão sobre a impedância de carga $Z_{L}$ é dado por:

$$
\Gamma=\frac{Z_{L}-Z_{0}}{Z_{L}+Z_{0}}
$$

O coeficiente de reflexão $(\Gamma)$ pode ser expresso, também, por:

$$
\Gamma=\sqrt{\frac{P_{r e f}}{P_{i n}}}
$$

- $\quad P_{\text {in }}$ é a potência incidente [W]; e

- $\quad P_{\text {ref }}$ é a potência refletida [W]. 


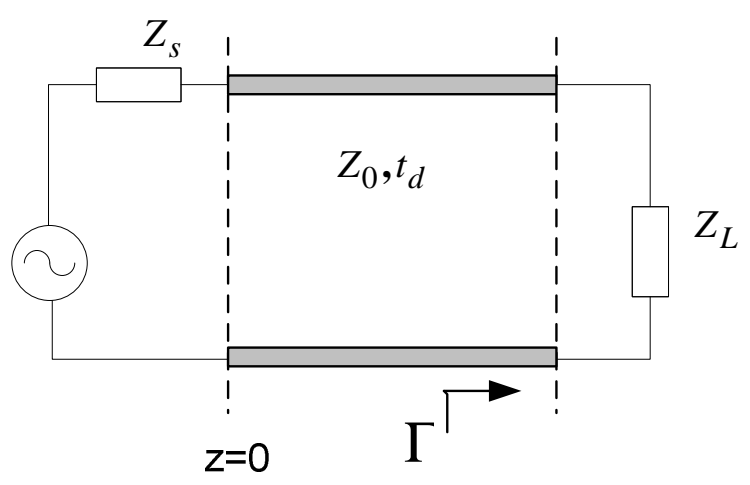

Figura 3 - Circuito equivalente para cálculo do coeficiente de reflexão.

Assim, rearranjando a equação (47), pode-se calcular a impedância de carga $Z_{L}$, em função dos valores de $\Gamma$ e $Z_{0}$ :

$$
Z_{L}=\frac{1+\Gamma}{1-\Gamma} Z_{0}
$$

\subsubsection{Taxa de Onda Estacionária (TOE)}

Define-se TOE como a razão entre o valor máximo pelo mínimo da onda estacionária. Pode ser dado em tensão, corrente ou em potência. Ao considerar os valores de tensão, tem-se:

$$
\mathrm{VTOE}=\frac{V_{\max }}{V_{\min }}
$$

A Taxa de Onda Estacionária pode, também, ser definida por:

$$
T O E=\frac{1+|\Gamma|}{1-|\Gamma|}
$$

\subsubsection{Campo elétrico resultante na consideração da carga}

Nesta seção são apresentadas as análises quando se considera uma linha de transmissão finita no espaço aberto, com a aplicação de diferentes cargas.

De uma maneira similar ao desenvolvimento teórico apresentado anteriormente para as linhas de transmissão, o campo E pode ser escrito como uma somatória das ondas incidente e refletida das ondas TEM. 


$$
\mathrm{E}(x, y, z)=\mathbf{E}_{T E M}(x, y)\left(e^{-j k_{0} z}+\Gamma e^{+j k_{0} z}\right)
$$

onde: Гé o coeficiente de reflexão complexo, dado por:

$$
\Gamma=\frac{Z_{c}-Z_{L}}{Z_{c}+Z_{L}}
$$

Pode-se considerar os seguintes casos particulares: linhas de transmissão com impedâncias casadas e linhas de transmissão com carga aberta ou curto-circuitada:

1) Linhas de transmissão com impedâncias casadas (assemelha-se a uma câmara TEM): não há reflexão.

$$
\Gamma=0=>|\mathbf{E}(x, y, z)|=\left|\mathbf{E}_{T E M}(x, y)\right|
$$

Consequentemente, neste caso, o campo é independente de z. O desvio padrão depende apenas das características no plano transverso. Note-se que as câmaras TEM são concebidas desta forma.

2) Linhas de transmissão com carga curto-circuitada ou circuito aberto: há reflexão e é criada uma onda estacionária no entorno da linha de transmissão, dependente da direção de propagação:

$$
\Gamma \pm 1=>=-1 \Rightarrow|\mathrm{E}(x, y, z)|=2\left|\mathbf{E}_{T E M}(x, y) \operatorname{sen}\left(k_{0} z\right)\right|
$$

\subsubsection{Onda estacionária}

Em duas situações não são geradas reflexões na linha de transmissão: quando a linha é infinita ou quando a linha terminada em carga com impedância igual à impedância característica da linha de transmissão. Isso significa que toda a potência aplicada na linha pelo gerador na entrada é absorvida pela carga na saída. Uma linha com estas características é denominada na literatura como não-ressonante [81]. 
O efeito resultante da reflexão nos terminais da $L T$, e do descasamento de impedâncias, no nosso caso é desejado. Desta forma, vamos tirar proveito da onda estacionária gerada dentro da câmara através do descasamento da linha de transmissão com a carga.

Por outro lado, se uma linha de transmissão sem perdas $(\gamma=j \beta)$ de comprimento finito é terminada em uma carga de valor diferente da impedância característica, ocorrerão reflexões, formando uma onda estacionária. Este efeito é descrito através das equações (56)-(59).

$$
\begin{gathered}
\dot{V}(z)=\dot{V}_{0}^{+} e^{-j \beta z}+\Gamma \dot{V}_{0}^{+} e^{+j \beta z} \\
\dot{I}(z)=\frac{1}{Z_{0}}\left(\dot{V}_{0}^{+} e^{-j \beta}-\Gamma \dot{V}_{0}^{+} e^{+j \beta}\right)
\end{gathered}
$$

onde:

$V_{0}^{+}$- onda progressiva;

$$
\begin{aligned}
& |\dot{V}(z)|=\left|\dot{V}_{0}^{+}\right| \sqrt{(1+|\Gamma|)^{2} \cos ^{2}\left(\beta z-\frac{\theta}{2}\right)+\left(1-|\Gamma|^{2} \operatorname{sen}^{2}\left(\beta z-\frac{\theta}{2}\right)\right)} \\
& |\dot{I}(z)|=\frac{\left|\dot{V}_{0}^{+}\right|}{Z_{0}} \sqrt{(1+|\Gamma|)^{2} \cos ^{2}\left(\beta z-\frac{\theta}{2}\right)+\left(1-|\Gamma|^{2} \operatorname{sen}^{2}\left(\beta z-\frac{\theta}{2}\right)\right)}
\end{aligned}
$$

\subsubsection{Linhas de transmissão como ressonadores}

As ondas de tensão e corrente que são resultantes na linha de transmissão geram campos eletromagnéticos associados e então, de acordo com as relações mostradas no item 2.5.1, a equação do campo instantâneo gerado pela onda estacionária e a envoltória das amplitudes podem ser obtidas. Um desenvolvimento detalhado deste equacionamento é apresentado em [81].

O campo instantâneo na direção $x$ ao considerar a direção de propagação em z gerado pela onda estacionária de tensão, será dado por: 


$$
\begin{aligned}
& \dot{E}_{x}(z, t)=\operatorname{Re}\left[\dot{E}_{x}(z) e^{j \omega t}\right] \\
& =\sqrt{\left(\dot{E}_{0}^{+}\right)^{2}+\left(\dot{E}_{0}^{-}\right)^{2}+2 \dot{E}_{0}^{+} \dot{E}_{0}^{-} \cos (2 \beta z) \times \cos \left[\omega t-\operatorname{tg}^{-1}\left\{\frac{\dot{E}_{0}^{+}-\dot{E}_{0}^{-}}{\dot{E}_{0}^{+}+\dot{E}_{0}^{-}} \operatorname{tg}(\beta z)\right\}\right]}
\end{aligned}
$$

Ainda, o envelope dos valores máximos do campo instantâneo, chamado de amplitude da forma de onda, é dado por:

$$
\left|\dot{E}_{x}(z)\right|=\sqrt{\left(\dot{E}_{0}^{+}\right)^{2}+\left(\dot{E}_{0}^{-}\right)^{2}+2 \dot{E}_{0}^{+} \dot{E}_{0}^{-} \cos (2 \beta z)}
$$

Na direção $y$, equações similares são aplicáveis.

\subsubsection{Independência de campos gerados dentro de envoltórias metálicas}

Referências Collin [85], Ramo [90].

Supondo uma linha de transmissão consistindo de três condutores paralelos (1 externo e dois internos), conforme a Figura 4 , assume-se que os condutores são perfeitamente condutores (PEC) e que o meio que os envolve é o ar $\left(\varepsilon \approx \varepsilon_{0}\right.$ e $\left.\mu \approx \mu_{0}\right)$.

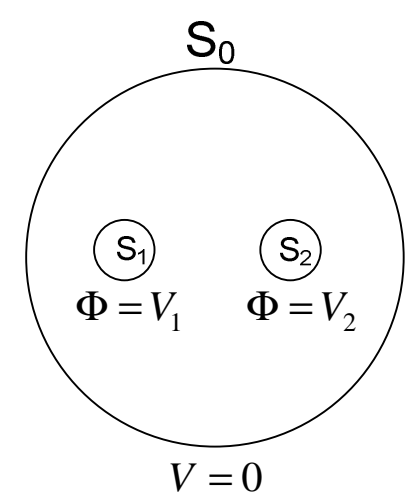

Figura 4 - Linha de transmissão com três condutores, excitação independente dos condutores centrais e condutor externo como referência.

Considerando que o potencial é arbitrário, a blindagem $\mathrm{S}_{0}$ pode ser escolhida como potencial zero, ou referência. Note-se que o potencial pode ser arbitrariamente especificado sobre $S_{1}$ e $S_{2}$. Mostra-se que existem duas soluções linearmente independentes para as ondas TEM nesta configuração de linha de transmissão. Uma solução equivalente, para linhas coaxiais é provida em [85]. Uma vez que 
tenhamos uma superfície $\mathrm{S}_{0}$ que encerre $\mathrm{N}$ condutores, obtém-se $\mathrm{N}$ soluções de onda TEM independentes.

\subsubsection{Influência da defasagem entre as excitações}

A somatória dos campos $\mathrm{E}$ gerados por duas linhas de transmissão, não acopladas e fechadas por uma contenção externa metálica, é dado pela superposição dos campos produzidos por cada uma das linhas de transmissão. Os campos, então, são independentes, conforme descrito no item 2.5.6.

\subsubsection{Efeito no tempo/espaço}

Ao se considerar uma combinação de duas ondas planas uniformes senoidais de mesma frequência, propagando-se no mesmo sentido, mas com diferentes fases, amplitudes e orientações dos vetores de campo, os componentes dos campos na direção $x$, podem ser expressos por:

$$
\begin{aligned}
& \dot{E}_{x 1}=\operatorname{Re}\left(\dot{E}_{x 1}\right)+j \operatorname{Im}\left(\dot{E}_{x 1}\right)=E_{x 1 \max } \cos \left[\omega\left(t-\frac{z}{v}\right)+\phi_{1}\right] \\
& \dot{E}_{x 2}=\operatorname{Re}\left(\dot{E}_{x 2}\right)+j \operatorname{Im}\left(\dot{E}_{x 2}\right)=E_{x 2 \max } \cos \left[\omega\left(t-\frac{z}{v}\right)+\phi_{2}\right]
\end{aligned}
$$

Assume-se que os campos possuem polarização elíptica, e com propagação na direção $z$.

O componente resultante na direção $x$, pode ser obtido por:

$$
\dot{E}_{x}=\dot{E}_{x 1}+\dot{E}_{x 2}
$$

Admitindo-se:

$$
E_{x m a ́ x}=\sqrt{\left(E_{x 1 \text { máx }} \cos \phi_{1}+E_{x 2 \text { máx }} \cos \phi_{2}\right)^{2}+\left(E_{x 1 \text { máx }} \operatorname{sen} \phi_{1}+E_{x 2 \text { máx }} \operatorname{sen} \phi_{2}\right)^{2}}
$$

e 


$$
\phi=\operatorname{tg}^{-1} \frac{\left(\mathrm{E}_{x 1 \max } \operatorname{sen} \phi_{1}+\mathrm{E}_{x 2 \max } \operatorname{sen} \phi_{2}\right)}{\left(\mathrm{E}_{x 1 \max } \cos \phi_{1}+\mathrm{E}_{x 2 \max } \cos \phi_{2}\right)}
$$

Pode-se escrever a resultante do campo na direção $x$ como

$$
\mathrm{E}_{x}=\mathrm{E}_{x \max } \cos \left[\omega\left(t-\frac{z}{v}\right)+\phi_{x}\right]
$$

A Figura 5 representa os três componentes $\left(\dot{\mathrm{E}}_{x}, \dot{\mathrm{E}}_{y}, \dot{\mathrm{E}}_{z}\right)$ resultantes da superposição de $\left(\dot{\mathrm{E}}_{1}+\dot{\mathrm{E}}_{2}\right)$ e que serão recombinadas, para cálculo do campo resultante total $\left(\dot{\mathbf{E}}_{\text {TOT }}\right)$

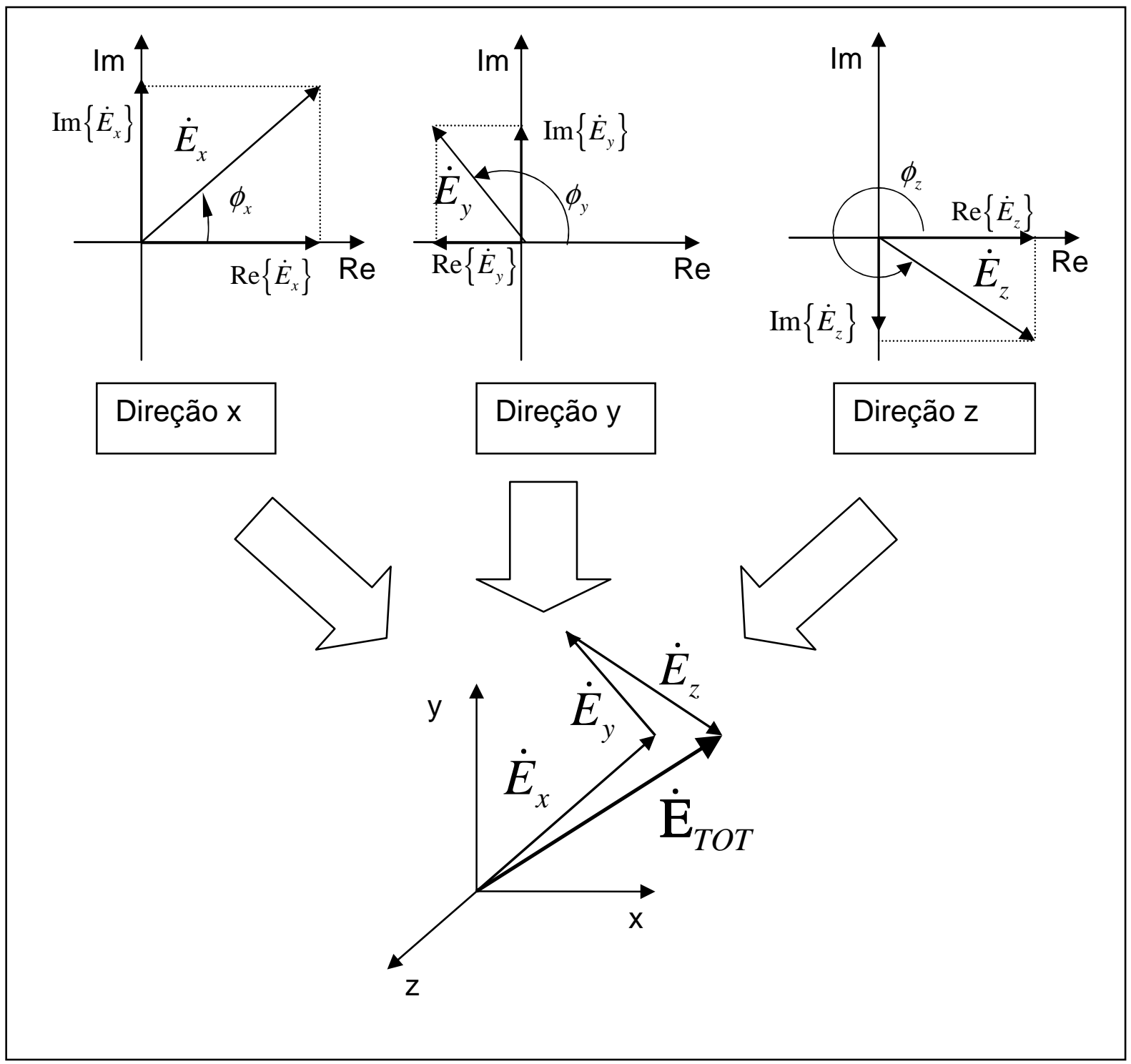

Figura 5 - Campos Ex, Ey e Ez, com as respectivas projeções nos eixos Real e Imaginário e o campo resultante $E_{T O T}$. 


\subsection{Parâmetros de espalhamento [S]}

Referências: Pozar [88], Collin [85], Maio [103], Sadiku [106], Lavergetta [107], Ginzton [108] .

A matriz espalhamento [S] é definida como a relação entre as ondas incidentes e refletidas nas portas de excitação do dispositivo, enquanto que as matrizes impedância e admitância relacionam as correntes e tensões totais nas portas. A matriz [S] apresenta como característica o fato de sua aplicação ser adequada às medidas diretas em altas frequências. Os parâmetros $S$ podem ser medidos diretamente utilizando um analisador de rede vetorial (Vectorial Network Analyser VNA).

A partir do momento em que obtemos os parâmetros [S] da rede, outros parâmetros podem ser calculados a partir destes.

A Figura 6 representa uma rede de $\mathrm{N}$ portas cuja matriz espalhamento ou matriz [S] é definida com relação às ondas de tensão incidente $\left(V^{+}\right)$e refletida $V^{-}$e sua matriz equivalente é dada em (68).

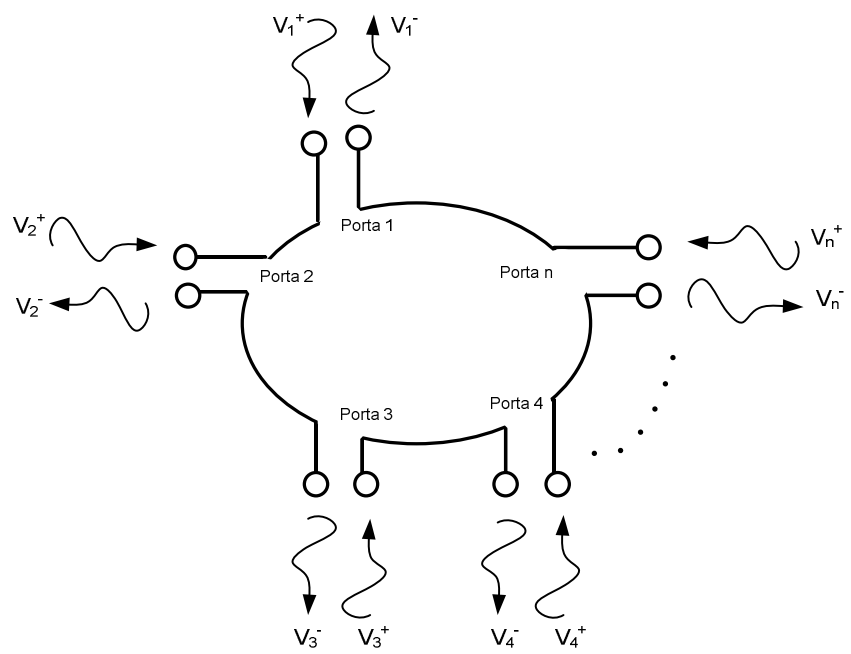

Figura 6 - Representação esquemática de rede com $N$ portas, utilizada na definição de [S]. 


$$
\left[\begin{array}{c}
V_{1}^{-} \\
V_{2}^{-} \\
\cdots \\
V_{n}^{-}
\end{array}\right]=\left[\begin{array}{cccc}
S_{11} & S_{12} & \ldots & S_{1 n} \\
S_{21} & S_{22} & & \\
\ldots & & \ldots & \\
S_{n 1} & & & S_{n n}
\end{array}\right]\left[\begin{array}{c}
V_{1}^{+} \\
V_{2}^{+} \\
\ldots \\
V_{n}^{+}
\end{array}\right]
$$

Sadiku [106] define os parâmetros de espalhamento como propriedades fixas de circuitos lineares que descrevem como a energia se acopla entre os pares de portas (ou linhas de transmissão) correspondentes ao circuito analisado.

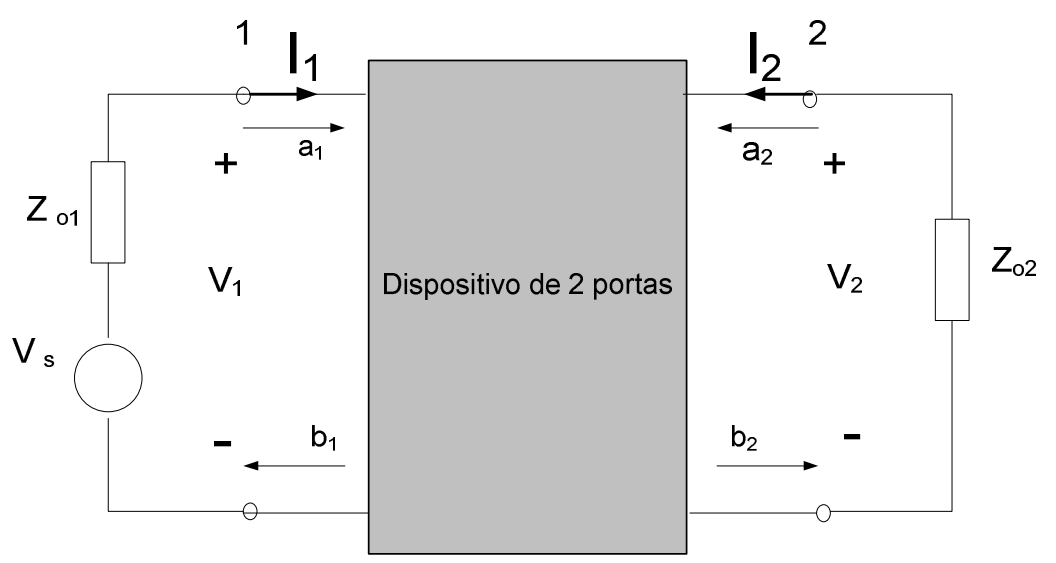

Figura 7 - Circuito para dedução dos parâmetros S.

Para uma rede de duas portas, como a da Figura 7, que apresenta uma entrada e uma saída, as equações são, então, dadas por:

$$
\left[\begin{array}{l}
V_{1}^{-} \\
V_{2}^{-}
\end{array}\right]=\left[\begin{array}{ll}
S_{11} & S_{12} \\
S_{21} & S_{22}
\end{array}\right]\left[\begin{array}{c}
V_{1}^{+} \\
V_{2}^{+}
\end{array}\right]
$$

Os parâmetros $S$ são adimensionais, complexos e, frequentemente, são expressos em decibéis, conforme abaixo:

$$
S_{i j}(d B)=20 \log _{10}\left|S_{i j}\right|
$$

As perda por retorno ("return loss") são definidas [106] como: 


$$
\begin{gathered}
S_{11}=\frac{Z_{i n 1}-Z_{o 1}}{Z_{i n 1}+Z_{o 1}}=\frac{V_{1}-Z_{o 1} I_{1}}{V_{1}+Z_{o 1} I_{1}} \\
S_{22}=\frac{Z_{i n 2}-Z_{o 2}}{Z_{i n 2}+Z_{o 2}}
\end{gathered}
$$

As perdas de inserção ("Insertion Loss") são definidas assumindo que todas as portas estão casadas, como [106]:

$$
S_{21}=\frac{V_{2}-Z_{o 2} I_{2}}{V_{2}+Z_{o 2} I_{2}}=\frac{2 V_{2}}{V_{s}}
$$

onde:

$Z_{0 k}$ é a impedância de referência na porta $\mathrm{k}$.

$Z_{i n 1}$ e $Z_{i n 2}$ são as impedâncias de entrada nas portas 1 e 2 quando a porta 1 ou 2 está carregada com $Z_{o 2}$ ou $Z_{o 1}$, respectivamente.

Cada termo da matriz $\mathrm{S}$ tem um significado físico. Os termos na diagonal ( $\mathrm{S} 11$, S22, expressos em dB), são conhecidos como "perda por retorno" (RL), quando as portas estão casadas. As $R L$ são definidas como a razão da potência refletida pela potência incidente, e dadas por:

$$
R L=10 \log _{10} \frac{P^{+}}{P^{-}}=-20 \log _{10}\left|\Gamma_{n}\right| d B
$$

A perda de inserção ("Insertion Loss" - IL) corresponde aos valores fora da diagonal. É a perda adicional entre a fonte e a carga, causada pela inserção do equipamento sob teste (EST). 
Os termos restantes, para uma rede com mais de duas portas, seriam os termos referentes ao isolamento entre as portas de saída. É a medida do ganho de tensão ou de potência da porta de saída i até a porta de saída j e o isolamento perfeito ocorreria quando o ganho é zero (ou infinito em dB).

\subsection{Modelagem Numérica}

Embora diversos métodos numéricos possam ser aplicados, este trabalho foi desenvolvido utilizando-se a plataforma de simulação CST- MicroWave Studio ${ }^{\circledR}$, que tem como base a Técnica de Integração Finita (FIT) [93].

A descrição detalhada dos modelos adotados, refinamentos e comparações encontram-se nos capítulos 3.2, 4.2 e 4.3, e uma breve explicação do método é descrita no Anexo A

\subsection{Métodos de Otimização}

Neste capítulo é apresentada uma breve discussão sobre os métodos de otimização, e suas aplicações. O desenvolvimento da implementação e os resultados obtidos, encontram-se nos itens 3.5 e 4.6 .

Segundo [96], a otimização, num sentido estrito, pode significar a busca da melhor solução para um determinado problema. Por outro lado, o próprio processo de busca da melhor solução, se for bem conduzido e se as ferramentas utilizadas permitirem, pode levar a uma melhor compreensão do problema. Assim, neste caso, otimizar pode ser um sinônimo de aprendizado sobre o sistema analisado.

A implantação desta metodologia permite-nos realizar um estudo de sensibilidade, proporcionando uma melhor avaliação da CELT, em busca da configuração ótima.

Nota-se que existem muitos métodos de otimização e cada um deles alcança melhores resultados em determinados tipos de sistemas e que a escolha do método a ser aplicado depende de uma série de características do sistema a ser otimizado. Para esta escolha, faz-se necessário um bom conhecimento das ferramentas de otimização disponíveis [95]-[101]. 
Basicamente, de acordo com as características dos problemas, podem-se classificar as ferramentas de otimização em dois grandes grupos: programação linear e programação não-linear, as quais dividem-se em alguns subgrupos, tais como os representados na Figura 8.

Em particular, as técnicas para programação não-linear podem ser subdivididas em três subgrupos:

- métodos determinísticos: concebidos utilizando o cálculo de derivadas das equações que descrevem o problema, ou em aproximações destas. Necessitam, portanto, de alguma informação do vetor gradiente, seja procurando o ponto onde ele se anula ou usando a direção para a qual aponta. Normalmente necessitam também de uma estimativa inicial bastante apropriada para que o sistema tenha convergência. Uma desvantagem é que caso a estimativa inicial seja mal definida, podem convergir para pontos de máximos (ou mínimos) locais da função e não os máximos (ou mínimos) globais, como desejado;

- métodos estocásticos: utilizam um conjunto de ações probabilísticas que buscam a solução ótima de maneira 'aleatória orientada', sem necessitar de qualquer informação de derivadas ou sobre o comportamento detalhado do problema;

- métodos enumerativos: fazem uma varredura completa (busca exaustiva) de todas as possíveis soluções, o que, na maior parte dos problemas, implica em tempo excessivo de cálculo.

Observa-se que os sistemas eletromagnéticos, geralmente, são altamente complexos e caracterizados como não-lineares, de difícil representação e, ainda, necessitam de métodos numéricos para se obter a solução de cada configuração. Por isto, as ferramentas de programação não-linear estocásticas mostram-se como as mais aptas para a otimização destes problemas [101]. 


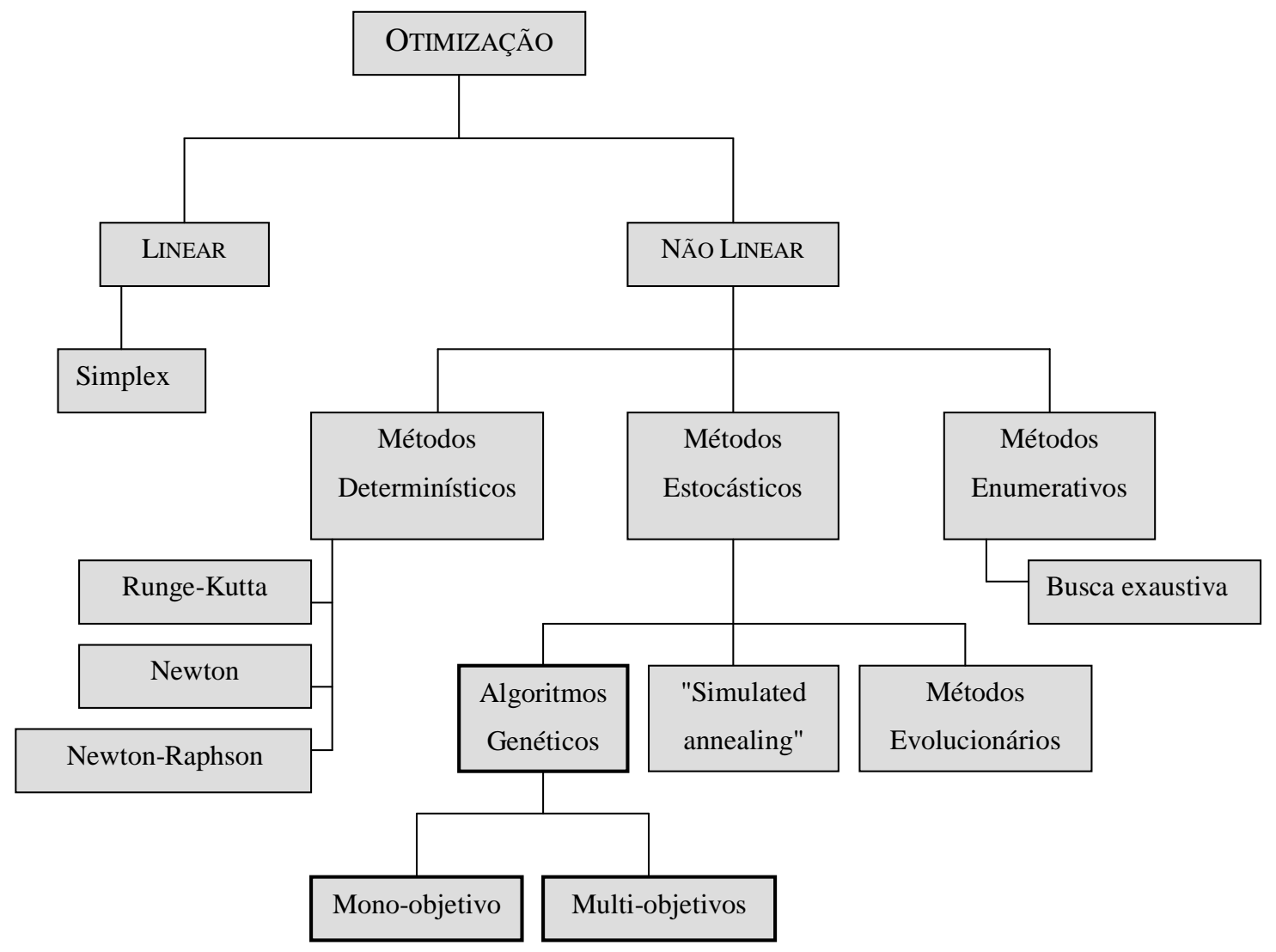

Figura 8 - Métodos de Otimização

Outra importante consideração, é a de que em muitos problemas a solução ótima não deve levar em conta somente uma única característica, ou função, que deve ser minimizada ou maximizada que, neste caso, seria resolvida via abordagem mono-objetivo). Assim, uma abordagem multi-objetivos do problema, considerando as várias características de interesse, pode ser necessária.

Os objetivos a serem otimizados são escolhidos de forma a que sejam conflitantes ou antagonistas, ou seja, a melhora de um acarreta na deterioração de outro(s), levando a resposta de um problema multiobjetivo a corresponder a um grupo de soluções que caracteriza o comprometimento entre os diversos objetivos (assim chamadas de soluções não-dominadas) [101]. Neste caso uma forma de apresentação dos dados gera uma Fronteira Pareto, que corresponde às soluções não dominadas. A Figura 9 ilustra como este conjunto configura a fronteira de 
soluções, correspondentes às melhores soluções possíveis para o problema e são chamadas de soluções Pareto.

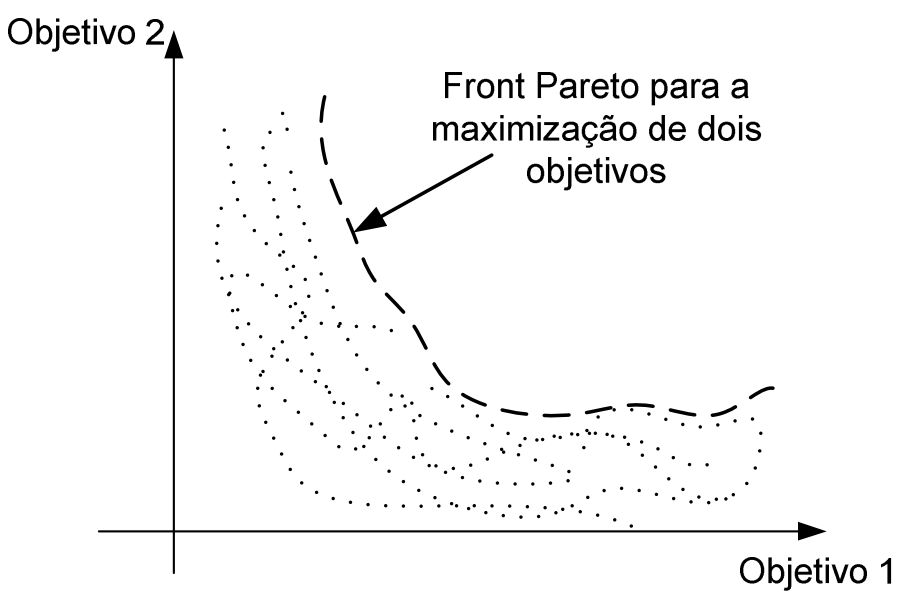

Figura 9 - Ilustração do comprometimento de duas funções objetivo e Fronteira Pareto para maximização de ambos.

Os Algoritmos Genéticos (AG) destacam-se entre os métodos estocásticos, devido à sua robustez, simplicidade de implementação e capacidade de poderem resolver o problema matemático sem a necessidade do conhecimento prévio do comportamento do sistema. Contrastam com outros métodos, já que não necessitam de uma estimativa inicial da solução, como nos métodos determinísticos, ou ainda, um número excessivo de cálculos, como na busca exaustiva.

Foram apresentados inicialmente por Holland [97], e após esse trabalho inicial, os AGs foram empregados para a otimização de problemas em eletromagnetismo, mostrando-se bastante adequados a essa aplicação, por trabalharem bem com sistemas de alta complexidade e não lineares. Além disto, apresentam como característica o fato de terem maior possibilidade de encontrar os máximos globais do sistema, ao passo que outros métodos podem se limitar à primeira solução encontrada, que pode ser um máximo local.

A Figura 10 apresenta um fluxograma simplificado das ações destas ferramentas e a definição dos termos utilizados e dos operadores genéticos é feita a seguir. 


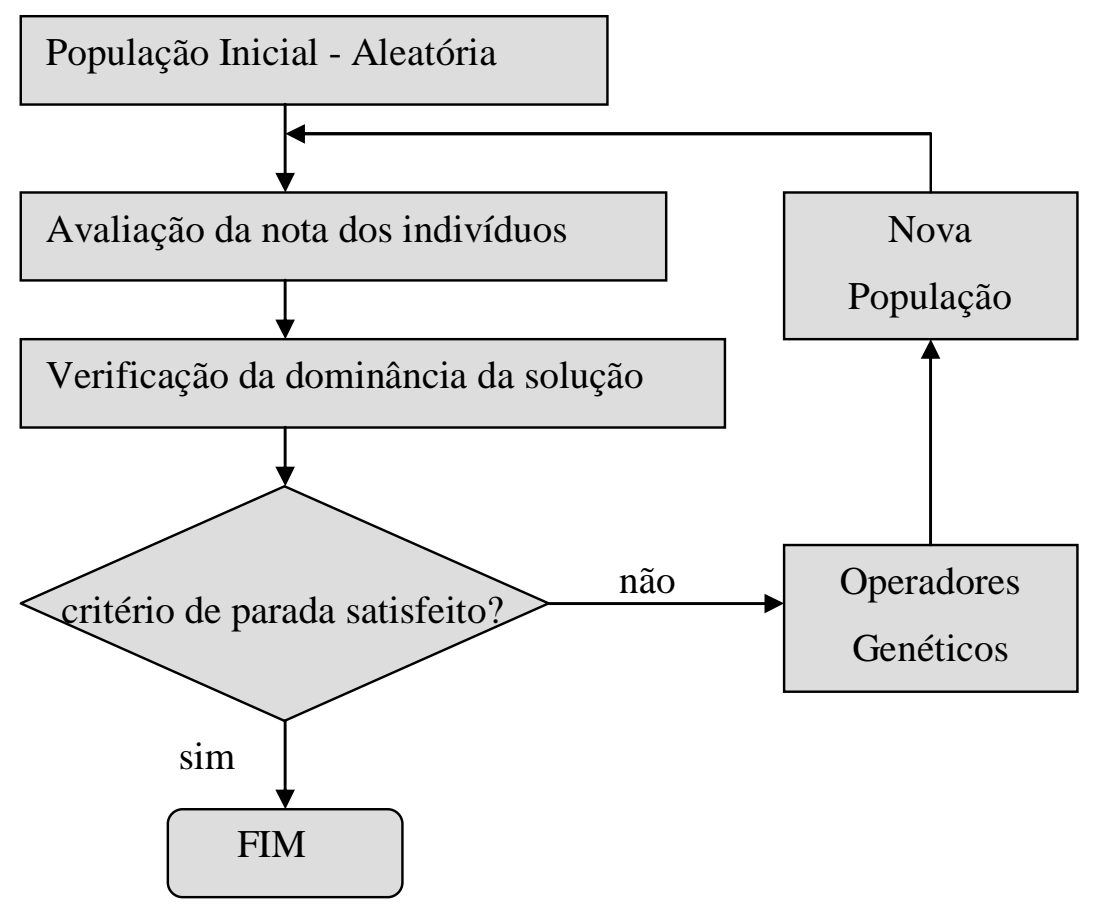

Figura 10 - Fluxograma metodológico das ferramentas de otimização de algoritmos genéticos.

As características de cada indivíduo analisado (equivalente aos genes deste indivíduo) descrevem os parâmetros que se deseja variar no processo de otimização. Podem ser, por exemplo, as posições de linhas de transmissão, as dimensões de um dispositivo, etc. A definição destas características gera as regras que delimitam o espaço de busca das soluções.

Neste contexto, a população é o conjunto de indivíduos que será analisado e que, inicialmente, é criada aleatoriamente obedecendo a um espaço de busca previamente delimitado.

Então, à partir desta população inicial todos os indivíduos são avaliados perante o problema e, a cada avaliação, a solução obtém uma nota (ou "fitness" do indivíduo).

Quando o problema é a busca pela melhora de um só quesito, ou seja, cada solução será avaliada em só um aspecto do problema (apenas uma nota), tem-se o problema como mono-objetivo. Por outro lado, em problemas multi-objetivo, cada solução receberá um "vetor de notas". 
Uma vez as soluções avaliadas, têm-se duas abordagens diferentes: se o problema for mono-objetivo, as soluções são ordenadas de acordo com o valor das suas notas (da melhor para a pior, ou vice-versa), ou ainda uma curva aproximada pode ser gerada. Por outro lado, se o problema for multi-objetivo, as soluções são separadas em dois grupos: soluções dominadas e soluções não-dominadas, que representam, respectivamente as soluções que atendem aos requisitos, mas não apresentam os melhores compromissos entre os objetivos; e as soluções que atendem aos requisitos e ainda apresentam os melhores compromissos entre os objetivos.

Após a categorização das soluções iniciais, e a verificação do critério de parada, são aplicados os operadores genéticos, os quais irão gerar uma nova geração de soluções na esperança de que os filhos sejam melhores que os pais. Esta esperança é traduzida por um processo aleatório-orientado com base na evolução das espécies. Como exemplo dos operadores genéticos podem ser citados: a seleção; o cruzamento; a mutação; e o elitismo.

A seguir é dada uma breve descrição dos operadores genéticos e o critério de dominância Pareto. Mais detalhes podem ser encontrados em [102]-[104].

- Seleção: responsável pela escolha dos casais que sofrerão os operadores genéticos de cruzamento e mutação. A seleção deve, ao mesmo tempo, garantir a rápida definição da fronteira Pareto e não conduzir à concentração da população em um só ponto. Assim, o processo de seleção auxilia a promover rápida convergência porém mantendo diversidade das soluções. O importante é, através das soluções selecionadas, amostrar adequadamente a população corrente, permitindo ao operador de seleção a possibilidade de explorar bem o espaço de busca. Após a seleção, os operadores que geram novos indivíduos são aplicados: cruzamento e mutação.

- Cruzamento: geração de novos indivíduos (filhos) por permutação de valores dos genes dos pares (pais) entre os pares de indivíduos previamente selecionados. Este operador é o maior responsável pela exploração do espaço de busca (através da criação de novos indivíduos). Então, após a formação aleatória dos 
pares, os indivíduos são submetidos ao cruzamento, de acordo com uma dada probabilidade. Normalmente, como ocorre na natureza, a probabilidade de cruzamento é alta (geralmente entre 70 e 100\%).

- Mutação: inserção aleatória de novos valores aos genes dos indivíduos, o que aumenta a diversidade da população. A mutação ocorre no indivíduo de acordo com uma dada probabilidade. Normalmente, um comportamento análogo ao da natureza é de que a probabilidade de mutação seja baixa (entre 0 e $5 \%$ ) para que a busca pelo conjunto ótimo não seja puramente aleatória ou muito errática.

- Elitismo: manutenção das soluções que apresentam alto valor do índice de avaliação no processo evolutivo. Quando ocorre a geração e posterior avaliação de novos indivíduos, todos indivíduos são reavaliados perante o problema.

O ciclo de geração de soluções e avaliações perante o problema cria um processo iterativo. Este processo é continuado até que algum critério de parada seja satisfeito, como por exemplo, uma quantidade pré-determinada de avaliações.

O conceito de dominância Pareto é definida para quaisquer 2 vetores de parâmetros $\vec{a}$ e $\vec{b}$, em um problema de maximização, como:

- $\vec{a}>\vec{b}(\vec{a}$ domina $\vec{b})$ se e somente se $\vec{f}(\vec{a})>\vec{f}(\vec{b})$.

- $\vec{a} \geq \vec{b}(\vec{a}$ domina fracamente $\vec{b})$ se e somente se $\vec{f}(\vec{a}) \geq \vec{f}(\vec{b})$.

- $\vec{a} \sim \vec{b} \quad(\vec{a} \quad$ é indiferente perante $\vec{b})$ se e somente se $\vec{f}(\vec{a}) \nsucceq \vec{f}(\vec{b}) \wedge \vec{f}(\vec{b}) \geq \vec{f}(\vec{a})$.

As definições para um problema de minimização $(<, \leq, \sim)$ são análogas.

São possíveis dois tipos de soluções:

- aquelas que, considerando todos os objetivos propostos serão piores que as outras. Estas soluções são chamadas de soluções dominadas ou não-eficientes. 
- aquelas que quando comparadas com todas as outras soluções são melhores em um ou mais objetivos e são piores em outros. Neste caso, são consideradas indiferentes, não é possível comparar essas soluções entre elas, ou dizer qual é a melhor. Estas soluções são chamadas eficientes ou não-dominadas.

A otimalidade de Pareto é definida para um vetor de parâmetros $\vec{a} \in X_{f}$ é dito não-dominado se e somente se $\nexists \vec{x} \in X_{f}: \vec{x}>\vec{a}$.

Assim $\vec{a}$ é declarado Pareto-ótimo se e somente se $\vec{a}$ é não-dominado em $X_{f}$.

A união de todas as soluções não-dominadas é chamada de conjunto Pareto ótimo e o conjunto de seus vetores objetivo forma a Fronteira Pareto - ótima.

Seja $A \subseteq X_{f}$ um conjunto de vetores de parâmetros:

1. O conjunto A é Pareto-ótimo local se e somente se:

$$
\forall \vec{a} \in A: \quad \nexists \vec{x} \in X_{f}: \quad \vec{x}>\vec{a} \wedge\|\vec{x}-\vec{a}\|<\varepsilon \wedge\|\vec{f}(\vec{x})-\vec{f}(\vec{a})\|<\delta
$$

onde \|\| é uma métrica para distância e $\varepsilon>0$ (raio mínimo no espaço de parâmetros), $\delta>0$ (raio mínimo no espaço de objetivos). Estes raios mínimos são determinados pelo projetista com a intenção de estudar uma região específica.

2. O conjunto A é Pareto-ótimo global se e somente se:

$$
\forall \vec{a} \in A: \nexists \vec{x} \in X_{f}: \vec{x}>\vec{a}
$$




\section{CÂMARAS EXCITADAS POR LINHAS DE TRANSMISSÃO (CELT)}

Neste capítulo são aplicados os conceitos apresentados nos capítulos anteriores, com o objetivo de caracterizar os efeitos predominantes e potencialidades das CELT, bem como os seus limites de operação.

As CELT são câmaras projetadas conforme a proposta de Perini e Cohen [23][25], sendo excitadas através de linhas de transmissão. A Figura 11 apresenta uma CELT de dimensões $(a \times b \times c)$ excitada através de duas linhas de transmissão paralelas. Essa câmara procura suprir as deficiências da câmara reverberante canônica que, como regra geral, opera apenas em frequências acima de 3 vezes a frequência de corte da câmara, o que para as câmaras blindadas padrão de mercado, significa operar acima de $80 \mathrm{MHz}$. Por exemplo, uma câmara reverberante com dimensões de $3 \mathrm{~m} \times 4 \mathrm{~m} \times 5 \mathrm{~m}$, teria a primeira frequência de ressonância em $30 \mathrm{MHz}$, então, ela teria os modos suficientes para operação sendo gerados a partir de $90 \mathrm{MHz}$.

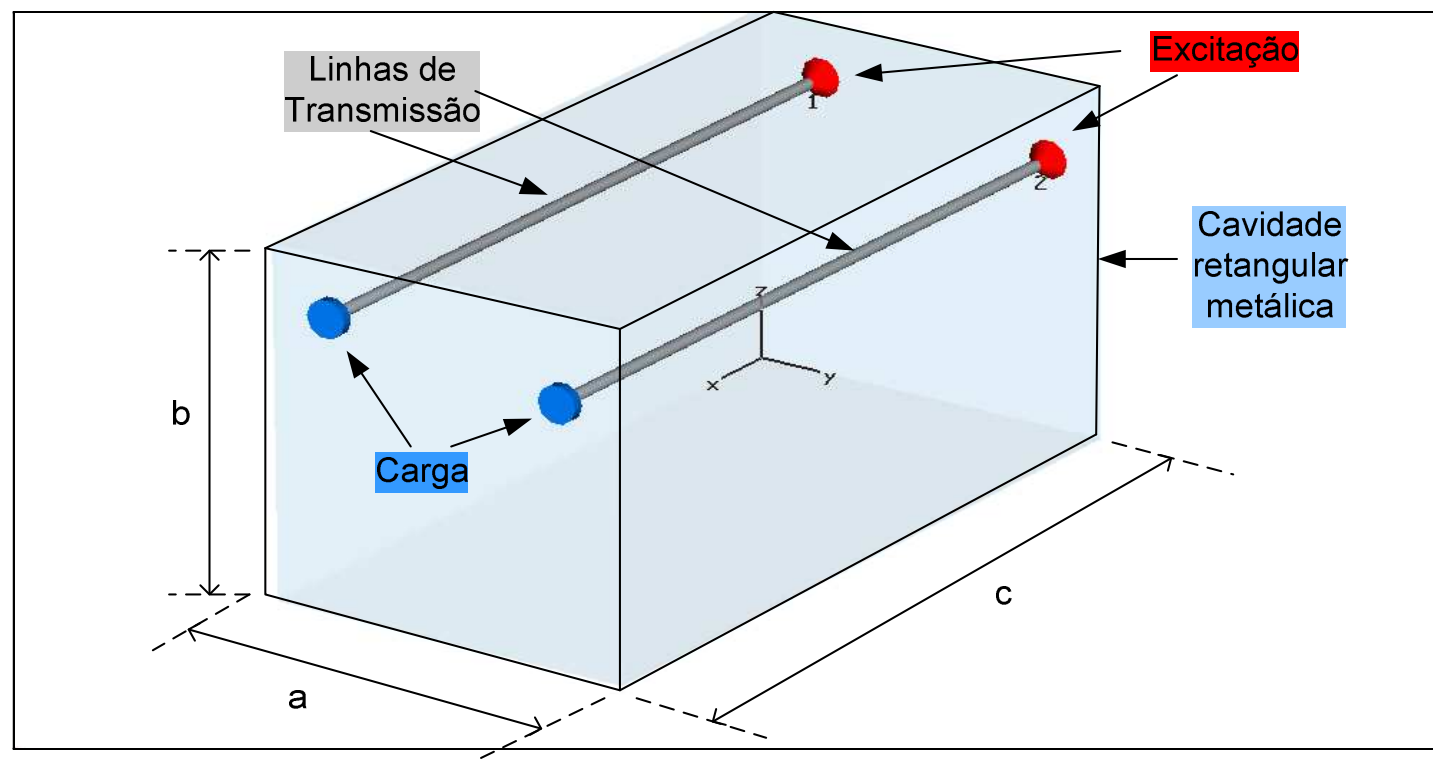

Figura 11 - Diagrama Esquemático da CELT

Através da introdução das linhas de transmissão, que geram modos TEM já acima da corrente contínua pode-se, em teoria, suprir as deficiências da câmara 
reverberante canônica e executar testes de imunidade irradiada em toda a faixa de frequências.

\subsection{Operação da CELT abaixo da frequência de corte (modo único)}

Este trabalho se concentrará na operação da CELT no modo de operação denominado de modo único.

Menciona-se que nesta configuração de câmara, os campos eletromagnéticos gerados obedecem às características de campo próximo e apresentam o modo TEM, característicos das linhas de transmissão. Assim, os campos na direção de propagação da onda na linha de transmissão, da CELT, devem apresentar baixos valores, que são provenientes apenas das reflexões nas paredes condutoras da câmara. Os valores dos campos EM nas demais direções obedecem às condições de cálculo de campo próximo TEM. Conforme mencionado no item 2.4.2, esse tipo de operação pode ser chamado de modo quase-TEM [84]

O efeito no confinamento metálico dos campos eletromagnéticos é o de gerar componentes de campo tangenciais na superfície do metal, diferentemente do que aconteceria na estrutura PEC, onde os campos tangenciais são nulos. Dessa forma, um componente de campo na direção de propagação será obtido, porém, com valor muito menor que aqueles obtidos no plano perpendicular ao de propagação [84].

Por outro lado, o efeito das cargas das linhas de transmissão poderá resultar em uma onda estacionária. Assim, pode-se controlar as características da onda estacionária através da variação da carga da linha de transmissão, visando-se atender aos requisitos de uniformidade da câmara.

Uma observação importante é de que a onda estacionária gera campos determinísticos, para cada configuração de linhas de transmissão e carga. Mas, considerando que a carga pode ser eletronicamente variada, e esta variação pode ser feita de acordo com uma regra pseudo-aleatória, pode-se adotar uma abordagem de independência estatística entre cada uma das ondas estacionárias e 
de campos eletromagnéticos gerados dentro da câmara. Então, são aplicáveis as propriedades estatísticas aos campos eletromagnéticos resultantes.

\subsection{Modelagem Numérica}

Conforme já citado, adotou-se a plataforma de simulação CST-MWS $\AA$, que utiliza a Técnica de Integração Finita (FIT) [93]. Uma breve descrição do método FIT é apresentada no Anexo A O tratamento chamado de pós-processamento foi efetuado via Matlab $\AA^{\circledR}$, cujos detalhes são descritos no APÊNDICE D

Esta plataforma foi escolhida devido a ser amplamente testada e utilizada na área de cálculo de campos eletromagnéticos e de CEM. Além disso, os resultados gerados para o caso CELT, por esse ambiente computacional já haviam sido validados através da comparação com outros programas comerciais e não comerciais, para o caso analisado [34]-[35], através de um modelo que neste trabalho é designado como modelo simplificado.

De posse deste estudo preliminar, através do modelo simplificado, desenvolveuse um estudo de refinamento do modelo computacional, aplicando-se as ferramentas e potencialidades do programa CST-MWS considerando os detalhes dos acessórios e construtivos da CELT.

As principais características dos modelos simplificado e detalhado são descritas na Tabela 1.

O modelo simplificado foi utilizado, principalmente, em análises que requeiram várias simulações computacionais como, por exemplo, na otimização das configurações da CELT e no estudo de efeito da variação das defasagens no perfil do campo resultante.

Por outro lado, o modelo detalhado foi utilizado para comparação com os resultados experimentais, do campo $\mathrm{E}$ e do parâmetros $\mathrm{S}$.

Nota-se que algumas modificações introduzidas no modelo detalhado têm o objetivo de analisar qual é a influência de cada um desses fatores, tais como os efeitos das paredes condutoras e detalhamento do conector sobre os resultados de campos EM calculados e seu impacto no tempo de simulação. 
Tabela 1 - Modelos Detalhado e Simplificado - sumário comparativo

\begin{tabular}{lll}
\hline Modelo & Simplificado & Detalhado \\
\hline Parede & PEC $^{(1)}$ & Aço USP $^{(2)}$ \\
\hline Condutor & PEC & Cobre \\
\hline Conector & Não representado. & Tipo N $^{(3)}$ \\
\hline Excitação & Porta Discreta ${ }^{(4)}$ & Porta Guia de onda $^{(5)}$ \\
\hline Carga & $50 \Omega$ & $50 \Omega$ \\
\hline Condição de contorno & Espaço aberto & Espaço aberto \\
\hline Dielétrico & Vácuo & Vácuo
\end{tabular}

(1) PEC: material perfeitamente condutor $(\sigma \rightarrow \infty)$;

(2) Aço USP: definido de acordo com tabela de características gerais de aço comum $\left(\sigma=6 \times 10^{6} \mathrm{~S} / \mathrm{m}, \mu=10^{3}\right)$;

(3) Conector tipo N: modelado como uma passagem na carcaça da câmara, com tubo de diâmetro aproximado do conector tipo $\mathrm{N}$, dielétrico vácuo, com cilindro maciço condutor como o pino central, conforme a Figura 12.
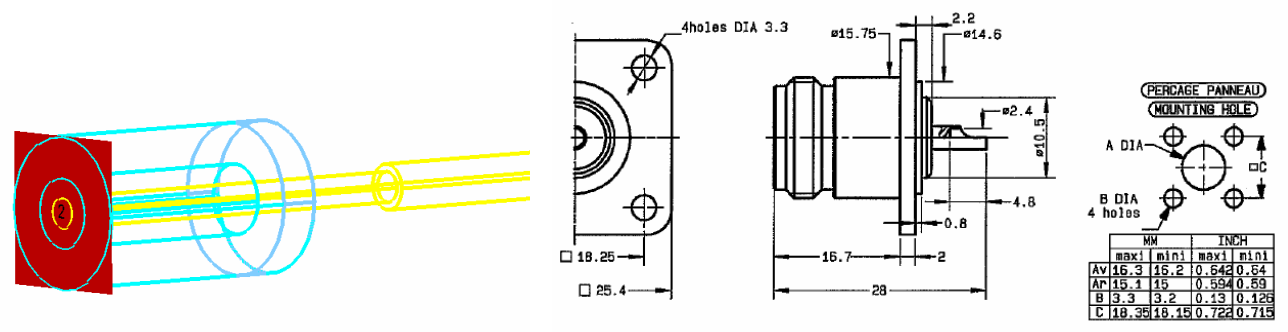

(a)

(b)

Figura 12 - Conector tipo N - (a) implementado na simulação (b) dados de catálogo.

(4) A porta discreta possui a impedância imposta pelo usuário (ou seja, não calcula a impedância real vista pela porta de excitação); também não possui controle da polarização. Consiste de um elemento concentrado único entre 
dois fios condutores perfeitos conectando a porta ao restante da estrutura. Uma certa relação tensão/corrente é introduzida ao longo do elemento concentrado e os parâmetros $S$ são calculados com base na tensões $e$ correntes dos elemento. É importante notar que pode ocorrer um efeito de transição da estrutura para a porta discreta. Este sempre será o caso quando a geometria da estrutura das linhas de transmissão é diferente da geometria das portas discretas. Por outro lado, a porta discreta provê uma forma conveniente e flexível de anexar portas a uma dada estrutura. A precisão da simulação é suficiente, normalmente, quando o tamanho da porta discreta é um décimo do comprimento de onda ou menor. É frequentemente utilizado como fonte pontual de alimentação de antenas ou como terminação de linhas de transmissão em frequências muito baixas [94].

(5) A porta tipo guia de onda permite resultados mais precisos, varredura da frequência para cálculo da impedância vista pela excitação, e permite um controle da polarização dos campos injetados, além de alcançar maior precisão de cálculo. Estas portas normalmente provêm níveis de reflexão e distorção muito baixos, e então, são as melhores escolhas quando uma alta precisão é necessária. Este tipo de porta simula guias de onda de comprimento infinito conectados à estrutura. Os modos de guia de onda deslocam-se para fora da estrutura em direção aos planos de contorno, então deixando o domínio de cálculo com baixo nível de reflexão. Baixa reflexão pode ser alcançada quando os padrões dos modos de guia de onda na porta casam perfeitamente com os padrões dos modos do guia de onda dentro da estrutura. Geralmente, a definição da porta guia de onda requer o enclausuramento completo do campo preenchendo o domínio da seção reta da linha de transmissão com a área da porta. A estratégia de definição correta dos parâmetros desta porta dependem do tipo da linha de transmissão [94].

O cálculo do campo elétrico resultante quando consideradas as defasagens entre as excitações com a simulação numérica da CELT utilizando duas linhas de transmissão distintas, pode ser efetuado utilizando-se de dados preliminares do

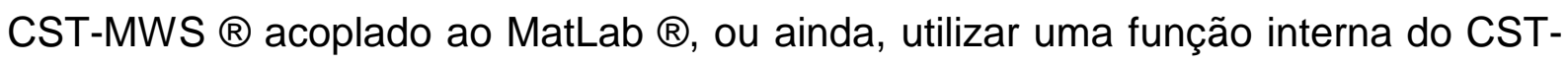


MWS ( MatLab®.

Este método se baseia nas deduções efetuadas no itens 2.5 .6 e 2.5.7, que considera a superposição dos campos gerados. Assim este método será aplicado no cálculo dos campos elétricos resultantes quando existe defasagem entre as excitações.

De uma forma sucinta, menciona-se que após cada simulação dos campos elétricos via CST-MWS $\AA$, os dados resultantes são lidos pelo MatLab ${ }^{\circledR}$, diretamente dos arquivos ASCII gerados pela ferramenta de exportação de dados do MWS, conforme detalhado no APÊNDICE D.

A partir dos dados resultantes, pode ser feita uma gama de tratamentos numéricos (pós-processamento) e o encadeamento com programas de otimização, em especial os AGs.

A defasagem da excitação foi considerada para a análise dos resultados de campo $\mathrm{E}$, e os resultados vetoriais para duas linhas de transmissão podem ser dados pela equação:

$$
\mathrm{E}_{T O T}=\left|\mathrm{E}_{L T 1}\right| e^{-j\left(\phi_{L T 1}\right)}+\left|\mathrm{E}_{L T 2}\right| e^{-j\left(\phi_{L T 2}+\varphi\right)}
$$

Onde $\mathrm{E}_{T O T}$ é o campo $\mathrm{E}$ total; $\mathrm{E}_{L T 1}$ é o campo $\mathrm{E}$ produzido pela LT1, $\phi_{L T 1}$ é o ângulo do campo $E$ produzido pela $L T 1, E_{L T 2}$ é o campo $E$ produzido pela $L T 2$, $\phi_{L T 2}$ é o ângulo do campo E produzido pela LT1, $\varphi$ é a defasagem aplicada na excitação.

\subsection{Análise Experimental}

Nesta seção são comentados sumariamente procedimentos e objetivos dos ensaios experimentais aplicáveis à avaliação de desempenho das configurações de CELT. 


\subsubsection{Medidas de Campo Elétrico}

$\mathrm{Na}$ avaliação experimental buscou-se uma avaliação do comportamento do campo elétrico, incluindo-se a primeira frequência de ressonância $(125 \mathrm{MHz})$, na faixa de $10 \mathrm{MHz}$ até $250 \mathrm{MHz}$.

O objetivo inicial desses testes foi analisar os aspectos operacionais do protótipo de CELT, construído no LMAG/CTMSP, e a adequação da rotina de testes às medidas de campos elétricos. Note-se que as principais características construtivas e materiais utilizados são descritos no APÊNDICE A.

Em seguida foram medidos os valores dos campos elétricos dentro da câmara com a variação da frequência de entrada $(10 \mathrm{MHz}-250 \mathrm{MHz})$ mantendo a potência de entrada constante. Os pontos avaliados são os indicados na Figura 13. Este procedimento foi repetido para a carga de $50 \Omega$, carga aberta e carga em curto circuito. Os detalhes relacionados a este procedimento de teste são apresentados no APÊNDICE B.

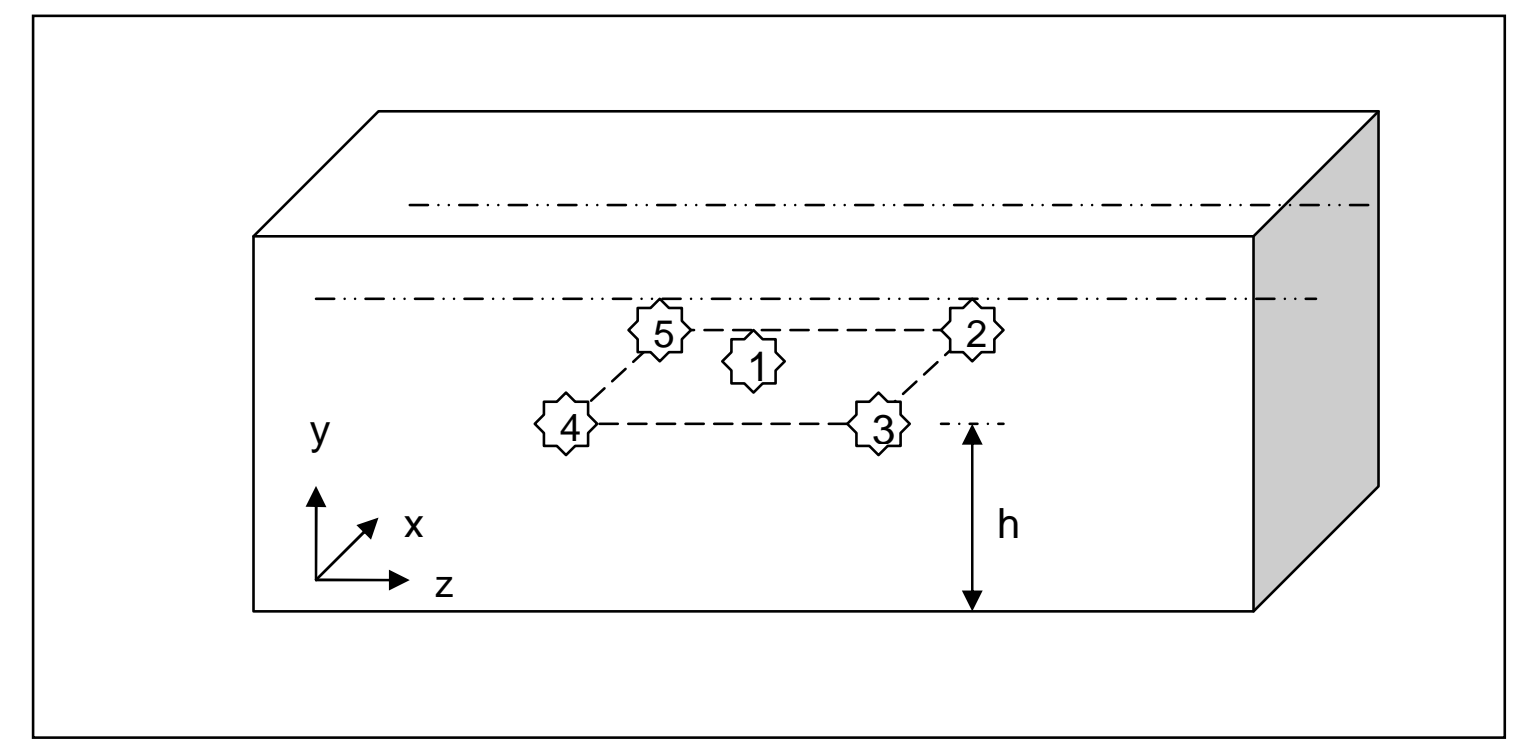

Figura 13 - Diagrama Esquemático da CELT - Pontos de medição, no plano correspondente a altura $h$. 


\subsubsection{Medidas de parâmetros com o Analisador Vetorial de Redes (VNA).}

A segunda etapa de medições teve por objetivo a caracterização da câmara e dos defasadores, através da utilização de um VNA, que permite obter os parâmetros $\mathrm{S}$, a carta de Smith, considerando os efeitos das cargas nestas medidas.

Uma caracterização das cargas utilizadas, também, foi efetuada, visando aumentar a precisão da análise dos ensaios, uma vez que os resultados são fortemente influenciados por essas cargas.

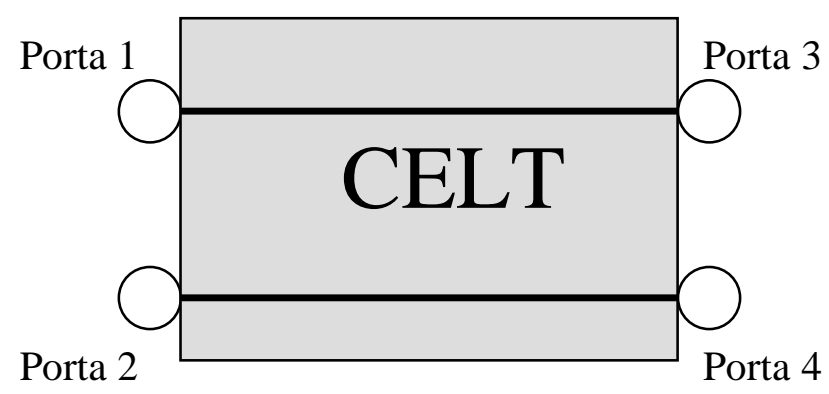

Figura 14 - Configuração de medidas de parâmetros S na CELT, com indicação das portas medidas.

A caracterização das cargas foi realizada através da avaliação dos parâmetros $S$, na faixa de frequência de $10 \mathrm{MHz}-250 \mathrm{MHz}$, com a consideração da numeração das portas conforme Figura 14.

Em seguida, realizou-se a caracterização da câmara, efetuando-se as medidas de S11, S22, S12, S13 na mesma faixa de frequência.

Ainda, foi efetuada a avaliação somente do parâmetro S11, a fim de avaliar os efeitos da variação das cargas no terminal de excitação da câmara, para carga de $50 \Omega$, carga aberta e carga curto-circuito.

A mesma avaliação foi realizada, porém, com a aplicação de defasadores (APÊNDICE C), como carga na CELT. Este procedimento foi efetuado aplicando-se diversas tensões de controle no defasador e em duas configurações distintas: carga $50 \Omega$ e carga aberta. 


\subsection{Critérios de Avaliação de Uniformidade na CELT}

Nesta seção apresentam-se os índices de avaliação de uniformidade utilizados neste trabalho, um determinístico e outro estatístico.

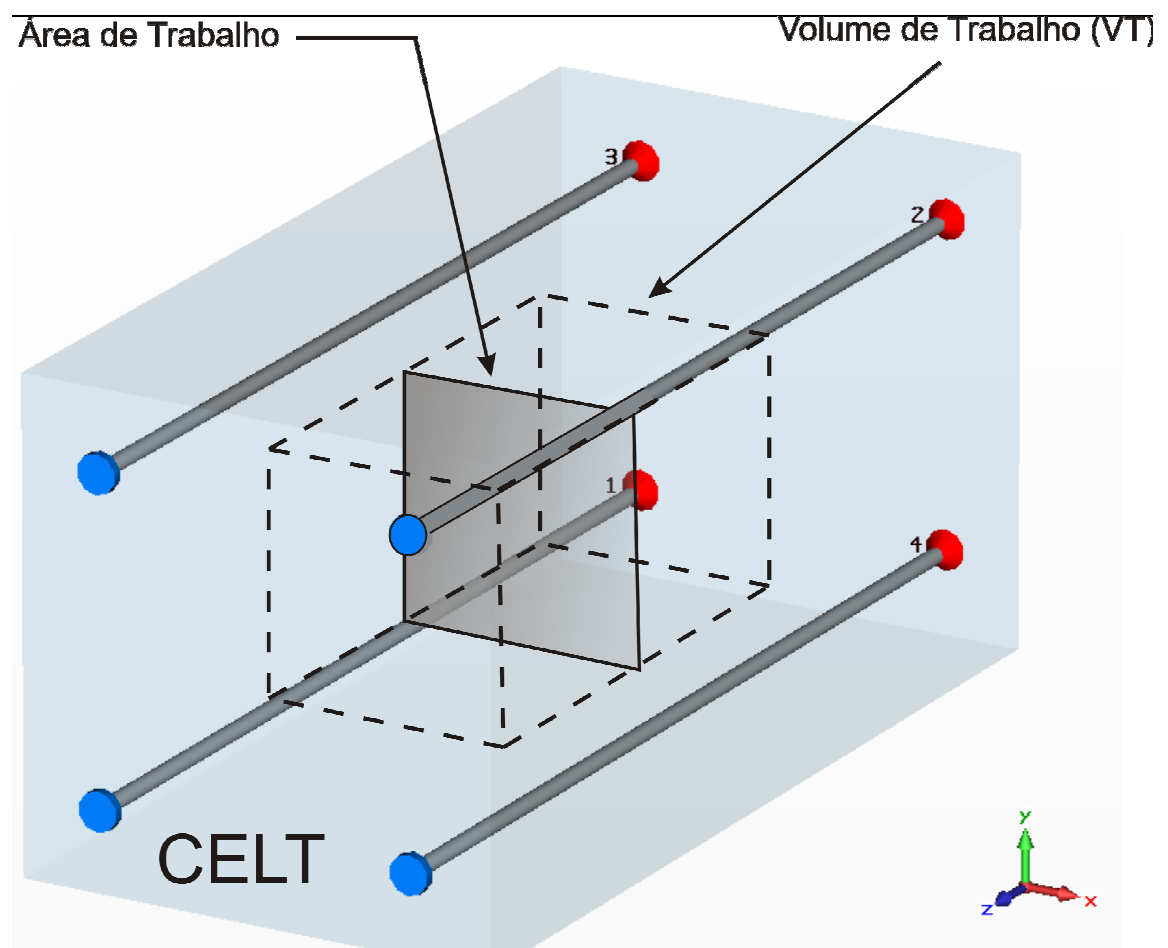

Figura 15 - Desenho esquemático da CELT com 4 linhas de transmissão e locais de avaliação - Área de Trabalho e Volume de Trabalho.

Antes da apresentação dos critérios utilizados, é necessário definir-se a área de trabalho e o volume de trabalho. A área de trabalho é definida como área da seção transversal às linhas de transmissão, numa dada posição $z$, cujos pontos possuam um afastamento arbitrário mínimo das paredes. Define-se o volume de trabalho como sendo o volume que contém os pontos que possuam um afastamento arbitrário mínimo das paredes, nas três direções x, y e z. Estes dois conceitos são ilustrados na Figura 15, e podem ser empregados para qualquer configuração de CELT.

Os critérios abaixo definidos, determinístico e o estatístico, são aplicados conforme a conveniência, simultaneamente nos dois locais de avaliação e seus resultados são apresentados e comparados no item 4.4. 


\subsubsection{Critério determinístico de uniformidade}

O campo $\mathrm{E}$ médio $(\bar{E})$, o desvio padrão $(\sigma)$ e o desvio padrão em $\mathrm{dB}(\hat{\sigma})$ podem ser calculados através das equações descritas a seguir.

Define-se numericamente o campo $\mathrm{E}$ médio $(\bar{E})$ de um componente do campo $\xi$ por [4]:

$$
\bar{E} \xi(k)=\frac{1}{N} \sum_{k=1}^{N} E_{\xi_{k}}, \quad \xi=x, y
$$

onde:

- N é o número de pontos onde o campo é avaliado dentro da área de trabalho; e

- $E_{\xi_{k}}$ é a amplitude do campo elétrico no ponto de índice $k$, na direção $\xi$.

A dispersão é então quantificada pelo desvio padrão entre o campo elétrico em cada ponto e o campo elétrico médio área de trabalho. Para o componente $\xi$, temse [4]:

$$
\sigma_{\xi}(k)=\sqrt{\frac{1}{N-1} \sum_{k=1}^{N}\left(E_{\xi_{k}}-\bar{E}_{\xi}\right)^{2}}
$$

$\mathrm{E}$, finalmente, o desvio padrão (normalizado pela média) em $\mathrm{dB}$, é dado pela relação [4].

$$
\hat{\sigma}_{\xi}=20 \log _{10}\left(\frac{\bar{E} \xi+\sigma_{\xi}}{\bar{E}_{\xi}}\right)
$$

Assim, obtém-se o desvio padrão para os diversos componentes individuais $\left(\overline{\mathrm{E}}_{\xi}, \sigma_{\xi}, \hat{\sigma}_{\xi}\right)$. Para as combinações $\left(\bar{E}_{x y}, \sigma_{x y}, \hat{\sigma}_{x y}\right)$ a definição é similar. 
Esta abordagem é parecida com um estudo estatístico (no formato), mas no caso em que não se introduz a variação de fase, ela se trata de um campo totalmente determinístico. Deve-se antes de tudo, então, considerar as equações (78), (79) e (80) como uma medida da distribuição do campo na área de trabalho sem fazer uma alusão aos conceitos estatísticos.

\subsubsection{Critério estatístico}

Uma vez que se introduz a variação de fases, deve-se reconsiderar a definição da dispersão espacial do campo $\mathrm{E}$. Em cada ponto $k$ da zona de trabalho, o campo $\mathrm{E}$ não é mais determinístico, mas sim uma variável aleatória dependente da variação de fase (uma vez que esta seja aleatória). O que nos interessa sobretudo é o efeito médio da variação de fase. Consequentemente, pode-se reescrever as equações (78), (79) e (80) como (82), (83) e (81):

$$
\begin{gathered}
E_{\xi_{k} m e d}(\phi)=\int_{0}^{2 \pi} E_{\xi_{k}}(\phi) \frac{1}{2 \pi} d \phi \\
\bar{E} \xi_{m e d}(k, \phi)=\frac{1}{N} \sum_{k=1}^{N} E_{\xi_{k} m e d} \\
\sigma_{\xi m e d}=\sqrt{\frac{1}{N-1} \sum_{k=1}^{N}\left(E_{\xi_{k} m e d}-\bar{E}_{\xi m e d}\right)^{2}}
\end{gathered}
$$

onde:

- $E_{\xi_{k}}(\phi)$ é a amplitude do campo $E$ na direção $\xi$ no ponto $k$ para uma dada fase

$\phi$. Esta definição abrange o caso em que a fase varia uniformemente entre $0 \mathrm{e}$ $2 \pi$.

Assim, toma-se aqui o efeito médio da variação de fases em cada ponto. A dispersão calculada mede então a variação espacial deste campo médio. Em nenhum caso ele leva em conta a variabilidade do campo em torno do valor médio do campo no ponto $k$. 


\subsection{Aplicação dos Algoritmos Genéticos (AGs) na CELT}

Neste capítulo é efetuada uma discussão sobre a aplicação dos Algoritmos Genéticos na avaliação de desempenho da CELT. A discussão é iniciada pela descrição da adequação dos AGs à resolução do problema proposto. Após, é efetuada a caracterização da CELT aplicando-se a Fronteira Pareto e uma proposta de índice de mérito destinado à avaliação de diferentes configurações de CELT é apresentada. Na seção seguinte é feita uma descrição detalhada das estratégias adotadas, considerando que os AGs foram inicialmente utilizados para aumentar o conhecimento do sistema. Finalmente, um método de otimização das configurações da CELT utilizando-se de várias camadas de métodos de AGs, aqui chamado de método híbrido devido à aplicação de uma camada externa com Algoritmo Genético Mono-objetivo (AGM) e outra interna com Algoritmo Genético Multi-Objetivo (AGMO), é analisado.

As ferramentas de otimização, AGM e AGMO, foram utilizadas para melhorar a compreensão da CELT, além de prover recursos para decisão do projetista e definir uma otimização livre da câmara [100]-[101]. Estas ferramentas foram programadas no ambiente Matlab $\AA$, o que permite uma grande flexibilidade, incluindo a possibilidade de interação e comando de outros programas computacionais, tais como o CST-MWS (B que foi utilizado para cálculo dos campos elétricos resultantes devidos a cada configuração dentro da CELT.

Considerando a câmara com dimensões pré-estabelecidas, procurou-se compreender a relação existente entre campo elétrico e volume de trabalho, com o objetivo de se obter a melhor utilização da CELT. Aplicou-se um processo de busca, onde para cada arranjo dos alimentadores existe a necessidade de estabelecer o compromisso entre o volume de trabalho e o campo elétrico. Ressalta-se que, neste caso, obtém-se um compromisso tipo "Fronteira Pareto" e não apenas uma única solução ótima.

Desta forma, para cada arranjo de linhas de transmissão, obtém-se um outro compromisso (volume de trabalho versus campo elétrico), gerando assim, uma nova Fronteira Pareto. 
Para comparação do desempenho relacionado a cada arranjo de condutores, foi aplicada uma figura de mérito, denominada critério LA (que será detalhada nas seções seguintes), e então aplicou-se o Algoritmo Genético mono-objetivo, para encontrar o melhor indivíduo, em um problema não-linear de uma variável.

Nas seções seguintes é feito um detalhamento das ferramentas e estratégias utilizadas, além dos critérios de seleção.

\subsubsection{Compromisso Volume de Trabalho versus Campo Elétrico}

Inicialmente abordou-se o cálculo do compromisso entre o volume de trabalho e o campo elétrico para uma dada configuração de câmara.

Assim, admitindo-se um leiaute pré-fixado (tamanho de paredes, arranjo de LT, cargas), procura-se encontrar maior volume de trabalho nominal que atende aos requisitos relativos ao campo elétrico especificado e seus desvios padrão. Neste caso, o compromisso volume $x$ campo $E$ (combinado) é representado pela Fronteira Pareto que está associado ao leiaute da câmara.

Com o objetivo de obter-se esta Fronteira Pareto, aplicou-se o método de AGMO caracterizando-se a câmara. Neste procedimento, uma população de volumes de trabalho, sorteada aleatoriamente, é avaliada com relação às restrições do sistema. Assim, cada indivíduo desta população de volumes sorteados deve atender um valor pré-determinado de desvio padrão do campo para que seja um indivíduo válido. Caso não atenda a este requisito, o indivíduo é considerado não-válido, e aplica-se uma penalidade. Um módulo principal de programação desenvolvido no Matlab comanda e chama, um por vez, os arquivos de apoio. Um dos módulos de apoio é o responsável por testar as possíveis soluções. É quem, portanto, comanda o programa computacional de cálculo de campos eletromagnéticos (CST-MWS). As estratégias da AGMO utilizadas, como elitismo, cruzamento, mutação, são aquelas detalhadas em [93]-[97].

A avaliação da uniformidade nos volumes de trabalho é feita dentro de um elipsóide, conforme mostrado na Figura 16, e não nos vértices de um 
paralelepípedo, conforme apregoa a norma [4]. Este procedimento foi utilizado para minimizar as comparações necessárias, quando se testa se um determinado ponto está dentro ou fora do volume de trabalho. Este procedimento não gera distorção, uma vez que a correlação entre os valores calculados de desvio padrão e campo elétrico médio para volume tipo paralelepípedo e elipsóide são lineares [111].

De forma caracterizar graficamente as elipsóides, nos próximos capítulos serão sempre mostrados os pontos que a definem, conforme a Figura 16 (b).

Note-se que a utilização do volume de trabalho como um paralelepípedo na norma [4] é eminentemente prática. Desta forma, prevê oito pontos de coleta de dados de campo elétrico dentro da câmara reverberante (CR), um em cada vértice do paralelepípedo e com distâncias fixas $(1 \mathrm{~m})$ das paredes, antenas e pás metálicas. Isto gera um grande volume inutilizado dentro da CR.

A vantagem do método de busca dos volumes de trabalho, é que é disponibilizada a flexibilidade tanto ao projetista quanto ao usuário para utilizarem altos valores de campo elétrico médio com volumes de trabalho pequenos ou pequenos valores de campo elétrico médio com grandes volumes de trabalho. Lembrando que os campos elétricos médios e desvios padrão associados a cada um dos volumes são calculados através das equações (78)-(80). 


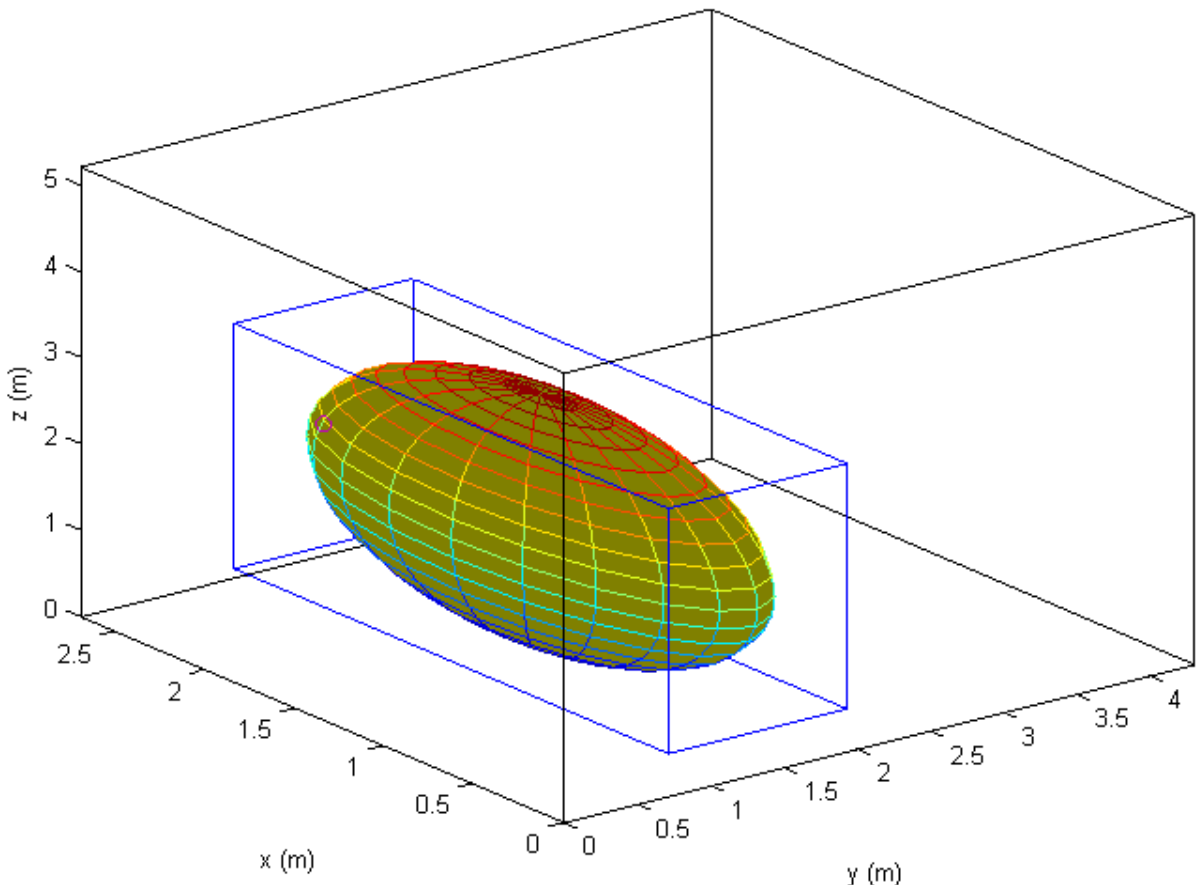

(a)

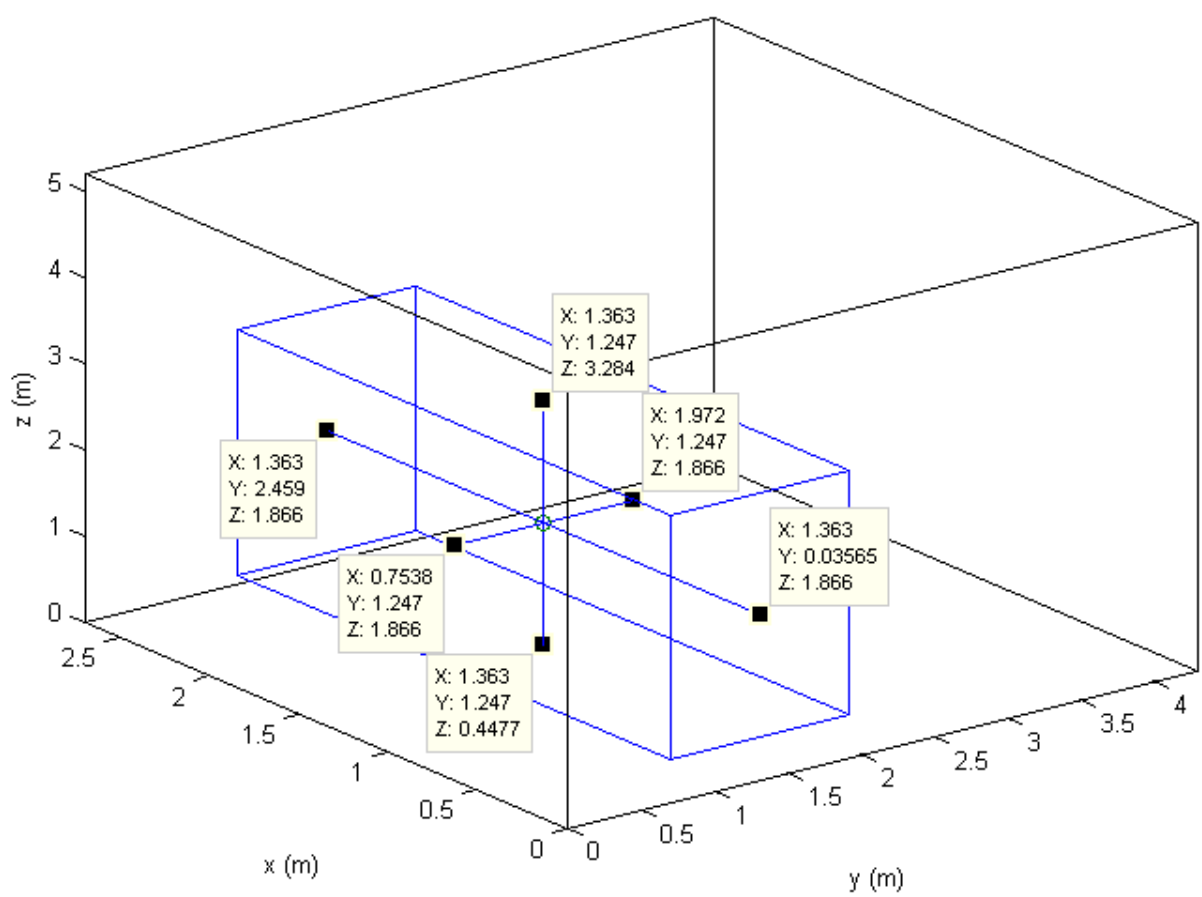

(b)

Figura 16 - Definição da elipsóide interna ao paralelepípedo (a) elipsóide (b) pontos que definem a elipsóide 


\subsubsection{Critério de decisão $L A$}

Após a busca dos volumes de trabalho não dominados para cada configuração da CELT, foi notada a necessidade de efetuar a comparação entre estas configurações.

Então, um critério de comparação entre as configurações da CELT foi definido, a partir das propostas de Lebensztajn \& Ávila (LA), pois para cada configuração (por exemplo, posições de linhas de transmissão, cargas, dimensões da câmara), pode gerar várias soluções de volumes de trabalho, todas não dominadas e que atendam às restrições de uniformidade [116].

Então, poder-se-ia utilizar três critérios clássicos de decisão, associados às funções objetivo volume de trabalho e campo elétrico:

1. as soluções que possuam pequeno volume e alto campo;

2. as soluções que possuam grande volume e campo pouco intenso; e

3. as soluções que possuam volume mediano e campo mediano.

Neste trabalho, propôs-se como uma alternativa a estes critérios clássicos, a escolha da configuração com o melhor compromisso "médio", levando-se em conta todas as soluções encontradas, ou seja, utilizar a área abaixo da curva do Fronteira Pareto como figura de mérito. Este critério proposto foi designado de LA e é detalhado a seguir.

Desta forma, utilizando-se a técnica de algoritmos genéticos com múltiplos objetivos, várias Fronteiras Pareto são obtidas. A Figura 17 mostra, como ilustração, o comprometimento de campo $E$ versus volume de trabalho, para oito posições de condutores, para uma câmara de dimensões (4,6 m x 2,7 m x 5,2 m), procurando-se maximizar o volume de trabalho e o campo elétrico, submetidos à restrição de desvio padrão menor que $4 \mathrm{~dB}$.

Neste caso, a curva que apresentar a maior área sob a Fronteira Pareto, ou seja, melhor comprometimento volume versus Campo E, será a que tem a melhor 
configuração, neste caso as posições dos condutores, por exemplo, no caso da Figura 17 seria a curva referente a $y=3,1 \mathrm{~m}$.

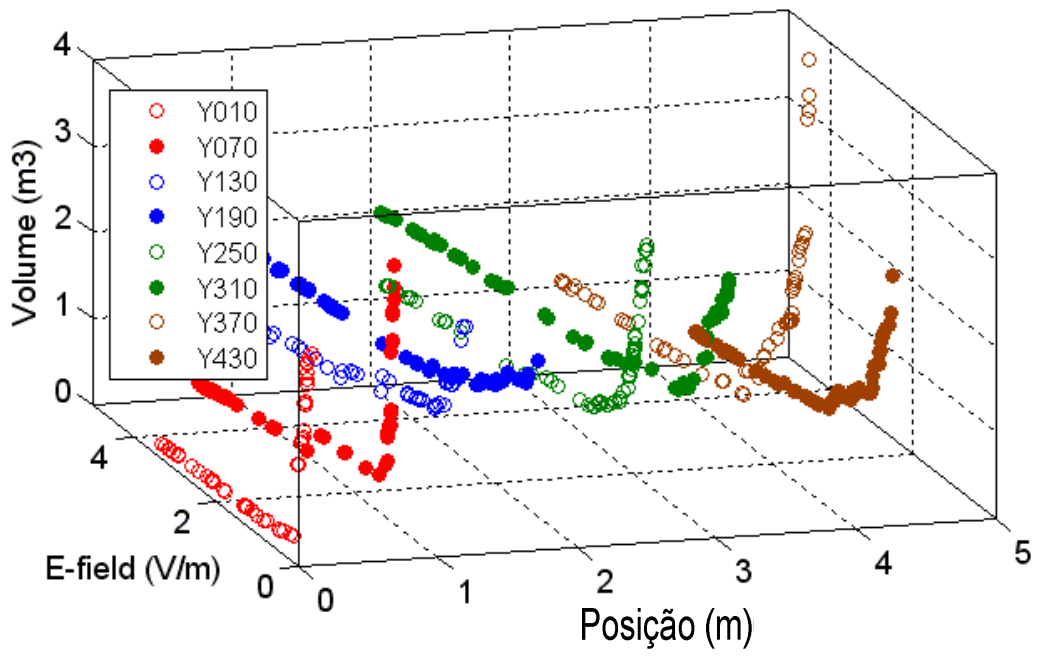

Figura 17 - Múltiplos Paretos, considerando várias posições dos condutores.

\subsubsection{Estratégias de Otimização}

Nesta seção serão apresentadas as estratégias de solução de vários problemas postulados, utilizando-se GA mono-objetivo e multi-objetivos, aplicados à CELT. Como já citado, inicia-se por uma descrição dos problemas postulados para análise de sensibilidade dos parâmetros e métodos AG mono-objetivo e multi-objetivos, passando-se pela definição dos parâmetros de decisão e, finalmente descrevendose a proposta de uma estratégia híbrida.

Uma vez determinada a Fronteira Pareto para cada configuração de câmara, a questão que surge é como fazer uma otimização livre da câmara. Entende-se por otimização livre, a possibilidade de variar a configuração física da câmara, ou seja, parâmetros estruturais (dimensões da câmara, posições das linhas de transmissão, etc.), sem a necessidade de interferência humana nos processos intermediários de busca da melhor configuração.

Neste processo, um fator importante é a verificação de quanto tempo todo o sistema levará para avaliar uma configuração. Se esta avaliação ocorrer em um tempo satisfatório não haverá necessidade de se adotar simplificações do modelo de cálculo de campos. Desta forma, o tempo de simulação de cada uma das 
configurações indicará a estratégia a se adotar em termos de equipamentos e modelos numéricos.

Neste caso deve-se considerar as possíveis variáveis do problema: dimensões da câmara (3); fases (3); posição dos condutores (3); e posição/dimensões do volume de trabalho (6). Isto resulta num total de 15 variáveis de otimização.

Note-se que as variáveis de otimização passam a ser as posições dos fios (acrescidas das dimensões da câmara, fases, cargas). Numa primeira abordagem, a redução da quantidade de variáveis do problema pode ser adotada, retirando-se as variáveis referentes às dimensões da câmara, além da variação de fases ou de cargas.

Então, o problema descrito de uma forma sob um ponto de vista particular: de posse de uma câmara blindada disponível (de dimensões já conhecidas), passa a ser, por exemplo, quais serão as posições das linhas de transmissão que melhor atendem aos requisitos.

Observa-se, no entanto, que os métodos descritos nesta seção podem ser aplicados à câmaras de diversas dimensões e arranjos de linhas de transmissão e que várias configurações foram analisadas, devido à flexibilidade dos métodos e estratégias utilizados.

Destaca-se que alguns resultados obtidos para duas configurações de CELT, uma para CELT protótipo LMAG/CTMSP e para uma câmara blindada do tamanho de uma sala, serão apresentados no item 4.6.3.

\subsubsection{Otimização Mono-objetivo}

A análise de sensibilidade da CELT, em conjunto com a declaração dos problemas a serem resolvidos é iniciada pela otimização mono-objetivo.

Definindo-se, desta forma, um problema de otimização geral, mono-objetivo, este pode ser escrito da seguinte forma: maximizar o volume de trabalho com duas restrições: campo $E$ (por exemplo, igual a $1 \mathrm{~V} / \mathrm{m}$ ) e desvio padrão $\leq 4 \mathrm{~dB}$. 
Ou, escrevendo-se em notação matemática:

$$
\begin{aligned}
& \operatorname{Max}(\text { Volume de Trabalho) } \\
& \text { Sujeito a }\left\{\begin{array}{l}
\left(\sigma_{x}, \sigma_{y}, \sigma_{z}, \sigma_{x y z}\right) \leq 4 \mathrm{~dB} \\
\bar{E}_{x, y, z}=1 \quad \mathrm{~V} / \mathrm{m}
\end{array}\right.
\end{aligned}
$$

Neste formato é possível comparar diretamente dois (ou mais) volumes de trabalho resultantes de diversos arranjos de posições das linhas de transmissão, diversas dimensões de câmara ou, ainda, fases de excitação das linhas de transmissão.

Note-se que os valores do campo E médio, estipulados como restrição, estão relacionados aos tipos de aplicação do equipamento sob teste. Os volumes de trabalho têm dimensões e posições livres.

\subsubsection{Otimização Multi-objetivos}

Pode ser considerada também a opção de se utilizar somente o AGMO, para resolver o seguinte problema de otimização: maximizar o volume de trabalho e o campo E médio dentro deste volume, sujeito à uma restrição de desvio padrão $\leq 4 \mathrm{~dB}$.

Ou, escrevendo em notação matemática, equação (85).

$$
\begin{aligned}
& \left\{\begin{array}{l}
\text { Max Volume de Trabalho } \\
\operatorname{Max} \bar{E}_{x y z}
\end{array}\right. \\
& \text { Sujeito a }\left\{\sigma_{x}, \sigma_{y}, \sigma_{z}, \sigma_{x y z} \leq 4 \mathrm{~dB}\right.
\end{aligned}
$$

Considera-se então uma possível simplificação ao problema: manter uma posição central do volume de trabalho (não é considerada uma boa simplificação, pois os melhores volumes de trabalho não se encontram no centro da câmara). 
Neste processo, atenta-se para a dificuldade de se adotar conjuntamente posição-dimensões do volume de trabalho, já que não são considerados variáveis de otimização clássicas.

Assim, uma otimização multi-objetivos pode ser considerada como uma alternativa de avaliação da CELT, adotando-se fortes restrições, ou seja, criar um indivíduo que possua as características de posição dos condutores, assim como as posições dos volumes de trabalho, mencionadas na seção 3.5.1.

Um problema nesta abordagem é que indivíduos com boas características de posição dos cabos podem ser considerados incapazes devido às más características dos volumes de trabalho, e vice-versa. Assim, pode-se gerar uma grande quantidade de indivíduos incapazes, o que é constatado somente após a chamada da rotina de cálculos.

Nota-se que cada indivíduo apresenta as seguintes características (variáveis do problema): posições dos condutores $(x 1, y 1),(x 2, z 2),(y 3, z 3)$, raios do volume de trabalho (ra, rb, rc), deslocamentos do centro do volume de trabalho ( $d a, d b, d c)$.

A Figura 18 apresenta um fluxograma de aplicação do AGMO na otimização da CELT, contendo os principais passos do processo.

Observa-se que aos condutores é permitido o posicionamento dentro de um volume pré-definido, de modo a manter a área de teste e de operação livre. A área central da câmara torna-se então uma "região controlada".

Desta forma, este método se caracteriza pela grande quantidade de acessos ao programa de cálculo de campo, devido ao grande número de indivíduos gerados, visando mapear adequadamente o espaço de soluções, além da avaliação sumária do melhor indivíduo, ou seja, a configuração que apresenta o melhor compromisso volume de trabalho versus campo $\mathrm{E}$. 


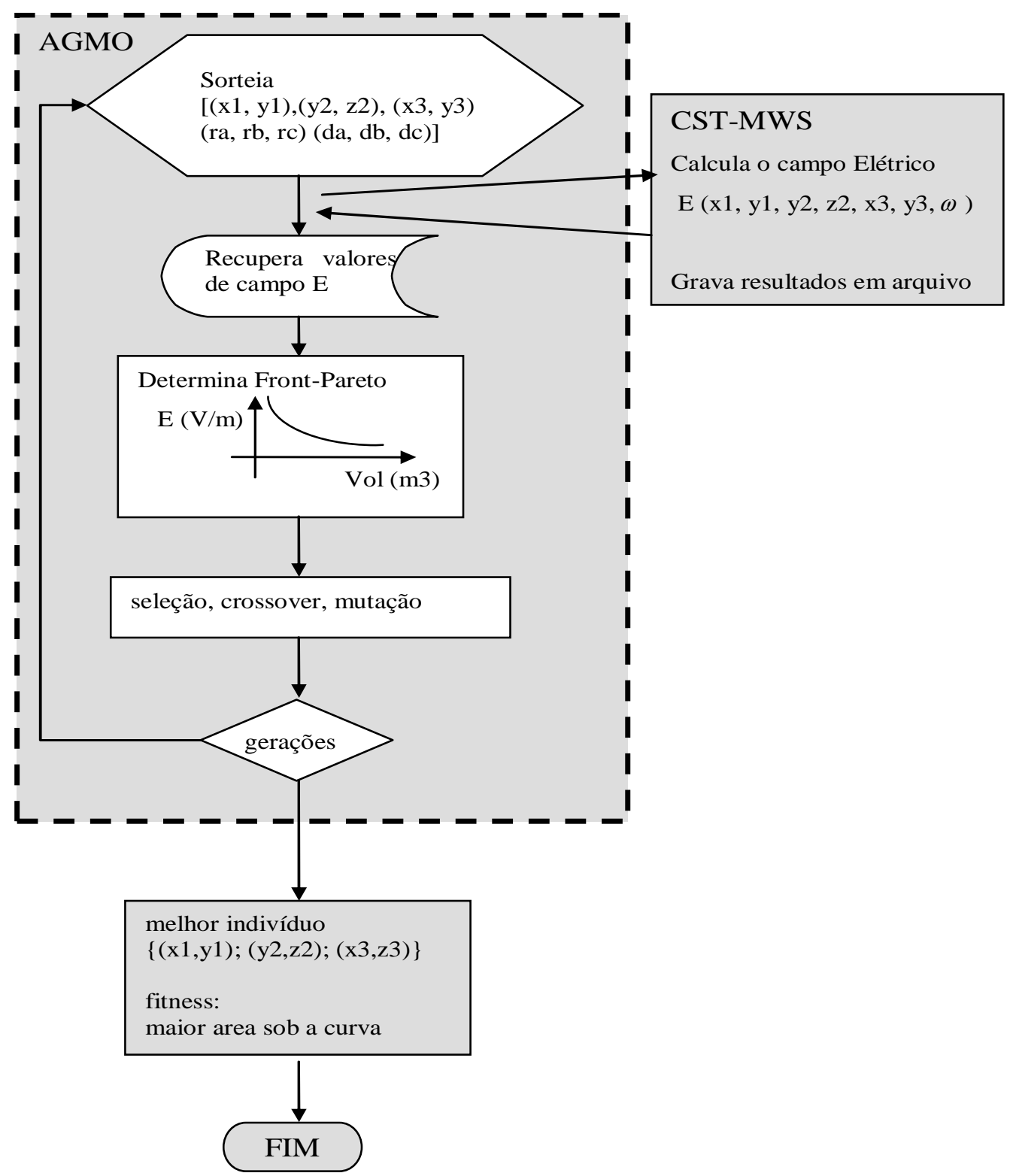

Figura 18 - Fluxograma de aplicação do AGMO na otimização da CELT

\section{Avaliação de posições de condutores - AGMO}

Inicialmente, numa estratégia AGMO aplicável à avaliação da CELT, pode-se considerar um indivíduo com as seguintes características: posições das Linhas de Transmissão (x1, y1, x2, y2, y3, z3), os marcadores para sinalizar as posições permitidas (flag1, flag2, flag3) e as características do Volume de Trabalho (raio do condutores (ra, rb, rc), deslocamento do centro do elipsóide (da , db, dc)). 
O procedimento adotado, então, tem seis passos fundamentais:

1) Conjuntos de posições aleatórias para as linhas de transmissão são geradas, assim como os as posições do centro dos volumes de trabalho e os raios das elipsóides;

2) As posições das linhas de transmissão são transferidas para a o programa de cálculo de campos eletromagnéticos (CST-MWS ${ }^{\circledR}$ - Anexo A);

3) O cálculo de campos eletromagnéticos na CELT é efetuado;

4) Os valores de campo E em cada ponto do espaço são exportados de volta para o ambiente de otimização;

5) $O$ volume de trabalho é calculado. Para a determinação do campo $E$ médio e do desvio padrão de um determinado volume de trabalho, as equações (78)-(80) são aplicadas.

7) Uma verificação das restrições de desvio padrão é aplicada e os conjuntos que não atendem, são eliminados;

6) O índice de mérito LA (item 3.5.2) é aplicado para decidir qual é a melhor configuração, dentre as configurações que atendem às restrições.

Conforme mencionado anteriormente, as normas de CEM adotam um paralelepípedo como o volume de controle, diferente do elipsóide aqui utilizado para caracterizar o volume de trabalho da CELT.

\subsubsection{Solução Híbrida - AGM e AGMO}

A Figura 19 apresenta o fluxograma que representa esta metodologia: associa-se um nível superior que busca a melhor configuração, através da avaliação de um índice de mérito (LA) e aplicando a otimização mono-objetivo (AGM), a um nível inferior, que gera os dados para a montagem do índice de mérito através de uma otimização multi-objetivos. 
A escolha do método AGMO para melhor compromisso e AGM para a busca da melhor posição das linhas de transmissão visa evitar uma desvantagem do AGMO, que é o excesso de chamadas da função objetivo (por conseguinte, excesso de chamadas do CST-MWS $\left.{ }^{\circledR}\right)$, e consequente aumento do tempo de cálculo. O AGM comanda o programa de cálculo de campos $\mathrm{E}$, passando as informações sobre as posições de campos e grava os resultados em um arquivo será utilizado pelo AGMO.

Um critério de avaliação é necessário, de forma a tratar as informações do nível inferior (compromisso) para fomentar o nível superior de otimização e, assim, o critério LA foi adotado. Um problema é que o resultado é bastante dependente da amostragem realizada, por exemplo, pode-se tomar $n$ pontos que não caracterizam a câmara e gerar um valor LA não significativo.

Mantendo-se constantes as fases entre os condutores e as dimensões da câmara CELT, pode-se escrever matematicamente o método híbrido:

- Mono-objetivo

Variáveis do problema: posição dos condutores [(x1, y1), (y2, z2), (x3, z3)]

$$
\operatorname{Max}\{\mathrm{LA}\}
$$

- Multi-objetivo

Variáveis do problema: posição do centro da elipse (da, db, dc); e dimensões do volume de trabalho (ra, rb, rc)

$$
\begin{aligned}
& \operatorname{Max}\left\{\begin{array}{l}
\text { Volume de Trabalho } \\
\bar{E}_{x y z}
\end{array}\right. \\
& \text { Sujeito a }\left\{\sigma_{x}, \sigma_{y}, \sigma_{z}, \sigma_{x y z} \leq 4 \mathrm{~dB}\right.
\end{aligned}
$$

Os passos fundamentais para este problema podem ser escritos como 
1.Fazer uma otimização (mono-objetivo) sobre o interpolador para determinar a posição ótima das linhas de transmissão;

1.1 Criar n conjuntos de posições de linhas de transmissão;

1.2 Fazer uma otimização multi-objetivos,

1.2.1 Criar $k$ conjuntos de posições do centro dos elipsóides e raios dos elipsóides;

1.2.2 Calcular a Fronteira Pareto para cada um dos $n$ conjuntos de linhas de transmissão;

1.2 Calcule o índice LA;

1.3. Procurar a configuração de linhas de transmissão que resultem na maior área abaixo da Fronteira Pareto, por ordenamento simples dentre a população corrente. 


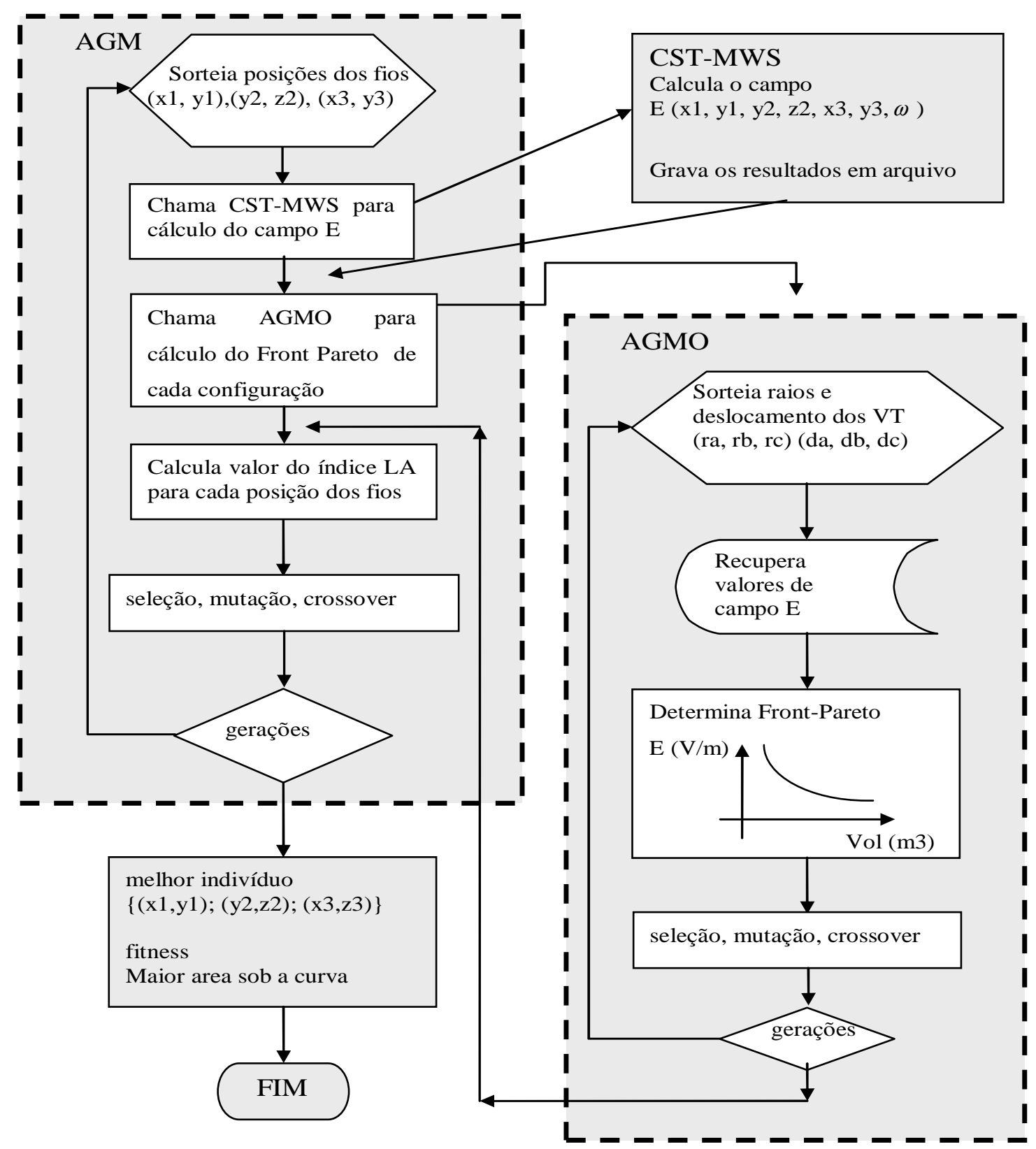

Figura 19 - Fluxograma do método híbrido 


\section{RESULTADOS}

Neste capítulo são apresentados os resultados obtidos, basicamente com foco no protótipo da CELT, em quatros abordagens distintas: analítica, simulações numéricas tridimensionais, avaliações experimentais e estudos de otimização. Á medida em que vão sendo apresentados, os resultados são discutidos e, quando possível, comparados.

Na parte dedicada aos resultados analíticos, inicia-se com a análise de cavidades ressonantes através da análise modal, e em seguida a aplicação do conceito de coeficiente de reflexão em linhas de transmissão é realizado.

Em seguida, dedica-se às simulações numéricas, iniciando-se com a comparação de um modelo simplificado e outro detalhado. Após, são analisados os efeitos da defasagem na excitação, os efeitos das posições das linhas de transmissão e os efeitos das cargas. Ainda, a avaliação de uniformidade em função das configurações da CELT e das estratégias de excitação.

Dedicamo-nos, então, à apresentação dos resultados experimentais, com medições de campo E no protótipo e de parâmetros S. Procurou-se aplicar ensaios padronizados, com carga $50 \Omega$, carga aberta e curto-circuitada, tanto para a avaliação do campo E quanto para os parâmetros S. A utilização de defasadores como cargas é analisada em algumas configurações.

Por fim, apresentam-se os resultados dos estudos de simulações numéricas utilizando várias estratégias de otimização (AGM, AGMO e Híbrido).

\subsection{Protótipo LMAG/CTMSP}

Com objetivo de validar as propostas de métodos de análise e, ao mesmo tempo, criar uma rotina adequada de testes, além de testar os conceitos envolvidos na CELT, foi projetado e construído um protótipo, com dimensões reduzidas $(1,2 \mathrm{~m} \times$ 
0,6m $\times 0,6 \mathrm{~m})$, tomando por base um protótipo construído por Weinzierl [34], [109] na BTU-Cottbus.

O protótipo construído é mostrado na Figura 20, sem as tampas superiores (a parte superior é 3 seções metálicas). Notem-se as linhas de transmissão paralelas que efetuam a excitação dos campos TEM. Outros detalhes construtivos são abordados no APÊNDICE A.

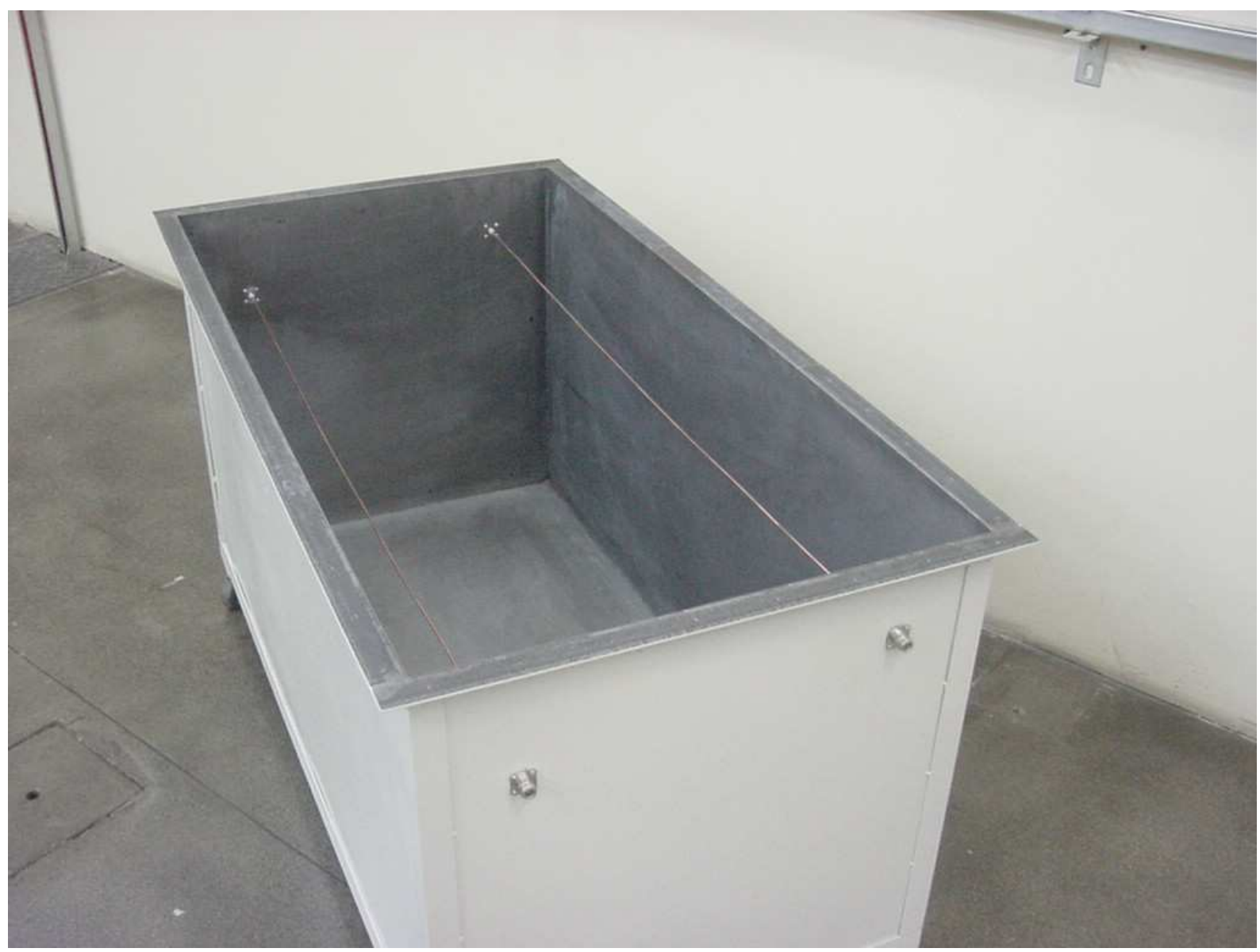

Figura 20 - Protótipo de CELT com linhas de transmissão LMAG/CTMSP.

Tomando as dimensões do protótipo e considerando as paredes como condutores perfeitos, são calculados os modos de ressonância para cavidade preenchida com dielétrico perfeito (vácuo), de acordo com a equação (36), e apresentados na Tabela 2. Um diagrama ilustrativo das frequências de ressonância é apresentado na Figura 21.

Na Tabela 2 pode-se observar que os modos de ressonância são proporcionais às dimensões da cavidade retangular $(1,2 \mathrm{~m} \times 0,6 \mathrm{~m} \times 0,6 \mathrm{~m})$, sendo o primeiro 
modo $\mathrm{TE}_{100}$ que ocorre em $125 \mathrm{MHz}$, e que o segundo, terceiro e quarto modos são degenerados. Devido à simetria entre dois eixos, muitos modos superiores apresentarão esta característica. Ainda, nota-se que o primeiro modo $\mathrm{TM}_{110}$ ocorre em 279,5 MHz (degenerado).

Tabela 2 - Modos e Frequências de Ressonância para o protótipo LMAG/CTMSP.

\begin{tabular}{|c|c|}
\hline Modo (TE/TM) & Frequência (MHz) \\
\hline TE 100 & 125 \\
\hline TE 010 & 250 \\
\hline TE 001 & \\
\hline TE 200 & \\
\hline TE 101 & 279,5 \\
\hline TM 110 & \\
\hline TE 201 & 353,5 \\
\hline
\end{tabular}

A Figura 21 ilustra as frequências de ressonância, calculadas pelo método analítico para uma cavidade preenchida com dielétrico perfeito (vácuo) com as mesmas dimensões do protótipo LMAG/CTMSP até 1,2 GHz. Nota-se que a primeira frequência de ressonância é $125 \mathrm{MHz}$, conforme já citado na Tabela 2, e a segunda frequência de ressonância (modo degeneradao) é $250 \mathrm{MHz}$.

Para efeito de exemplo, um modo superior $\left(\mathrm{TM}_{405}\right)$ é mostrado na Figura 22, para a condição de paredes com condutores perfeitos e com a cavidade com dielétrico perfeito (vácuo). Caso existam outros elementos dentro da câmara, ou paredes de material com perdas, esta distribuição de campos pode ser alterada. Note-se que estas configurações são teóricas e servem apenas para referência e análise preliminar. 


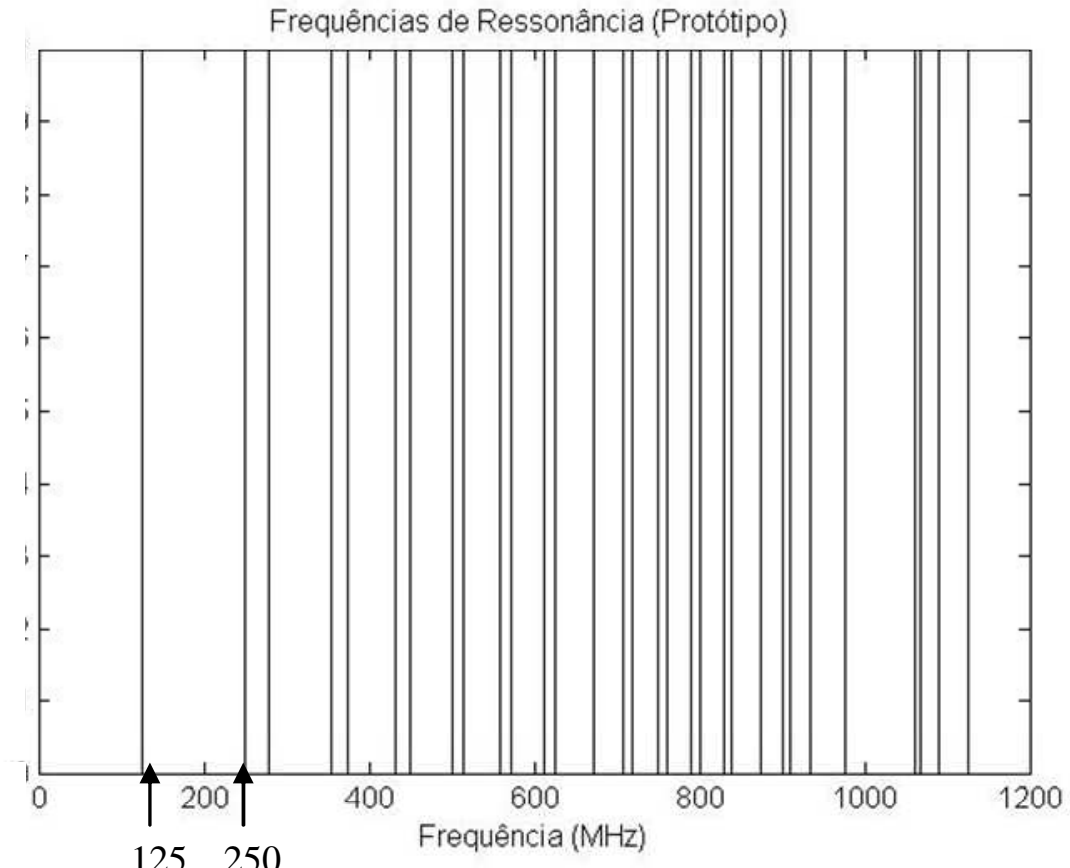

Figura 21 - Frequências de ressonância (resultado analítico) para o protótipo LMAG/CTMSP, sem excitação das linhas de transmissão.

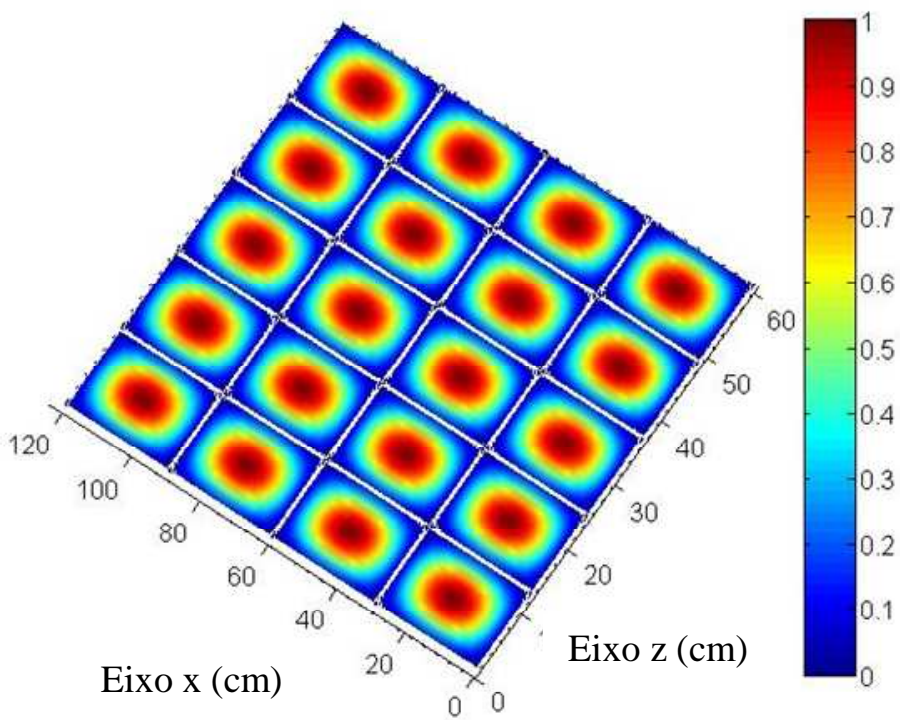

Campo E

normalizado

Figura 22 - Vista superior Modo TM405 - analítico para o protótipo LMAG/CTMSP, sem a inserção das linhas de transmissão. 


\subsubsection{Modelo de cálculo do campo elétrico resultante na consideração da carga}

Partindo-se das equações (52) e (53), varia-se o valor da carga $Z_{L}$, pode-se obter diferentes perfis de ondas estacionárias ao longo da direção de propagação, ou seja, ao longo da linha de transmissão. A Figura 23 ilustra o caso onde $Z_{L}$ e $Z_{c}$ (impedância de carga e impedância característica, respectivamente) são puramente reais. O ponto onde ocorre a mudança de impedâncias é identificado no eixo das distâncias do gráfico como o zero.

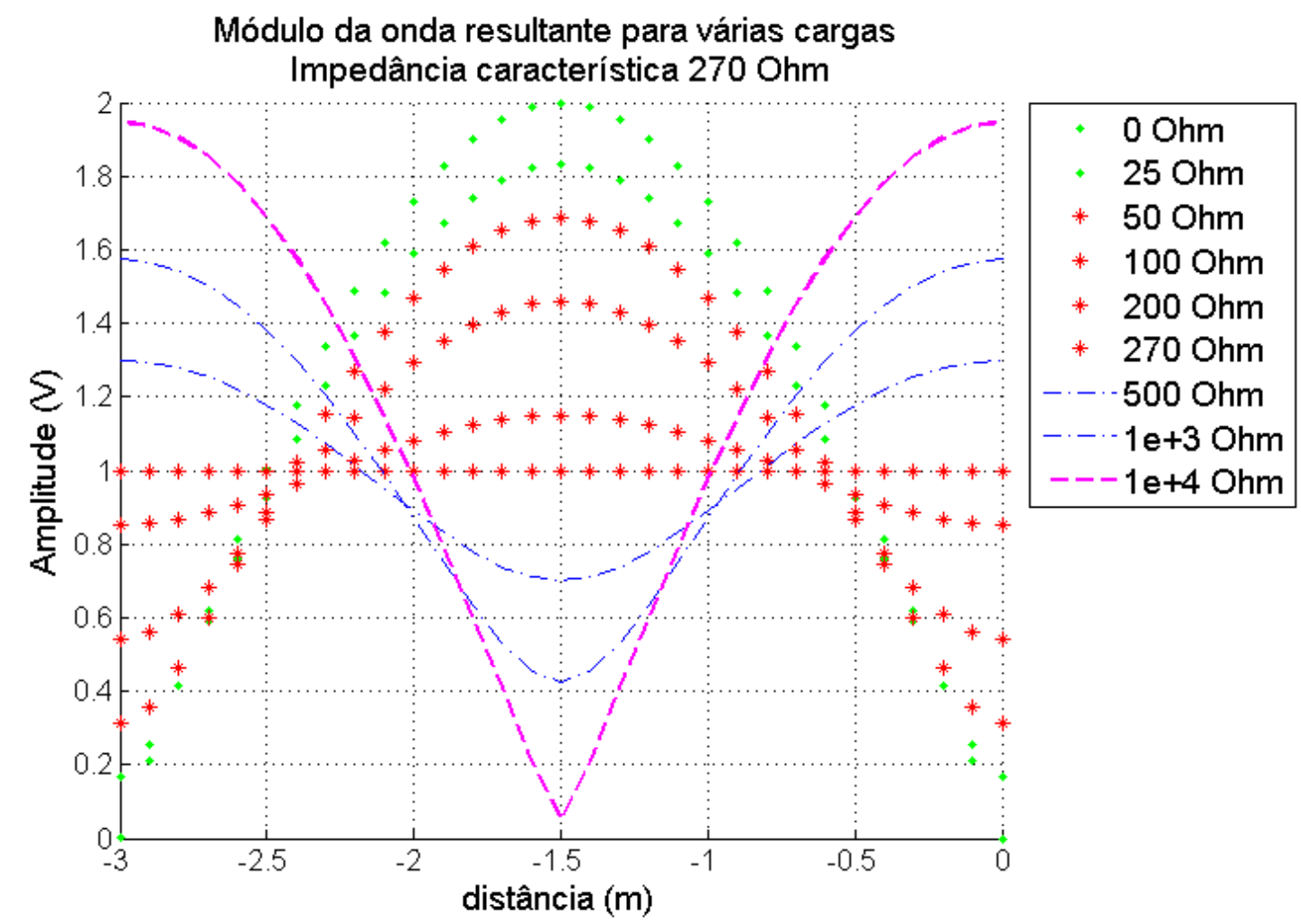

Figura 23 - Efeito da carga puramente real (resistiva) na onda resultante para impedância característica $=270 \Omega$ e cargas $0 \Omega, 25 \Omega, 50 \Omega, 100 \Omega, 200 \Omega, 270 \Omega, 500 \Omega, 1 \mathrm{k} \Omega, 10 \mathrm{k} \Omega$ $-50 \mathrm{MHz}$.

Observando-se as equações anteriores, nota-se que tanto para variar, quanto para defasar os valores de pico (máximos) poderia-se trabalhar sobre a fase de $\Gamma$ (uma vez que $\Gamma$ é complexo). 
Então, considerando $\Gamma=e^{j \phi}$, efetua-se o estudo apresentado na Figura 24, que mostra o comportamento da onda estacionária quando se varia somente $\phi$, ou seja, cargas puramente imaginárias (indutiva ou capacitiva).

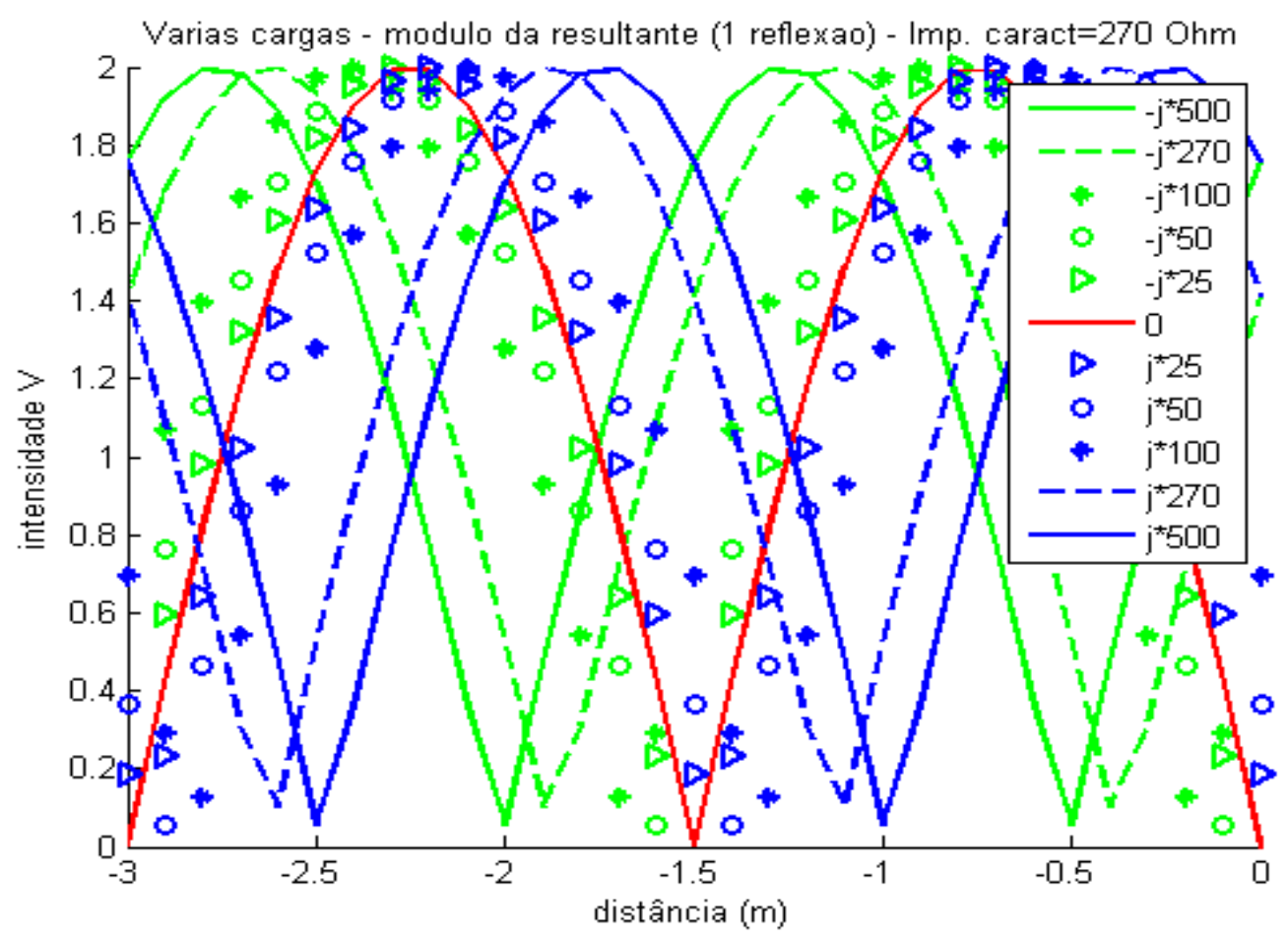

Figura 24 - Efeito da carga imaginária sobre a distribuição espacial de campo E gerada por uma linha de transmissão.

Ao se considerar os dois efeitos, a variação da carga real (resistiva) e a variação da carga imaginária (indutiva ou capacitiva), que deixam de ser casos puramente teóricos e mostram o que ocorre experimentalmente, pode-se observar o efeito resultante na Figura 25 


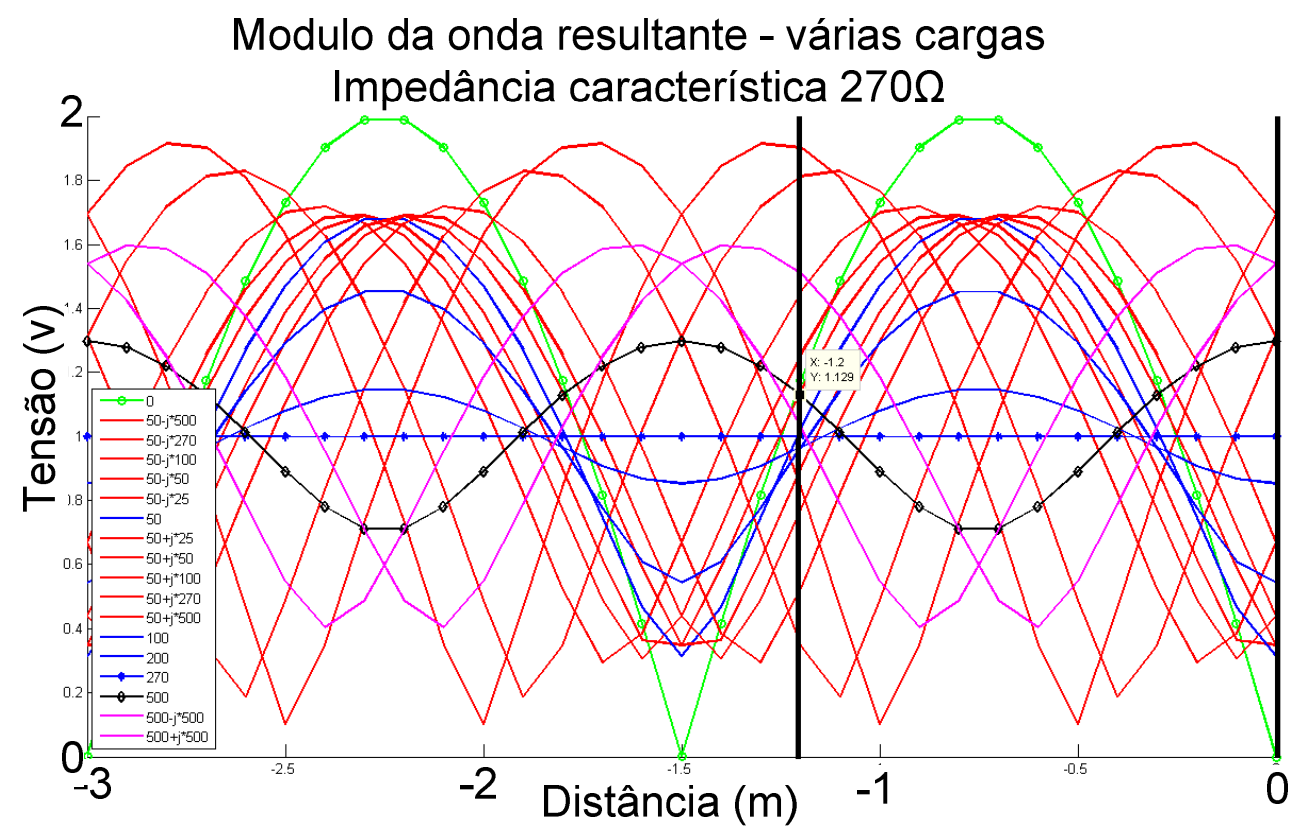

Figura 25 - Efeito da carga complexa sobre a distribuição espacial de tensão gerado sobre uma linha de transmissão com impedância característica $270 \Omega$. Valores de onda resultantes, para excitação com módulo 1 e várias cargas complexas.

\subsubsection{Formas de onda na câmara - operação "no-moded", "single-moded" e "over-moded"- resultados preliminares}

Alguns resultados preliminares com relação às formas de onda resultante dentro da câmara e valores de campo E, que podem ser obtidos na câmara foram efetuadas, utilizando o modelo simplificado. Alguns resultados, que procuram ressaltar a existência de ondas estacionárias dentro da câmara, são mostrados e comentados abaixo.

Por outro lado, quando excita a câmara preenchida com dielétrico perfeito (vácuo) através de uma pequena antena próxima a uma das faces, obtém-se os resultados mostrados na Figura 26, para excitação abaixo da frequência de corte da cavidade e na Figura 27, para excitação com frequência acima de três vezes a frequência de corte da cavidade.

Por outro lado, na Figura 28 é mostrada a forma de onda em um plano a 0,3 $\mathrm{m}$ da base para o protótipo LMAG/CTMSP, com duas linhas de transmissão excitadas em fase para a frequência de $100 \mathrm{MHz}$. Note-se que a frequência de corte da câmara é 
$125 \mathrm{MHz}$, portanto trabalha-se na faixa de frequência "modo único", que é a faixa típica de operação da CELT e que será exaustivamente analisada neste trabalho.

Os resultados apresentados indicam a existência de campos eletromagnéticos em todas as direções, chegando no máximo a $32 \mathrm{~V} / \mathrm{m}$, para uma entrada de potência de $1 \mathrm{~W}$ em cada linha de transmissão.

A Figura 29 apresenta os resultados para a frequência de $500 \mathrm{MHz}$. A câmara opera na faixa "over-moded", ou seja, acima de 3 vezes a frequência de corte.

No caso referente à operação em $500 \mathrm{MHz}$, o valor máximo de campo atingido é de cerca de $48 \mathrm{~V} / \mathrm{m}$ para a injeção de $1 \mathrm{~W}$ de potência em cada linha, existindo campos eletromagnéticos em todas as direções.

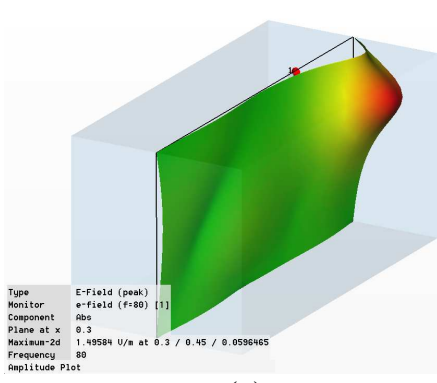

(a)

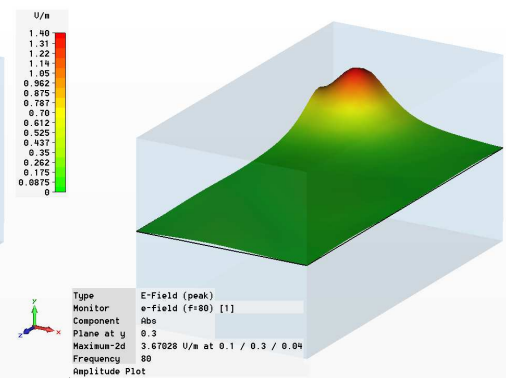

(b)

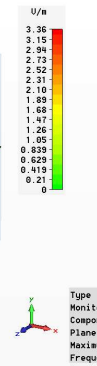

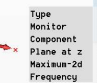

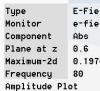

Figura 26 - Cavidade preenchida com dielétrico perfeito (vácuo) excitada com antena pequena na frequência $80 \mathrm{MHz}$ (a) Ex, (b) Ey, (c) Ez.

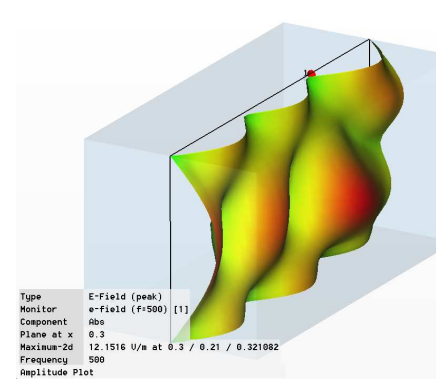

(a)

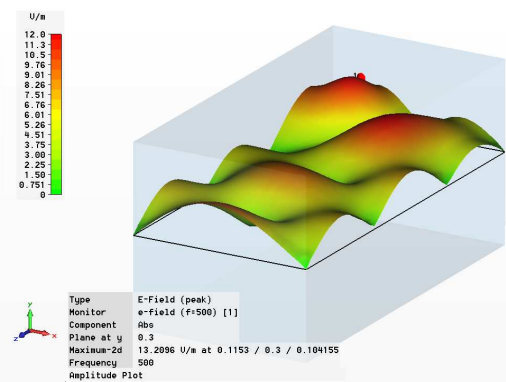

(b)
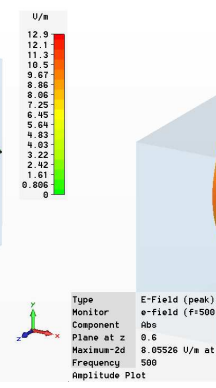

(c)

Figura 27 - Cavidade preenchida com dielétrico perfeito (vácuo) excitada com antena pequena na frequência $500 \mathrm{MHz}$ (a) Ex, (b) Ey, (c) Ez. 


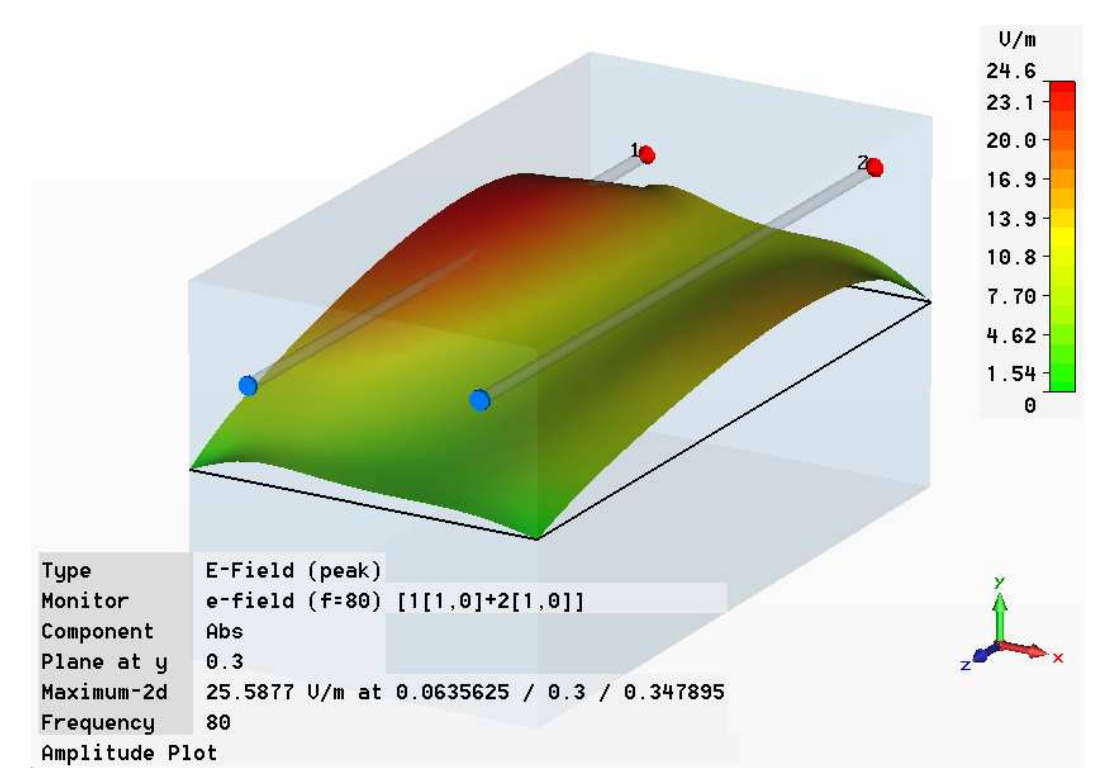

Figura 28 - Valor absoluto para campo E, plano 0,3 m, fase 210 graus, $100 \mathrm{MHz}$, PEC.

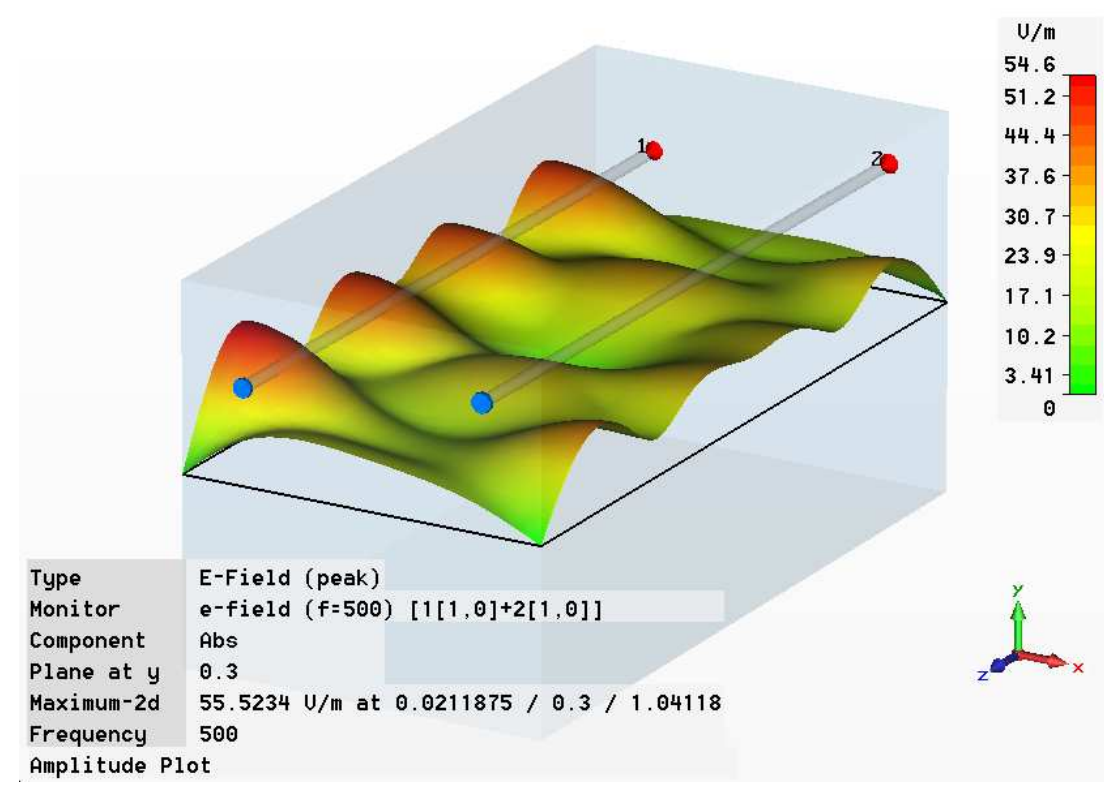

Figura 29 - Valor absoluto para campo E, plano 0,3 m, fase 210 graus, $500 \mathrm{MHz}$, PEC.

\subsection{Análise das simulações numéricas do protótipo LMAG/CTMSP}

As simulações foram efetuadas utilizando o CST-MWS $®$ para o cálculo de campos eletromagnéticos. Uma visão geral do método é transcrita no Anexo A. A ferramenta de resolução Transitória foi utilizada nas simulações. Esta ferramenta, basicamente simula numericamente a injeção de um sinal de excitação na estrutura analisada, calculando os campos eletromagnéticos através do método FIT, monitorando a energia do sistema, e quando a energia cai abaixo de um nível pré- 
determinado, o sistema é considerado em regime e o processo iterativo de cálculo é finalizado. Os resultados podem ser analisados através das diversas soluções de visualização do CST-MWS $\AA_{\text {, }}$ ou serem exportados para outros ambientes numéricos, como o Matlab ${ }^{\circledR}$.

No caso deste trabalho, as frequências de 80 e $100 \mathrm{MHz}$ foram escolhidas para análise, por estarem abaixo da frequência de corte desta câmara (como visto no item anterior, $f_{c}=125 \mathrm{MHz}$ ) e permitirem uma análise da CELT no limite da faixa definida como de interesse (poucos $\mathrm{MHz}$ a $100 \mathrm{MHz}$ ).

É interessante notar que uma abordagem similar utilizando-se um modelo simplificado foi publicada em [112], para uma câmara de tamanho maior, que se assemelha às câmaras padrão de mercado. Neste trabalho é abordado preferencialmente o caso do protótipo LMAG/CTMSP, que possui dimensões reduzidas e destina-se à comparação entre os resultados simulados e experimentais.

Iniciando-se o trabalho de simulação numérica da CELT, em especial do protótipo construído, foi efetuada uma depuração do modelo preliminarmente apresentado para representação da CELT [112], denominado modelo simplificado, aplicando os elementos mais precisos (tal como a excitação via porta guia de onda), as descrições de materiais mais completas (tal como metal com perdas). Uma descrição dos modelos simplificado e detalhado é dada na seção 3.2 deste trabalho.

Nota-se que a inserção de maiores detalhes nos modelos aumenta o tempo de simulação de minutos (no modelo simplificado - cerca de 20 mil células na malha de resolução) para horas (no modelo detalhado - cerca de 500 mil células na malha de resolução). Este grande tempo para resolução de cada configuração do modelo detalhado, na prática, inviabiliza a utilização de métodos de otimização que utilizem chamadas recursivas ao programa de simulação numérica. Devido a isso, optou-se por utilizar o modelo simplificado para as análises onde ocorram variações de configuração que exijam re-cálculo do problema eletromagnético (tais com alterações de posições de condutores, alteração de cargas) e utilizou-se o modelo 
detalhado para as análises da variação da amplitude da excitação e variação da defasagem na excitação.

Os detalhes relativos aos componentes utilizados são comentadas nos itens seguintes.

\subsubsection{Porta discreta versus porta guia de onda}

Uma primeira comparação foi efetuada mantendo-se o modelo com paredes e condutores PEC, mas com a troca das portas discretas, indicadas na Figura 30 pela cor vermelha, pelas portas tipo guia de onda.

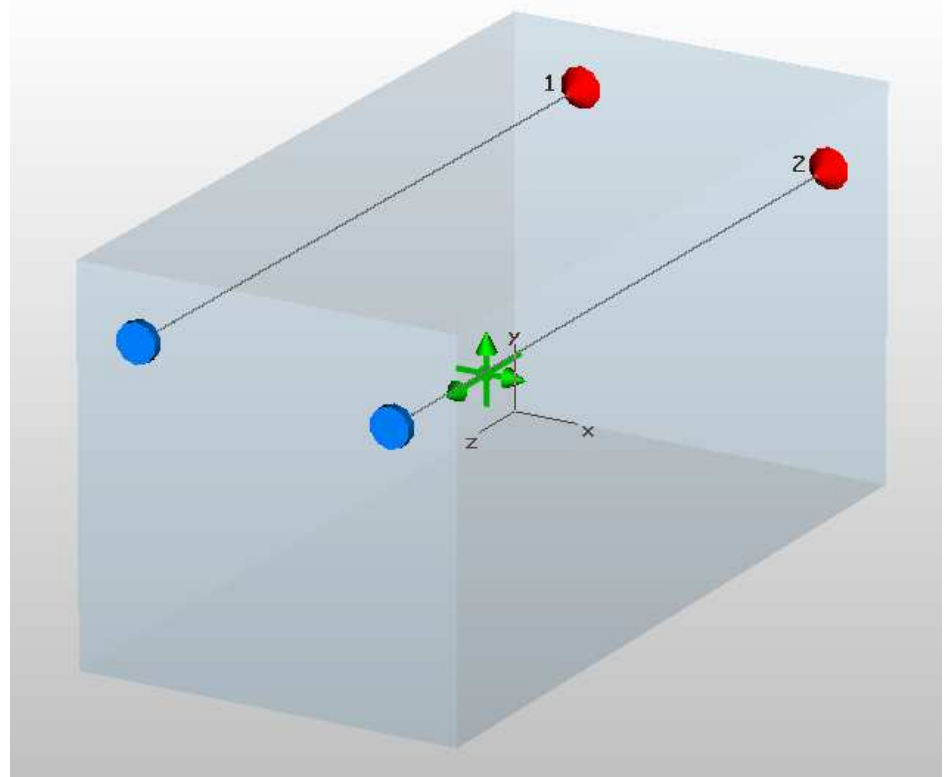

Figura 30 -Posição dos sensores virtuais $x, y$ e $z$ no centro da câmara $(0,3 m, 0,3 m, 0,6 m)$.

Os resultados de campo $E$, com relação à frequência no ponto $(0,3 ; 0,3 ; 0,6) \mathrm{m}$ (indicado pelas setas verdes na Figura 30 ) das duas configurações de simulação numérica são apresentados na Figura 31 (a) e as diferenças encontradas são mostradas na Figura 31 (b). As máximas diferenças de campo $E$ encontrados foram: $1,32 \mathrm{~V} / \mathrm{m}, 0,9755 \mathrm{~V} / \mathrm{m}, 0,2437 \mathrm{~V} / \mathrm{m}$, nos eixos $\mathrm{x}$, y e $z$, respectivamente. Em porcentagem $5,4 \%, 7,6 \%, 40,4 \%$, respectivamente. Como os valores de Ez são considerados residuais, o grande erro nesta direção não é considerado significativo nesta fase. 


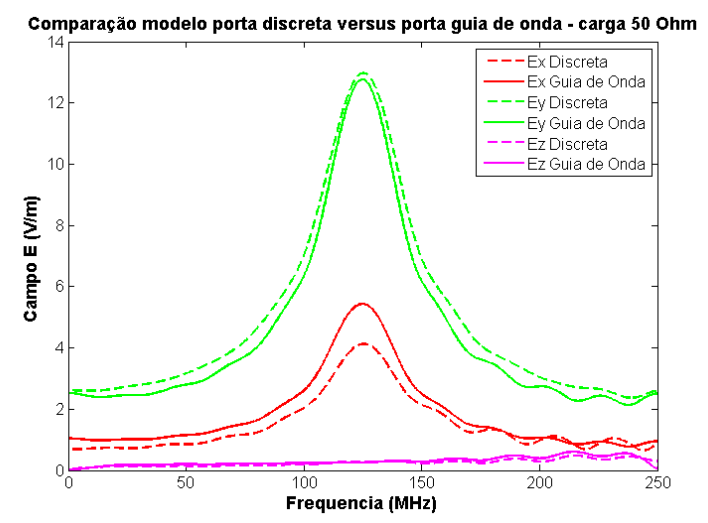

(a)

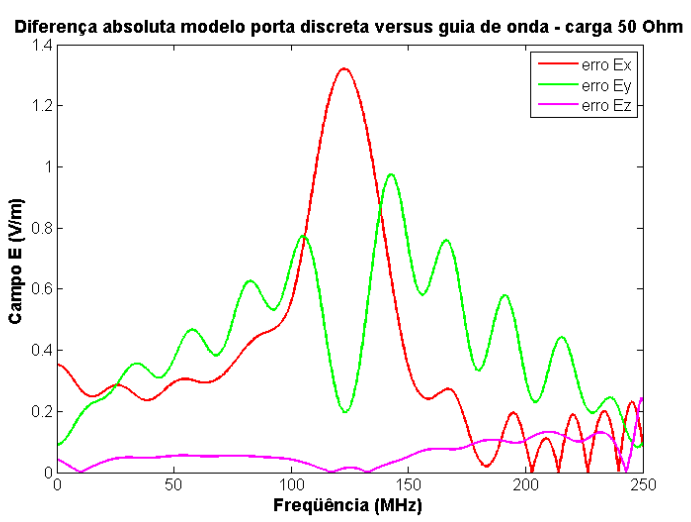

(b)

Figura 31 - Campo E no centro da CELT, modelo com porta discreta e porta guia de onda (a)Componentes Ex, Ey e Ez (b) diferença de valores entre os modelos.

\subsubsection{Parede PEC versus parede com perdas}

Na Figura 32 apresentam-se os valores de campo $E$ no plano y $=0,3 \mathrm{~m}$, obtidos nas simulações com paredes com perdas (aço: $\sigma=5 \times 10^{6} \mathrm{~S} / \mathrm{m}$ e $\mu=1 \times 10^{2}$ ) e paredes PEC. Nota-se que as maiores distorções concentram-se próximas às paredes e a máxima diferença em valor absoluto de campo $E$ é $(0,1085 \mathrm{~V} / \mathrm{m})$ o que equivale em porcentagem a $0,53 \%$.

Comparação: modelo de parede com perdas e sem perdas - $100 \mathrm{MHz}-1 \mathrm{~W} / \mathrm{LT}$

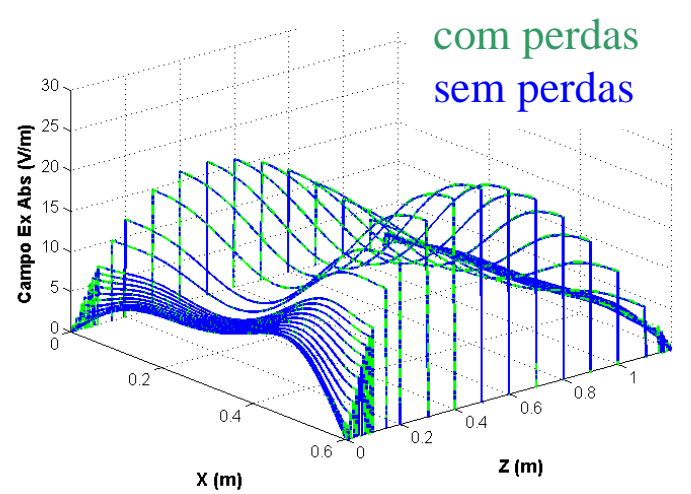

(a)
Erro absoluto entre o modelo de parede com perdas e sem perdas - $100 \mathrm{MHz}-1 \mathrm{~W} / \mathrm{LT}$

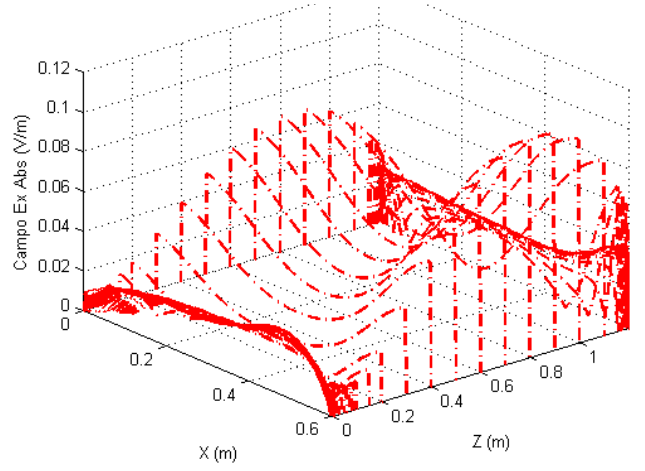

(b)

Figura 32 - (a) Campo EAbs simulado sobre linhas paralelas ao eixo $X$, no plano $y=0,3 m$, modelos paredes com perdas e sem perdas. (b) valores da diferença entre os modelos, ponto a ponto. 


\subsection{Resultados de Simulações Numéricas}

Neste capítulo são apresentadas simulações utilizando o Matlab ${ }^{\circledR}$ e o CSTMWS ${ }^{\circledR}$, conforme apresentado no APÊNDICE C. Estas simulações foram realizadas com o objetivo de compreender melhor qual a influência da mudança de posições das linhas de transmissão, além dos efeitos da mudança de cargas, no envoltório da variação dos campo E. Ainda sobre esses efeitos, foi aplicada a variação de defasagens na excitação, para análise da excursão dos valores de campos $\mathrm{E}$.

\subsubsection{Efeitos da defasagem na excitação da CELT}

As ondas estacionárias resultantes de campos gerados pela linha de transmissão 1 e pela linha de transmissão $2\left(\mathrm{E}_{\mathrm{LT} 1}+\mathrm{E}_{\mathrm{LT} T 2}\right)$ são mostradas da Figura 33 até a Figura 38, considerando-se diferentes arranjos das linhas de transmissão (curvas verdes) e, também, a inserção de defasagens nas excitações destas (curvas azuis).

Nota-se que os campos resultantes das defasagens têm excursões diferentes a cada posição considerada das linhas de transmissão.

A avaliação numérica foi efetuada utilizando-se o método FIT e considerando o modelo em três dimensões de forma a tornar a simulação mais representativa possível. Nesta simulação foram utilizadas: excitação com porta discreta $1 \mathrm{~W} / 50$ $\Omega$, linhas de transmissão e paredes PEC, espaço interno da câmara como vácuo e cargas resistivas de $50 \Omega$.

Após o primeiro cálculo de campos eletromagnéticos devido às LT1 e LT2, representados respectivamente pelas curvas em verde e vermelho da Figura 33, foram aplicadas defasagens na excitação e somados os campos $E(L T 1+L T 2)$, representados pelas curvas em azul na mesma Figura 33. A mesma idéia será aplicada em seções posteriores para cálculo dos efeitos da defasagem no volume de trabalho. O resultado seguinte foi obtido utilizando-se um modelo simplificado da CELT, para uma frequência de $100 \mathrm{MHz}$. 


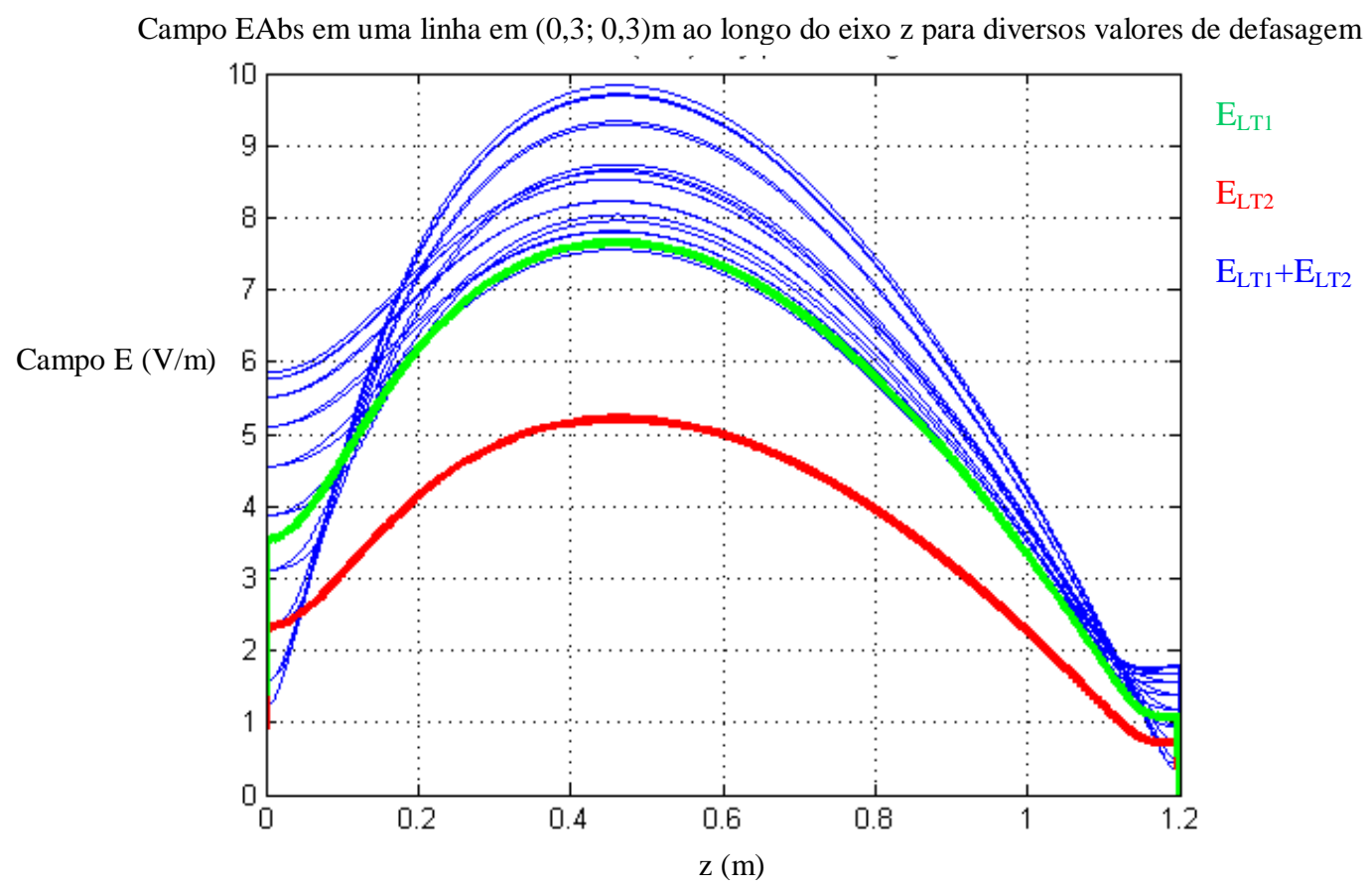

Figura 33 - Campos EAbs resultantes da excitação da LT1 (verde), LT2 (Vermelho) sem defasagem. Campo E (LT1+LT2) com diversas defasagens da $L T 2$ - $0^{\curvearrowright} 360^{\circ}$ passo $20^{\circ}$ (azul), na CELT para uma carga $50 \Omega$.

Nota-se que o ponto de máximo valor de campo EAbs permanece próximo da posição $z=0,5 \mathrm{~m}$, para quaisquer valores de defasagens da excitação. Ainda, considerando que as duas linhas de transmissão permaneçam com excitação constante, uma excursão máxima de cerca de $2,5 \mathrm{~V} / \mathrm{m}$ é obtida no ponto de máximo valor do campo EAbs. Ou seja, altera-se somente o valor de amplitude máxima da onda estacionária, mas não a posição física deste máximo.

Por outro lado, aplicando-se a simulação numérica para verificar os efeitos das defasagens na excitação, quando se observa somente um ponto no centro da CELT $(0,3 ; 0,3 ; 0,6) \mathrm{m}$, com relação à frequência, são mostrados na Figura 34 .

Nota-se que da mesma forma como o pico de máximo valor no espaço não se desloca com a aplicação da defasagem, também assim se comporta o valor da frequência de ressonância com a aplicação da defasagem. A frequência de ressonância permanece próxima de $125 \mathrm{MHz}$, para todos os valores de campo $\mathrm{E}$, com a defasagem aplicada na excitação da CELT, desde que mantidas as condições de carga e posições das linhas de transmissão. 


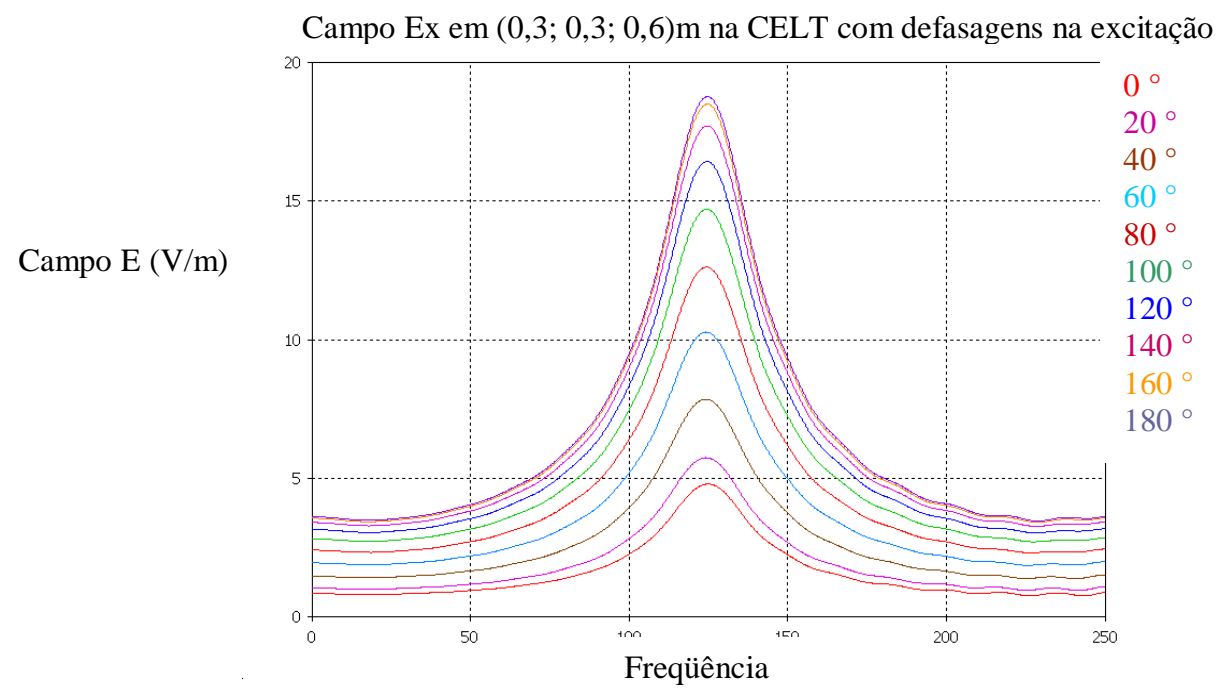

(a)

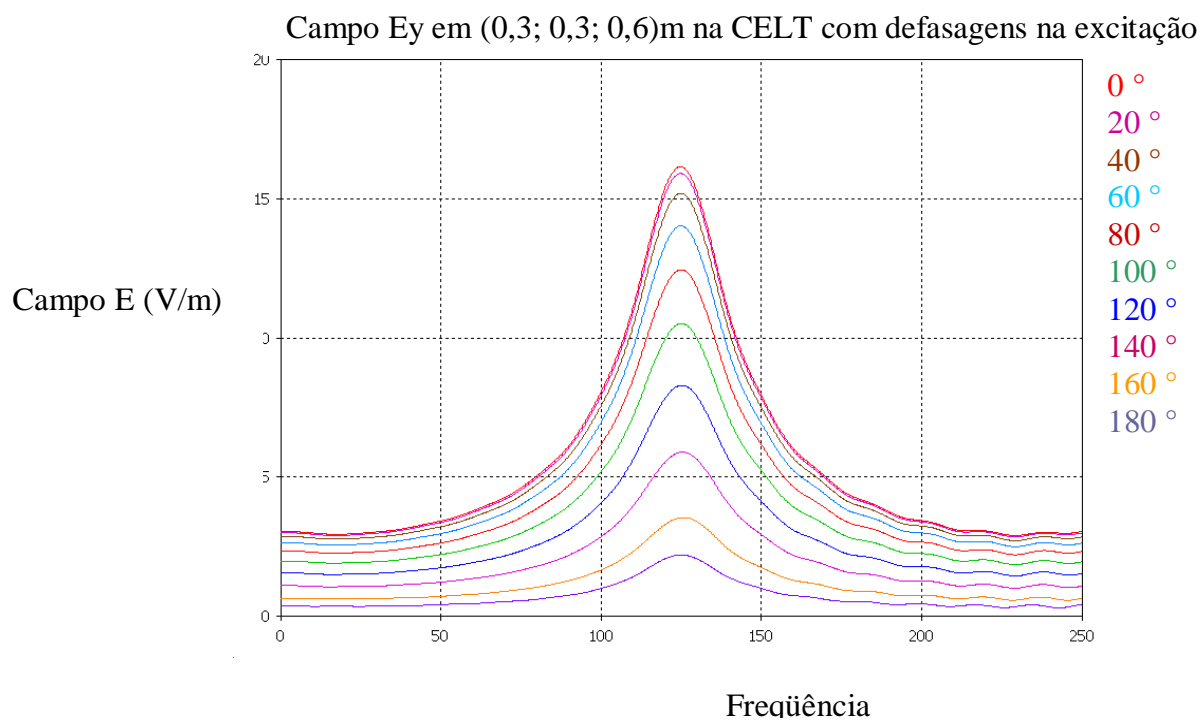

(b)

Figura 34 - Efeito na frequência quando se varia a defasagem entre a excitação dos condutores na entrada da CELT - carga $50 \Omega$, centro da câmara protótipo.(a) Abs(Ex); (b)Abs(Ey).

Uma abordagem dos efeitos da variação das posições das linhas de transmissão será apresentada na seção seguinte.

\subsubsection{Efeito da variação das posições das Linhas de Transmissão na CELT}

Os resultados mostrados da Figura 35 a Figura 38, referem-se à variação da excursão dos valores de campo EAbs (curvas verdes) resultante da excitação com fases iguais e amplitudes iguais de LT1 e LT2, obtidos via simulação numérica no CST-MWS®, quando se consideram as variações nas posições dos condutores. Posteriormente, inclui-se os efeitos da variação das defasagens (curvas azuis). 0 
modelo utilizado foi o simplificado, com carga $=50 \Omega, 100 \mathrm{MHz}$, e os campos EAbs resultantes são avaliados no plano $\mathrm{y}=0,3 \mathrm{~m}$.

Para avaliar a excursão do campo EAbs resultante com relação às defasagens de excitação, foram efetuados os gráficos mostrados, e esta abordagem mostra com clareza quais são os limites de variação (envoltória da variação). Assim, quanto maior a envoltória, maiores serão os efeitos produzidos pela defasagem da excitação.

Alguns resultados representativos são mostrados e as posições das linhas de transmissão consideradas são na Figura $35(x 1=0,1 \mathrm{~m}, \mathrm{y} 1=0,45 \mathrm{~m}, \mathrm{x} 2=0,5 \mathrm{~m}$, y2 $=0,5 \mathrm{~m})$, na Figura $36(\mathrm{x} 1=0,3 \mathrm{~m}, \mathrm{y} 1=0,45 \mathrm{~m}, \mathrm{x} 2=0,5 \mathrm{~m}, \mathrm{y} 2=0,5 \mathrm{~m})$, Figura 37 $(x 1=0,1 \mathrm{~m}, \mathrm{y} 1=0,1 \mathrm{~m}, \mathrm{x} 2=0,5 \mathrm{~m}, \mathrm{y} 2=0,5 \mathrm{~m})$ e Figura $38(\mathrm{x} 1=0,5 \mathrm{~m}, \mathrm{y} 1=0,1 \mathrm{~m}$, $x 2=0,5 \mathrm{~m}, \mathrm{y} 2=0,5 \mathrm{~m})$.

Campo EAbs simulado no plano $\mathrm{y}=0,3 \mathrm{~m}$ com aplicação de defasagens

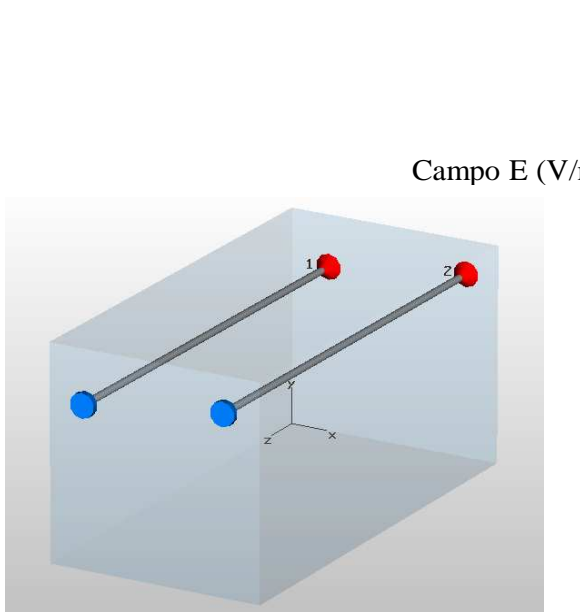

(a)

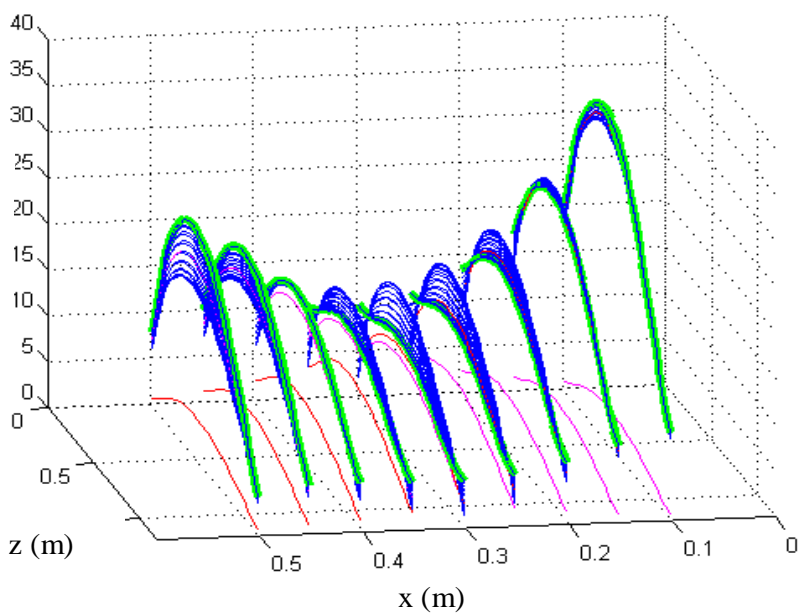

(b)

Figura 35 - Valores de Campo E Abs em y =0,3 m, $100 \mathrm{MHz}$, com aplicação de defasagens na excitação $\left(0 \sim 360^{\circ}\right)$. (a) Posição dos condutores $x 1=0,1 \mathrm{~m}, y 1=0,45 \mathrm{~m}, x 2=0,5 \mathrm{~m}, \mathrm{y} 2=$ $0,5 \mathrm{~m}$; (b) Perfil de campo $\mathrm{E}$. 


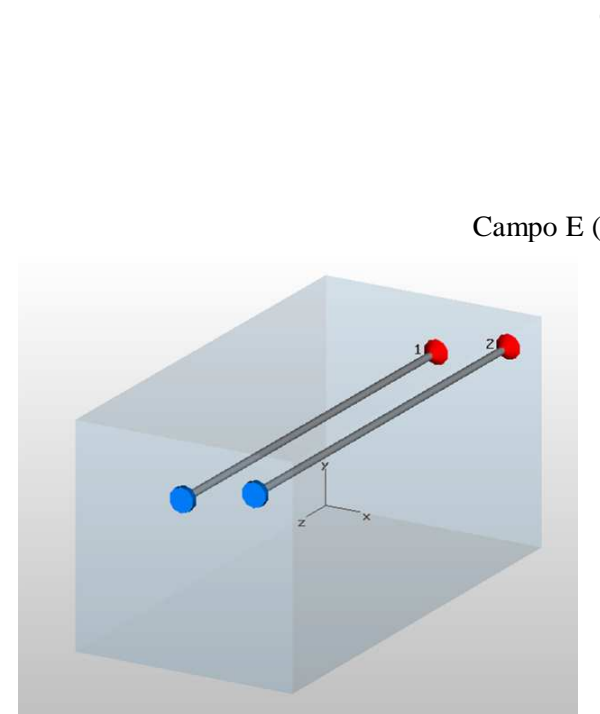

(a)
Campo EAbs simulado no plano $\mathrm{y}=0,3 \mathrm{~m}$ com aplicação de defasagens

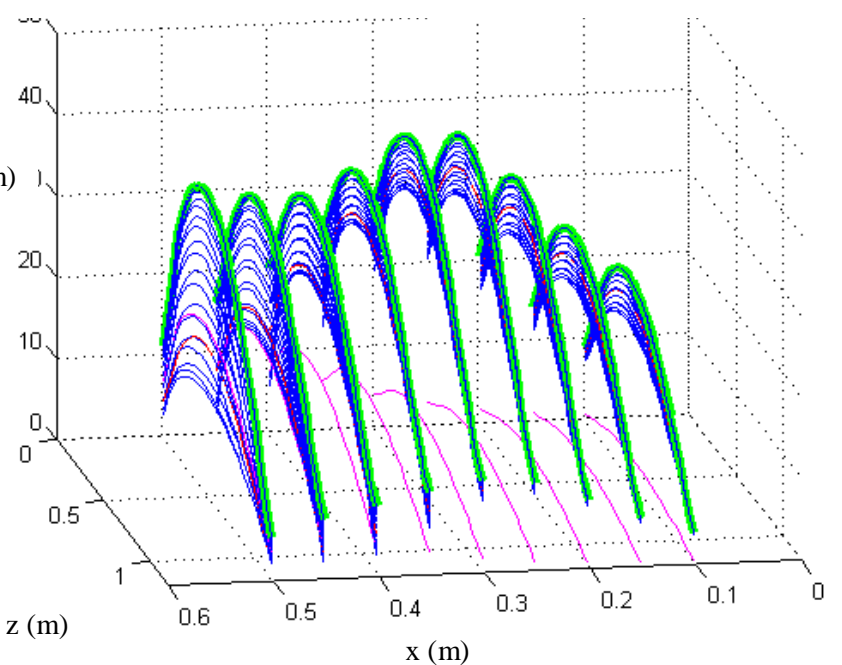

(b)

Figura 36 - Valores de Campo E Abs em y =0,3 m, $100 \mathrm{MHz}$, com aplicação de defasagens a excitação $\left(0 \sim 360^{\circ}\right)$. (a) Posição dos condutores $x 1=0,3 \mathrm{~m}, y 1=0,45 \mathrm{~m}, x 2=0,5 \mathrm{~m}, \mathrm{y} 2=$ $0,5 \mathrm{~m}$; (b) Perfil de campo $\mathrm{E}$.

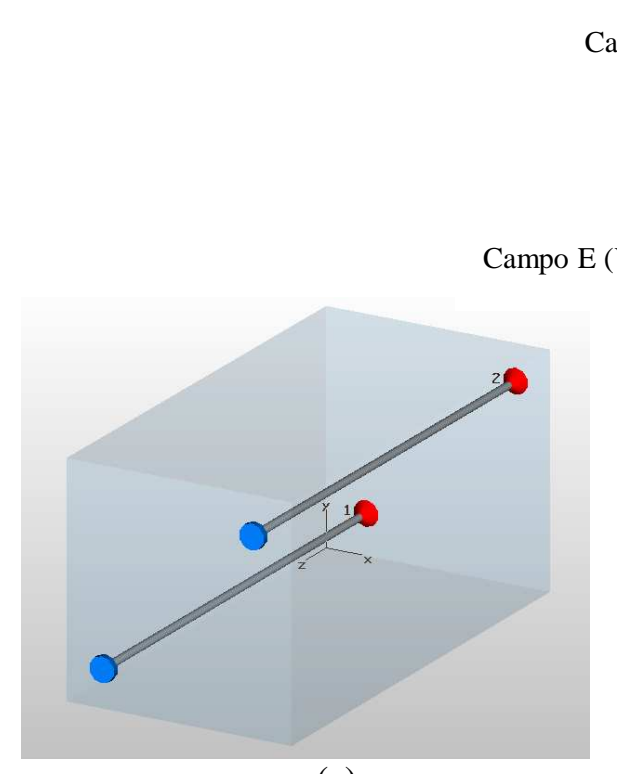

(a)

Campo EAbs simulado no plano y=0,3m com aplicação de defasagens

Figura 37 - Valores de Campo E Abs em y =0,3 m, $100 \mathrm{MHz}$, com aplicação de defasagens a excitação (0 360) (a) Posição dos condutores $x 1=0,1 \mathrm{~m}, y 1=0,1 \mathrm{~m}, x 2=0,5 \mathrm{~m}$, y2 = $0,5 \mathrm{~m}$; (b) Perfil de campo EAbs. 


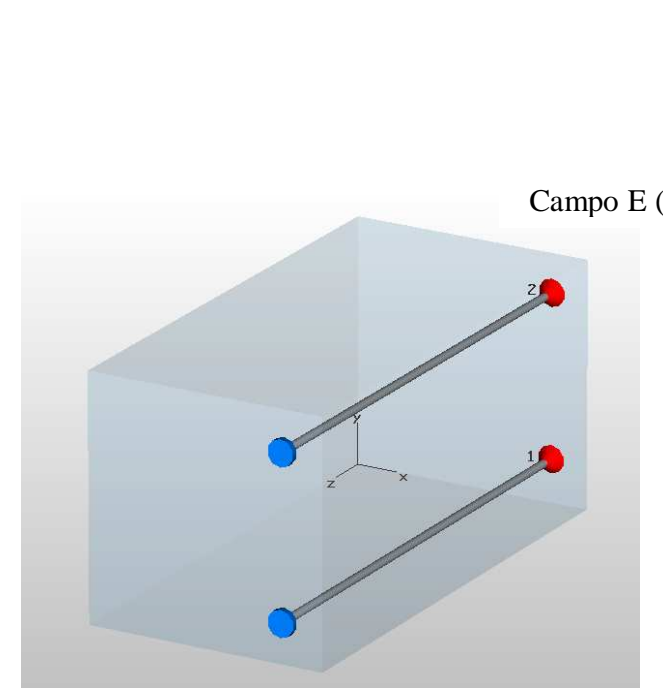

(a)

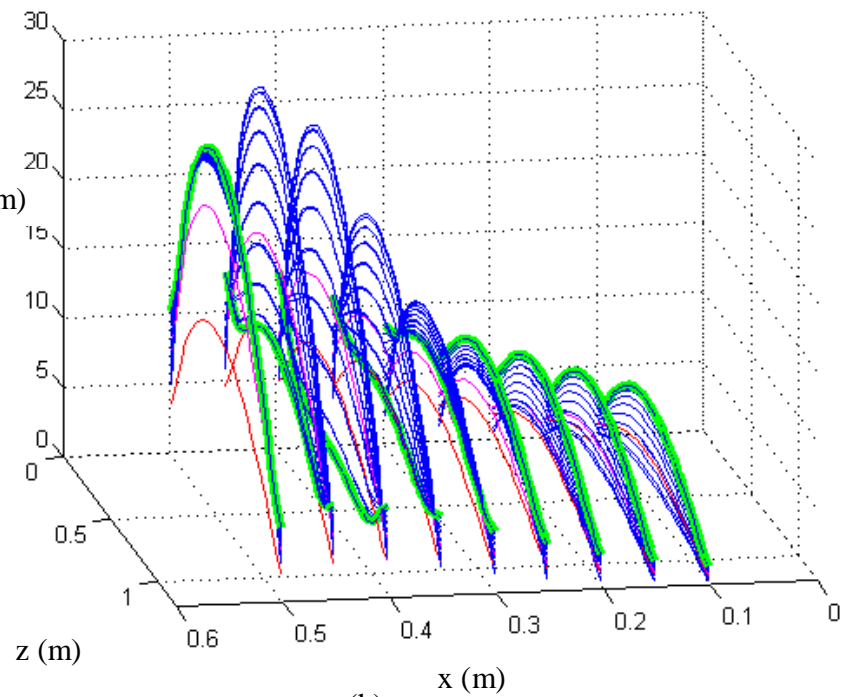

(b)

Figura 38 - Valores de Campo E Abs em y=0,3 m, $100 \mathrm{MHz}$, com aplicação de defasagens a excitação $\left(0 \sim 360^{\circ}\right)$. (a) posição dos condutores $x 1=0,5 \mathrm{~m}, y 1=0,1 \mathrm{~m}, x 2=0,5 \mathrm{~m}, y 2=$ $0,5 \mathrm{~m}$ (b) Perfil de campo EAbs.

Dos resultados, visualmente, nota-se que as maiores variações dos valores do campo $E$, na região central da câmara é obtida com a configuração mostrada na Figura 37, e a configuração que pode resultar em menor variação deste é a da Figura 35.

Por outro lado, os maiores valores de campo EAbs são obtidos com a configuração da Figura 36, que geram campos da ordem de 30 a $40 \mathrm{~V} / \mathrm{m}$ no plano avaliado e ainda mais, mantém um perfil do valor do campo EAbs mais constante, quando comparado às outras configurações.

Lembrando que estas avaliações preliminares foram efetuadas somente no plano $y=0,3 \mathrm{~m}$, para o módulo do campo elétrico total $\left(\mathbf{E}_{x y z}\right)$. Porém, as normas exigem a avaliação para volumes e, além do módulo do campo elétrico $\left(\mathbf{E}_{x y z}\right)$, também exigem a avaliação para todos componentes de campo elétrico nas direções $x, y$ e z $\left(\mathrm{E}_{x}, \mathrm{E}_{y}, \mathrm{E}_{z}\right)$. 


\subsubsection{Efeito da variação das cargas na CELT}

Os efeitos da aplicação de diferentes cargas nos final das linhas de transmissão da CELT com a configuração mostrada na Figura 39 foram simulados numericamente, e alguns resultados obtidos são apresentados na Figura 40, para a frequência de $100 \mathrm{MHz}$, no plano $\mathrm{y}=0,3 \mathrm{~m}$. A Figura 39 mostra o arranjo de LTs, indicando onde são aplicadas diferentes cargas.

Observa-se que a forma de onda estacionária do campo $\mathrm{E}$ varia de acordo com a mudança de cargas. Uma análise visual dos resultados permite afirmar que o perfil de campo $\mathrm{E}$ varia daquele com um único máximo centralizado (50 $\Omega$ ) para um perfil de dois máximos situados próximos às paredes da $\operatorname{CELT}(255 \Omega$ e $500 \Omega$ ). A onda estacionária apresenta um só pico, para valores de carga que sejam menores que a impedância característica da LT e dois picos defasados de $90^{\circ}$ elétricos, para valores de resistências de carga acima da impedância característica da LT. Como nos casos simulados, as resistências de carga sempre foram definidas iguais para as duas linhas de transmissão, obtém-se sempre um comportamento igual na resultante. Caso as resistências de cargas fossem diferentes entre as linhas de transmissão, poderia-se obter perfis diferentes de campos $\mathrm{E}$.

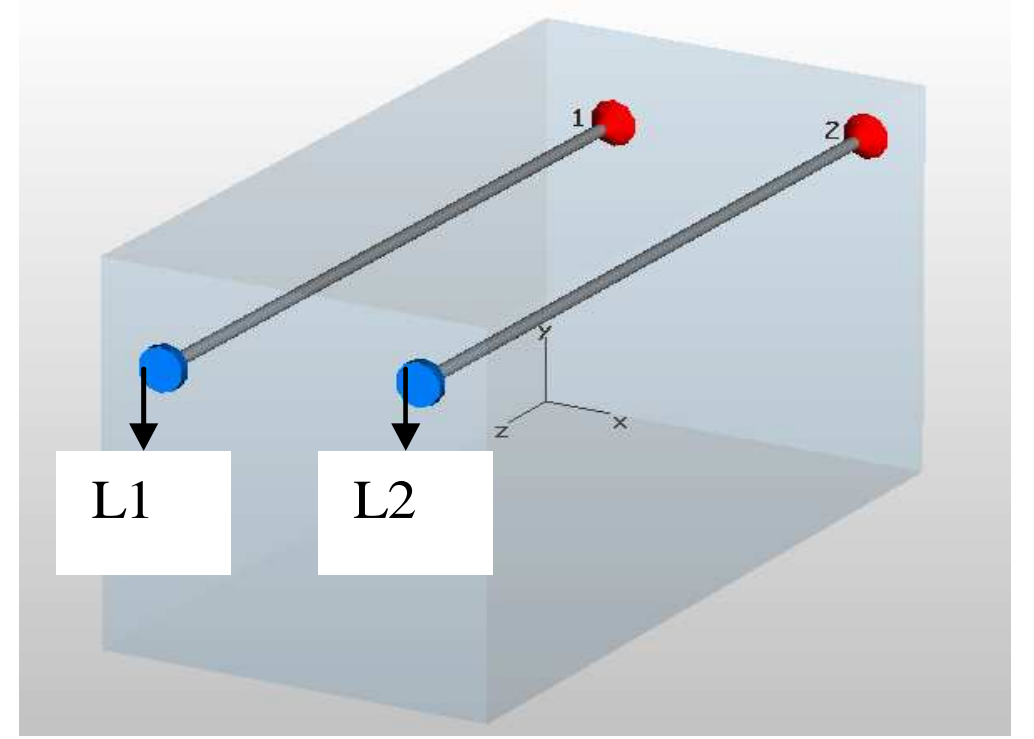

Figura 39 - Arranjo da CELT para análise de efeitos de carga. 


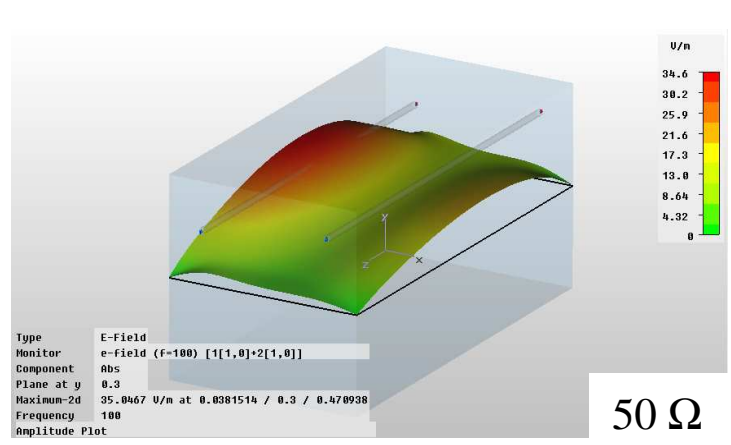

(a)

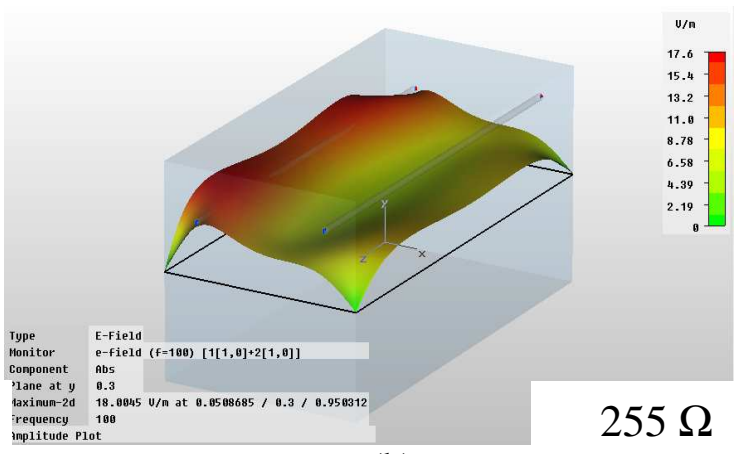

(b)

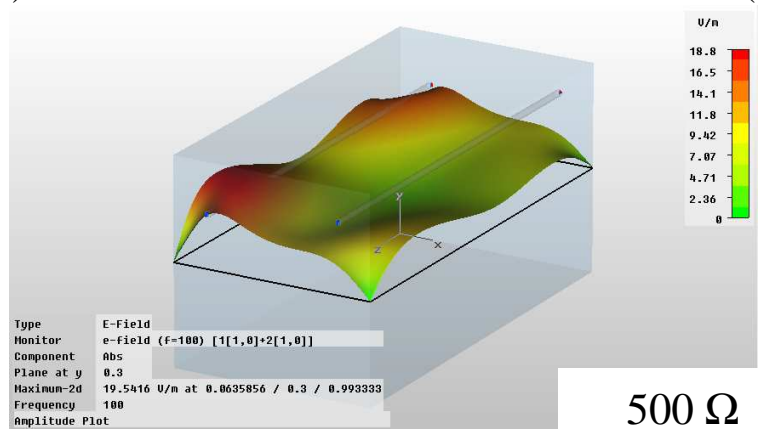

(c)

Figura 40 - Perfis de Campo EAbs no plano y=0,3m, frequência igual a $100 \mathrm{MHz}$, (a) carga $50 \Omega$ (b) carga $255 \Omega$ (c) $500 \Omega$.

Uma outra abordagem pode ser analisada posicionando sensores virtuais em um determinado ponto do modelo da CELT e verificando a resposta em frequência, para várias cargas diferentes. Na Figura 41 são mostrados alguns resultados relacionados ao perfil do campo $E$ nas direções $x$ e y, não se considerando a inserção da defasagem. Nota-se que picos próximos à frequência de ressonância da cavidade, para valores de carga de $0 \Omega$ até o valor próximo ao de casamento de impedâncias entre a LT e a carga (aproximadamente $255 \Omega$ ) podem ser observados. A partir deste valor, observam-se dois picos de campo $E$, simetricamente afastados do valor da frequência de ressonância da cavidade. Nota-se, ainda, um valor de frequência (aproximadamente $105 \mathrm{MHz}$ ) em que ambas as componentes, Ex e Ey, decrescem de acordo com crescimento da resistência de carga e tendem a se anular quando a carga aproxima-se do circuito aberto.

Os valores de EzAbs são considerados residuais, pois são produzidos devido às reflexões nas paredes, e não serão abordados nesta seção.

Ainda, um estudo efetuado utilizando a simulação numérica, para prever o comportamento dos valores de campo E na CELT quando há variação de cargas, foi 
o de aplicar somente cargas indutivas e variá-las, observando os efeitos sobre a frequência de ressonância, de maneira semelhante à simulação com cargas puramente resistivas. Os resultados obtidos nestas simulações com variação de cargas puramente indutivas, são mostrados na Figura 42.

O efeito observado é de que a carga altera não só a forma da onda estacionária, como também a frequência de ressonância, conforme pode ser observado na Figura 41 e na Figura 42. Estas propriedades, somadas à defasagem da excitação podem aumentar a capacidade de se "misturar" o campo da câmara. Esta mistura, então, poderia ser feita alterando-se a defasagem da excitação e a carga da terminação de forma aleatória, através de componentes não lineares ou controláveis (tais como defasadores).

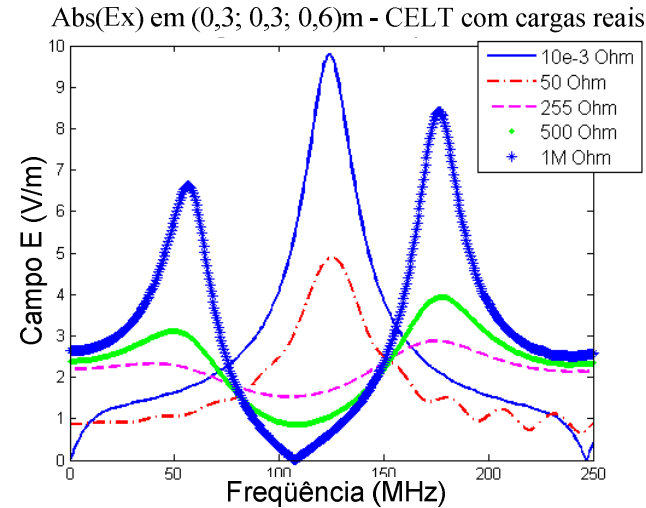

(a)

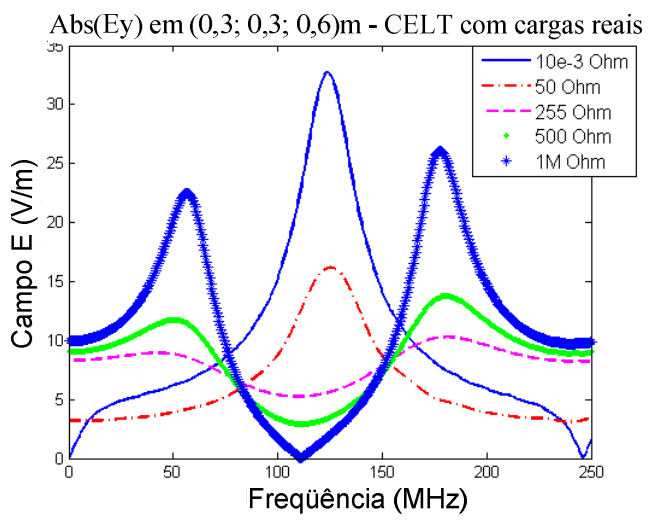

(b)

Figura 41 - Componentes do campo E, resultantes da CELT com duas linhas de transmissão, com cargas reais (a) Ex; (b) Ey.

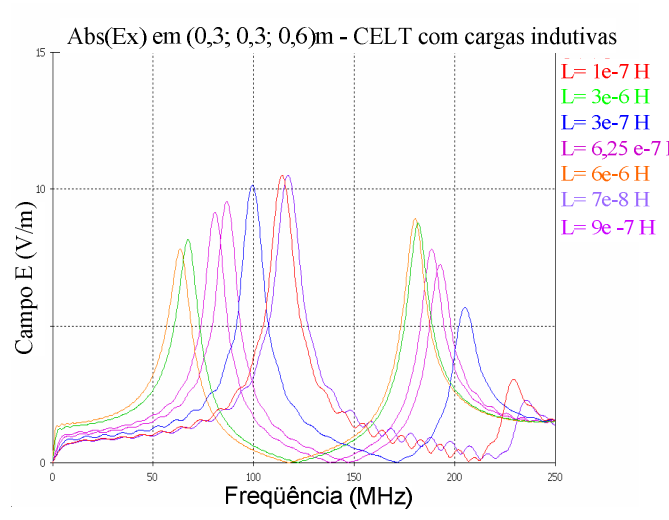

(a)

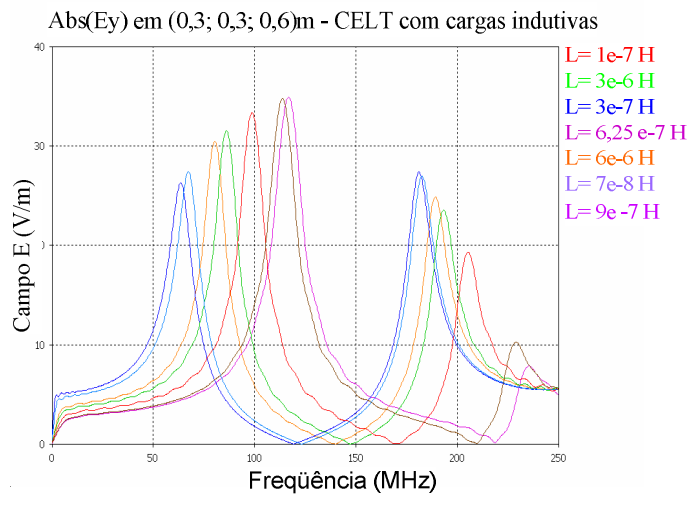

(b)

Figura 42 - Componentes do campo E, resultantes da CELT com duas linhas de transmissão, com cargas indutivas (a) Ex; (b) Ey. 


\subsection{Avaliação Numérica da Uniformidade de Campo E}

A avaliação da uniformidade de campo $E$ dentro de um volume pré-definido da câmara é realizada visando verificar-se o atendimento dos requisitos das normas [4]. Várias propostas de arranjos de linhas de transmissão, defasagem de excitação, e estratégias de excitação foram simuladas numericamente, e analisadas, de acordo com os critérios de avaliação de uniformidade apresentados na seção 3.4. Os resultados obtidos são apresentados nas seções seguintes:

Inicia-se a série de avaliações com os arranjos de linhas de transmissão, com uma, duas (arranjos oposto e superior) e quatro linhas de transmissão paralelas ao eixo z. as posições das linhas de transmissão foram fixadas em (LT1 $\{x 1=0,1 \mathrm{~m}$; y1 $=0,1 \mathrm{~m}\}, \operatorname{LT} 2\{x 1=0,5 \mathrm{~m} ; \mathrm{y} 1=0,5 \mathrm{~m}\}, \operatorname{LT} 3\{\mathrm{x} 1=0,1 \mathrm{~m} ; \mathrm{y} 1=0,5 \mathrm{~m}\}, \operatorname{LT} 4\{x 1=0,5 \mathrm{~m}$; $\mathrm{y} 1=0,1 \mathrm{~m}\})$. Estas configurações foram definidas a fim de gerar uma comparação direta entre as simulações bidimensionais (semi-analíticas), apresentadas no Anexo $\mathrm{B}$, e as tridimensionais (numéricas), aplicando-se os campos TEM na mesma direção. Caso houvesse a opção por linhas de transmissão ortogonais, haveria o aparecimento de componentes na direção z, o que inviabilizaria a comparação direta e subsequente validação dos métodos.

Nesta seção levando em conta que os cálculos de campo $E$ médio e desvios padrão realizados no Anexo $B$, levam em conta somente os componentes Ex e Ey. Desta forma, estes são considerados nos cálculos tridimensionais. Outras avaliações, considerando o componente campo Ez são efetuadas nas demais seções deste capítulo.

A fim de evitar as distorções numéricas e, também, as distorções geradas pelas paredes da CELT, escolheu-se fazer a avaliação dos campos $E$ em um volume de trabalho pré-fixado $(0,15 \leq \mathrm{x} \leq 0,45 ; 0,15 \leq \mathrm{y} \leq 0,45 ; 0,3 \leq \mathrm{z} \leq 0,9) \mathrm{m}$, a uma distância de $15 \mathrm{~cm}$ das paredes, conforme mostrado na Figura 15. A avaliação do desvio padrão no volume de trabalho foi efetuada, e os resultados são mostrados na Tabela 3. 
Note-se que no cálculo dos campos resultantes devido à variação aleatória, foram considerados 480 valores aleatórios do parâmetro variado, sejam defasagens ou amplitudes de excitação.

A sequência de simulações numéricas visa avaliar o efeito geral causado pela inclusão de linhas de transmissão, com estratégias de inversão ou não da amplitude de excitação, defasagens entre as excitações, entre outras.

Então inicia-se as simulações com apenas uma linha de transmissão, aumentando-se o número de linhas gradativamente até chegar a quatro linhas. Entre estas adições de linhas de transmissão, simula-se defasagens aleatórias uniformemente variadas $\left(0^{\circ} \leq \phi \leq 180^{\circ}\right)$. Aplica-se também inversão de fases da amplitude de excitação, seguidas de simulações utilizando-se valores de amplitudes de excitação uniformemente variadas $(-1 \leq P \leq 1)$. Para finalizar são simuladas variações aleatórias concomitantes de amplitudes e fases de excitação, com excitação em $100 \%$ do tempo de todas as linhas de transmissão, e ainda uma proposta de operação das linhas de transmissão, duas a duas, de acordo com um planejamento prévio, de forma que não ocorra a possibilidade de haver duas linhas com excitação diferente de zero ao mesmo tempo (assim havendo excitação em cada linha em $50 \%$ do tempo).

Observa-se que na simulação numérica tridimensional foi utilizado o modelo simplificado, já detalhado no item 3.2, com aplicação de cargas fixas de $50 \Omega$ no final das linhas de transmissão e arranjos de linhas paralelas conforme Figura 15.

Tabela 3 - Resultados de desvios padrão com método numérico - modelo simplificado carga $50 \Omega$.

\begin{tabular}{cccccccc}
\hline $\begin{array}{c}\text { Caso } \\
\#\end{array}$ & $\begin{array}{c}\text { Quantidade de LTs } \\
\text { amplitude da excitação }\end{array}$ & $\begin{array}{c}\text { Defasagem } \\
\text { Local de Avaliação }\end{array}$ & $\hat{\sigma}_{x}$ & $\hat{\sigma}_{y}$ & $\hat{\sigma}_{x, y}$ & $\overline{\mathrm{E}}_{x}$ & $\overline{\mathrm{E}}_{y}$ \\
\hline 1 & 1 & $\begin{array}{c}\text {----- } \\
\text { Área de Trabalho em } \\
\text { z=0,6m } \\
\text { Volume de Trabalho }\end{array}$ & 6,16 & 6,14 & 6,15 & 4,42 & 4,43 \\
& & 7,32 & 7,31 & 7,32 & 4,22 & 4,23 \\
\hline
\end{tabular}




\begin{tabular}{|c|c|c|c|c|c|c|c|}
\hline $\begin{array}{c}\text { Caso } \\
\#\end{array}$ & $\begin{array}{l}\text { Quantidade de LTs } \\
\text { amplitude da excitação }\end{array}$ & $\begin{array}{c}\text { Defasagem } \\
\text { Local de Avaliação }\end{array}$ & $\hat{\sigma}_{x}$ & $\hat{\sigma}_{y}$ & $\hat{\sigma}_{x, y}$ & $\overline{\mathrm{E}}_{x}$ & $\overline{\mathrm{E}}_{y}$ \\
\hline \multirow[t]{2}{*}{2} & $\begin{array}{c}2 \text { (superior }- \text { LT } 2 \text { and } \\
3 \text { ) } \\
\mid 1=12\end{array}$ & $\begin{array}{c}\text { Não } \\
\text { Área de Trabalho em } \\
z=0,6 \mathrm{~m}\end{array}$ & 7,70 & 3,64 & 4,94 & 0,006 & 0,018 \\
\hline & & Volume de Trabalho & 7,87 & 3,85 & 5,14 & 0,006 & 0,017 \\
\hline \multirow[t]{2}{*}{3} & $\begin{array}{c}\text { 2(opostas - LT } 1 \text { and } \\
\text { 2) } \\
|1=| 2\end{array}$ & $\begin{array}{c}\text { Não } \\
\begin{array}{c}\text { Área de Trabalho em } \\
\mathrm{z}=0,6 \mathrm{~m}\end{array}\end{array}$ & 5,36 & 5,36 & 5,36 & 0,012 & 0,012 \\
\hline & & Volume de Trabalho & 5,53 & 5,53 & 5,53 & 0,012 & 0,012 \\
\hline \multirow[t]{2}{*}{4} & $\begin{array}{c}2 \text { (opostas }-L T 1 \text { and } \\
2 \text { ) } \\
\mid 1=-12\end{array}$ & $\begin{array}{c}\text { Não } \\
\text { Área de Trabalho em z=0,6 } \\
\mathrm{m}\end{array}$ & 4,25 & 4,25 & 4,25 & 0,018 & 0,018 \\
\hline & & Volume de Trabalho & 4,42 & 4,42 & 4,42 & 0,017 & 0,017 \\
\hline \multirow[t]{2}{*}{5} & $\begin{array}{c}2 \text { (superior }- \text { LT } 2 \text { and } \\
3 \text { ) } \\
\mid 1=12\end{array}$ & $\begin{array}{c}\text { Sim, aleatória uniforme } \\
\text { Área de Trabalho em } \\
\text { z=0,6m }\end{array}$ & 5,91 & 4,04 & 4,84 & 5,35 & 8,07 \\
\hline & & Volume de Trabalho & 6,08 & 4,24 & 5,02 & 5,15 & 7,76 \\
\hline \multirow[t]{2}{*}{6} & $\begin{array}{c}2 \text { (opostas - LT } 1 \text { and } \\
2 \text { ) } \\
I 1=\mathrm{I} 2\end{array}$ & $\begin{array}{c}\text { Sim, aleatória uniforme } \\
\text { Área de Trabalho em } \\
\text { z=0,6m }\end{array}$ & 4,68 & 4,68 & 4,68 & 6,98 & 6,98 \\
\hline & & Volume de Trabalho & 4,86 & 4,86 & 4,86 & 6,72 & 6,72 \\
\hline \multirow[t]{2}{*}{7} & $\begin{array}{c}4 \\
(I 1=|2=| 3=\mid 4=1)\end{array}$ & $\begin{array}{c}\text { Não } \\
\text { Área de Trabalho em } \\
z=0,6 \mathrm{~m}\end{array}$ & 6,80 & 6,80 & 6,80 & 4,36 & 4,36 \\
\hline & & Volume de Trabalho & 6,92 & 6,92 & 6,92 & 4,27 & 4,27 \\
\hline \multirow[t]{2}{*}{8} & $\begin{array}{c}4 \\
(|1=| 4=1 ;|2=| 3=-1)\end{array}$ & $\begin{array}{c}\text { Não } \\
\begin{array}{c}\text { Área de Trabalho em } \\
z=0,6 \mathrm{~m}\end{array}\end{array}$ & 6,45 & 2,69 & 3,83 & 0,012 & 0,036 \\
\hline & & Volume de Trabalho & 6,56 & 2,94 & 4,03 & 0,012 & 0,034 \\
\hline \multirow[t]{2}{*}{9} & $\begin{array}{c}4 \\
(I 1=|2=| 3=\mid 4=1)\end{array}$ & $\begin{array}{l}\text { Sim, aleatória uniforme } \\
\text { Área de Trabalho em } \\
\text { z=0,6m }\end{array}$ & 3,87 & 3,89 & 3,88 & 9,92 & 9,84 \\
\hline & & Volume de Trabalho & 4,06 & 4,09 & 4,07 & 9,57 & 9,50 \\
\hline \multirow[t]{2}{*}{10} & $\begin{array}{c}4 \\
\text { amplitude aleatória } \\
\text { uniforme }\end{array}$ & $\begin{array}{c}\text { Não } \\
\begin{array}{c}\text { Área de Trabalho em } \\
z=0,6 \mathrm{~m}\end{array}\end{array}$ & 3,58 & 3,61 & 3,59 & 5,56 & 5,52 \\
\hline & & Volume de Trabalho & 3,78 & 3,80 & 3,79 & 5,36 & 5,33 \\
\hline
\end{tabular}




\begin{tabular}{|c|c|c|c|c|c|c|c|}
\hline $\begin{array}{c}\text { Caso } \\
\#\end{array}$ & $\begin{array}{l}\text { Quantidade de LTs } \\
\text { amplitude da excitação }\end{array}$ & $\begin{array}{c}\text { Defasagem } \\
\text { Local de Avaliação }\end{array}$ & $\hat{\sigma}_{x}$ & $\hat{\sigma}_{y}$ & $\hat{\sigma}_{x, y}$ & $\overline{\mathrm{E}}_{x}$ & $\overline{\mathrm{E}}_{y}$ \\
\hline \multirow[t]{3}{*}{11} & 4 & Sim, aleatória uniforme & & & & & \\
\hline & $\begin{array}{l}\text { com amplitude } \\
\text { aleatória uniforme- } \\
50 \% \text { do tempo cada } \\
\text { excitação }\end{array}$ & $\begin{array}{l}\text { Área de Trabalho em } \\
\qquad z=0,6 m\end{array}$ & 2,97 & 2,96 & 2,97 & 3,69 & 3,73 \\
\hline & & Volume de Trabalho & 3,20 & 3,19 & 3,20 & 3,55 & 3,58 \\
\hline
\end{tabular}

A seguir são discutidos e apresentados os resultados relacionados às configurações simuladas, através de gráficos de intensidade de campos Abs(Exy) médios resultantes, e ainda, quando for o caso, gráficos mostrando os valores adotados para os parâmetros que foram variados.

- Caso 1 - 1LT

Neste primeiro caso, foi excitada somente a linha de transmissão \#1, com amplitude constante.

A Figura 43 mostra a área de trabalho, com os campos Exy médios resultantes, devido à excitação de uma linha de transmissão, com módulo 1.

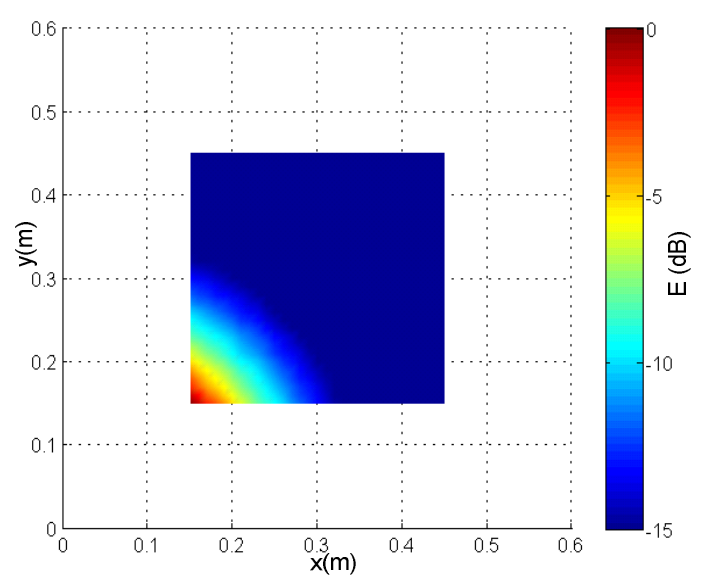

Figura 43 - Campo Exy médio na área de trabalho devido à excitação de somente uma linha de transmissão.

- Caso 2 - 2LT arranjo superior, sem defasagem 
Prosseguindo-se com as simulações numéricas, efetuou-se o cálculo excitando com amplitude constante e fase constante as linhas 2 e 3, resultando no gráfico de distribuição do campo Exy mostrado na Figura 44.

Nota-se que o gradiente dos valores de campo E é elevado, com os valores muito mais elevados $(0 \mathrm{~dB})$ nas proximidades da linhas de transmissão, parte superior da câmara, e os menores $(-15 \mathrm{~dB})$ na extremidade oposta da área de trabalho.

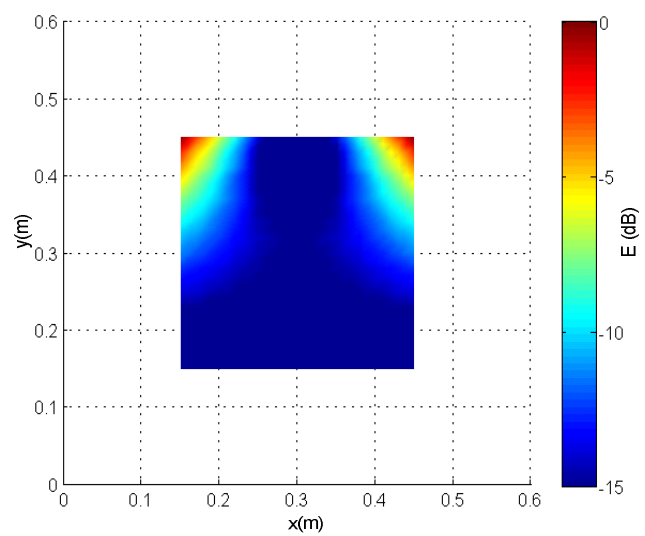

Figura 44 - Campo Exy médio na área de trabalho devido à excitação de duas linhas de transmissão.

- Caso 3 - 2LT (arranjo oposto) sem defasagem $(I 1=\mid 2=1)$

Opcionalmente, pode-se excitar com amplitude e fase constantes as linhas transmissão 1 e 2, que situam-se em extremidades opostas da câmara

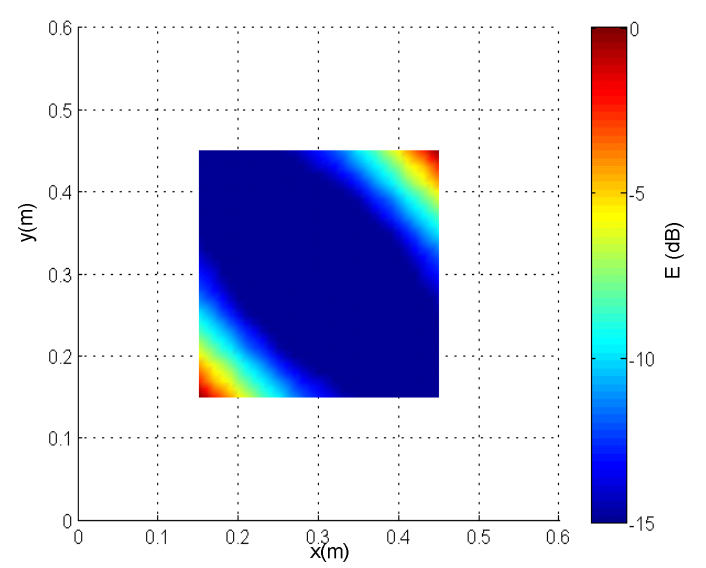

Figura 45 - Campos E médios na área de trabalho devido à excitação de duas linhas de transmissão em posições opostas e excitação fixa $(I 1=12)$. 
A Figura 46 apresenta os gráficos de distribuição campos Exy (quando se trata de caso determinístico) e da distribuição de campos Exy médios (quando se trata do caso estatístico), para os casos 4; 5; 6; 8; 9 e 10 da Tabela 3.

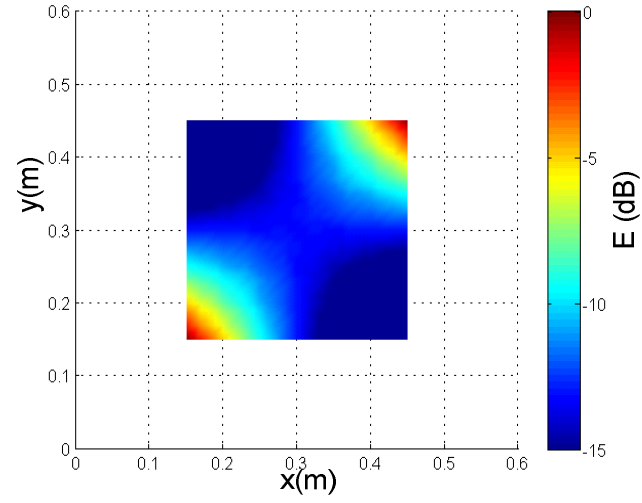

(a)

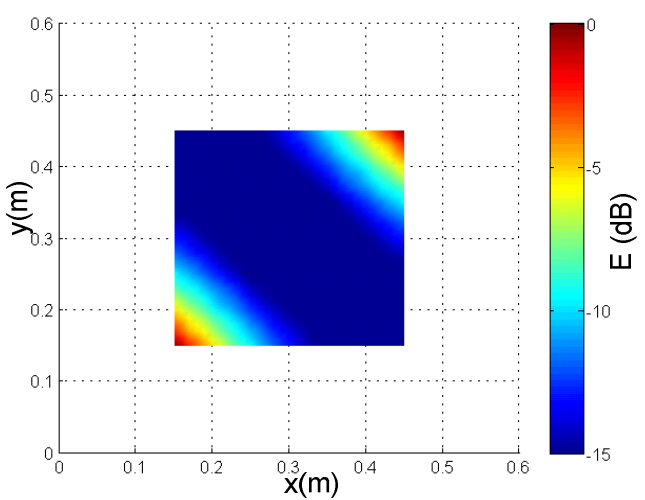

(c)

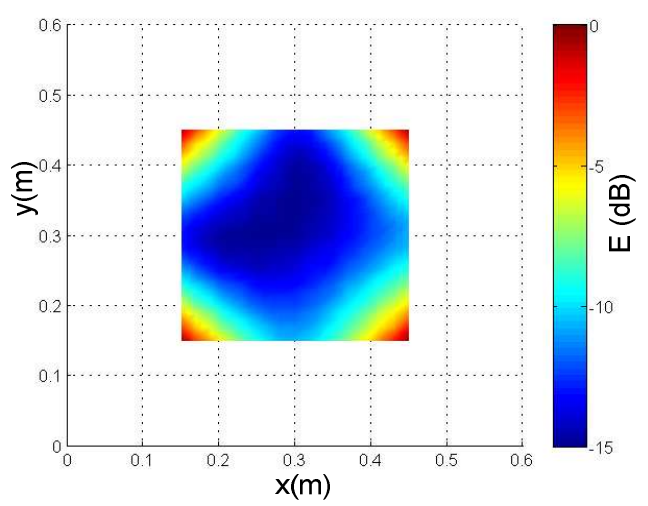

(e)

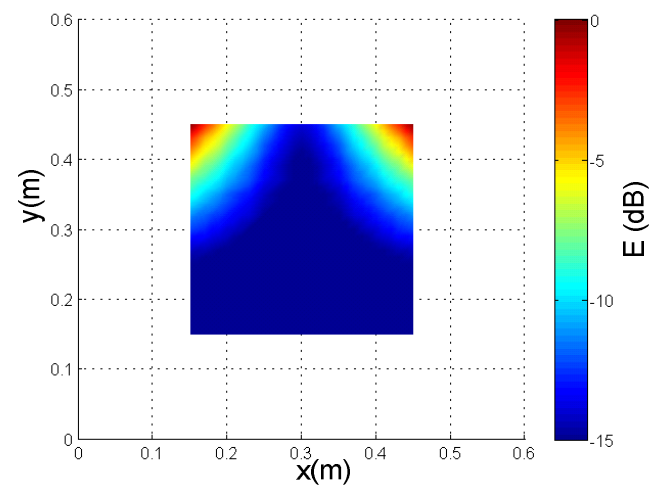

(b)

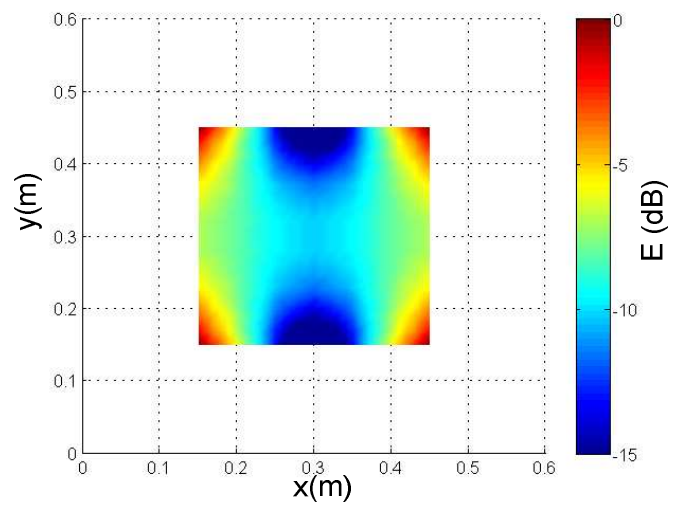

(d)

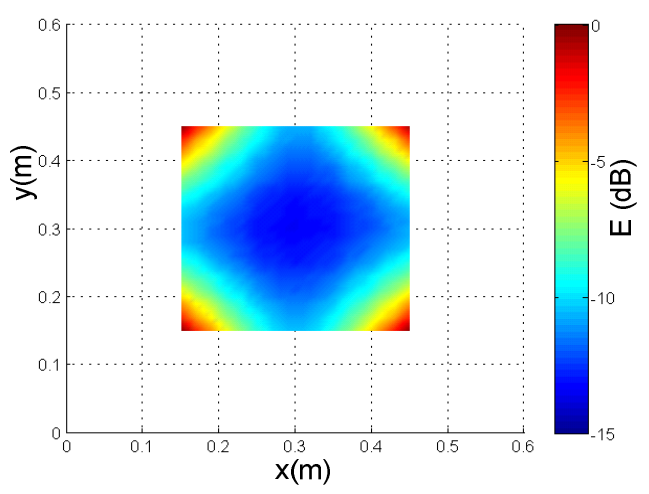

(f)

Figura 46 - Campos Ex médios (a) Caso 4; (b) Caso 5; (c) Caso 6; (d) Caso 8; (e) Caso 9;

(f) Caso 10.

Assim, nota-se que a distribuição de campo Exy gradualmente mostra um incremento da uniformidade conforme são adotadas as diferentes estratégias. 
Observa-se que, a partir do Caso 10, conforme demonstram os resultados da Tabela 3 (Figura 46 (f)), os requisitos de uniformidade são atendidos.

Apresenta-se detalhadamente a estratégia que melhor atende aos requisitos de uniformidade no volume de trabalho, que é o caso 11, abaixo descrito:

- Caso 11 - 4LT com variação aleatória uniforme da amplitude de excitação durante $50 \%$ do tempo e com defasagens aleatórias uniformes

O gráfico de campos Exy médios na área de trabalho, mostrado na Figura 47, foi calculado utilizando-se de 480 amostras aleatórias uniformes, geradas para cada uma das amplitudes de excitação, e ordenadas de forma a se obter as linhas de transmissão excitadas duas a duas, durante 50\% do tempo, conforme Figura 48 (a). Ao mesmo tempo, a cada sinal de excitação foi atribuída uma defasagem aleatória, dentre 480 amostras uniformes, conforme mostrado na Figura 48 (b).

Esta estratégia permite obter desvio padrão de 3,2 dB no volume de trabalho, e valores médios de campo Ex e Ey da ordem de 3,5 V/m, para valores máximos potência de excitação de $1 \mathrm{~W}$ em cada LT.

Nota-se que alguns valores de campo Ex e Exy médios apresentam-se acima dos observados no caso 11. Menciona-se que nenhum desses casos (5 a 10) utiliza a estratégia de desligamento das linhas durante $50 \%$ do tempo, o que, obviamente, gera a uma queda nos valores médios, uma vez que os valores médio são obtidos para o total de excitações, das quais metade dos valores são zero no caso 11.

De qualquer forma, já no caso 10, o critério de uniformidade de desvio padrão menor do que $4 \mathrm{~dB}$ no volume de trabalho é atendido. Mostra-se, assim, através das simulações numéricas que a CELT, caso seja adequadamente projetada e operada, pode atender e ainda superar os padrões de uniformidade exigidos pelas normas internacionais para as câmaras canônicas [4]. 


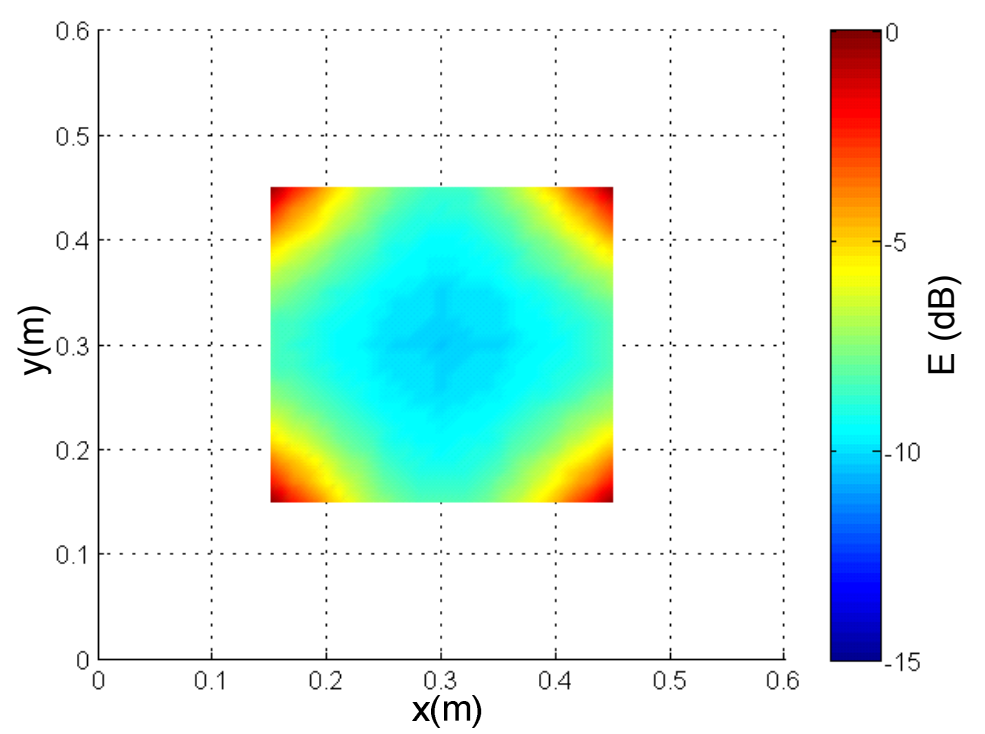

Figura 47 - Campos E médios na área de trabalho para arranjo de 4 linhas de transmissão,

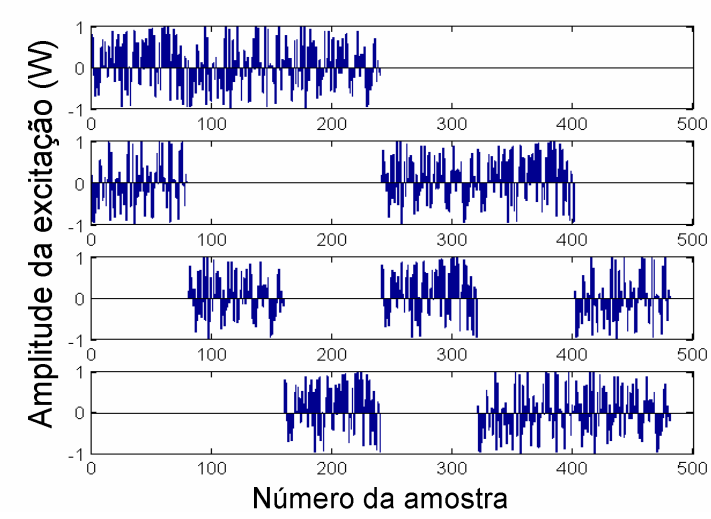

(a)

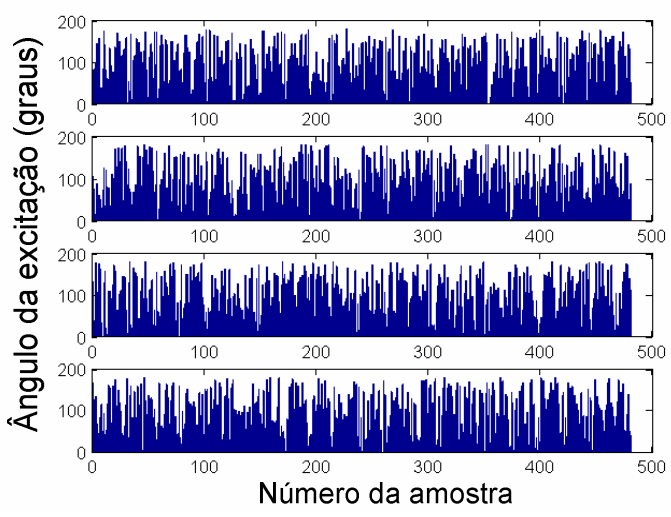

(b)

Figura 48 - .(a) Variação de amplitude de excitação - aleatória uniforme durante $50 \%$ do tempo (b) Defasagem da excitação uniformemente variada. 


\subsection{Resultados Experimentais}

Com o propósito de validar as previsões teóricas e das simulações numéricas, foram efetuados experimentos, nas dependências do INPE/LIT e no IEE/USP, com configurações de testes pré-determinadas, conforme os procedimentos descritos no APÊNDICE B

\subsubsection{Medidas de Campo E}

$\mathrm{Na}$ Figura 49 são apresentados somente os resultados das medidas considerando-se a excitação das linhas de transmissão (LT1) e (LT2), com 5 W cada uma, separadamente, e varrendo as frequências de $10 \mathrm{MHz}$ a $250 \mathrm{MHz}$. As medidas foram efetuadas utilizando cargas de $50 \Omega$ e cargas em circuito-aberto

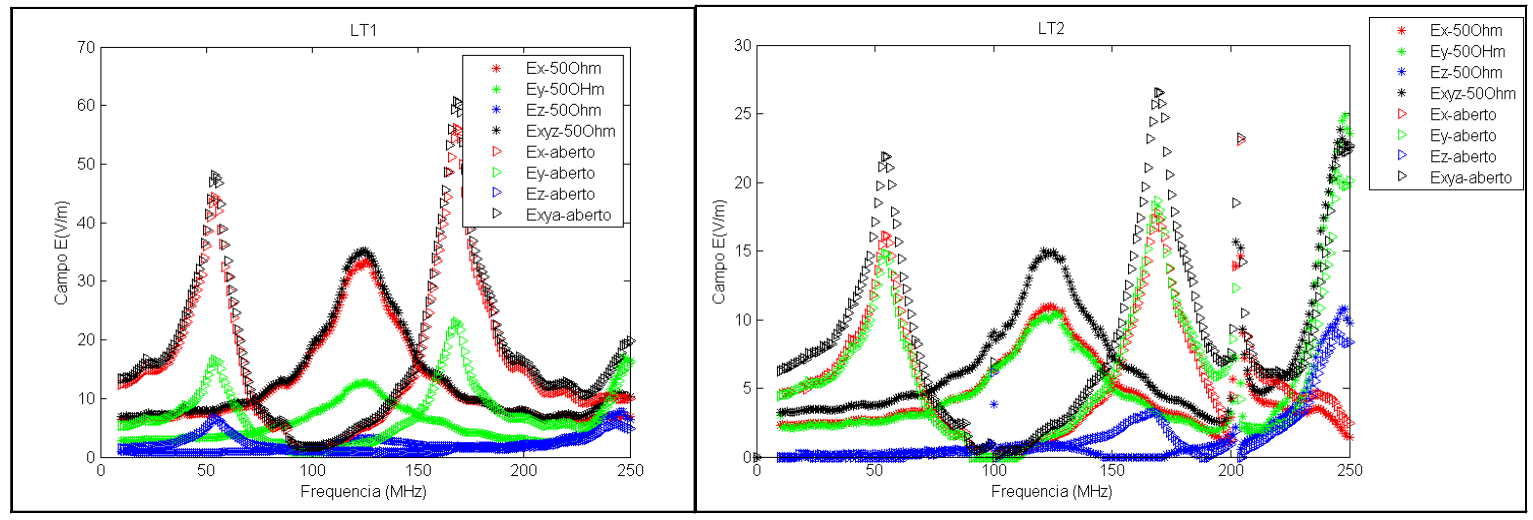

(a)

(b)

Figura 49 - Campos $E$ medidos com excitação individual 5 W e cargas $50 \Omega$ e circuitoaberto (a) $L T 1$ e (b) $L T 2$.

Comparando-se os resultados experimentais com os resultados simulados (calculados com o modelo detalhado), foram obtidos os gráficos mostrados na Figura 50. Nota-se uma concordância satisfatória entre os valores medidos e simulados para Ex. Por outro lado, os valores de Ey, não apresentam uma boa concordância, ressaltando-se, no entanto a manutenção do valor da frequência onde são observados dos valores de pico, em torno de $125 \mathrm{MHz}$. Os valores de Ez são considerados residuais, em ambos os casos, simulado e medido. 


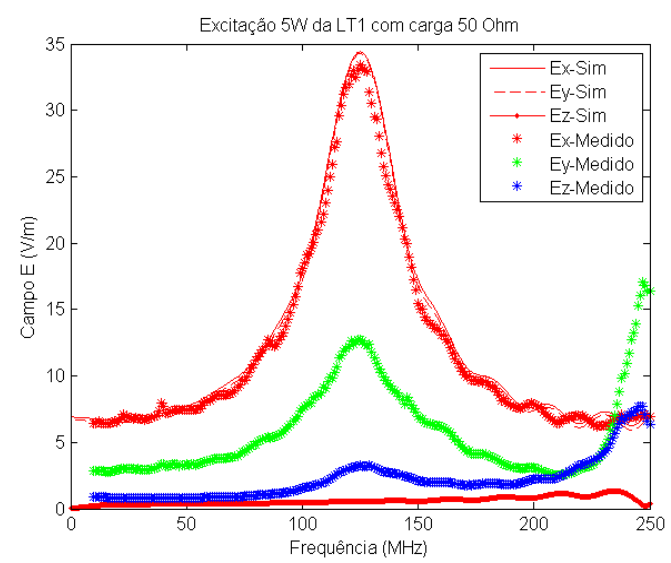

(a)

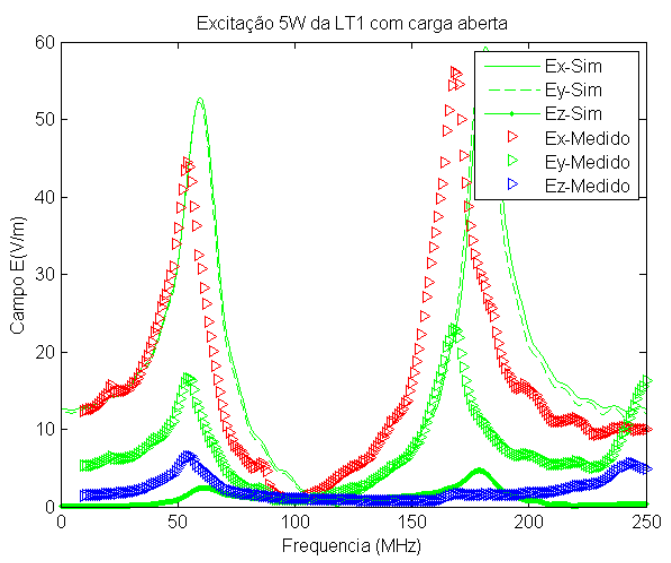

(b)

Figura 50 - Componentes de campo E gerados pela excitação da Linha de Transmissão 1, no centro da CELT. Valores Medidos e Simulados. (a) carga $50 \Omega$ (b) carga aberta.

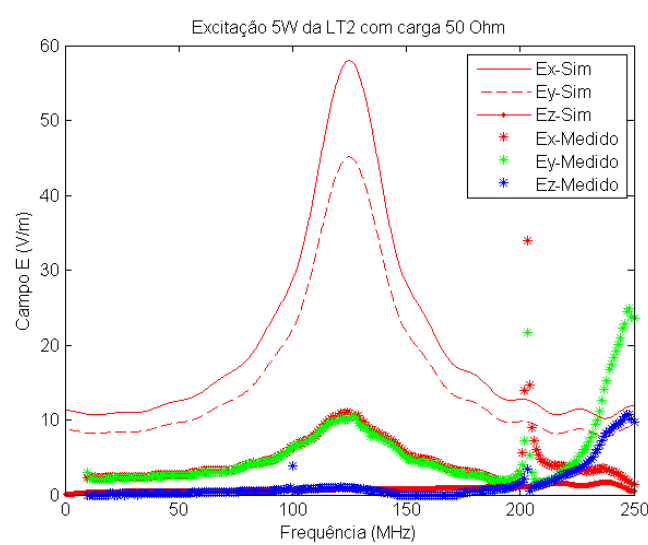

(a)

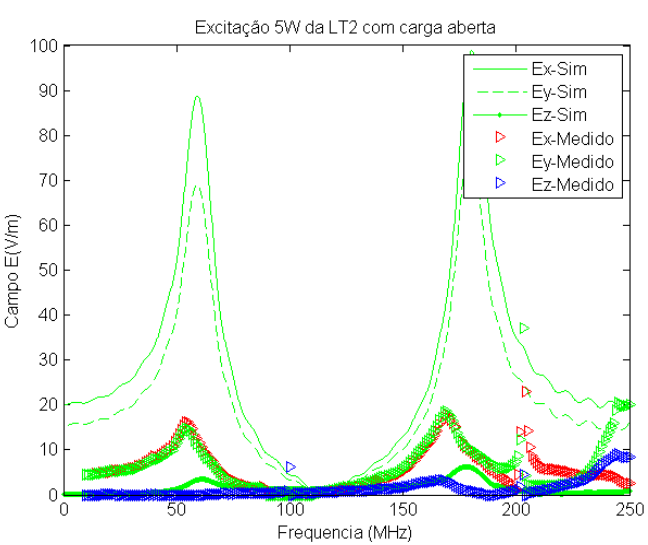

(b)

Figura 51 - Componentes de campo E gerados pela excitação da Linha de Transmissão 2, no centro da CELT. Valores Medidos e Simulados. (a) carga $50 \Omega$ (b) carga aberta.

Ainda, o mesmo procedimento de medida e de comparação com os resultados simulados foram aplicados à LT2, considerando-se, sempre, as antenas no centro da câmara, ou como definido no APÊNDICE B o ponto P1. Os resultados obtidos são mostrados na Figura 51. Os valores medidos e simulados apresentam discrepâncias, em valores absolutos, mas o formato da resposta em frequência parece bastante adequada. 


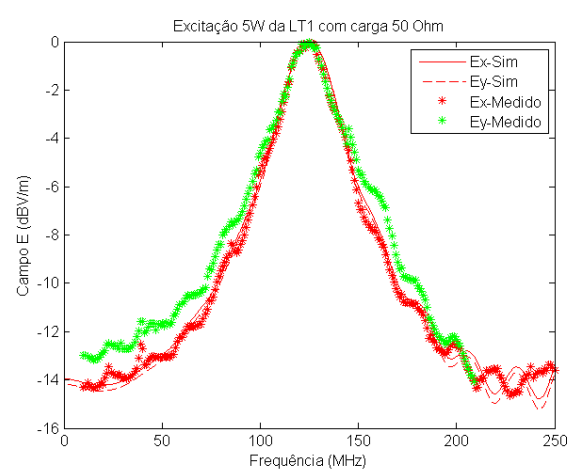

(a)

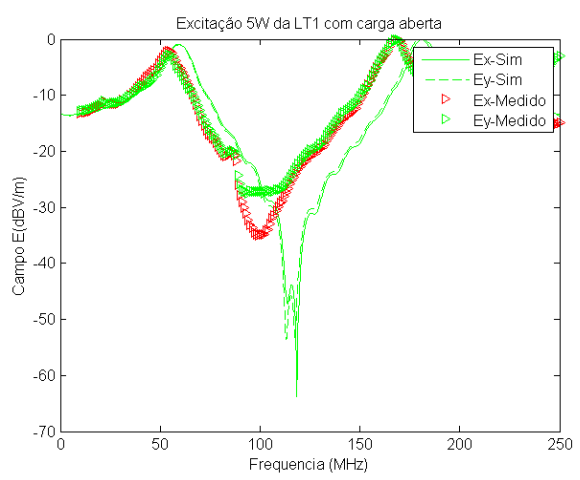

(b)

Figura 52 - Campos E (dBV/m) parametrizados pelos valores máximos, gerados pela excitação da Linha de Transmissão 1. Valores medidos e simulados. (a) carga $50 \Omega$ (b) carga aberta.

Para sanar a dúvida, se os formatos da resposta em frequência estão adequados, um recurso muito usado na literatura, quando se trata da comparação de medidas experimentais e simuladas, é a parametrização pelo máximo valor de campo $E$ em decibéis $(\mathrm{dB})$. Após a aplicação desta técnica, os resultados são os mostrados na Figura 52 e na Figura 53 e apresentam resultados bastante próximos, desconsiderando-se o eixo z, por tratarem-se de valores residuais.

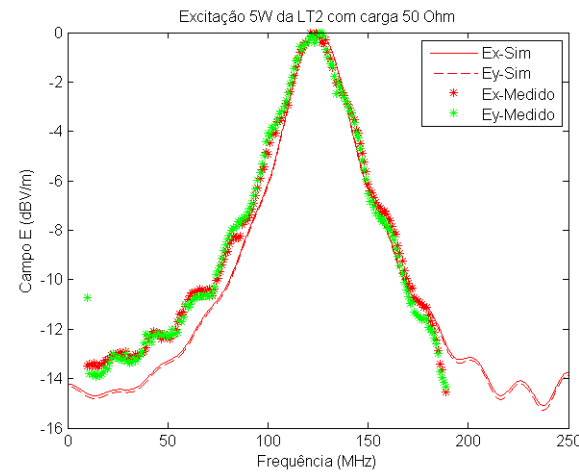

(a)

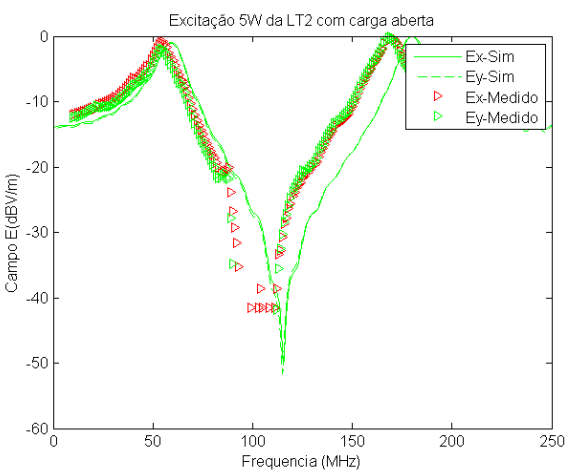

(b)

Figura 53 - Campos $E(d B V / m)$ parametrizados pelos máximos, gerados pela excitação da Linha de Transmissão 2 . Valores medidos e simulados. (a) carga $50 \Omega$ (b) carga aberta.

\subsubsection{Medidas de campo E em vários pontos (sem defasagem na excitação)}

Nesta seção são apresentados os resultados das medidas de campo $E$ em vários pontos da câmara (Figura 54 até Figura 58), com a excitação simultânea das duas linhas de transmissão, conforme os procedimentos apresentados no APÊNDICE B. A primeira sequência de medidas refere-se à cada linha de transmissão conectada a 
uma carga de $50 \Omega$. Na outra sequência de medidas, as cargas foram retiradas e o circuito permaneceu aberto. As medidas são comparadas com os valores simulados numericamente através do modelo detalhado.

\subsection{Carga $50 \Omega$}

Os valores medidos para a câmara excitada, simultaneamente, através das duas linhas de transmissão e com carga $50 \Omega$, para em cinco pontos da câmara (conforme Figura 13 e APÊNDICE B), são apresentados na

Figura 54 (a)-(e). São mostrados, também, nas mesmas figuras, os resultados das simulações numéricas utilizando o modelo detalhado nos mesmos pontos.

É interessante notar que o gráfico da Figura 54 (a) difere daqueles já apresentados na Figura 50 e Figura 51, por se tratar dos campos gerados em conjunto pela linha 1 e linha 2, então trata-se de $E(L T 1+L T 2)$.

Em todos os casos, Figura 54 (a)-(e), os valores medidos de Ey ficaram abaixo dos valores simulados. Em apenas um caso Figura 54 (a), os valores de Ex corresponderam perfeitamente, enquanto nos demais (b)-(e), os valores simulados são maiores do que os valores medidos. Quanto à frequência de ressonância, 125 $\mathrm{MHz}$, foi atendida em maior ou menor grau por todas os resultados. Lembrando que os campos Ez são residuais em todos os casos, medidos e simulados. 


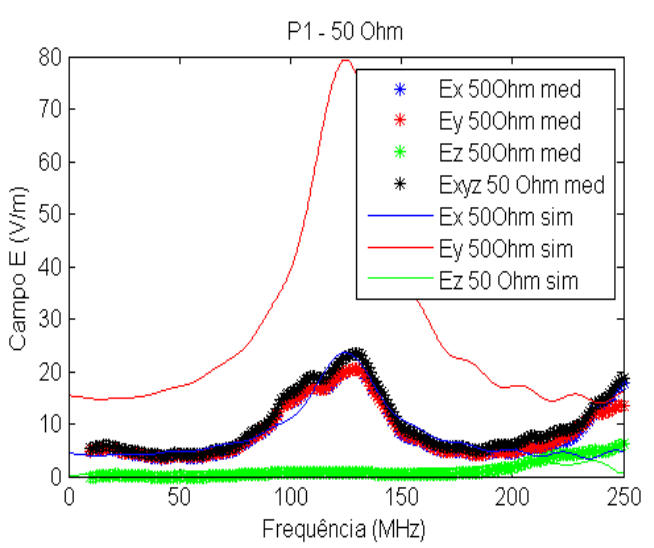

(a)

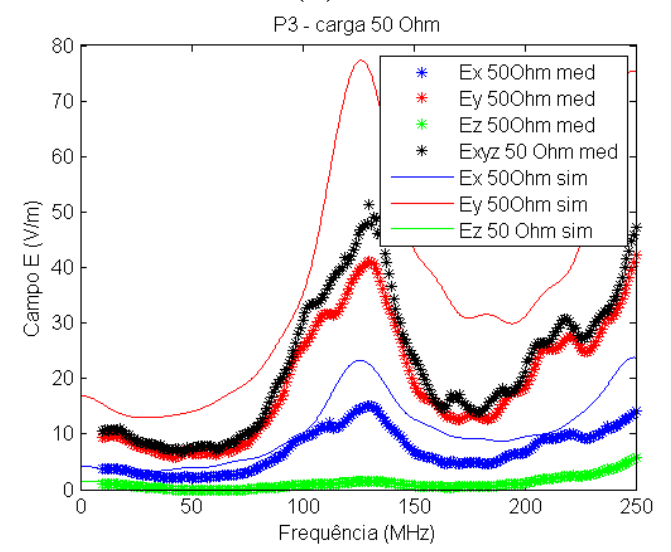

(c)

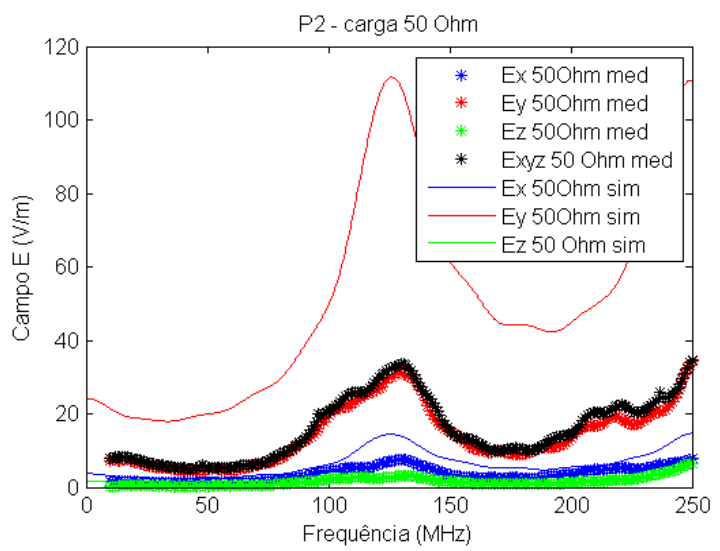

(b)

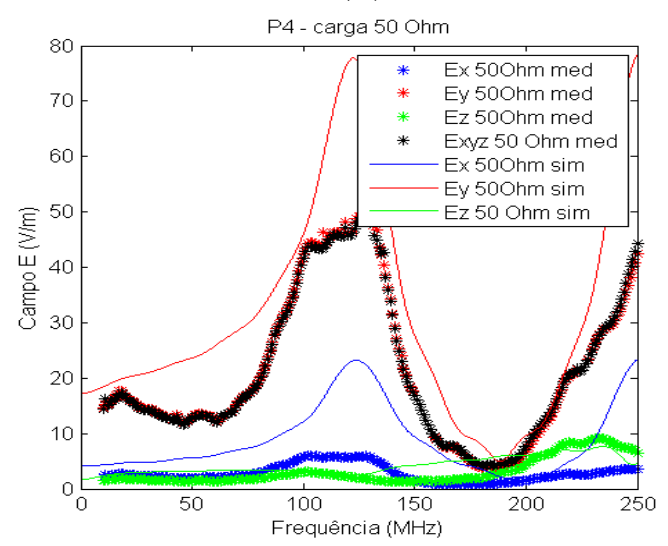

(d)

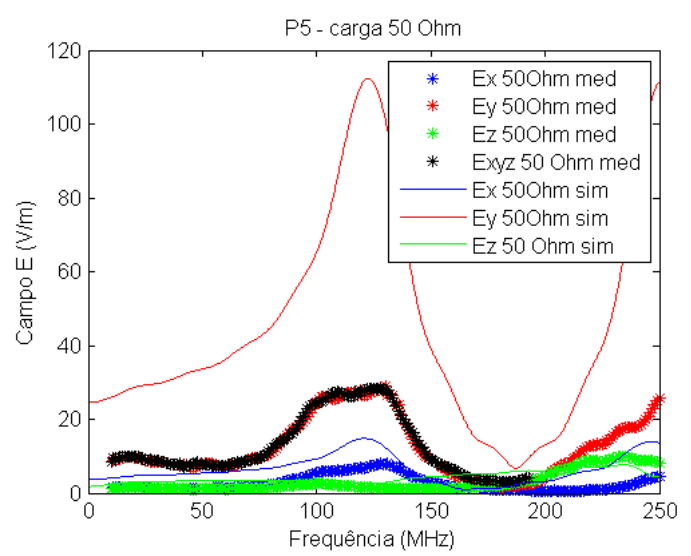

(e)

Figura 54 - Campo E Medido e Simulado na CELT com carga $50 \Omega$ (a) $P 1(0,3 ; 0,3 ; 0,6) \mathrm{m}$; (b) P2 $(0,4 ; 0,3 ; 0,8) \mathrm{m}$; (c) P3 $(0,2 ; 0,3 ; 0,8) \mathrm{m}$; (d) P4 (0,2;0,3;0,4) m; e (e) P5 $(0,4 ; 0,3$; $0,4) m$.

\subsection{Carga Aberta}

Os valores medidos com a variação da frequência para a câmara excitada simultaneamente através das duas linhas de transmissão e com carga aberta, em cinco pontos da câmara, são mostrados na Figura 55 (a)-(e), onde também são 
mostrados os valores obtidos através de simulação numérica utilizando o modelo detalhado.

São notadas duas frequências que apresentam valores máximos de campo E: 50 $\mathrm{MHz}$ e $170 \mathrm{MHz}$.

Os resultados de simulação numérica possuem, em todos os casos, valores maiores que os medidos. Somente na Figura 55 (b) os valores do campo Ey simulados e medidos apresentam valores similares, mas somente para a primeira frequência de pico, nos demais valores, a forma da curva é mantida, mas os valores do campo Ey não são similares.

Nota-se ainda um pequeno deslocamento com relação à frequência dos picos de campo E. Em uma primeira instância, supõe-se que este fato pode resultar de diferenças de características de materiais, ou ainda da influência da própria antena, que tem grandes dimensões elétricas, quando comparada ao tamanho da câmara.

A antena isotrópica utilizada para medida de campo elétrico foi o modelo HI422 da Holaday (atualmente ETS Lindgreen) com dimensões $(15 \mathrm{~cm} \times 15 \mathrm{~cm} \times 15 \mathrm{~cm}$ ), com captação através de três dipolos e módulo eletrônico de conversão de sinal analógico em sinal digital, além da transmissão de sinais ao sistema de aquisição através de fibra ótica. Outros detalhes, por exemplo o material construtivo da carcaça, não são fornecidos pelo fabricante.

Outra representação gráfica é apresentada, onde para cada frequência, são mostrados os valores de campo $\mathrm{E}$ nos pontos medidos (Figura 56 a Figura 58). Passou-se, assim, a utilizar esta técnica para obter o mapeamento do perfil de campo E na câmara. 


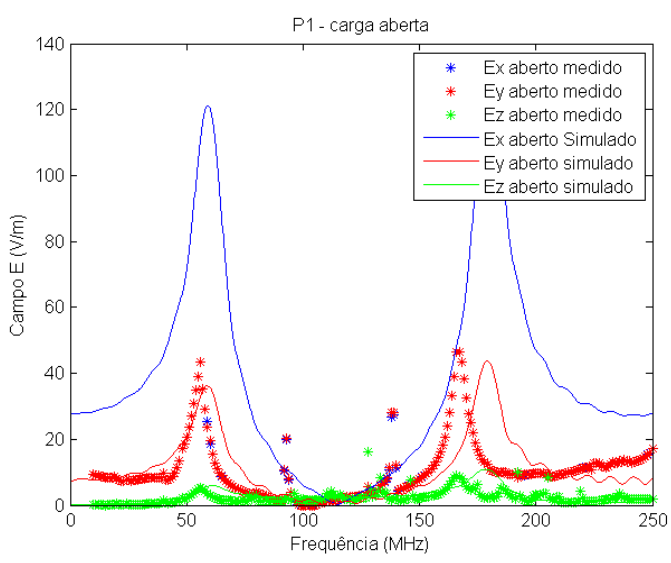

(a)

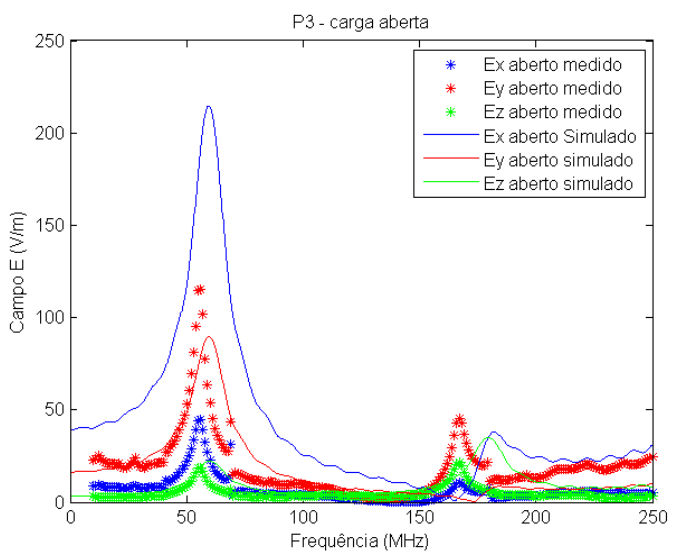

(c)

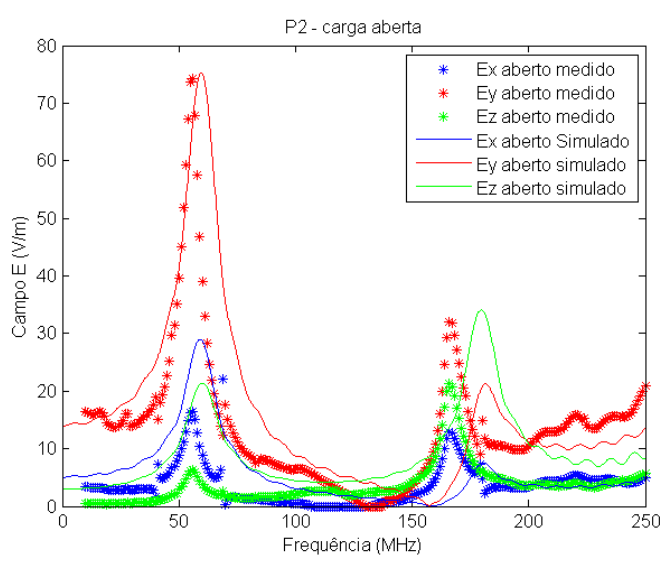

(b)

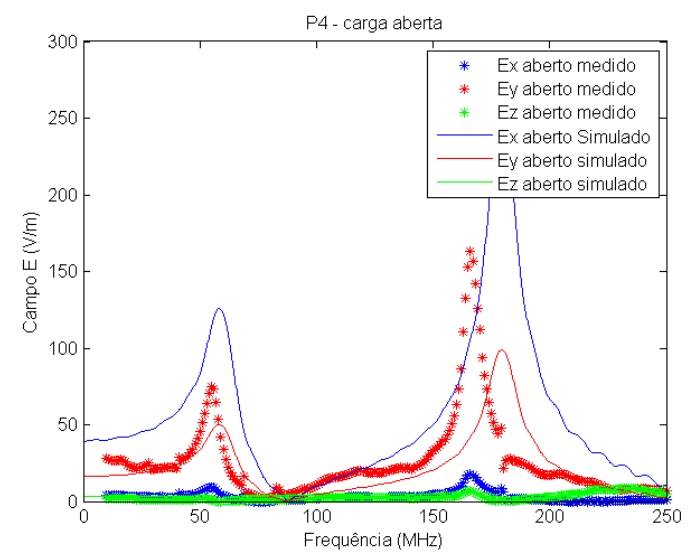

(d)

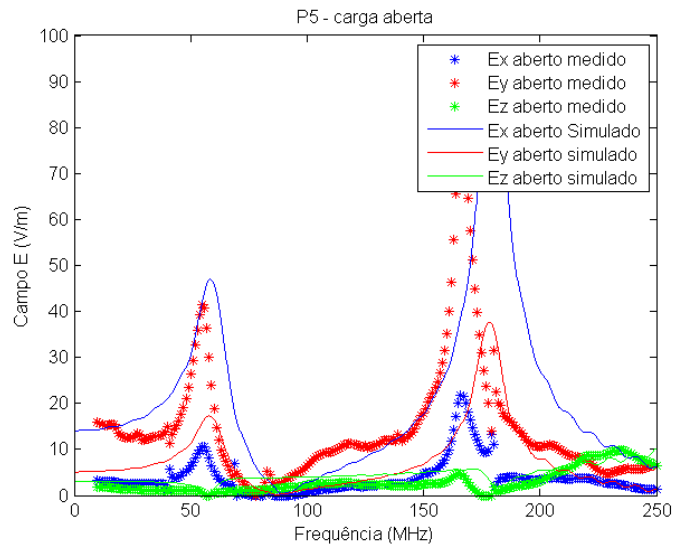

(e)

Figura 55 - Campo E Valores medidos e simulados. Carga Aberta (a) ponto $1(0,3 ; 0,3 ; 0,6)$ $m$; (b) ponto $2(0,4 ; 0,3 ; 0,8) m$; (c) ponto $3(0,2 ; 0,3 ; 0,8) m$; (d) ponto $4(0,2 ; 0,3 ; 0,4) m$; e (e) ponto $5(0,4 ; 0,3 ; 0,4) \mathrm{m}$.

No mapeamento de perfis de campo E apresentado da Figura 56 a Figura 58 observam-se os componentes de campo Ex, Ey, Exyz apresentam valores elevados, nas faixas de frequência entre $100 \mathrm{MHz}-160 \mathrm{MHz}$, e também acima de $220 \mathrm{MHz}$, quando comparados com os valores das demais frequências consideradas. Esta 
característica está relacionada às frequências de ressonância da cavidade. Na faixa de $10 \mathrm{MHz}$ até $70 \mathrm{MHz}$, observa-se que os perfis de campo $\mathrm{E}$ não apresentam alteração significativa.

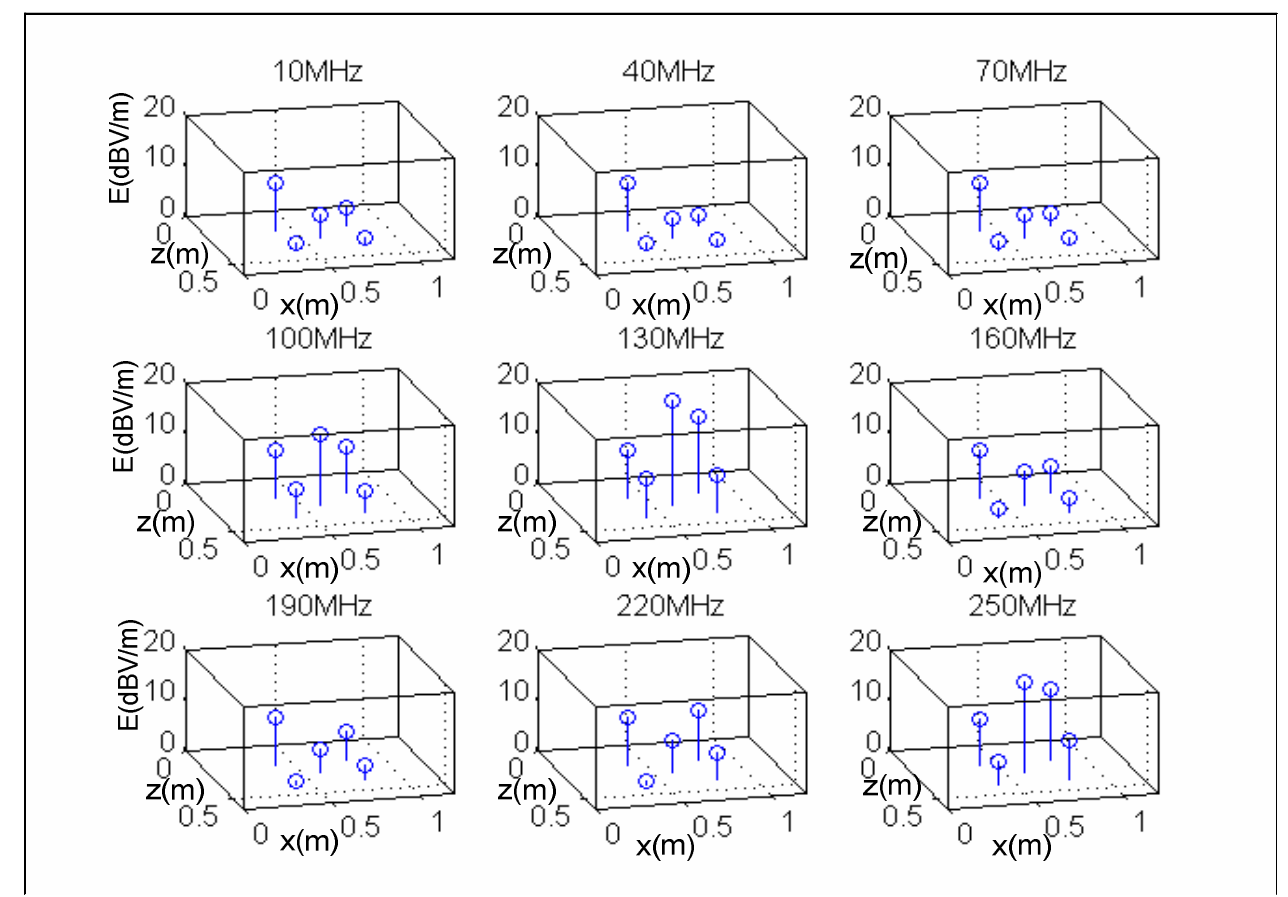

Figura 56 - Medidas de Campo Abs(Ex), em várias posições da câmara, e várias frequências com carga aberta.
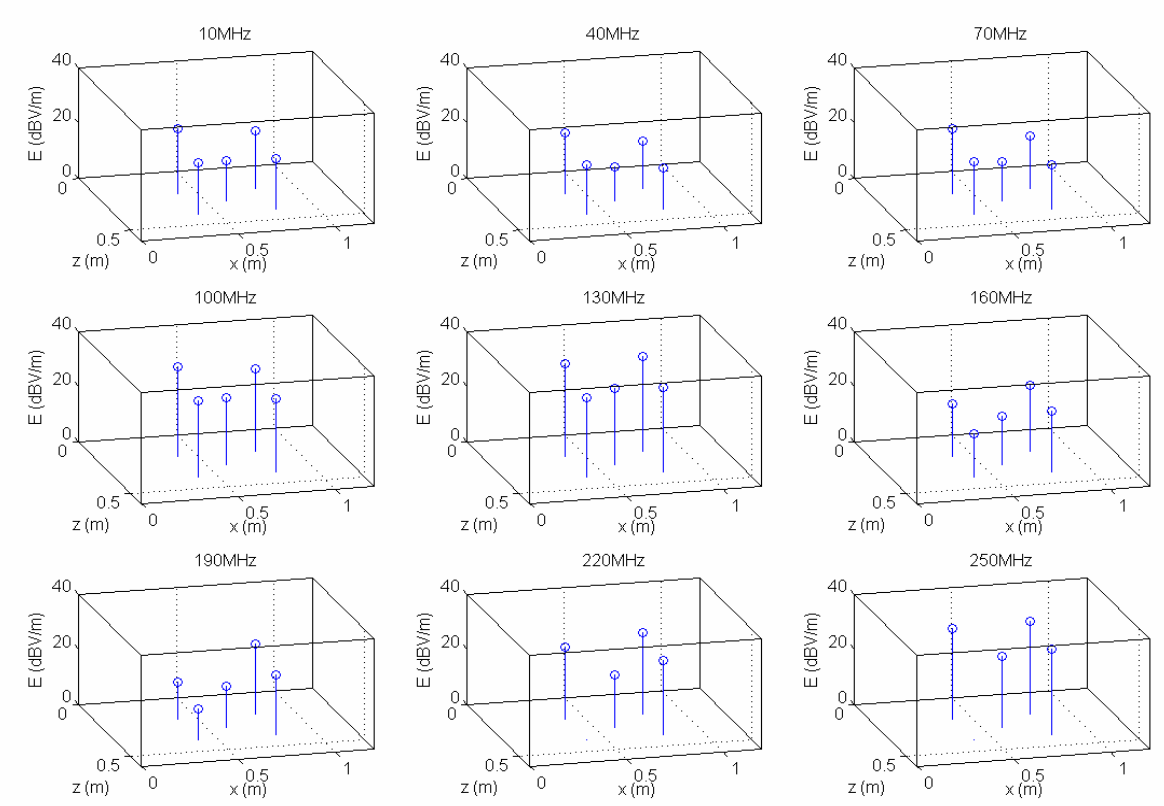

Figura 57 -Medidas de Campo Abs(Ey), em várias posições da câmara e várias frequências com carga aberta 

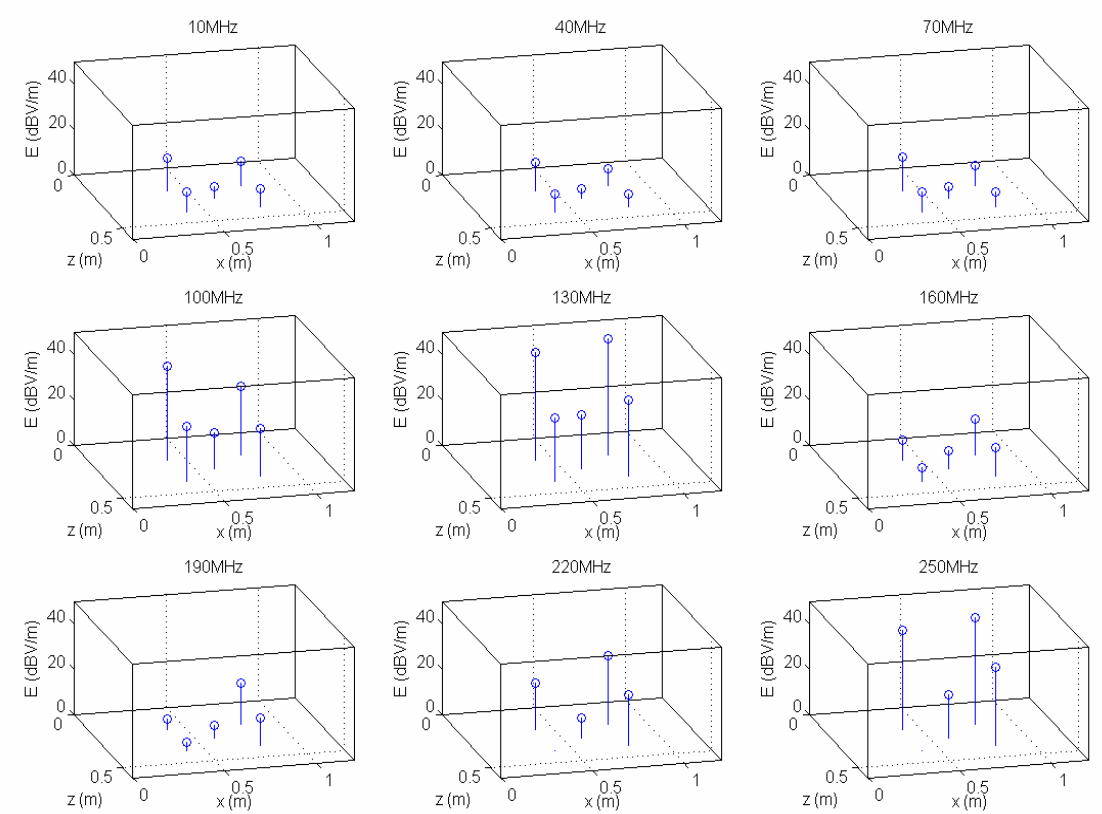

Figura 58 - Medidas de Campo E resultante [Abs(Exyz]) em várias posições da câmara e várias frequências com carga aberta.

\subsubsection{Medidas de parâmetros com o Analisador Vetorial de Redes}

As medidas dos parâmetros S utilizando o Analisador Vetorial de Redes (Vetorial Network Analyzer - VNA), foram executadas de acordo com os procedimentos detalhados no APÊNDICE B.

Resumidamente, inicia-se os ensaios aplicando-se três condições de carga da linha de transmissão durante as medidas: $50 \Omega$, curto-circuito e carga aberta (são os ensaios básicos aplicados em altas frequências). Numa segunda etapa, os defasadores foram instalados como cargas das LTs da CELT. Variando-se as tensões de referência dos defasadores, levantou-se os parâmetros $S$ e as impedâncias vistas a partir da excitação da câmara.

\subsubsection{Caracterização da CELT - carga $50 \Omega$}

Note-se que todas as medidas utilizando o VNA foram feitas utilizando referência de $50 \Omega$ e as simulações com o modelo numérico também foram efetuadas utilizando as mesmas condições visando compará-las. 
Conectando-se o analisador vetorial de rede nas entradas e saídas das linhas de transmissão, com uma conexão por vez, manteve-se todas as portas conectadas com cargas padrão $50 \Omega$ e mediu-se os parâmetros S11, S22, S12 e S13.

As cartas de Smith medidas na entrada de LT1 e LT2, Figura 59(a) e Figura 60(a) mostram que o ponto na qual o melhor casamento de impedâncias pode ser obtido corresponde à frequência de $124 \mathrm{MHz}$. Isto reflete nas amplitudes de S11 e S22, que têm seus valores de pico na mesma frequência Figura 59 (b) e Figura 60 (b)

Nota-se ainda, na Figura 59 (c) e na Figura 60 (c), que a inversão de fase ocorre em $124 \mathrm{MHz}$, e as passagens por zero ocorrem em $61 \mathrm{MHz}$ (ponto \#1) e próximo de170 MHz.

Para os circuitos com carga de $50 \Omega$, os TOE medidos são mostrados na Figura 59(d) e Figura 60(d) corroboram os resultados anteriores indicando os mesmos valores de frequência de melhor casamento de impedâncias. Então, nota-se que para frequência de $124 \mathrm{MHz}$ o TOE se aproxima de 1, ou seja, a tensão tem pequena reflexão $\left(V_{i n c} \approx V_{\text {res }}\right)$. No restante da faixa de frequências, o casamento de impedâncias mostra-se não adequado, chegando a um TOE da ordem de 30 (pontos indicados \#1 e \#2).

OBS: Foi utilizada a porta 1 do VNA para levantamento dos parâmetros da câmara (os gráficos estão identificados como S11, mas as medidas foram distintas através de procedimento). 


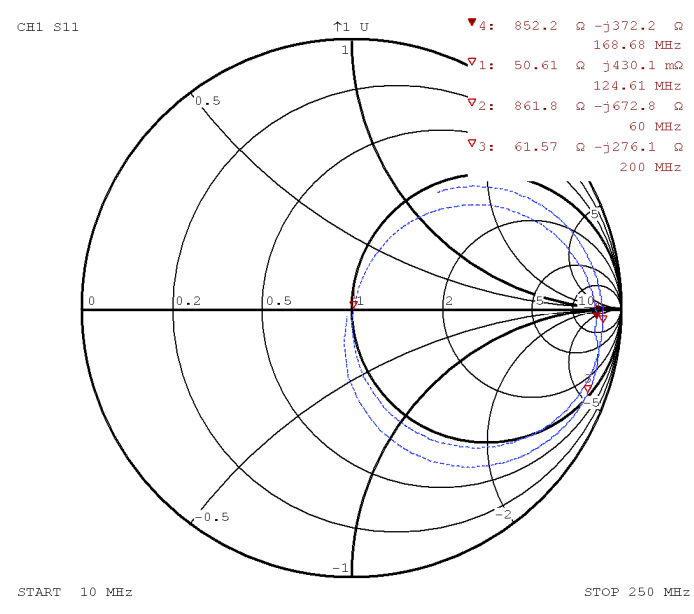

(a)

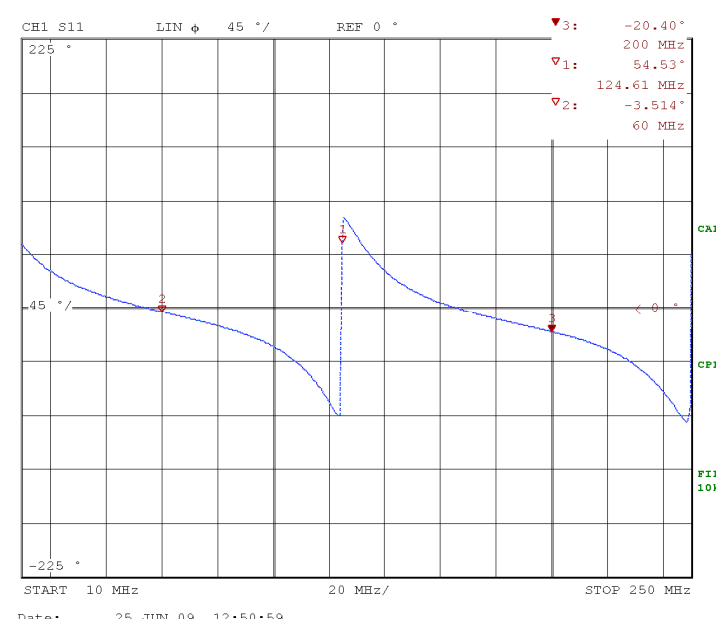

(c)

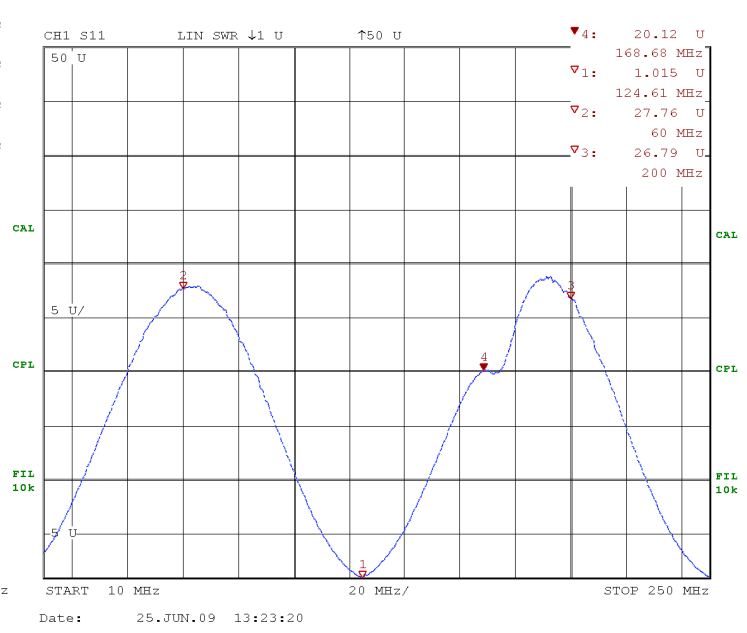

(b)

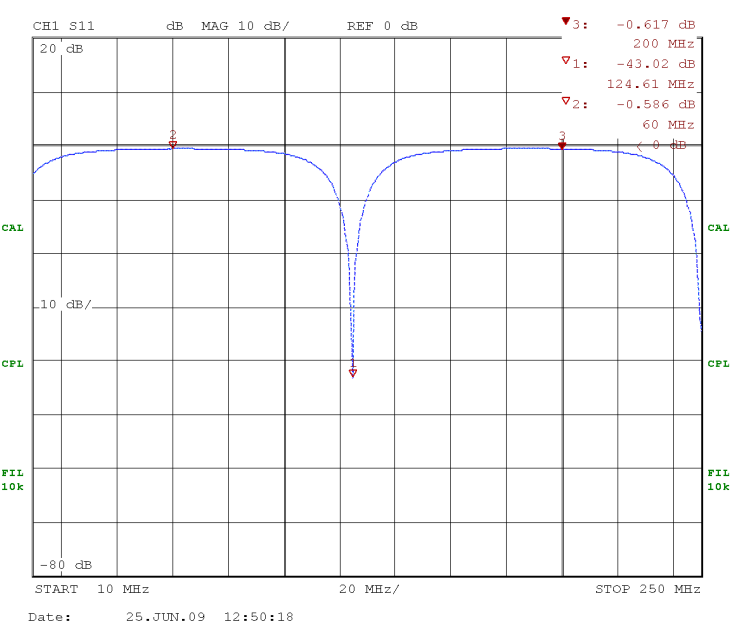

(d)

Figura 59 - Caracterização da câmara - resultados direto do VNA - linha de transmissão 1 com carga $50 \Omega$.(a) carta de Smith (b)TOE (c)Amplitude $S 11 \mathrm{~dB}$ (d) Ângulo de $S 11 \mathrm{em}$ graus. 


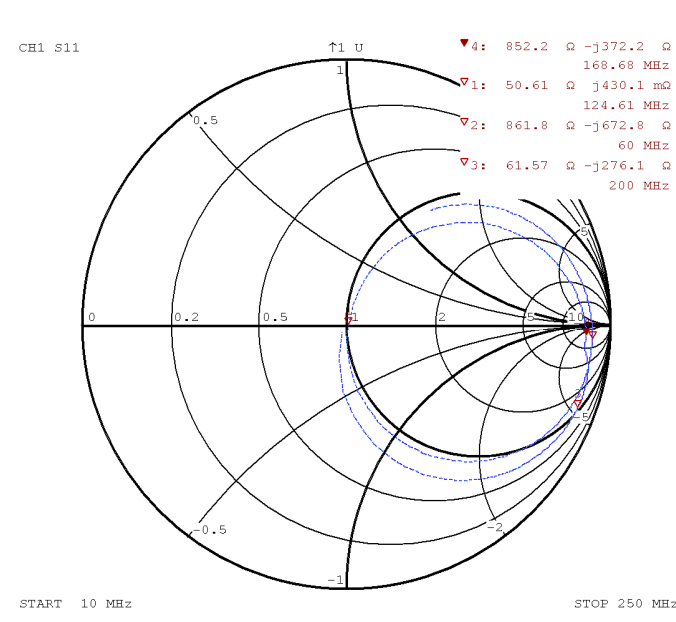

(a)

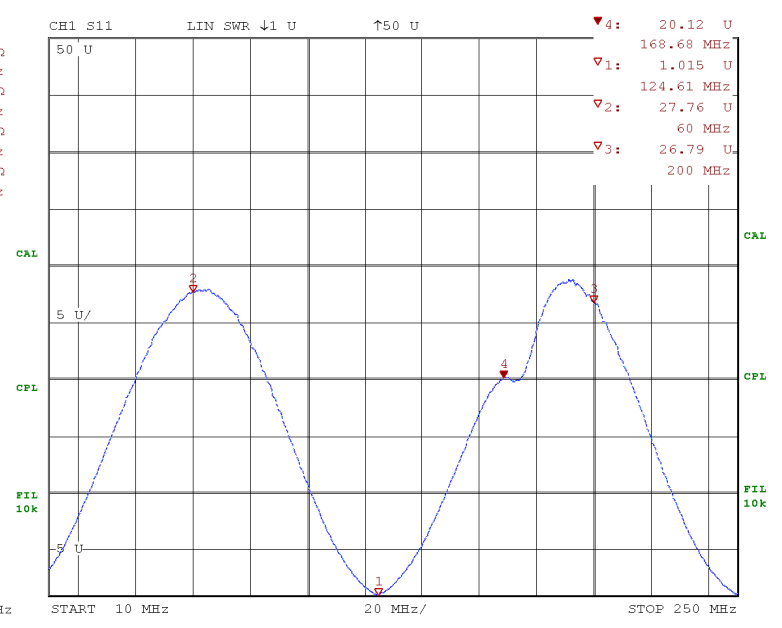

(b)

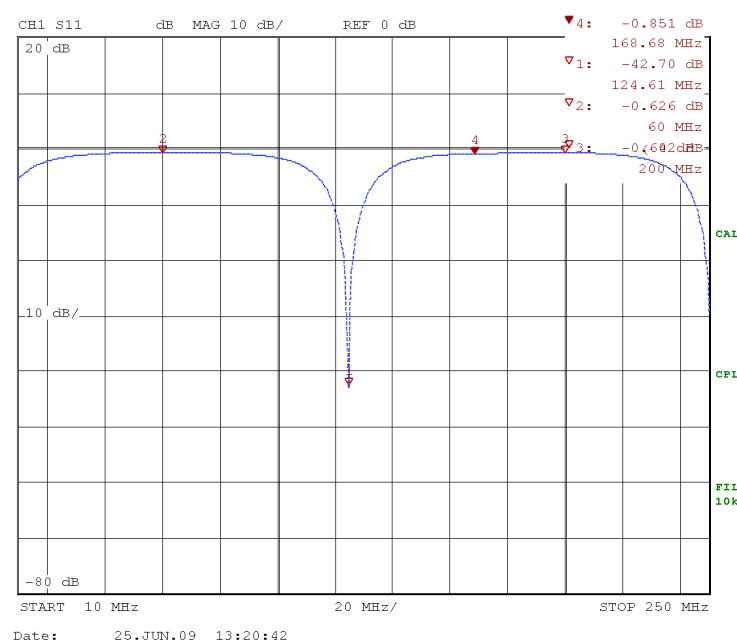

(c)

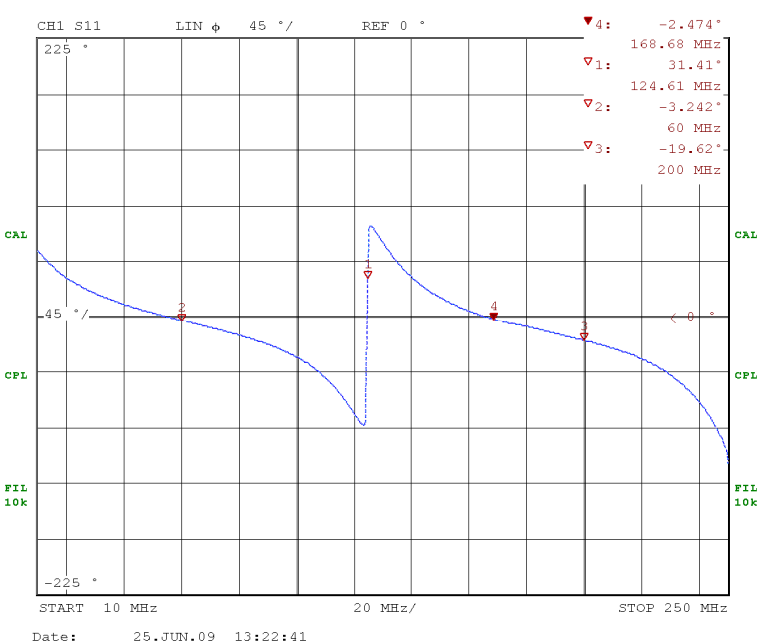

(d)

Figura 60 - Caracterização da câmara - resultados direto do VNA - linha de transmissão 2 com carga $50 \Omega$.(a) carta e Smith (b) TOE (c) Amplitude S22 dB (d) Ângulo de S22 em graus.

$\mathrm{Na}$ Figura 61 são mostradas as comparações entre os valores medidos e os resultados das simulações numéricas. Observa-se na Figura 61 (a), que os de S11 valores medidos e simulados numericamente apresentam comportamento bastante similar. Ainda, na Figura 61 (b) os valores medidos de S13 apresentam algumas distorções, mas o comportamento geral é satisfatório. 
Comparação de Parâmetros S11 e S22 - Medidos e Simulados

$S(d B)$

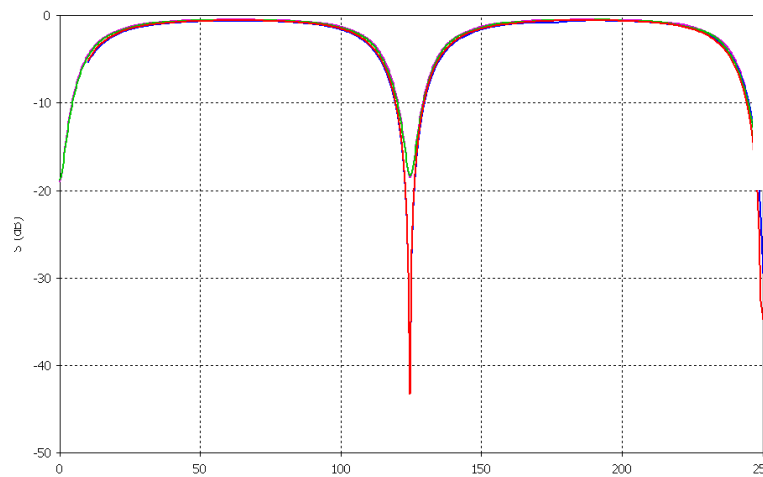

Freqüência (MHz)
S11 Medido

S11 Simulado

S22 Medido

S22 Simulado

$\mathrm{S}(\mathrm{dB})$

Comparação de Parâmetros S13 - Medidos e Simulados

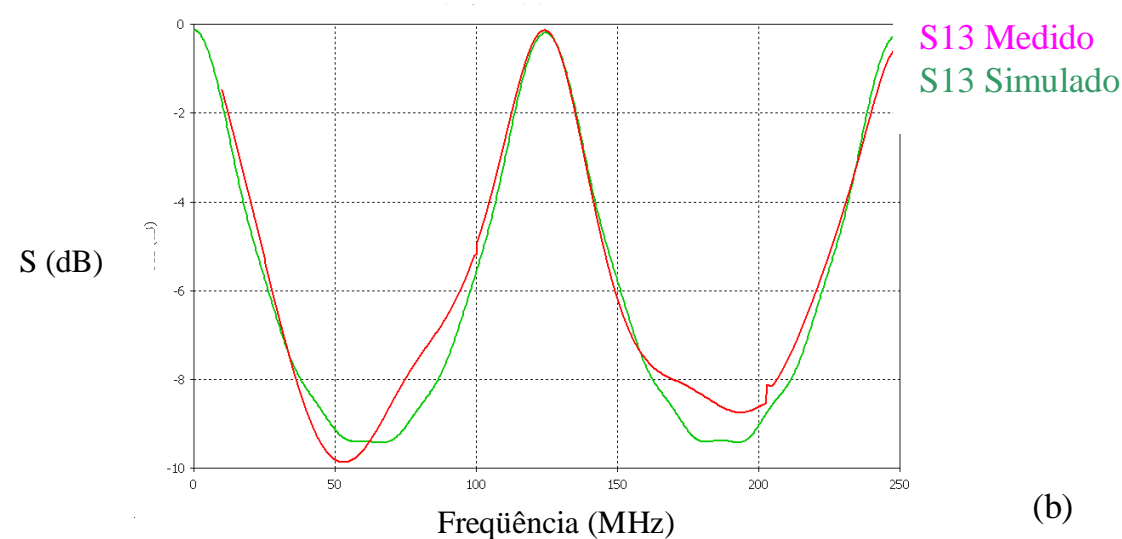

(a)

(b)

Comparação de Parâmetros S12 - Medidos e Simulados

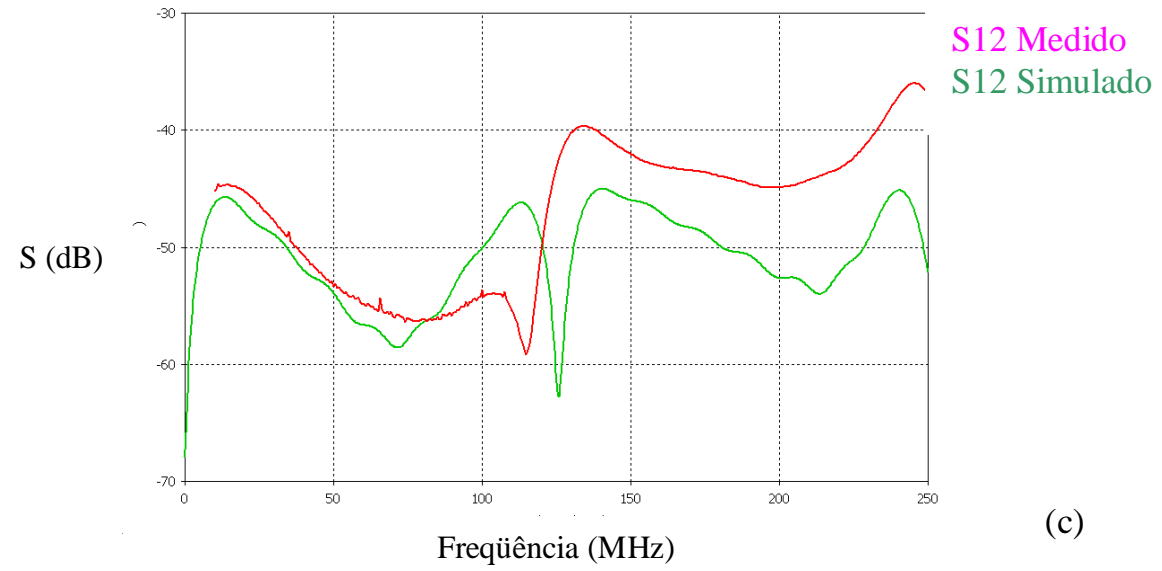

Figura 61 - Caracterização da câmara com carga $50 \Omega$. Comparação dos valores em dB, medidos e simulados. (a) S11; (b) S13; (c)S12. 


\subsubsection{Carga infinita}

Quando se avalia a CELT (protótipo LMAG/CTMSP) com a carga aberta, a carta de Smith mostrada na Figura 62 (a) apresenta valores tendendo ao infinito para toda a faixa de frequências medida e os pontos de mínimo da amplitude de $S 11$ são quase imperceptíveis Figura 62 (b).

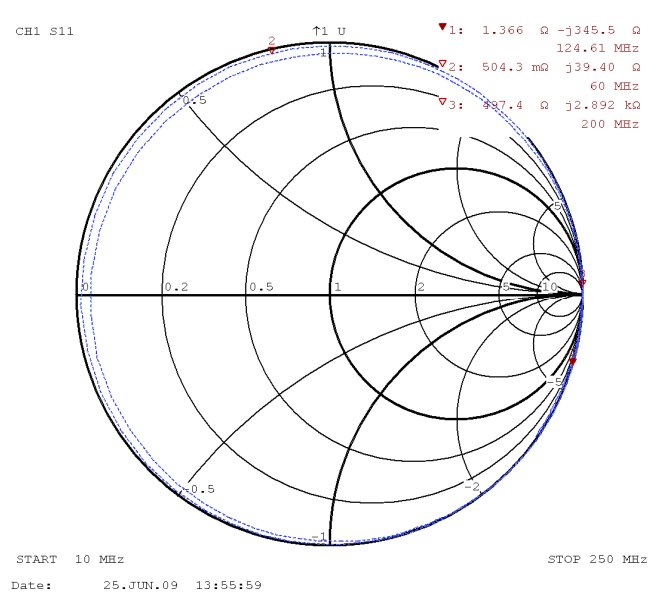

(a)

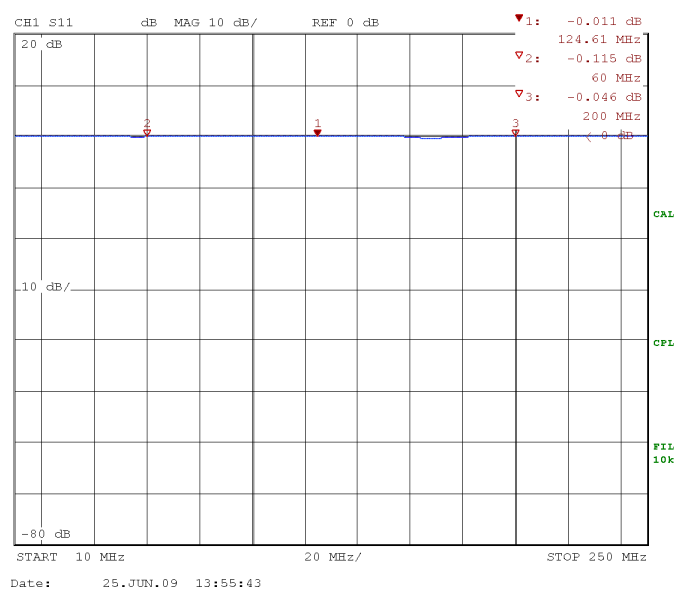

(c)

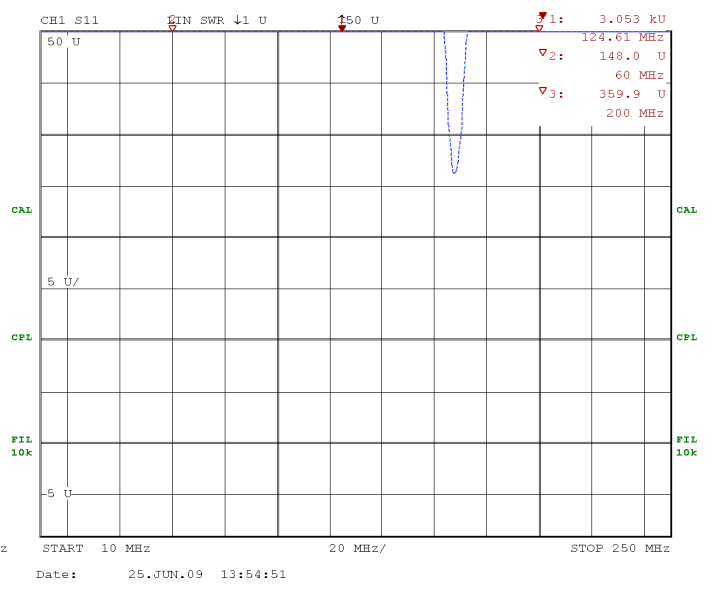

(b)

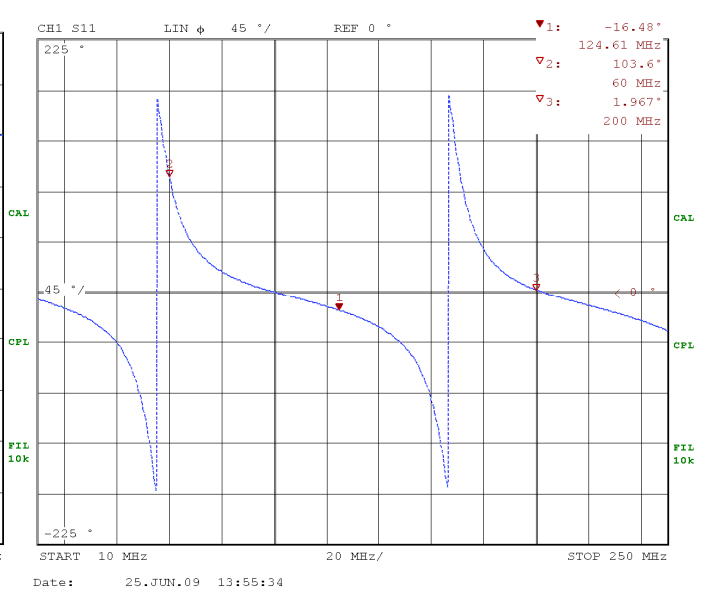

(d)

Figura 62 - Linha de Transmissão 1 com carga infinita (a) carta e Smith (b)TOE (c)Amplitude $S 11 d B(d)$ Ângulo de $S 11$ em graus.

Observa-se na Figura 62 (c), que a inversão de fase ocorre em dois pontos aproximadamente. $60 \mathrm{MHz}$ e $168 \mathrm{MHz}$ (ponto \#2). Além de duas passagens pelo zero (103 MHz; e ponto $\# 3-208 \mathrm{MHz}$ ), que indicam os valores de frequência em que o circuito equivalente da CELT entra em ressonância. Os valores de TOE Figura 
62 (d) mostram que praticamente toda a energia injetada é refletida, a menos de uma estreita faixa de frequência próxima de $170 \mathrm{MHz}$.

Ainda, foi efetuada a comparação dos valores medidos e simulados de S11 e S22 quando o circuito opera com carga aberta e os resultados são mostrados na Figura 63. Os resultados da simulação mostrados, são compatíveis com os medidos, a menos de diferenças da ordem de $0,5 \mathrm{~dB}$, nos valores de pico e de cerca de $20^{\circ} \mathrm{de}$ defasagem nas frequências de pico. Mas de qualquer forma, os dois máximos encontram-se presentes, por volta de $60 \mathrm{MHz}$ e $170 \mathrm{MHz}$ (conforme já notado quando foi efetuada a medida utilizando-se o sensor isotrópico de campo elétrico).

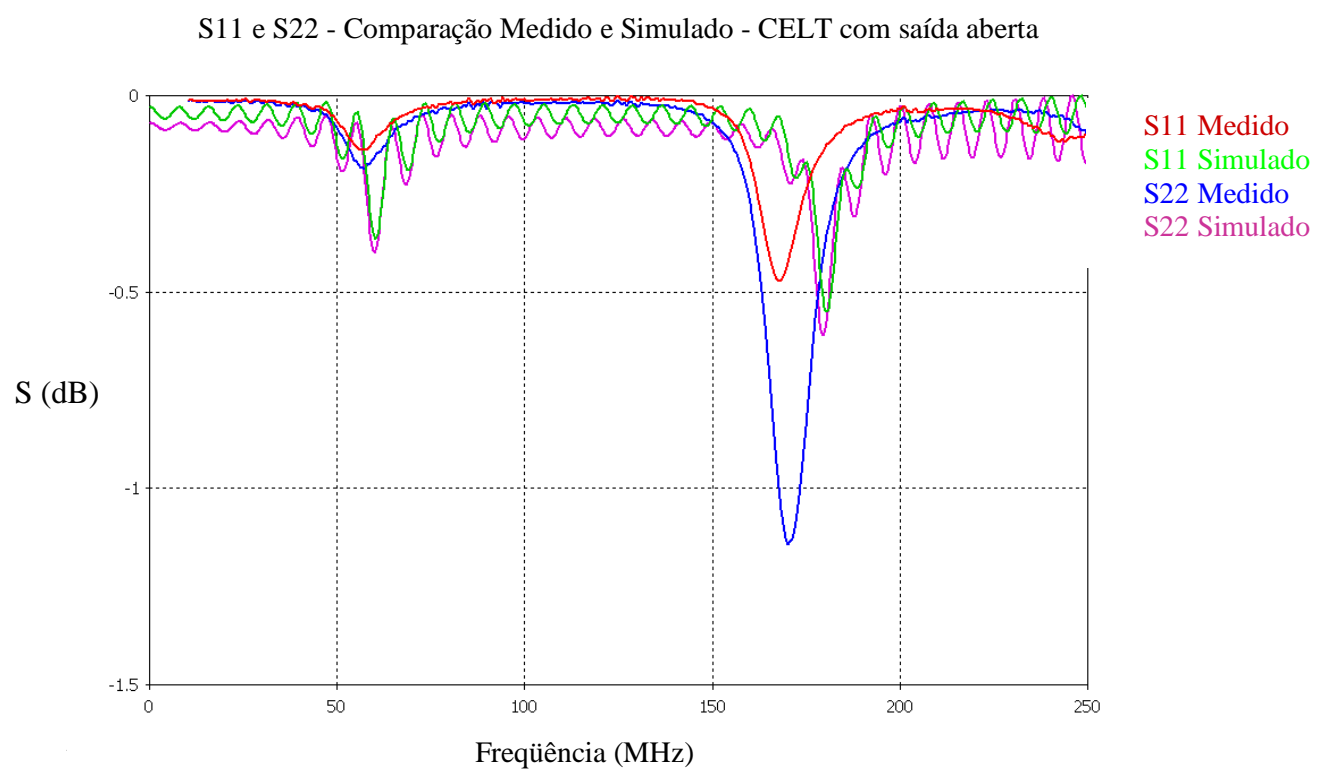

Figura 63 - Parâmetros S11 e S22 da CELT com carga aberta.

\subsubsection{Carga em curto-circuito}

Além dos ensaios com carga $50 \Omega$ e carga aberta, um outro ensaio clássico em altas frequências é o de carga curto-circuitada. $O$ ensaio foi efetuado de acordo com os procedimentos revistos no APÊNDICE $B$, utilizando o VNA para verificar a resposta na entrada do sistema, quando a carga encontra-se em curto-circuito.

Os resultados obtidos são mostrados na Figura 64 e nota-se, pela carga de Smith Figura 64 (a) que o sistema se comporta como uma carga tendendo ao infinito em toda a faixa de frequência medida. O TOE reitera esta tendência Figura 64 (b), 
indicando que não haverá, praticamente, nenhuma potência sendo injetada na câmara, assim como a amplitude de S11, Figura 64 (c). O ângulo de S11, Figura 64 (d), apresenta inversão de fase em $124 \mathrm{MHz}$ e uma segunda inversão próxima de $250 \mathrm{MHz}$.

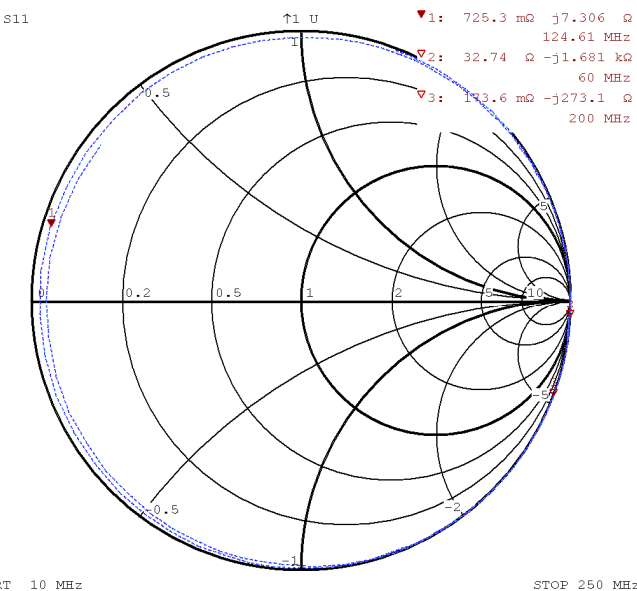

(a)

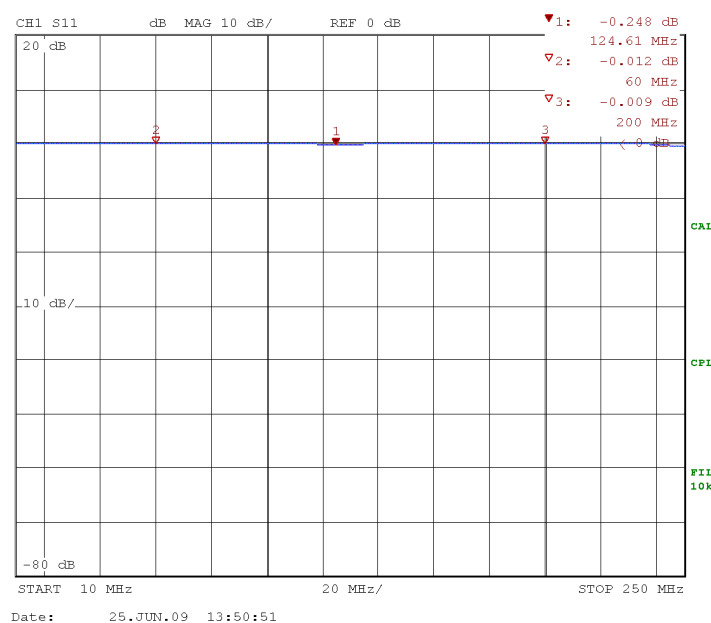

(c)

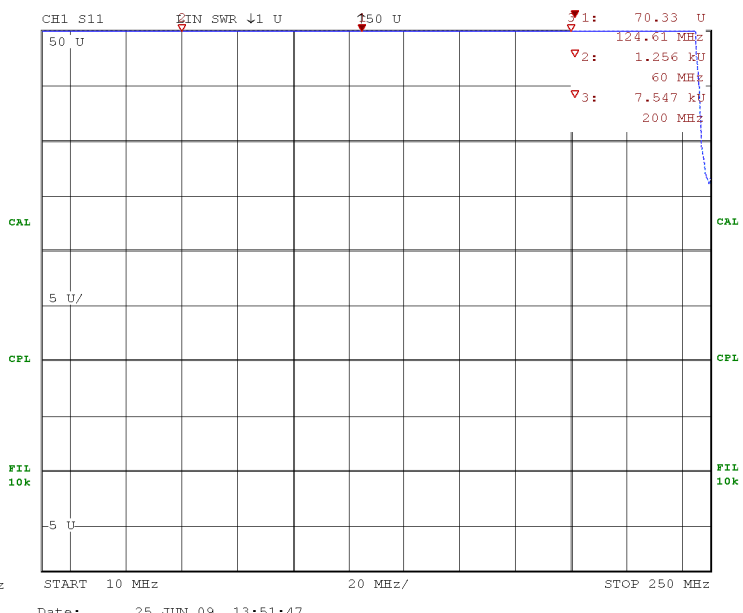

(b)

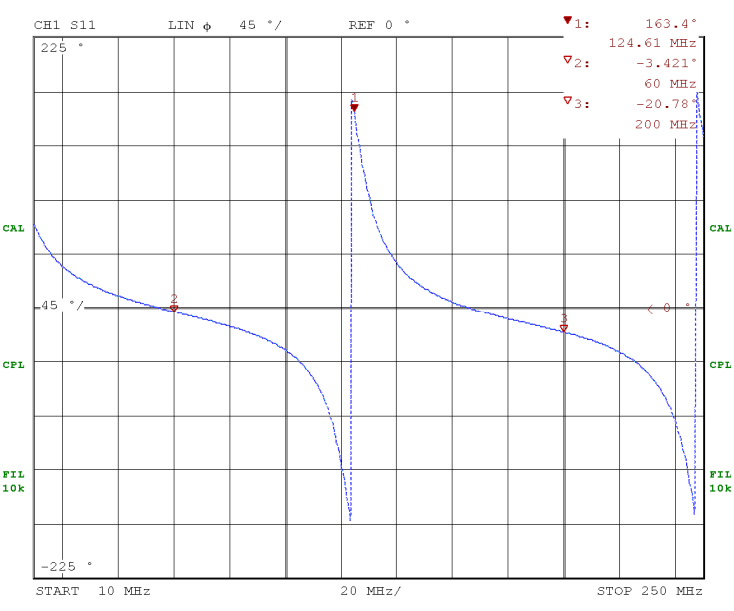

(d)

Figura 64 - LT1 com carga curto-circuito (do kit de calibração do VNA)(a) carta de Smith (b)TOE (c)Amplitude S11 dB (d) Ângulo de $S 11$ em graus.

Da mesma forma, foi efetuada uma comparação dos valores medidos para CELT com carga em curto-circuito, e os resultados da simulação numérica. Nota-se que os resultados medido e simulado são bastante coerentes, ocorrendo os valores de mínimos de S11 e S22 na mesma frequência, por volta de $125 \mathrm{MHz}$ e que corresponde à primeira frequência de ressonância da câmara. Ainda, nota-se uma 
instabilidade na solução numérica, mas tomando-se a curva média da oscilação obtêm-se no pior caso uma diferença de -0,3 dB (em $125 \mathrm{MHz}$ ). Um segundo valor mínimo surge nas imediações de $250 \mathrm{MHz}$, que corresponde à segunda frequência de ressonância da câmara.

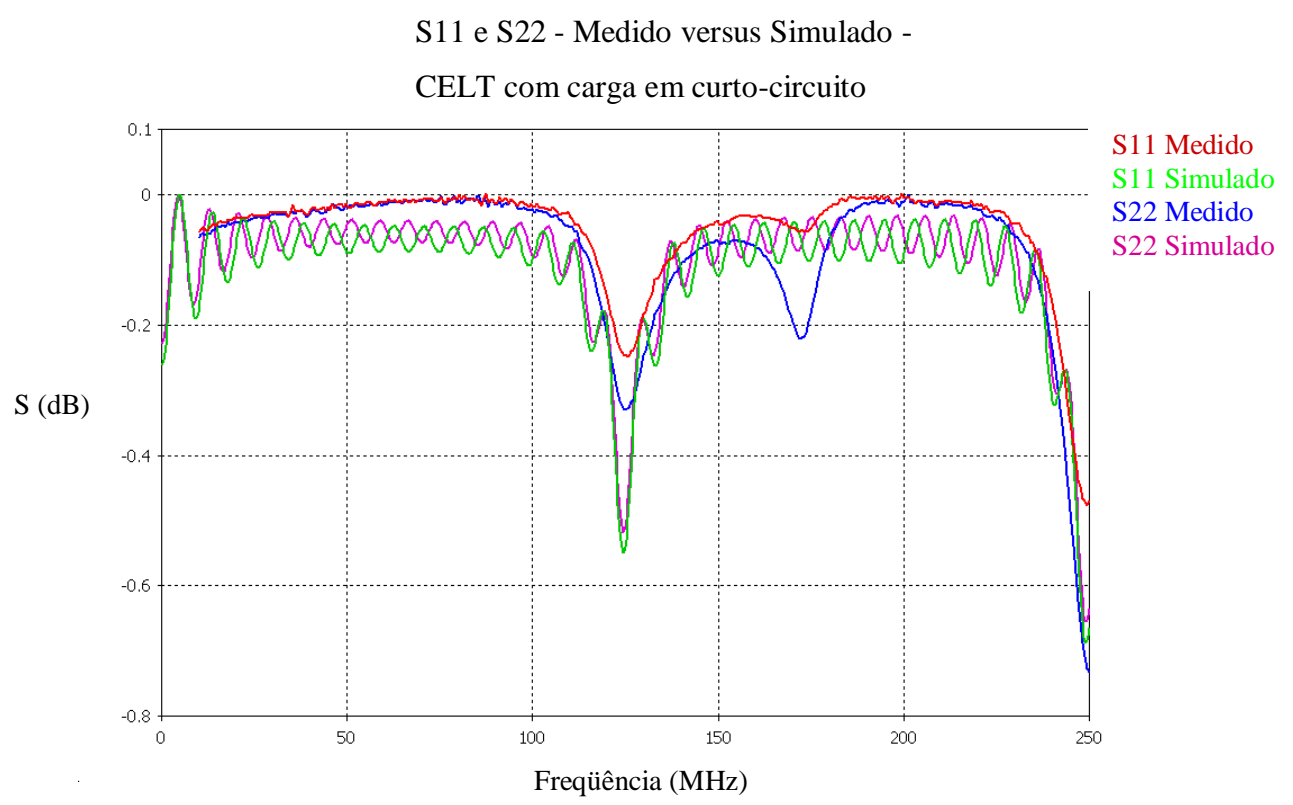

Figura 65 - S11 e S22 da CELT com carga em curto-circuito.

\subsubsection{Comportamento do protótipo da CELT com defasadores na carga}

Nesta seção é apresentado o levantamento experimental do comportamento da CELT, quando se conecta os defasadores Pulsar ${ }^{\circledR}$ (vide curvas características de defasagem e de impedância dos defasadores no APÊNDICE C) como carga em apenas uma das linhas de transmissão da CELT.

Basicamente foram ensaiadas duas configurações de cargas: uma com o defasador e mais uma carga padrão de $50 \Omega$; outra com o defasador com saída aberta.

Na Figura 66 é mostrada a montagem básica (lado carga) utilizada nos ensaios desta seção, apresentando o defasador como carga no final da linha de transmissão da CELT, e a conexão com o gerador de tensão Vcc, que controla a defasagem (por conseguinte a impedância) dos defasadores. 


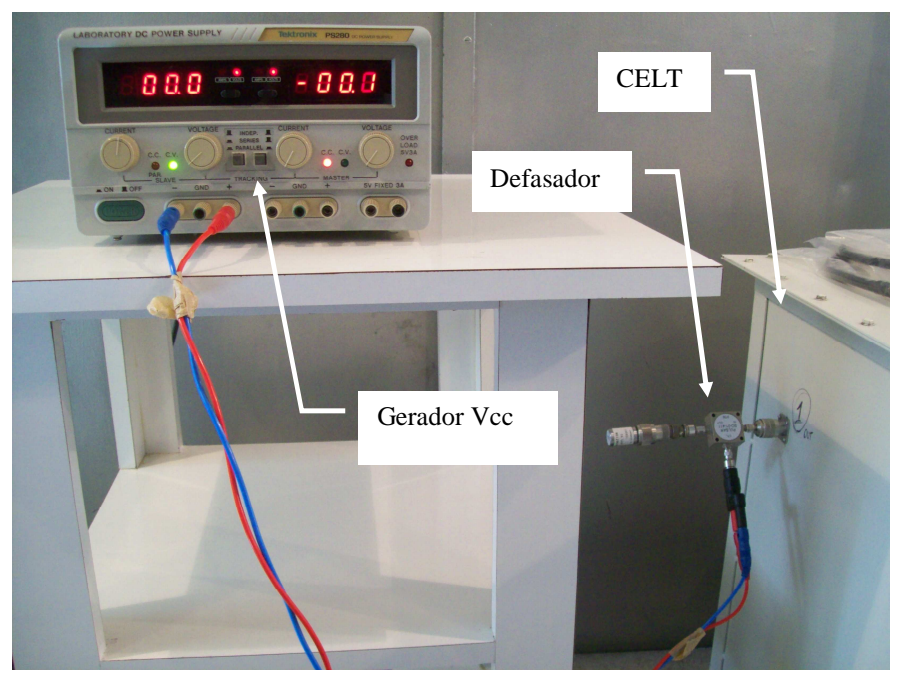

Figura 66 - Gerador Vcc controlando o defasador

No lado excitação, é conectado somente o VNA no conector correspondente àquele da linha de transmissão na qual a montagem da carga variável foi também instalado. Essa medida sempre mostrará o que está sendo visto pelo gerador ou, em síntese, o comportamento das impedâncias globais do sistema em relação à impedância da excitação.

\subsection{Defasador com Carga $50 \Omega$ na saída da câmara}

Os ensaios desta série foram montados conectando-se os defasadores como carga da linha de transmissão e ainda uma carga padrão $50 \Omega$ na saída do defasador, conforme mostrado na Figura 67.

Os resultados foram importados no Matlab, a partir de arquivos ASCIl produzidos pelo VNA, de forma a gerar gráficos que pudessem comparar os comportamentos para as diversas tensões de referência injetadas no controle do defasador. 


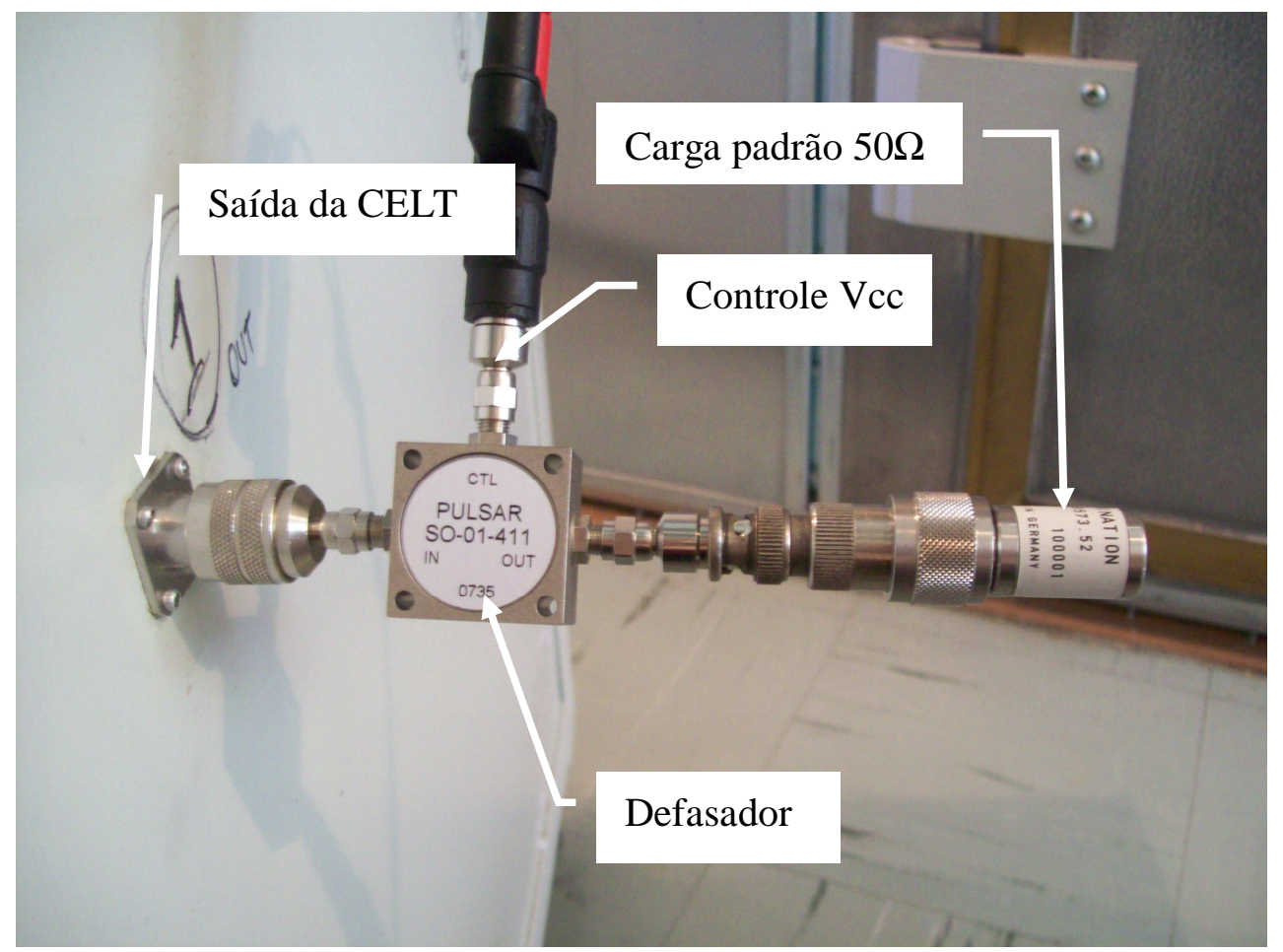

Figura 67 - Defasador conectado na saída da CELT com carga $50 \Omega$.

Os resultados obtidos são mostrados da Figura 68 até a Figura 71, para quatro defasadores que cobrem cada um uma determinada faixas de frequência, que sejam 10-20 MHz / 20-40 MHz / 100-190 MHz / 150-250 MHz.

O primeiro defasador (mod. SO-01) foi ensaiado na faixa de $10-20 \mathrm{MHz}$ e os resultados são mostrados na Figura 68.

A carta de Smith, Figura 68 (a), mostra que todo o conjunto de carga variável $($ CELT + defasador + carga $50 \Omega$ ) apresenta uma excursão muito pequena dentro da faixa de frequência e que o comportamento é equivalente a uma indutância. $O$ que pode ser observado na Figura 68 (b), é que a amplitude de $\$ 11$ cresce quase linearmente com a frequência e o ângulo decresce também de uma forma aproximadamente linear com a frequência. A variação da tensão de controle do defasador não surte grande efeito nesta configuração. 
Smith - S11 CELT com defasador 01 e carga 500hm - faixa 10-20MHz

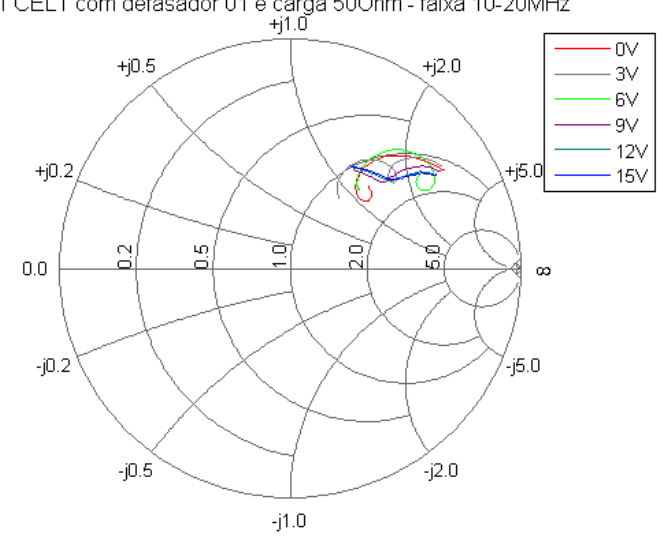

(a)
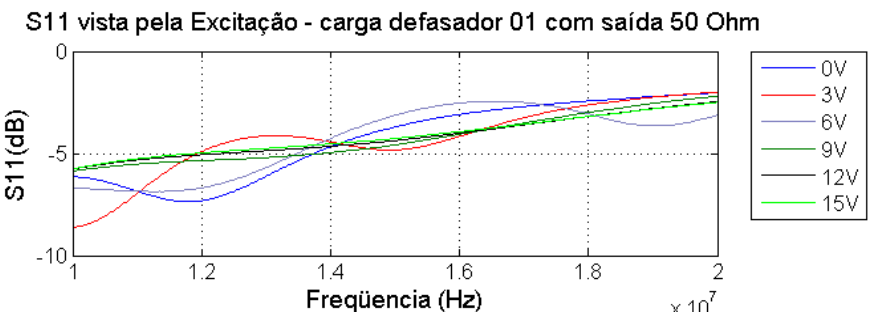

S11 vista pela Excitação - carga defasador $01 \mathrm{com}$ saída 50 Ohm

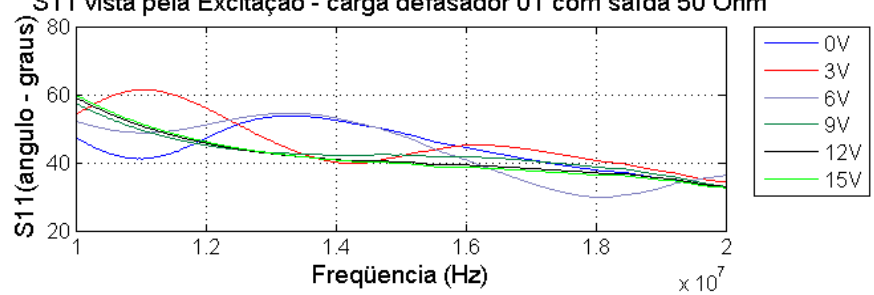

(b)

Figura 68 - Caracterização da câmara com defasador SO-01 na saída e carga $50 \Omega$ (10-20 $\mathrm{MHz}$ ) (a) Carta de Smith (b) S11 Módulo e Angulo

O segundo defasador (mod. SO-02) foi ensaiado na faixa de 20-40 MHz e os resultados são mostrados na Figura 69. Afora que os valores de impedâncias e variações são diferentes dos verificados no caso anterior, verifica-se que a variação da tensão de controle do defasador também não surte efeito para esta configuração. 
I Smith - S11 CELT com defasador 02 e carga 50 Ohms - faixa 20-40MHz

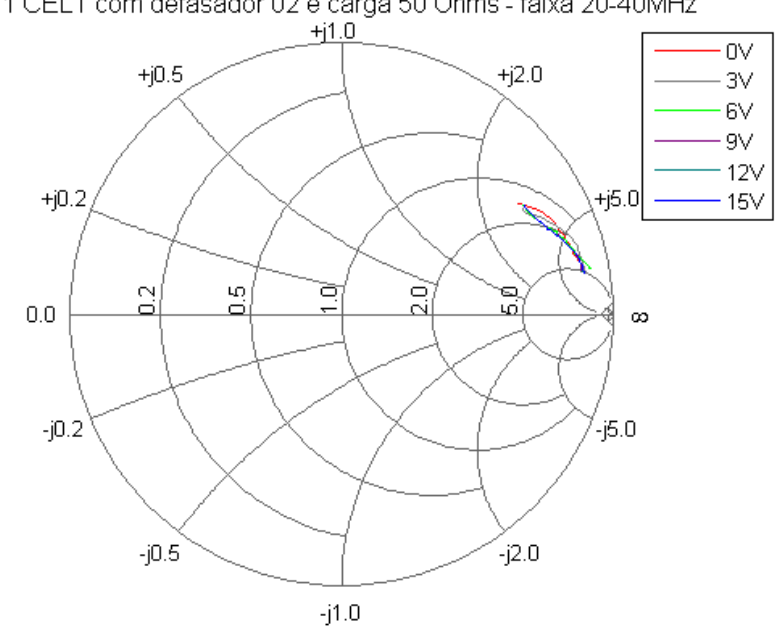

(a)
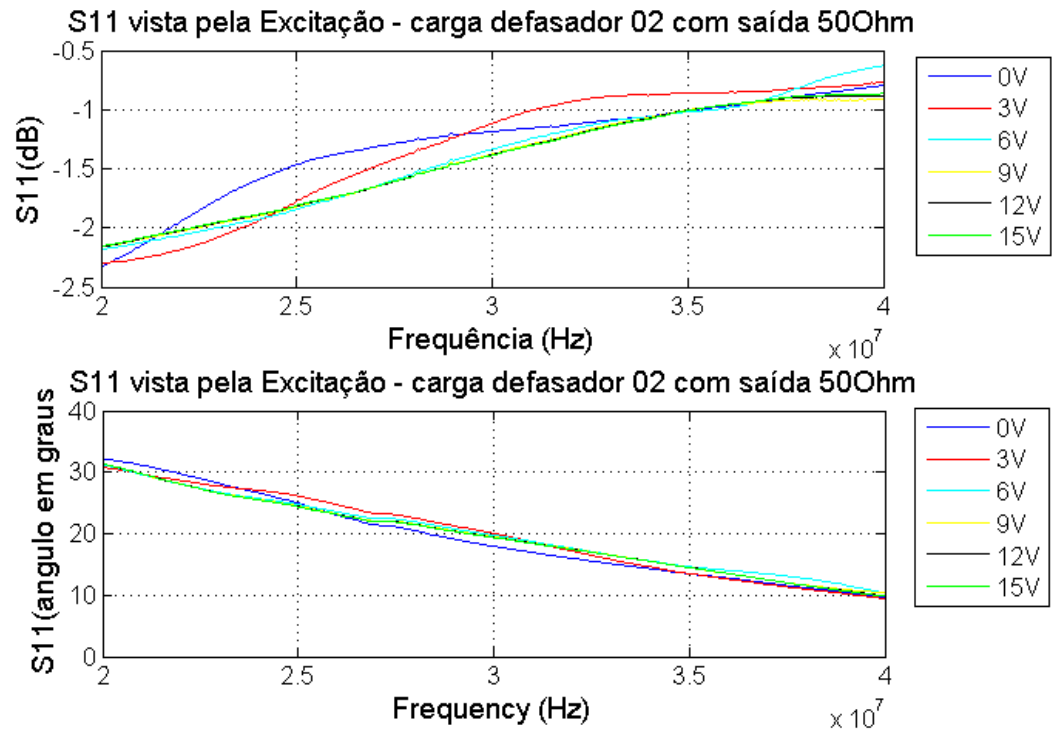

(b)

Figura 69 - Caracterização da câmara com defasador SO-02 na saída e carga $50 \Omega$ (20 $\mathrm{MHz}-40 \mathrm{MHz}$ ) (a) Carta de Smith (b) S11 Módulo e Angulo

O terceiro defasador (mod. SO-05) foi ensaiado na faixa de $100-190 \mathrm{MHz}$ e os resultados são mostrados na Figura 70. A excursão de frequência do defasador testado é maior do que os anteriores, então consegue-se cobrir praticamente uma volta completa na carta de Smith, Figura 70 (a). As curvas de amplitude e de ângulo de S11, Figura 70 (b), mostram que a frequência de ressonância característica da câmara permanece inalterada pela inserção desta carga variável (defasador + carga $50 \Omega$ ) no sistema.

Então, vista da excitação, esta montagem pouco altera a característica do conjunto. 


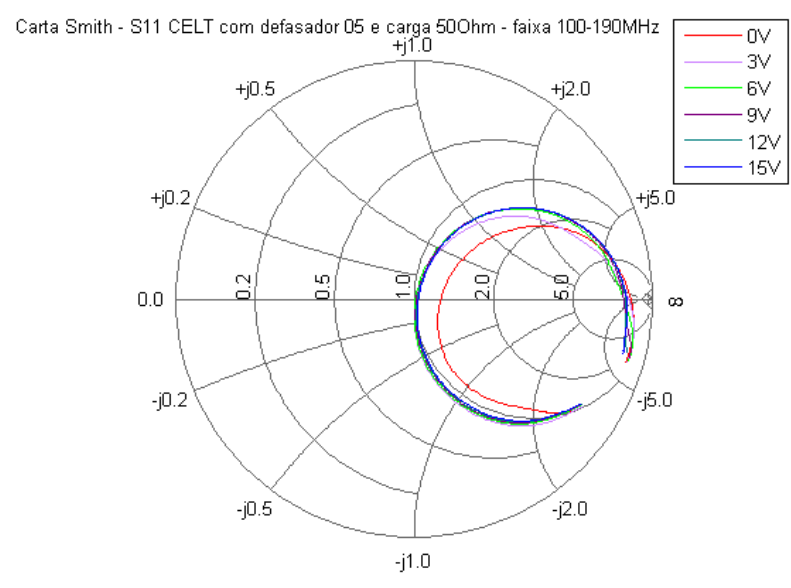

(a)

S11 vista pela Excitação - carga defasador 05 saída $500 \mathrm{hm}$
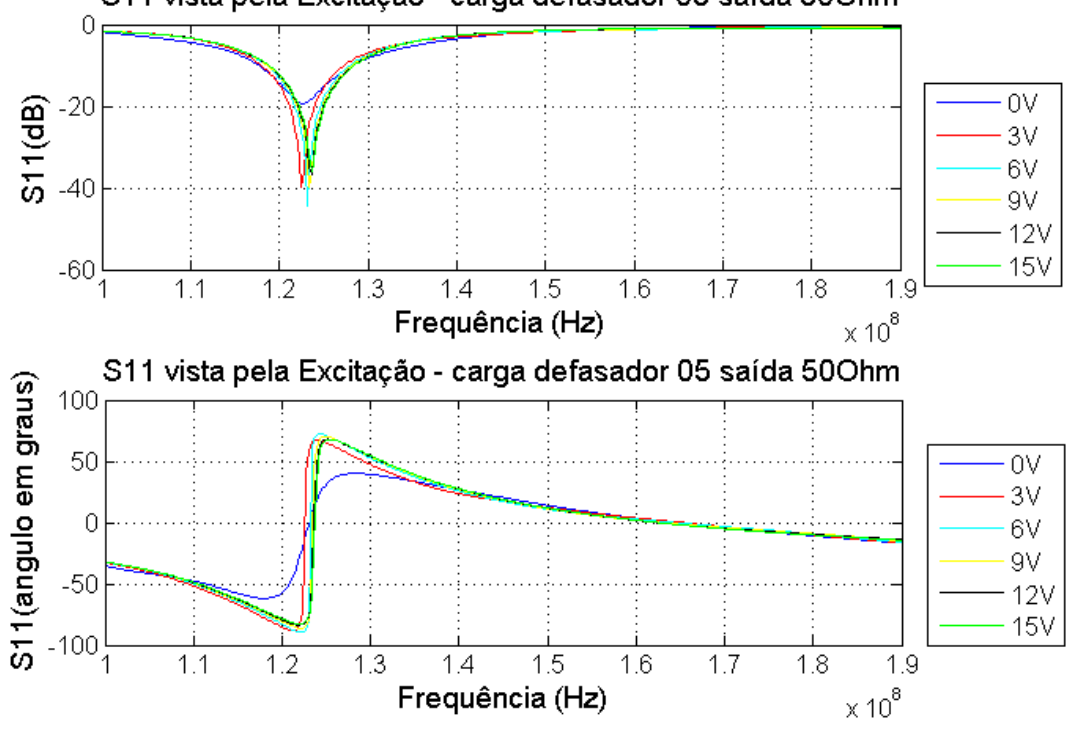

(b)

Figura 70 - Caracterização da câmara com defasador SO-05 na saída e carga $50 \Omega$ (100 $\mathrm{MHz}-190 \mathrm{MHz}$ ) (a) Carta de Smith (b) S11 Módulo e Angulo

O quarto defasador disponível (mod. SO-06) foi ensaiado na faixa de 150 - 250 $\mathrm{MHz}$ e os resultados são mostrados na Figura 71. Os resultados seguem o mesmo padrão dos anteriores, ou seja, a característica do conjunto, vista da excitação, não se altera quando a tensão de controle do defasador é variada. 
Smith - S11 CELT com defasador 06 e saida aberta - faixa 150-250MHz

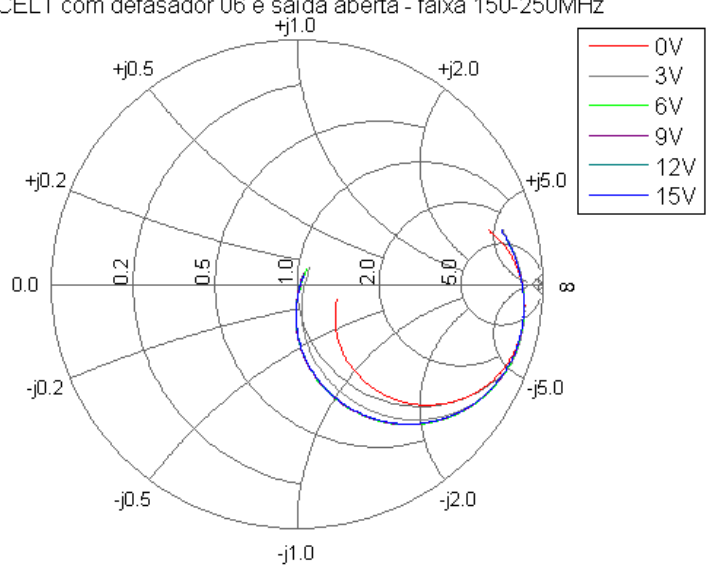

(a)
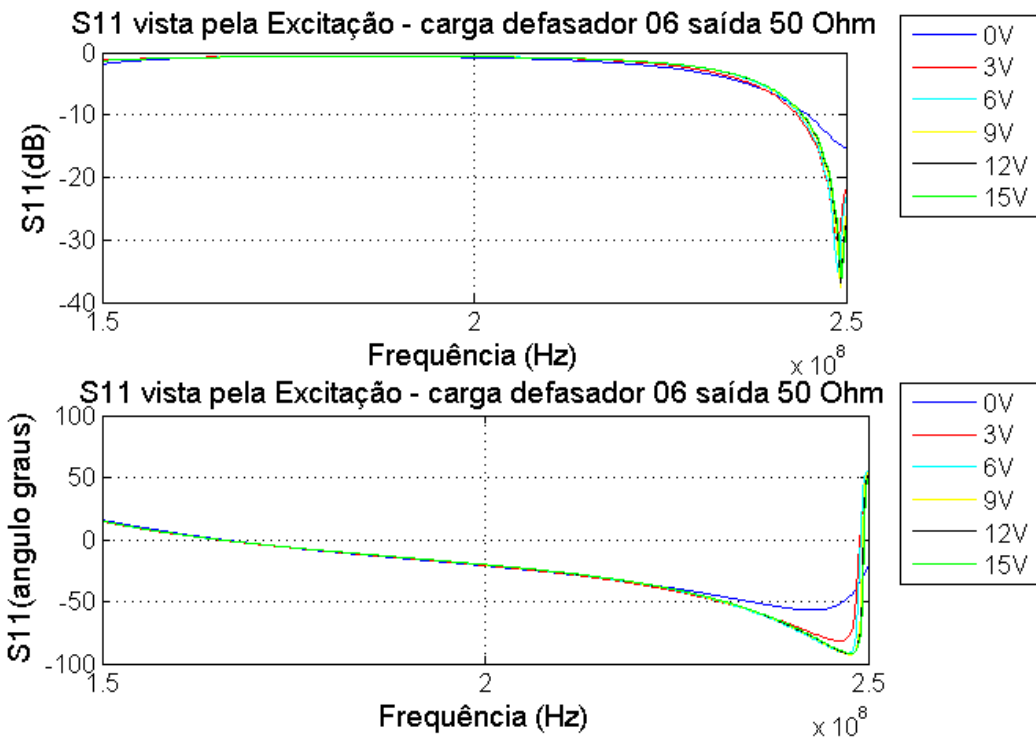

(b)

Figura 71 - Caracterização da câmara com defasador SO-06 na saída e carga $50 \Omega$ (150 $\mathrm{MHz}-250 \mathrm{MHz}$ ) (a) Carta de Smith (b) S11 Módulo e Angulo. 


\subsection{Defasador com carga aberta na saída da câmara}

Os ensaios desta série foram montados conectando-se os defasadores como carga de uma das linha de transmissão do protótipo e a saída dos defasadores foi deixada aberta.

Os resultados foram importados para o Matlab, a partir de arquivos ASCII disponibilizados pelo VNA, de forma a gerar gráficos que pudessem comparar os comportamentos destes para as diversas tensões de referência injetadas no controle do defasador.

Os resultados obtidos são mostrados da Figura 72 até a Figura 75, para quatro defasadores que cobrem cada um uma determinada faixas de frequência: 10 - 20 $\mathrm{MHz} / 20-40 \mathrm{MHz} / 100-190 \mathrm{MHz} / 150-250 \mathrm{MHz}$.

O primeiro defasador (mod. SO-01) foi ensaiado na faixa de $10-20 \mathrm{MHz}$ e os resultados são mostrados na Figura 72. Nesta Figura observa-se um comportamento bastante diferente daqueles mostrados no série anterior, que utilizava uma carga $50 \Omega$ na saída do defasador.

Os principais aspectos observados na Figura 72(a) são que as excursões dos valores de impedância, vistas pela excitação, chegam quase a completar uma volta a carta de Smith para todas as tensões de controle impostas ao defasador, além de não tenderem ao infinito, como seria de se supor devido à saída aberta. Na Figura 72(b) nota-se que as amplitudes de $\$ 11$ apresentam valores de mínimos que dependem da tensão de controle aplicada ao defasador. Ainda, sobre os valores de S11, observa-se que para a tensão de controle igual a $3 \mathrm{~V}$ ocorrem dois valores de mínimos, um próximo de $12 \mathrm{MHz}$ e outro próximo de $17,5 \mathrm{MHz}$. 
Smith - S11 CELT carga defasador 01 com saída aberta - faixa 10-20MHz

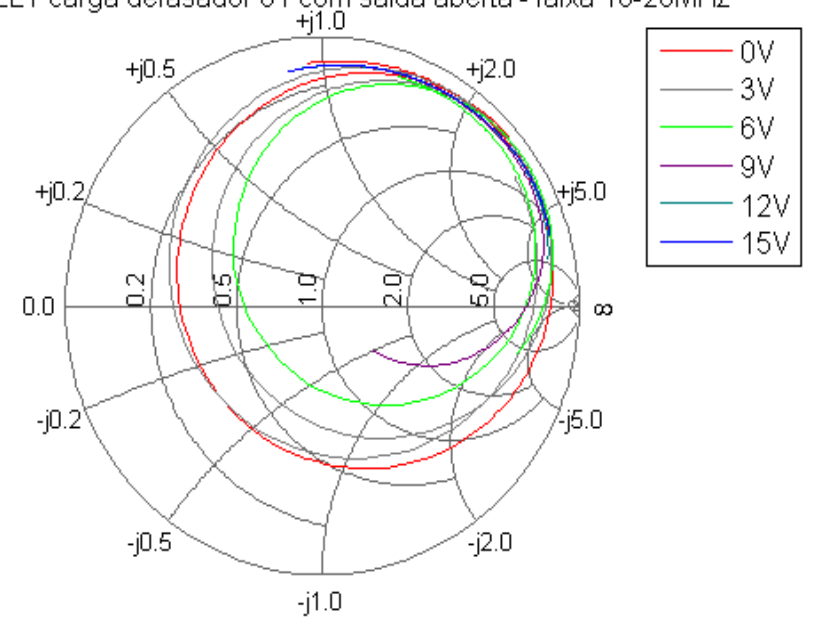

(a)

S11 vista pela Excitação - carga defasador 01 com saída aberta
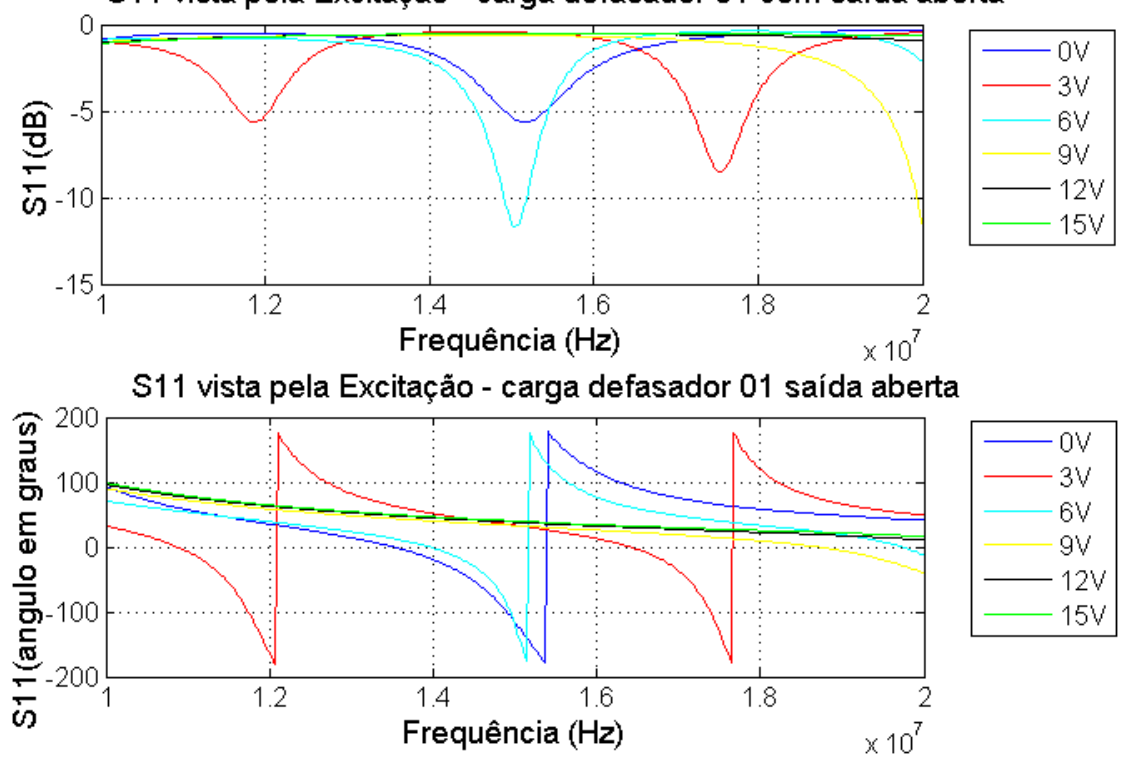

(b)

Figura 72 - Caracterização da câmara carga defasador 1 com saída aberta (10 MHz - 20 MHz) (a) Carta de Smith (b) S11 Módulo e Angulo.

O segundo defasador (mod. SO-02) foi ensaiado na faixa de $20-40 \mathrm{MHz}$ e os resultados são mostrados na Figura 73 apresentam-se bastante similares aos da Figura 72. Ou seja, começa-se a estabelecer um padrão de comportamento, que poderá ser explorado, quando trabalhar-se com valores aleatórios. 


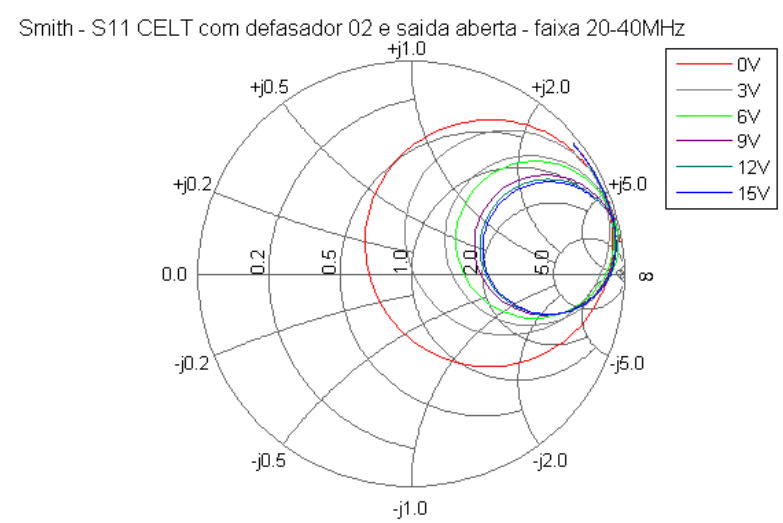

(a)
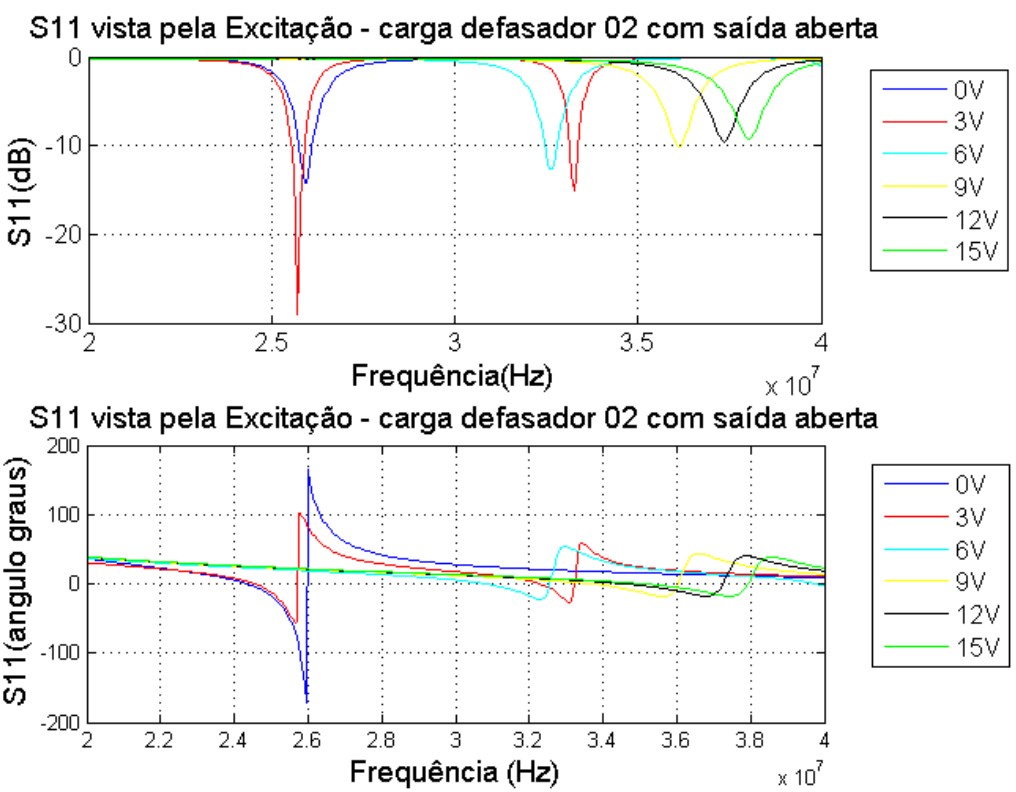

(b)

Figura 73 - Caracterização da câmara carga defasador 2 com saída aberta ( $20 \mathrm{MHz}-40$ MHz) (a) Carta de Smith (b) S11 Módulo e Angulo.

Para o terceiro defasador (mod. SO-05), os resultados mostrados na Figura 74 são ainda mais interessantes, pois as amplitudes chegam a apresentar três valores de mínimos, para uma só tensão de controle aplicada ao gerador (3V). Isto equivale a dizer que as impedâncias vistas pelo gerador aproximam-se em três oportunidades das impedâncias características do gerador (b). Ou seja, apesar de não haver um perfeito casamento de impedâncias, as potências injetadas dentro da câmara aumentam sensivelmente. 


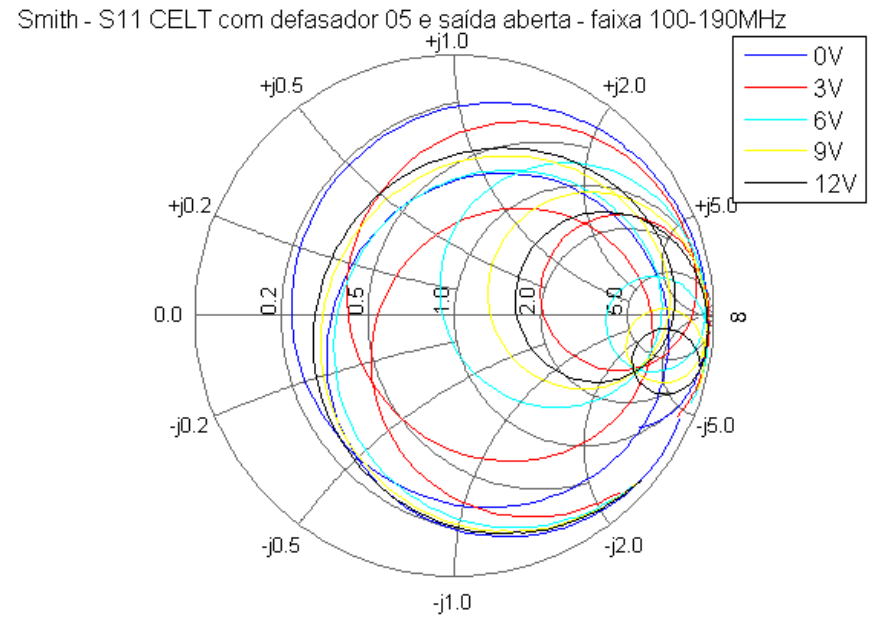

(a)
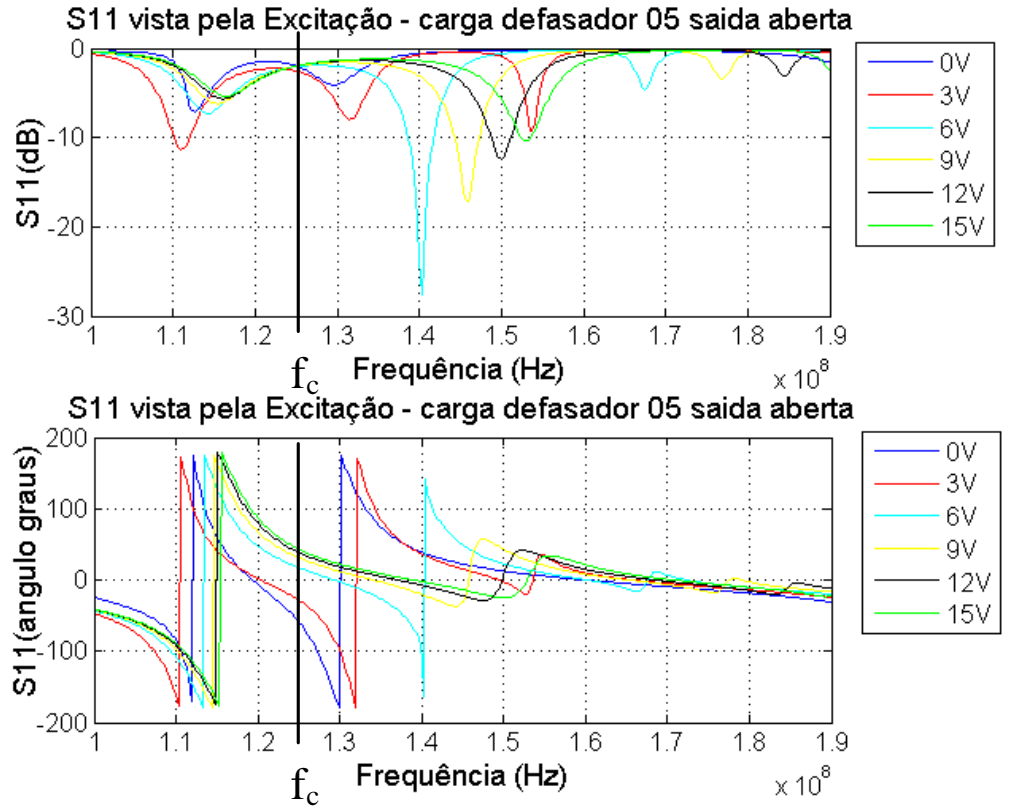

(b)

Figura 74 - Caracterização da câmara carga defasador 5 com saída aberta (100 MHz - 190 MHz) (a) Carta de Smith (b) Z11 Real versus Imaginário (c) S11 Módulo e Angulo.

Para o quarto defasador, os resultados são mostrados na Figura 75 e seguem o mesmo padrão, de variação ainda mais acentuada nos valores de impedâncias vistas pela excitação. 
Smith - S11 CELT com defasador 06 e saida aberta - faixa 150-250MHz

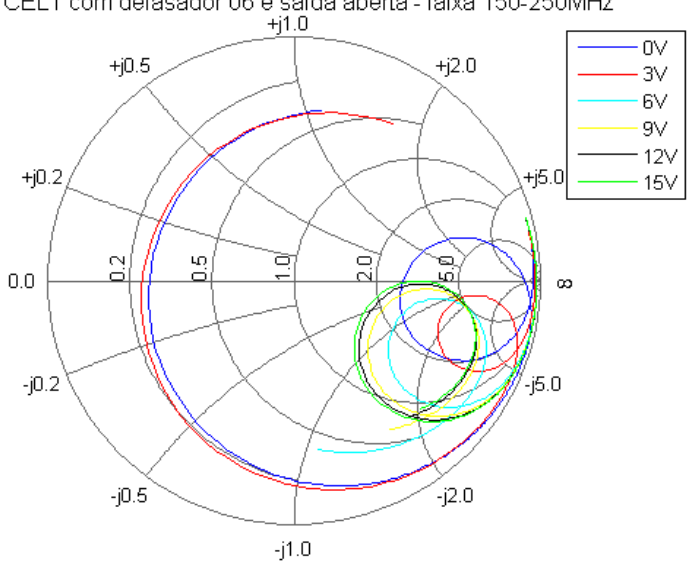

(a)
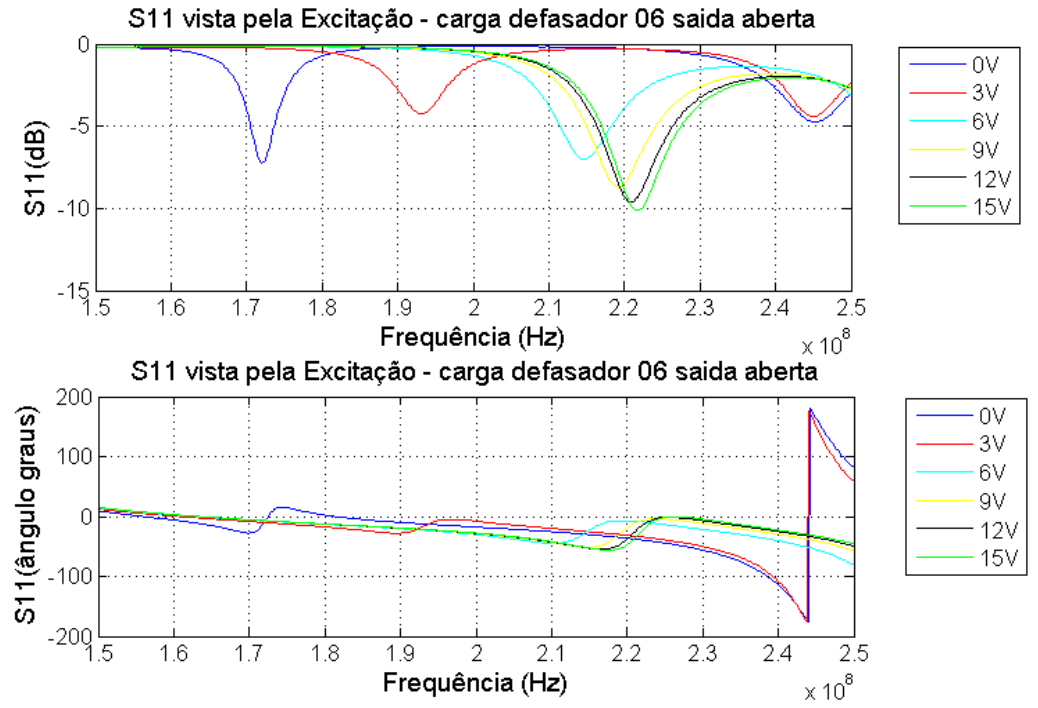

(b)

Figura 75 - Caracterização da câmara carga defasador 6 com saída aberta (150 MHz - 250 $\mathrm{MHz}$ ) (a) Carta de Smith (b) S11. 


\subsection{Otimização}

Os resultados foram obtidos com base nas simulações computacionais utilizando o modelo simplificado e aplicando as técnicas de Algoritmos Genéticos Mono (AGM) e Multi-objetivos (AGMO), de acordo com as técnicas descritas no item 3.5.

Considerando que uma configuração de CELT já foi analisada em termos modelagem numérica no CST-MWS $®$ em [25], [35] ela foi escolhida para aplicação de estudos otimização. Esta configuração aqui será denominada CELT "padrão" para diferenciar da CELT protótipo (analisada nos outros capítulos deste trabalho). Trata-se de uma sala blindada de dimensões ( $x=4,6 \mathrm{~m} ; \mathrm{y}=2,7 \mathrm{~m} ; \mathrm{z}=5,2 \mathrm{~m}$ ), com três linhas de transmissão ortogonais entre si. Esta configuração é considerada pelos autores citados como uma forte candidata a fornecer resultados satisfatórios em termos de campo elétrico médio e de desvio padrão em todas as direções. Uma vez estabelecido o método de otimização e apresentado à comunidade científica utilizando os resultados referentes à câmara "padrão", pode-se estender esta abordagem à outras dimensões de câmaras e configurações de linhas de transmissão. Para estas configurações da CELT foram adotadas as direções de eixos indicadas na Figura 76.

A sequência de simulações numéricas com aplicação das técnicas de otimização foi iniciada com um estudo aplicando-se o AGM (conforme descrito no item 3.5.3.1) e logo depois o AGMO (item 3.5.3.2), de forma a aumentar o conhecimento do comportamento da câmara e ajustar-se os parâmetros, tanto os do indivíduo, quanto os do método como um todo.

Em seguida, após a definição dos parâmetros a serem otimizados, foi iniciada a otimização livre da câmara, ou seja, a busca das configurações de linhas de transmissão que melhor pudessem satisfazer os requisitos de uniformidade de campo E. Iniciou-se esta aplicação com o método AGMO, conforme descrito no item 0 , definindo-se para um mesmo indivíduo parâmetros de posições das linhas de transmissão e também dos volumes de trabalho. Finalmente, foi implementado o 
método híbrido, que utiliza os métodos $A G M$ e AGMO em conjunto, em uma otimização em camadas, conforme descrito no 3.5.3.3.

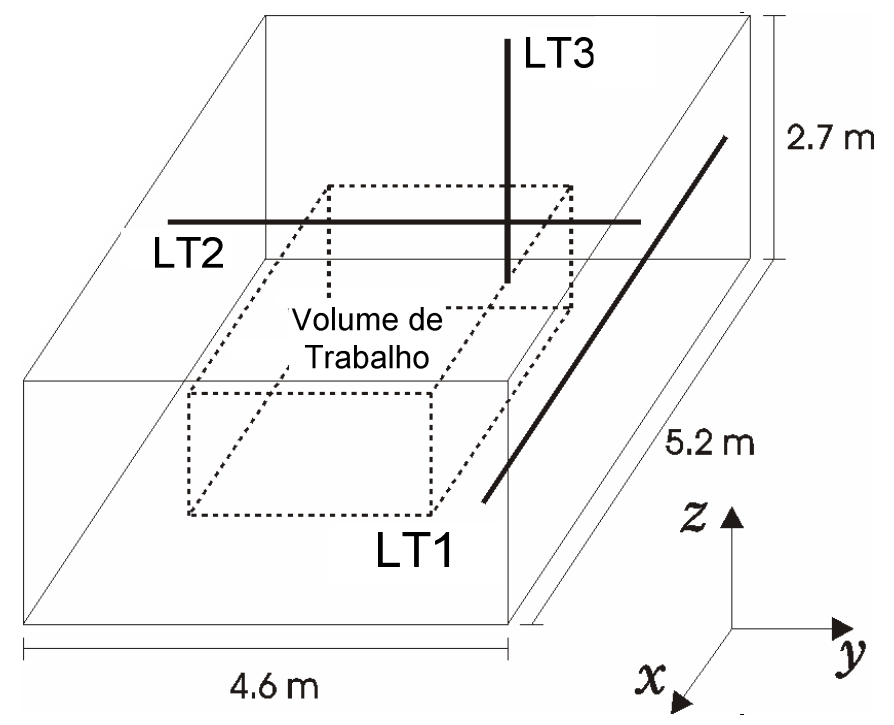

Figura 76 - Configuração da câmara com três condutores.

\subsubsection{Mono-objetivo}

A otimização mono-objetivo através de algoritmos genéticos aplicada à CELT descrita em [35] procura a maximização do volume de trabalho, com o atendimento de restrições como valor de campo $E\left(E_{\text {presc }}\right)$ e valores máximos de desvio padrão $\left.\sigma_{x}, \sigma_{y}, \sigma_{z}, \sigma_{x y z}\right)$. Esta abordagem foi publicada em [110], [113] e [114].

Algumas variáveis de otimização foram definidas e também seus limites, conforme a Tabela 4, para resolução da CELT mostrada na Figura 76. Lembrandose que, a fim de simplificar o tratamento dos dados, foi definido que a avaliação seria efetuada dentro de um elipsóide, ao invés de um paralelepípedo. O que foi analisado e verificou-se que não haveriam grandes distorções de valores, uma vez que as correlações de valores de campos $E$ médios e de desvios-padrão são aproximadamente lineares [111].

As equações (88) e (89) apresentam de forma sintética a função objetivo e as restrições utilizadas para cálculo e para as quais são apresentados os resultados seguintes. 
Max (Volume de Trabalho)

Sujeito a $\left\{\begin{array}{c}\bar{E}_{x, y, z}=E_{\text {presc. }} \\ \operatorname{Max}\left(\hat{\sigma}_{x}, \hat{\sigma}_{y}, \hat{\sigma}_{z}, \hat{\sigma}_{x, y, z}\right) \leq 4 \mathrm{~dB}\end{array}\right.$

Tabela 4 - Variáveis de otimização.

\begin{tabular}{|c|c|c|c|c|c|c|}
\hline & \multicolumn{3}{|c|}{$\begin{array}{l}\text { Raios dos eixos do } \\
\text { Elipsóide }\end{array}$} & \multicolumn{3}{|c|}{$\begin{array}{c}\text { Deslocamento do Centro da } \\
\text { Câmara }\end{array}$} \\
\hline & $\mathrm{X}$ & $\mathrm{Y}$ & $\bar{Z}$ & $\bar{x}$ & $\bar{Y}$ & $\bar{Z}$ \\
\hline Mínimo (m) & 0 & 0 & 0 & $-2,6$ & $-2,3$ & $-1,35$ \\
\hline Máximo (m) & 2,6 & 2,3 & 1,35 & 2,6 & 2,3 & 1,35 \\
\hline
\end{tabular}

A solução encontrada para o método mono-objetivo apresenta volume de trabalho $=1,81 \mathrm{~m}^{3}$, com um campo $\bar{E}_{x, y, z}$ de $1 \mathrm{~V} / \mathrm{m}$. Para este elipsóide resultante, os raios dos eixos foram encontrados e o deslocamento a partir do centro da câmara, e são mostrados na Figura 77 e Tabela 5.

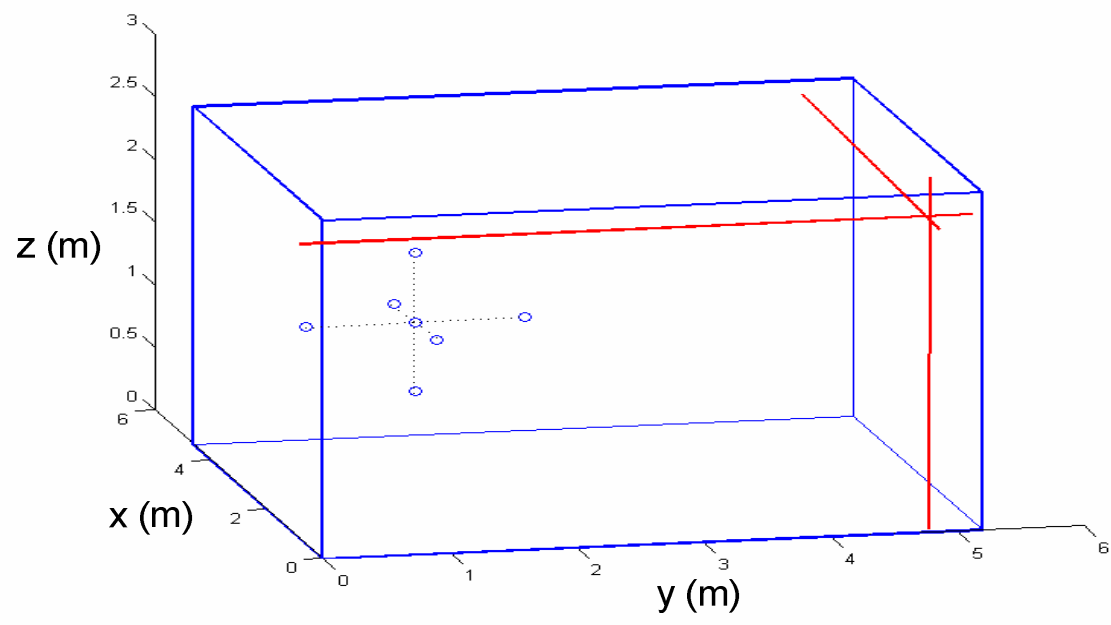

Figura 77 - CELT com posição dos eixos do elipsóide que atende às condições monoobjetivo. 
Tabela 5 - Características do Volume de Trabalho resultante mono-objetivo.

\begin{tabular}{lllll}
\hline & $\mathrm{X}$ & $\mathrm{Y}$ & $\mathrm{Z}$ & CoMBINADO \\
& & & & \\
\hline Campo E (V/m) & 0,73 & 1,16 & 1,10 & 1,0 \\
& & & & \\
\hline Desvio Padrão (dB) & 3,79 & 3,61 & 3,48 & 3,96 \\
& & & & \\
\hline
\end{tabular}

\subsubsection{Multi-objetivo}

Após a fase inicial de exploração dos comportamento dos resultados buscados na otimização da CELT, que foi efetuada aplicando-se o AGM ao problema da câmara, verificou-se que utilizando-se as mesmas variáveis, já definidas, poder-se-ia aumentar o número de objetivos, a partir da percepção de que poderiam existir vários volumes que atendessem à restrição de uniformidade, mas com valores diferentes de campos $\bar{E}_{x, y, z}$.

Então, a otimização multi-objetivos através de AGs foi aplicada à CELT descrita em [35], os resultados foram publicados em [110] e [113]. As equações (90) e (91) apresentam de forma sintética as funções objetivo e a restrição de uniformidade.

$$
\begin{gathered}
\left\{\begin{array}{r}
\text { Max Volume de Trabalho } \\
\operatorname{Max} \bar{E}_{x, y, z}
\end{array}\right. \\
\text { Sujeito a: } \operatorname{Max}\left(\hat{\sigma}_{x}, \hat{\sigma}_{y}, \hat{\sigma}_{z}, \hat{\sigma}_{x, y, z}\right) \leq 4 \mathrm{~dB}
\end{gathered}
$$

Obteve-se, então, uma curva de compromisso entre o volume de trabalho versus campo $\bar{E}_{x, y, z}$ dentro deste volume de trabalho, que atendessem à restrição de uniformidade, mostrada na Figura 78. 


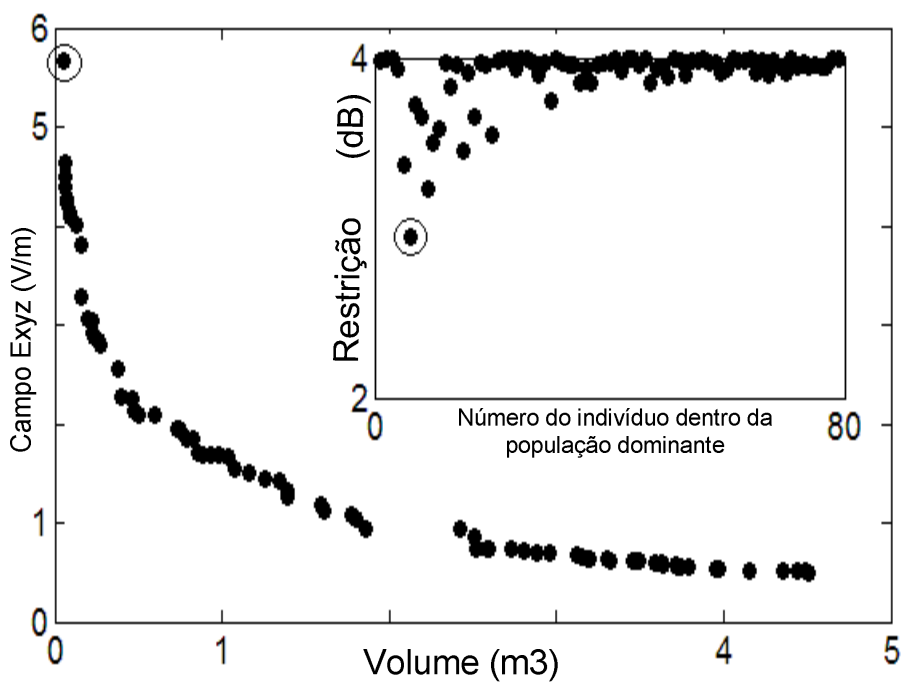

Figura 78 - Caracterização da câmara através da Fronteira Pareto.

Os resultados mostraram-se, como esperado, mais abrangentes do que a estratégia mono-objetivo inicialmente utilizada. As soluções encontradas, além de incluir as de volume e campo $E$ da solução mono-objetivo, incluem volumes menores com campos $E$ maiores, e vice-versa.

\subsubsection{Otimização da Posição das Linhas de Transmissão utilizando AGMO}

Conhecendo-se, então, a forma de cálculo do compromisso entre o volume de trabalho e o campo E para uma determinada configuração de linhas de transmissão na CELT, procurou-se implementar uma forma de busca que pudesse comparar as diversas configurações possíveis de linhas de transmissão.

Uma primeira estratégia de otimização utilizando AGMO em um único estágio foi implementada, conforme descrito no item 0 deste trabalho, e as variáveis de otimização passam a ser, então: posições das linhas de transmissão (6), raios dos volumes de trabalho (3) e posição do centro dos volumes de trabalho (3). Então, um problema AGMO com seis variáveis foi transformado em um problema de doze variáveis, e uma comparação sumária dos índices de mérito (índice LA) definidos para cada configuração de CELT foi feito.

Assim, esta abordagem foi utilizada, de forma a explorar as possibilidades do método para a CELT protótipo, devido a esta possuir um volume muito menor que a 
câmara padrão utilizada nos algoritmos de otimização e um resultado é mostrado na Figura 79.

Apesar das restrições de posição e desvios-padrão, a Figura 79 permite-nos verificar que é possível a obtenção de um volume de trabalho máximo levando em consideração um determinado nível de campo elétrico. Por exemplo, obtém-se aproximadamente $15 \mathrm{e} 10^{-3} \mathrm{~m}^{3}$ para um nível de campo $\mathrm{E}$ de $15 \mathrm{~V} / \mathrm{m}$. Lembrando que o volume total da câmara é de $0,432 \mathrm{~m}^{3}$.

Finalmente, avaliando-se o tempo de cálculo despendido neste método, optou-se pelo não prosseguimento desta abordagem.

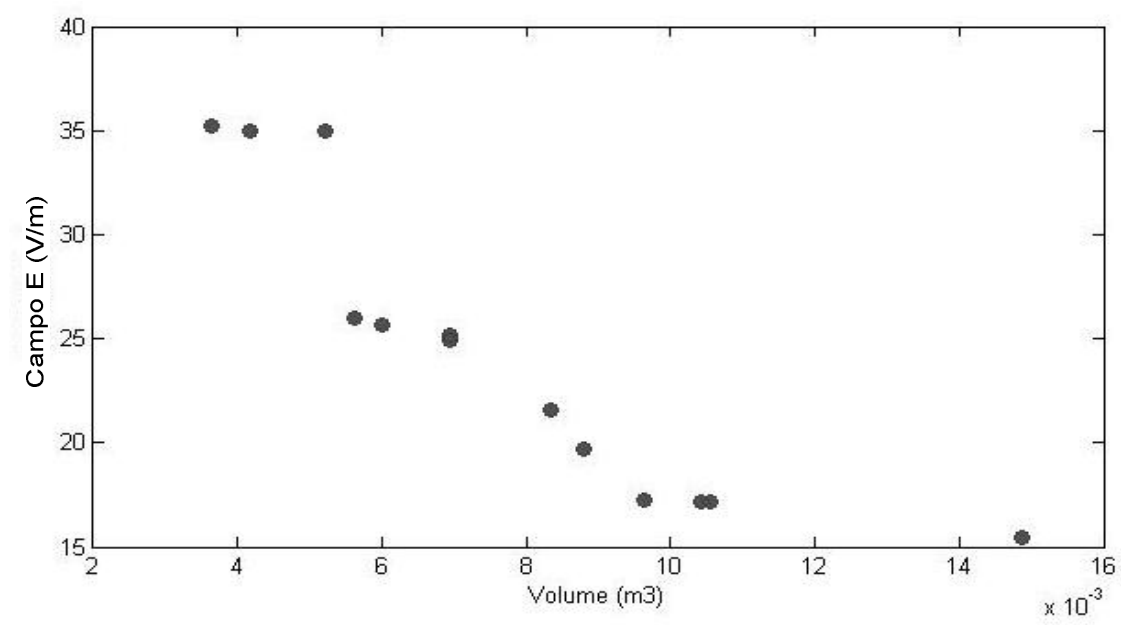

Figura 79 - Compromisso entre volume de trabalho e campo $E$.

\subsubsection{Otimização do arranjo de condutores (LT) - método híbrido}

Tendo em vista que o método anterior resultou em um tempo excessivo de cálculo e grande ineficiência na procura dos indivíduos mais aptos, ou seja, aqueles com maior valor do índice de mérito (índice LA), uma abordagem diferente foi proposta. A utilização do método AGM para o sorteio de posições das linhas de transmissão (poderia ser qualquer outro método de busca unidimensional, mas como não se tem uma boa estimativa inicial, optou-se pelo AGM), seguida da utilização do método AGMO, conforme item anterior, para a caracterização da CELT.

Esta estratégia foi implementada conforme descrito no item 3.5.3.3. 
Uma restrição extra foi inserida - limitações para a excursão de posição das linhas de transmissão. Assim, a Figura 80 mostra um diagrama genérico da CELT com um volume não-permitido às linhas de transmissão. Em primeiro lugar, cada linha de transmissão é posicionada paralelamente a um dos três eixos da câmara. Então, cada linha de transmissão poderá ser posicionada apenas nas regiões delimitadas em cinza, pois estas linhas não poderão estar perto demais das paredes, e se forem posicionadas no centro da câmara (volume controlado), poderá inviabilizar a aplicação prática da câmara. Ainda, é necessário considerar-se que as linhas de transmissão não podem se cruzar.

Assim, alguns casos foram simulados numericamente aplicando a estratégia híbrida. Aqui são mostrados um caso da câmara padrão $(x=4,6 \mathrm{~m} ; \mathrm{y}=2,7 \mathrm{~m} ; \mathrm{z}=$ $5,2 \mathrm{~m}$ ) e um caso da câmara protótipo ( $x=0,6 \mathrm{~m} ; \mathrm{y}=0,6 \mathrm{~m} ; \mathrm{z}=1,2 \mathrm{~m}$ ).

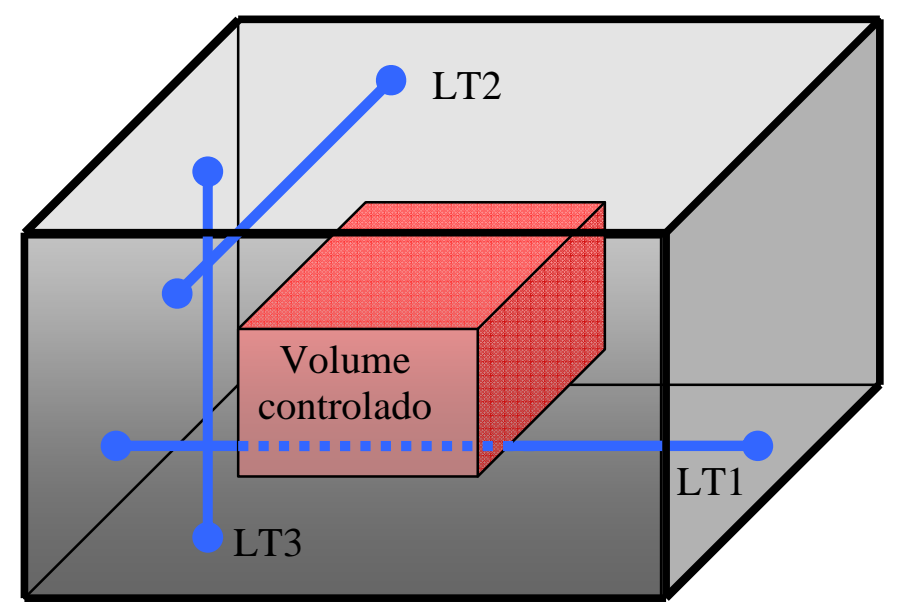

Figura 80 - Diagrama genérico da CELT com posições permitidas para as linhas de transmissão.

\subsubsection{Aplicação do método híbrido na câmara padrão.}

Em primeiro lugar é abordada a simulação numérica aplicando-se a otimização através do método híbrido na câmara padrão com a implementação de três linhas de transmissão ortogonais, como indicado na Figura 80, incluindo as restrições de posicionamento das linhas de transmissão ( $40 \%$ dos valores máximos em cada eixo interditadas no centro da câmara). Assim, são listadas algumas definições e métodos utilizados, por exemplo, quantidade de indivíduos por geração, número de 
gerações, elitismo, entre outros. Para concluir esta análise, são listados os resultados do melhor indivíduo.

Camada externa: Algoritmo Genético Mono-objetivo, aplicando a maximização (índice LA), com número de indivíduos por geração igual a 15; número de gerações igual a 15. Foram aplicadas as seguintes técnicas: seleção tipo torneio, adaptação de probabilidades e elitismo global. As probabilidade de cruzamento foi definida igual a $50 \%$ e a probabilidade de mutação igual a 50\%;

Camada interna: Algoritmo Genético Multi-objetivo, aplicando a maximização, com dois objetivos (Volume de Trabalho e Campo $\overline{\mathrm{E}}$ ) e restrição de desvio padrão menor ou igual a $4 \mathrm{~dB}$, com número de indivíduos por geração igual a 500, número de gerações igual a 15. Foram aplicadas as seguintes probabilidades: cruzamento igual a 50\%, mutação igual a $90 \%$.

Os resultados curvas de compromisso resultantes da última geração, que possui 15 indivíduos, do AG Mono-objetivo, são apresentados na Figura 81 (a). Foram indicados alguns indivíduos a título de exemplo, por exemplo: o arranjo 1, que possui um índice LA de 25,8; o arranjo 14 que possui o melhor índice LA desta geração $(28,76)$; e o arranjo 13 , que possui o pior índice LA $(\sim 1,0)$. Note-se que o arranjo 13 possui pequenos volumes e poucos pontos dominantes na Fronteira Pareto, quando comparado aos arranjos 1 e 14. Ainda, os maiores campos médios atingidos são da ordem de $3,5 \mathrm{~V} / \mathrm{m}$, e os maiores volumes da ordem de $14 \mathrm{~m}^{3}$. Considerando que o volume total da câmara é $60 \mathrm{~m}^{3}$, atinge-se cerca de $23 \%$ de área útil.

O melhor indivíduo teve um índice de qualidade ( $L A$, ou seja, área abaixo da curva da Fronteira Pareto) igual a 33,12 e as coordenadas das linhas de transmissão: LT1(x1 = 4,05 m; y1 = 0,62 m); LT2 (x2 = 3,85 m; z2=3.94 m); LT 3 (y3 $=2,06 \mathrm{~m} ; \mathrm{z3}=4,37 \mathrm{~m}$ ), ilustrado na Figura $81(\mathrm{~b})$. 

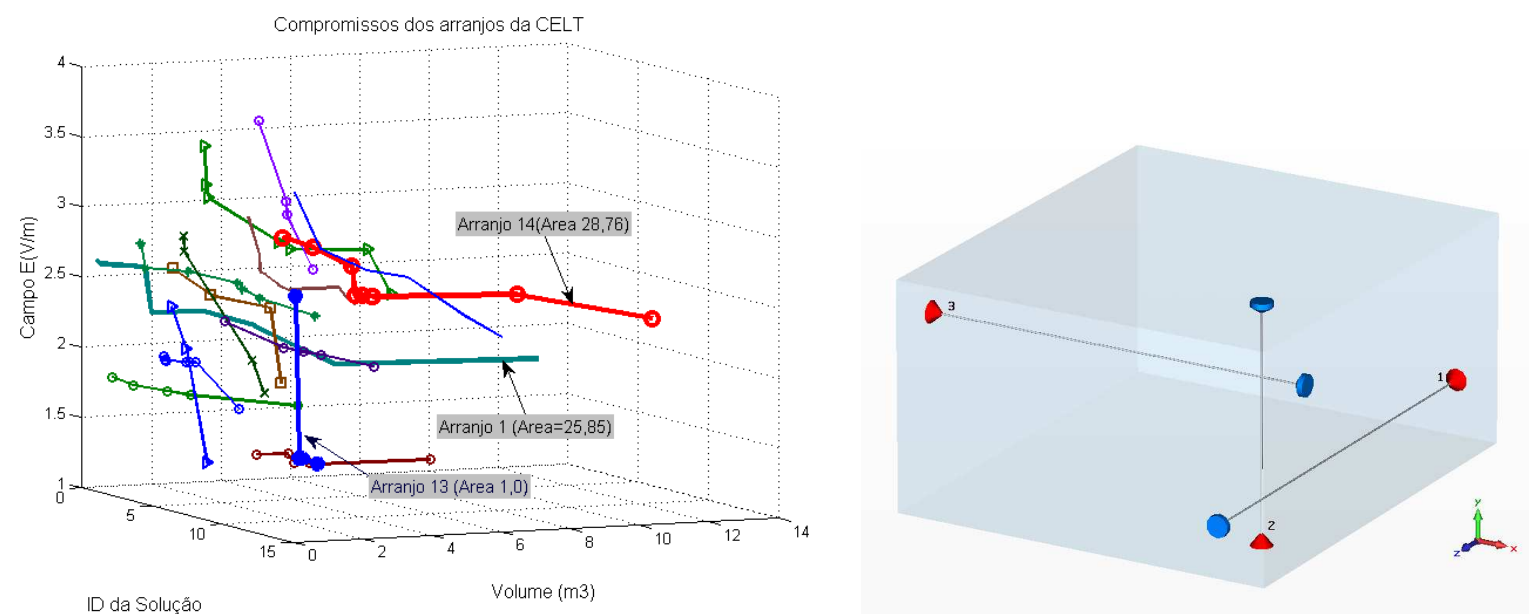

Figura 81 - Otimização híbrida da câmara "padrão"(a) Fronteiras Pareto (b )arranjo de Condutores com melhor índice $L A$.

\subsubsection{Aplicação do método híbrido de otimização na câmara protótipo}

Em segundo lugar, foi aplicado o método de otimização híbrido foi aplicado à CELT protótipo, que possui dimensões reduzidas ( $x=0,6 \mathrm{~m} ; y=0,6 \mathrm{~m}, z=1,2 \mathrm{~m}$ ), com a implementação de três linhas de transmissão ortogonais, como indicado na Figura 80, incluindo as restrições de posicionamento das linhas de transmissão ( $40 \%$ do valor máximo em cada eixo no centro da câmara). Lembrando-se que a restrição de desvio padrão para uniformidade dentro dos volumes de trabalho é de 4 $\mathrm{dB}$.

Apresenta-se na Figura 82 (a) os resultados das curvas de compromisso resultantes de uma geração do AG mono-objetivo, a título de ilustração, e em seguida são listados as características do melhor indivíduo, após 20 gerações do processo mono-objetivo. Nota-se que foram geradas caracterizações pobres da CELT no estágio AGMO, e consequentemente distorcendo as áreas abaixo da Fronteira Pareto. Por outro lado, devido às pequenas dimensões da câmara, os campos $\mathrm{E}$ médios atingidos chegam a valores maiores na câmara protótipo do que na câmara padrão, com pequenos valores de volume. 


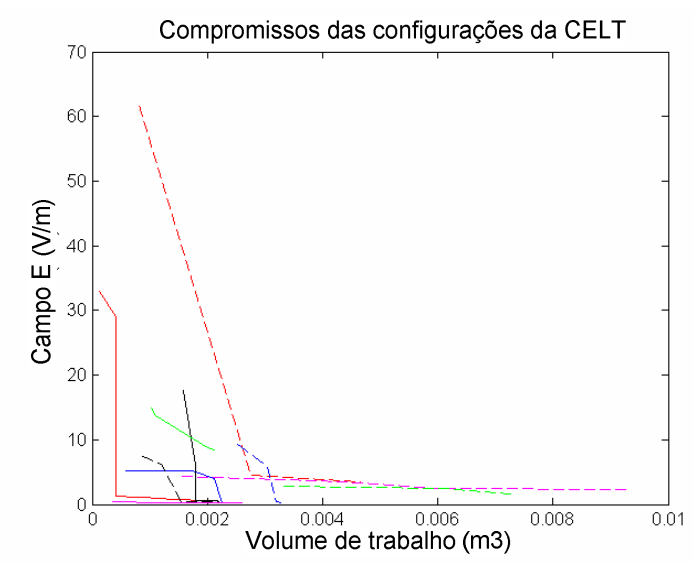

(a)

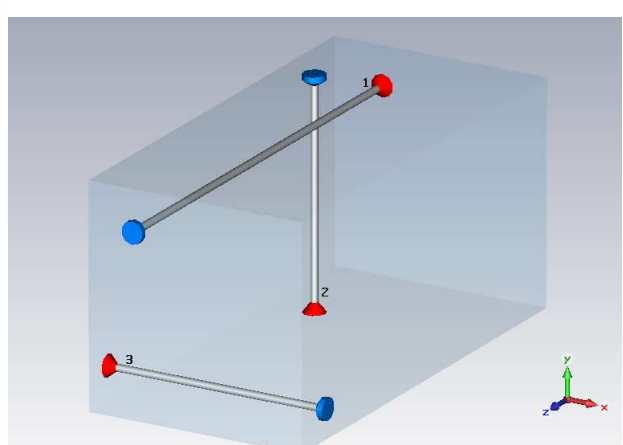

(b)

Figura 82 - Otimização híbrida da CELT protótipo (a) Fronteiras Pareto (b) melhor configuração de linhas de transmissão.

O melhor indivíduo tem como características, as seguintes posições das linhas de transmissão: LT1 $(x 1=0,129 \mathrm{~m} ; \mathrm{y} 1=0,49 \mathrm{~m})$; LT2 (y2 = 0,11 m; z2 = 0,29 m); LT3 $(x 3=0,08 \mathrm{~m} ; \mathrm{z3}=1,09 \mathrm{~m})$, Figura $82(\mathrm{~b})$, com índice de mérito (LA) igual a 0,099197 . 


\section{DISCUSSÃO}

Nesta seção será efetuada uma discussão sobre os resultados obtidos, inicialmente fazendo uma comparação entre os efeitos previstos analiticamente e os obtidos nos resultados das simulados numericamente. Na sequência comentam-se os resultados das simulações numéricas em comparação com os resultados experimentais. Os possíveis causadores de desvios, entre a gama de resultados apresentados neste trabalho são indicados e comenta-se quais as ações tomadas para diminuí-los. Finalmente, a eficácia da estratégia de otimização e sua aplicação na avaliação e comparação entre diferentes configurações de câmaras reverberantes é comentada.

Em primeiro lugar, destaca-se que, quando é analisado somente o efeito isolado da cavidade com as dimensões do protótipo da $\operatorname{CELT}(0,6 \mathrm{~m} \times 0,6 \mathrm{~m} \times 1,2 \mathrm{~m})$, a análise modal prevê que a primeira frequência de ressonância é $125 \mathrm{MHz}$. Nota-se que este valor refere-se a uma cavidade preenchida com dielétrico perfeito (vácuo) e que, acima desta frequência, os modos propagantes produzidos são TE ou TM, tomando a forma de ondas estacionárias dentro da cavidade. Neste caso, não há modos propagados abaixo de $125 \mathrm{MHz}$, somente modos atenuados, conforme analisado no item 2.4.1.

Por outro lado, relembra-se que uma linha de transmissão produz modos de propagação TEM em todo o espectro de frequência. Quando se aplica cargas não casadas no final da linha de transmissão, ocorrerão reflexões na linha de transmissão e, como consequência, uma onda estacionária será criada, conforme item 2.5.

Assim, com a introdução de linhas de transmissão em uma cavidade contendo um dielétrico perfeito, os efeitos da linha de transmissão e da cavidade se superpõem. Quando a carga e a linha de transmissão estão perfeitamente casadas, ou seja, não há reflexão na linha, o efeito da cavidade é preponderante e as ondas estacionárias serão geradas somente pelas frequências ressonantes, o que ocorre somente acima da frequência fundamental da cavidade. 
Quando a carga e a linha de transmissão estão descasadas, o efeito da linha de transmissão será preponderante e uma onda estacionária TEM será criada para toda a faixa de frequências entre a corrente contínua e a frequência de corte da câmara. Quando a frequência de operação encontra-se acima da frequência de corte, ocorrerão reflexões devido ao descasamento de impedâncias e também reflexões dentro da cavidade ressonante, em superposição.

Note-se que a abordagem teórica consegue fornecer os subsídios para as afirmações anteriores. Mas observando os resultados apresentados nas seções 2.4 e 3.2 nota-se que a limitação dos métodos analíticos é rapidamente alcançada, pois a abordagem teórica limita-se a modelar os modos existentes dentro de uma câmara preenchida com dielétrico perfeito, ou modelar linhas de transmissão finitas. Quando há a superposição de efeitos, como ocorre com a CELT, outras abordagens analíticas adicionais seriam necessárias, por exemplo a dedução de funções de Green ou métodos semi-analíticos adequados às configurações sob análise. Como exemplo de trabalhos utilizando estes métodos (bem sua utilidade em casos específicos), destaca-se um estudo efetuado por Hill [10] através de um modelo analítico bidimensional de uma câmara excitada por linhas de transmissão, considerando duas linhas de transmissão paralelas e variação eletrônica da excitação, concluindo que não se alcançaria o critério de uniformidade em uma determinada área dentro da câmara, mas não se atendo ao volume de trabalho ou efeitos das cargas nas linhas de transmissão. Em outro trabalho Voyer [119] aplicou um método semi-analítico incluindo quatro linhas de transmissão paralelas e variação de amplitudes e defasagens na excitação da câmara, concluiu que era possível obter a uniformidade em uma área dentro da câmara.

Porém, quando outros efeitos são incluídos, tais como o descasamento de impedâncias nas cargas, em conjunto com as defasagens na excitação, é necessária a utilização da modelagem e simulação numérica que, além de permitir obter os valores dos campos eletromagnéticos na CELT, possibilita alterações de parâmetros (amplitude de excitação, valores de cargas, defasagens das excitações, dimensões da cavidade), desde que o modelo numérico esteja bem ajustado à 
realidade. Ainda, outros parâmetros, tais como os parâmetros S, podem ser avaliados a partir das simulações numéricas.

Trabalhos anteriores efetuaram a modelagem tridimensional da CELT utilizando vários métodos numéricos, tais como, MoM (Perini [23]-[25]), TLM (Weinzierl [34]) e FIT (Weinzierl [35]). Apesar de alguns trabalhos de Perini indicarem os resultados simulados e experimentais com a aplicação de defasagens em combinações de noventa graus, não fica patente nesses trabalhos o detalhamento dos efeitos das cargas, ou a consideração estatística (ou seja, aplicação de valores aleatórios) das defasagens, das amplitudes de excitação ou das cargas das linhas de transmissão. Nos trabalhos efetuados por Weinzierl, foi explorada a validação de diversos modelos e métodos numéricos, além de configurações alternativas (como três linhas de transmissão ortogonais entre si).

Algumas das lacunas e contradições apontadas pelos trabalhos anteriores foram analisados neste trabalho como, por exemplo, a verificação da uniformidade no volume de trabalho através de modelos numéricos. Ainda, ressalta-se a verificação dos efeitos da variação das defasagens e cargas na resposta em frequência. Estas e outras questões nos motivaram a prosseguir com estes estudos aplicando uma ferramenta computacional que pudesse prover estas informações.

Assim, a modelagem tridimensional apresentada da neste trabalho foi efetuada com o método FIT, utilizando-se o CST-MWS® e teve por finalidade ressaltar os efeitos predominantes na CELT abaixo da frequência de corte da cavidade.

Então, observou-se que os efeitos predominantes seriam os das linhas de transmissão, com a produção de uma onda estacionária aliada a uma condição de campo quase-TEM, que foi chamado de operação modo único ou "single moded", conforme mostrado no item 4.1.2. Ressalta-se que este ponto foi fundamental durante a fase de ensaios práticos, pois já havia uma boa estimativa dos resultados que deveriam ser obtidos, permitindo-se o ajuste do conjunto de testes visando obter repetibilidade e confiabilidade. 
Enfatiza-se que através da análise dos resultados das simulações numéricas, foi notado que a resposta em frequência se altera, bem como o campo resultante no espaço, de acordo com a carga aplicada ao final das linhas de transmissão. Isto indica que uma nova configuração pode ser utilizada, visando melhorar os índices de mérito da câmara. Diversas simulações visando a análise das ondas estacionárias resultantes, de acordo com a carga aplicada na linha de transmissão foram realizadas, e observa-se que este efeito permite potencializar a mistura dos campos EM na câmara, conforme mostrado no item 4.3.3.

Note-se que com a aplicação do método numérico escolhido, ocorre a limitação referente ao número de células do problema (consequentemente influi-se no tempo de processamento despendido para cada simulação) e pela fidelidade do modelo ao efeito físico. Esta limitação, finalmente, torna-se uma disputa entre os dois compromissos (exatidão e tempo despendido), conforme observado nos modelos simplificado e detalhado apresentados nas seções 2.7 e 3.2 .

Então optou-se pela análise utilizando o modelo detalhado quando eram necessárias poucos acessos ao programa de cálculo de campos eletromagnéticos (por exemplo nas comparações diretas com resultados experimentais). Por outro lado, quando foi necessário um grande número de acessos ao programa de cálculo de campos, foi feita a opção pelo modelo simplificado (por exemplo para o cálculo dos efeitos da aplicação de defasagens na excitação). Ocorre uma distorção nos resultados entre estes modelos, que é notada próxima às paredes metálicas e que não compromete as avaliações de uniformidade, que ocorrem principalmente nas regiões centrais da câmara.

Nos ensaios, uma faixa de frequências de trabalho foi estabelecida, entre $10 \mathrm{MHz}$ e $250 \mathrm{MHz}$, devido à limitações dos equipamentos de medida existentes, e devido à característica dos campos elétricos na região "single moded". Na verdade, a faixa de trabalho abaixo dos $80 \mathrm{MHz}$, acaba despertando a atenção, pois é o limite inferior da norma [4] para funcionamento de câmaras reverberantes excitadas por pás misturadoras. Este fato gerou a motivação de criação desta nova concepção de 
câmara, que visa suprir a deficiência das câmaras canônicas em frequências abaixo dos $80 \mathrm{MHz}$.

$\mathrm{Na}$ comparação entre os resultados obtidos com os ensaios do protótipo e o modelo numérico, inicialmente notou-se algumas diferenças significativas quando se tratava de valores absolutos de campo elétrico. Quanto aos valores de frequência de ressonância, estes mantinham-se bastante próximos. A análise dos valores de campo elétrico utilizando a parametrização pelos máximos valores observados, que é uma abordagem utilizada na literatura [34], foi adotada e os valores passaram a se mostrar bastante satisfatórios, com um pequeno desvio nos valores de frequência de ressonância, quando a LT da CELT estava aberta. Este efeito pode ser causado pela presença de dielétricos não perfeitos dentro da câmara, tais como a antena de medição e o suporte da antena. Ainda, notou-se que a utilização de antenas para a medida de altas frequências pode gerar uma série de incertezas sobre as medições, devido a diversos fatores relacionados ao tamanho da antena, calibração, etc.

A opção de utilização de defasadores controlados por tensão apresenta-se, como uma opção para variação do perfil do campo, conforme já indicado por Perini [24] e [25]. Mas os defasadores adquiridos para este objetivo, vide APÊNDICE C, entraram em sobrecarga durante os ensaios de medida de campo elétrico gerado com defasagem na excitação e não resultaram em dados conclusivos.

A literatura ressalta a importância da utilização do analisador de rede vetorial para a realização de medidas de parâmetros em altas frequências, sobretudo em câmaras de testes em que a disponibilidade de antenas eletricamente pequenas não seja possível. Esta abordagem foi utilizada em câmaras reverberantes convencionais pela equipe de Corona em vários trabalhos [17] - [22] e em câmaras TEM por Klingler [39]. Assim, decidiu-se adaptar estes procedimentos para aplicação na CELT.

Uma vez que as medidas dos parâmetros $S$ mostram-se adequadas à caracterização de dispositivos, uma nova sequência de ensaios foi realizada, caracterizando-se experimentalmente a câmara via parâmetros S. 
Então, comparando-se os resultados de parâmetros [S] medidos com os resultados das simulações numéricas, verificou-se uma aderência quase que perfeita das curvas, em praticamente todos os casos. O único caso em que as medidas não foram coincidentes com os resultados simulados foi no acoplamento entre as linhas de transmissão (S12), nos quais as medidas situaram-se entre -40 $d B$ e -60 dB, ou seja, considera-se que as linhas de transmissão não interferem entre si. Então, os efeitos da carga descasada mostram-se predominantes na forma da onda estacionária e na posição do valor de máximo campo E. Assim, existem valores de carga (real e imaginária) que geram uma transmissão máxima de potência, em uma estreita faixa, o que foi verificado pelas medições de S11.

Procurou-se, então, uma configuração experimental que pudesse preencher os requisitos de carga variável e controlável. Esta configuração utilizaria os defasadores como carga variável, controlável eletronicamente, com a intenção de alterar as posições de máximos e mínimos das ondas estacionárias na câmara e os resultados foram mostrados no item 4.5.2.4.2. Analisando-se um dos resultados mais interessantes, que é aquele referente à câmara com o defasador 05 na saída e carga aberta (Figura 74), notou-se que os valores de mínima perda por retorno Abs (S11), poderiam ser excursionados por toda a faixa de frequência, com a variação ampla em função da tensão de controle do defasador. Os resultados obtidos demonstram que a variação de impedâncias é bastante elevada, refletindo-se nos perfis de campo elétrico.

É importante notar que existe uma grande dificuldade para garantir o controle e a precisão de medidas, quando se trata de ensaios em alta frequência. Neste caso vários efeitos podem ser superpostos, tais como a variação das características de componentes com a frequência, etc. Desta forma, é essencial a caracterização minuciosa de todos os componentes envolvidos no ensaios. Ainda, possíveis fontes de imprecisões nas medidas foram removidas das configurações de teste ou alteradas, como exemplo, menciona-se a avaliação cuidadosa do dispositivo utilizado como carga, visando obter resultados experimentais precisos para as configurações pré-definidas e controladas. O grande problema encontrado na utilização de cargas para o casamento de impedâncias é de que os componentes 
devem ter valores estáveis em uma grande faixa de frequências, o que se torna extremamente difícil, mesmo utilizando-se componentes de especificação militar. Então a avaliação criteriosa das cargas foi necessária, pois os resultados das pesquisas anteriores [23]-[25], de outros autores, geravam uma série de indefinições e dúvidas nos procedimentos de ensaio, culminando em resultados obtidos que dificilmente poderiam ser utilizados. Neste caso, somente a consulta direta aos pesquisadores envolvidos nos ensaios anteriores permitiria a utilização destes.

Outra vertente de nosso trabalho, foi o da otimização da CELT. Estes estudos tiveram por objetivo maximizar os índices de mérito relativos à homogeneidade de campo elétrico na CELT. Desta forma, incentivados pelos resultados alcançados nas análises numéricas, iniciaram-se estudos de aplicação de algoritmos visando à implementação de uma metodologia própria para a avaliação do máximo volume útil de trabalho que atendesse a requisitos de uniformidade que foram descritos na norma internacional de câmaras reverberantes (desvio padrão do campo elétrico, valor médio do campo elétrico, etc.) [4].

Em um dos trabalhos mais relevantes encontrado na literatura, Clegg [59] trata da otimização aplicado às câmaras reverberantes com pás misturadoras utilizando algoritmos genéticos para otimização das eficiência dos misturadores, através da avaliação da alteração promovida no vetor de Poynting por cada configuração de misturadores. Para o cálculo de campos dentro da câmara reverberante utilizou o método numérico TLM. Este trabalho nos mostrou uma possibilidade de utilização das ferramentas disponíveis FIT e AG para aplicação na CELT. Outros métodos de otimização, tais como os determinísticos [98], não se adaptavam às soluções possíveis do problema da CELT, tais como existência de vários pontos de máximos ou mínimos, imprevisibilidade à priori do comportamento do sistema e indefinição do critério de comparação entre configurações.

Então, a otimização das configurações das CELT tem início através da aplicação de AGs no processo de busca da melhores soluções de volume de trabalho versus valor médio de campo elétrico no espaço da câmara. Observou-se que as melhores localizações do volume de trabalho não se encontravam no centro da câmara. 
Utilizou-se, então, o AG multi-objetivos para caracterizar os compromissos de campos E médio versus volume de trabalho, gerando uma Fronteira Pareto para cada configuração de linhas de transmissão. Propôs-se utilizar a área abaixo da curva da Fronteira Pareto como índice de mérito para comparação entre as diversas configurações de linhas de transmissão, este índice foi denominado LA. Em seguida foi proposto um método híbrido, utilizando AG mono-objetivo como camada externa (onde seriam determinados os melhores arranjos de linhas de transmissão, comparando-se os índices LA) e um AG multi-objetivos como camada interna (para procura dos indivíduos com as melhores características, ou seja, dos melhores índices LA). Nota-se que os AGs não necessitam de estimativa inicial para fazer a procura dos pontos ótimos do sistema, mas por outro lado, possuem baixa exatidão. Como complemento à essa metodologia um método determinístico poderia ser utilizado, a partir destes resultados, de forma a aumentar a exatidão da otimização.

Assim, diversos trabalhos foram e estão sendo publicados visando divulgar e submeter à avaliação da comunidade científica os resultados relativos à otimização do arranjo de condutores da câmara obtidos até este momento [110]-[118].

\subsection{Trabalhos futuros}

Nesta seção são indicados algumas possibilidades de continuidade dos trabalhos de desenvolvimento da CELT. Inicia-se pela análise numérica e aplicações em otimização, em seguida apresentam-se as propostas para a análise experimental, e, finalmente, uma proposta de trabalho de integração da análise dos dados numéricos e experimentais.

Na área de modelagem numérica, poderia ser efetuada a inserção dos dados experimentais sobre a impedância dos defasadores nos modelos numéricos, coletados na forma de arquivos ASCII, gerando dados para análise estatística. Ainda, poderia-se prever a implementação de rotinas para cálculo de dispositivos em cascata utilizando-se os parâmetros $S$ de forma a prever os resultados (isso também depende da maior análise do tratamento analítico dos parâmetros $S$ em cascata); 
Na parte de otimização, pode-se propor a aplicação de estratégias de otimização para melhorar os efeitos de carga na uniformidade dos campos E na CELT, além de implementar-se um terceiro nível na estratégia híbrida, desta vez sequencial após a finalização dos AGs, utilizando-se métodos determinísticos, de forma a aumentar a exatidão do cálculo.

$\mathrm{Na}$ parte experimental uma das possibilidades de trabalhos futuros, seriam estudos visando adequar as impedâncias de entrada da CELT, o que maximizaria a injeção de potência.

Outra proposta de pesquisa seria a implementação de carga variável, sincronizada com a excitação, com o objetivo de controlar as reflexões na câmara e melhorar os índices de uniformidade no volume de trabalho.

Ainda outra contribuição futura refere-se à aplicação de microprocessadores para controle dos defasadores, com o objetivo de utilizar as curvas características de resposta ângulo versus frequência relacionada à tensão de referência, que foram levantadas experimentalmente. A implementação de uma função de ângulo de saída (correspondendo ao sinal de tensão de referência em função da frequência de trabalho) para cada um dos defasadores poderá ser realizada e implementada à simulação.

No protótipo propriamente dito, poderia ser implementada a configuração otimizada em posição e ensaiada de acordo com os procedimentos já estabelecidos, de forma a se analisar os ganhos obtidos efetivamente com a otimização.

$\mathrm{Na}$ integração da análise numérica e experimental, poderia ser implementada a análise direta aplicando parâmetros $\mathrm{S}$, entre MatLab, dados experimentais e CSTMWS. Isto é possível através de "toolbox" do Matlab e, também, da importação de dados direta do CST-MWS. Todos os programas (Matlab e CST-MWS) e equipamentos (VNA) são capazes de trabalhar com arquivos do tipo "Touchstone", que formata os dados de parâmetros $S$. 


\section{CONCLUSÕES}

Inicialmente, cita-se que durante o desenvolvimento da CELT, diferentes configurações foram analisadas e comparadas, e diferentes métodos de cálculo, ferramentas e abordagens foram aplicados, incluindo-se as simulações por métodos numéricos (FIT), otimização (algoritmos genéticos), além de ferramentas analíticas e métodos experimentais.

Menciona-se, também, a inclusão de configurações com variação das defasagens e das amplitudes dos sinais de excitação (que podem ser controlados eletronicamente, por exemplo com defasadores controlados por tensão), como parte dos nossos estudos, e a avaliação prévia da uniformidade do campo E, através das simulações numéricas tridimensionais.

Uma primeira constatação é de que uma contribuição significativa pode ser observada ao se analisarem os resultados simulados através de métodos numéricos. A proposta de se utilizar defasagens na excitação da CELT foi analisada na ferramenta de simulação numérica tridimensional desenvolvida e, numa análise preliminar, a contribuição para variações dos valores máximos e no perfil do campo E não foi significativa. Porém em uma análise mais apurada, incluindo diversas configurações de linhas de transmissão, permite-nos concluir que a utilização dos defasadores na excitação da câmara, com defasagens aleatórias entre as fases das linhas de transmissão, e variação aleatória da amplitude da excitação podem alcançar e exceder os valores recomendados de desvio padrão previstos nas normas internacionais, para tipos similares de câmara. Outros estudos teóricos e de simulação computacional desenvolvidos indicam que uma nova configuração poderia utilizar os defasadores como carga variável, controlável eletronicamente visando melhorar os índices de mérito da câmara. Desta forma, conclui-se pela viabilidade teórica da câmara.

Com relação à análise experimental, foram consolidados procedimentos específicos e detalhados para execução dos experimentos. Devido à inexistência de 
literatura específica para testes da CELT proposta, e de procedimentos padronizados de forma a criar repetibilidade, além de disponibilizar resultados para os grupos interessados em pesquisar CELTs. Ressalta-se, então, como uma das grandes preocupações deste trabalho, o estabelecimento de procedimentos e rotinas, que pudessem ser reproduzidas tanto em testes, quanto nas simulações numéricas.

Dos resultados experimentais conclui-se que os efeitos preponderantes na resposta em frequência para a faixa de frequências abaixo da primeira frequência de ressonância da cavidade são os efeitos devidos às linhas de transmissão, em consonância com a previsão dos modelos numéricos.

A defasagem eletrônica dos sinais de entrada foi testada experimentalmente e os resultados não apresentaram o impacto esperado na variação do campo elétrico. Os defasadores utilizados foram sobrecarregados, gerando a degradação dos mesmos, portanto o ensaio não foi conclusivo e os resultados não foram apresentados neste trabalho. Por outro lado, a utilização dos defasadores como carga variável mostra que é possível a variação controlada das posições de máximos dentro da câmara e demonstra a viabilidade experimental da câmara.

Nota-se, que as atividades desta pesquisa proporcionaram o desenvolvimento de outros trabalhos teóricos, tais como os relacionados à otimização da configuração do arranjo físico das linhas de transmissão da CELT. Menciona-se que estes estudos de otimização contribuíram para uma melhor compreensão do sistema, tais como quais seriam os parâmetros mais relevantes de projeto. Assim considerou-se que um parâmetro de projeto determinante seria o posicionamento das linhas de transmissão. Também foram definidos quais os compromissos que deveriam ser buscados de forma a caracterizar um bom desempenho da câmara, sendo definidos o campo E médio e o desvio padrão. Ainda, como contribuição significativa deste trabalho, foi criado o índice de mérito LA (definido como a área abaixo da Fronteira Pareto para comparação entre as configurações de CELT.

Em suma, a CELT é um sistema capaz de produzir modos quase-TEM dentro de uma cavidade com paredes condutoras, mesmo abaixo da primeira frequência de 
ressonância, e ainda , caso a impedância característica da linha de transmissão seja diferente da carga e da excitação, uma onda estacionária cujo efeito é similar ao de uma única frequência ressonante dentro de uma cavidade vazia. Por isso pode-se denominar este modo de propagação de "modo ressonante de uma única frequência" ou simplesmente "modo único". Ainda, nesta faixa de frequência, o efeito das paredes condutoras que atuam como blindagem, resultam em campos dentro da câmara decorrentes da superposição de vários campos independentes. Assim, de acordo com a posição e a impedância das linhas de transmissão, obtémse ondas estacionárias cujas características variam de acordo com a faixa de frequência de trabalho, defasagem da excitação e condição de carga.

Portanto, verificando-se o desenvolvimento teórico, os resultados simulados e experimentais apresentados neste trabalho, conclui-se que a CELT pode alcançar os critérios de uniformidade estatística para frequências abaixo da frequência de corte da cavidade e, consequentemente, é uma alternativa que supre as deficiências das câmaras padronizadas. 


\section{BIBLIOGRAFIA}

[1] PAUL, C. R. Introduction to Electromagnetic Compatibility. First Edition. John Wiley \& Sons, 1992.

[2] Safety Guide NS-G-1.3 - Instrumentation and Control Systems Important to Safety in Nuclear Power Plants - International Atomic Energy Agency IAEA. Vienna. 2002.

[3] Regulatory Guide 1.180 - Guidelines for Evaluating Electromagnetic and Radiofrequency interference in safety-related instrumentation and control systems, US Nuclear Regulatory Commission (USNRC).Washington/DC. 2003.

[4] INTERNATIONAL ELECTROTECHNICAL COMMISSION STANDARDS FROM ANSI. IEC61.000-4-21: Electromagnetic Compatibility (EMC) - PART 4-21: Testing and Measurement techniques- Reverberation chamber test methods. 2003.

[5] MIL-STD-461E - Requirements for the Control of Electromagnetic Interference Characteristics of Subsystems and Equipment - U. S. Department of Defense. Washington-DC. 1999.

[6] Digital Instrumentation and Control Systems in Nuclear Power Plants Safety and Reliability Issues - National Research Council - National Academy Press, Washington, D.C. 1997.

[7] ISO 11452-11 - Road vehicles - Component test methods for electrical disturbances from narrowband radiated electromagnetic energy - Part 11: Radiated immunity test method using a reverberation chamber (draft).

[8] IEC 61000-4-3, "Electromagnetic Compatibility (EMC) - Part 4: Testing and Measurement Techniques, Section 3: Radiated, Radio-Frequency, Electromagnetic Field Immunity Test," International Electrotechnical Committee, 1995.

[9] MENDES, H. A. A new approach to electromagnetic field-strength measurements in shield enclosures. Westcon Technical Papers - Western Electronic Show and Convention, Los Angeles, USA, 1968.

[10] HILL, D. A. A reflection coefficient derivation for the $Q$ of a reverberation chamber. IEEE Transactions on Electromagnetic Compatibility, v. 38, n. 4, p. 591-592, 1996.

[11] LADBURY, J.M.; KOEPKE, G. H.; CAMELL, D. G. Improvements in the CW Evaluation of Mode-Stirred Chambers. In Proceedings of IEEE International Symposium on EMC. p. 33-37. 1997. 
[12] LADBURY, J. M.; KOEPKE, G. H. Reverberation chamber relationships: corrections and improvements or three wrongs can (almost) make a right. In Proceedings of IEEE International Symposium on EMC, Seattle: p. 1-6, 1999.

[13] HOLLOWAY, C. L. et al. Requirements for an effective reverberation chamber: unloaded or loaded. IEEE Transactions on Electromagnetic Compatibility, v. 48, n. 1. p. 187-194, 2006.

[14] HILL, D. A. Boundary fields in reverberation chambers. IEEE Transactions on Electromagnetic Compatibility, v. 47, n. 2, 2005.

[15] HILL, D. A. et al. Assessing a loaded reverberation chamber: calculating threshold metrics. In Proceedings of IEEE International Symposium on EMC, p. 834-837, 2003.

[16] LEHMAN, T. H. A statistical theory of electromagnetic fields in complex cavities. Albuquerque, NM: Air Force Research Lab., EMP Interaction Note 494, 1993.

[17] CORONA, P. et al. Use of reverberating enclosure for measurements of radiated power in the microwave range, IEEE Transactions on Electromagnetic Compatibility, v. EMC-18, n. 12, p. 54-59, 1976.

[18] CORONA, P.; FERRARA, G.; MIGLIACCIO, M. Statistical electromagnetic field in reverberating chambers, chapter 13 , Statistical Techniques.

[19] CORONA, P. Reverberating chambers as sources of stochastic electromagnetic fields, IEEE Transactions on Electromagnetic Compatibility, v. 38, n. 3, p. 348-356, 1996.

[20] CORONA, P.; FERRARA, G.; MIGLIACCIO, M. Reverberating chamber electromagnetic field in presence of an unstirred component, IEEE Transactions on Electromagnetic Compatibility, v. 42, n. 2, p. 111-115, 2000.

[21] CORONA, P.; LADBURY, J.; LATMIRAL, G. Reverberation-chamber research then and now: a review of early work and comparison with current understanding, IEEE Transactions on Electromagnetic Compatibility, v. 44, n. 1, p. 87-94, 2002.

[22] CORONA, P., FERRARA, G. MIGLIACCIO, M. Generalized Stochastic Field Model for Reverberating Chambers, IEEE Transactions on Electromagnetic Compatibility, v. 48, n. 4, p. 655-660, 2004.

[23] PERINI, J.; COHEN, L. S. An alternative way to stir the fields in a mode stirred chamber. In Proceedings of IEEE-EMC International Symposium, v. 2, p. 633637, 2000.

[24] PERINI, J.; COHEN, L.S. Extending the Operation of Mode Stirred Chambers to Low Frequencies. In Proceedings of IEEE International Symposium on EMC, v. 2, p. 964-965, 2002. 
[25] PERINI, J.; COHEN, L. S.; SARTORI, C. A. F.; CARDOSO, J.R.; Uma solução alternativa para as atuais câmaras reverberantes de modos misturados, in Proceedings CBMag Congresso Brasileiro de Eletromagnetismo, Gramado/Brasil, 2002.

[26] RAHMAN, H.; PERINI, J.; Analysis of a wire in a rectangular cavity, in Microwave Symposium Digest - IEEE MTT-S International, v. 83, issue 1, p. 230-232, 1983.

[27] PERINI, J.; RAHMAN, H.; Currents induced in wire bundles in shielded enclosures, Proceedings of Antennas and Propagation Society International Symposium, Syracuse, v. 2, p. 884-887, 1988.

[28] RAHMAN, H.; PERINI, J.; Current on a wire parallel to two walls of a rectangular cavity, Journal of Electromagnetic Waves and Applications, v. 2, n. 3/4, p. 295-317, 1988.

[29] RAHMAN, H.; Coupling characterization of multiple in a rectangular cavity: part I - thin wire approximation, Journal of Electromagnetic Waves and Applications, v. 11, p. 77-88, 1997.

[30] TAI, C.; ROZENFELD, P.; Different Representations of Dyadic Green's functions for a rectangular cavity, IEEE Transactions on Microwave Theory and Techniques, v. MTT-24, n. 9, p. 597-601, 1976.

[31] SEIDEL, D.;Aperture excitation of a wire in rectangular cavity, IEEE Transactions on Microwave theory and techniques, v. MTT-26, n.11, p. 908914, 1978.

[32] WANG, J.; A unified and consistent view on the singularities of the electric dyadic Green's function in the source region, IEEE Transactions on Antennas and Propagation, v. AP-30, n. 3, 1982.

[33] VOYER, D.; Chambre avec les lignes de transmission, une approche semianalytique, rapport, Laboratoire Ampère, Lyon, 2009.

[34] WEINZIERL, D.; KOST, A.; RAIZER, A.; An analyses of a mode stirred chamber excited by wires using TLM and FEM, in Proceedings of ISEF 2005 XII International Symposium on Electromagnetic Fields in Mechatronics, Electrical and Electronic Engineering, Baiona, Spain, v. I, p. 1-6, 2005.

[35] WEINZIERL, D.; SARTORI, C. A. F., PEROTONI, M. B.; CARDOSO, J. R.; KOST, A. HELENO, E. F.; Numerical evaluation of non-canonical reverberation chamber configurations, IEEE Transactions on Magnetics, v. 44, n. 6, p. 1458-1461, 2008.

[36] KOUVELIOTS, N. K.; TRAKADAS, P. T.; CAPSALIS, C. N. FDTD calculation of quality factor of vibrating intrinsic reverberation chamber. IEE Electronics Letters, v. 38, n. 16, p. 861-862, 2002. 
[37] ARNAUT, L. R.; WEST. P. D. Electromagnetic reverberation near a perfectly conducting boundary. IEEE Transactions on Electromagnetic Compatibility, v. 48, n. 2, p. 359-371, 2006.

[38] CHUNG, S.Y., RHEE, J.G., RHEE, H.J. \& LEE, K.S., Field uniformity characteristics of an asymmetric structure reverberation chamber by FDTD Method, in Proceedings of the 2001 IEEE International Symposium on Electromagnetic Compatibility, Montreal, Canadá, p. 429-434, 2001.

[39] KLINGLER, M. et al. On the use of three-dimensional TEM cells for total radiated power measurements. In Proceedings of IEEE International Symposium on Electromagnetic Compatibility, Montreal, Canadá, p. 123-128, 2001.

[40] BUNTING, C. F. et al. Finite element analysis of reverberation chambers: a two-dimensional study at cutoff. In Proceedings of IEEE International Symposium on Electromagnetic Compatibility, Denver, CO, v. 1, p. $208-212$, 1998.

[41] BUNTING, C. F.; DAVIS. W. A., A functional for dynamic finite-element solutions in electromagnetics, IEEE Transactions on Antennas and Propagation, v. 47, n. 1, p. 149-156, 1999.

[42] BUNTING, C. F. Two-dimensional finite element analysis of reverberation chambers: the inclusion of a source and additional aspects of analysis, in Proceedings of IEEE International Symposium on Electromagnetic Compatibility, Seattle, WA, v. 1, p. 219-224, 1999.

[43] BUNTING, C. F. et al, A two-dimensional finite-element analysis of reverberation chambers, IEEE Transactions on Electromagnetic Compatibility, v. 41 , n. 4 , p. $280-289,1999$.

[44] BUNTING, C. F., Shielding effectiveness, statistical characterization and the simulation of a two-dimensional reverberation chamber using finite element techniques, in Proceedings of IEEE Digital Avionics Systems Conference, v. 1, p. 3A5/1 - 3A5/8, 2000.

[45] BUNTING, C. F., Shielding effectiveness in a reverberation chamber using finite element techniques, in Proceedings of IEEE International Symposium on Electromagnetic Compatibility, Montreal, Canada, p.740-745, 2001.

[46] BUNTING, C. F., Statistical Characterization and the simulation of a Reverberation Chamber using finite-element techniques, IEEE Transactions on Electromagnetic Compatibility, v. 44, n. 1, 2002.

[47] BUNTING, C. F.; YU, S. Statistical shielding effectiveness - an examination of the field penetration in a rectangular box using modal MOM, in Proceedings of IEEE International Symposium on Electromagnetic Compatibility, Minneapolis, p. 210-215, 2002. 
[48] BUNTING, C. F. Shielding effectiveness in two-dimensional reverberation chamber using finite-element techniques, IEEE Transactions on Electromagnetic Compatibility, Vol. 45, n. 3, p. 548-552, 2003.

[49] BRUNS, C.; VAHLDIECK, R. A closer look at reverberation chambers - 3-D simulation and experimental verification. IEEE Transactions on EMC, v. 47, n.3, p. 612-626, 2005.

[50] KOSTAS, J. G.; BOVERIE, B. Statistical model for a mode-stirred chamber. IEEE Transactions on Electromagnetic Compatibility, v. 33, n. 4, p. 366-370, 1991.

[51] LEHMAN, T.H. A Statistical Theory of Electromagnetic Fields in Complex Cavities, Philips Laboratory, Interaction Note 494, 1993.

[52] PRICE, R. H.; DAVIS, H.T.; WENAAS, E. P. Determination of the statistical distribution of electromagnetic-field amplitudes in complex cavities. Physical Review E, v. 48, n. 6, JAYCOR, Albuquerque, p. 4716-4719, 1993.

[53] PERINI, J. EMC Measurement Uncertainty - What is it? Workshop, IEEE Int. Symposium. On EMC, Washington, DC, 2000.

[54] CAROBBI, C. F. M.; CATI, M.; MILLANTA, L. M. Using the log-normal distribution in the statistical treatment of experimental data affected by large dispersion. In Proceedings of IEEE International Symposium on Electromagnetic Compatibility, Boston, p. 812-816, 2003.

[55] HALLBJÖRNER, P. Estimating the number of independent samples in Reverberation Chambers measurements from sample differences, IEEE Transactions on Electromagnetic Compatibility, v. 48, n. 2 , p. 354-358, 2006.

[56] ORJUBIN, G.; et al. Statistical model of an undermoded reverberation Chamber. IEEE Transactions on Electromagnetic Compatibility, v. 48, n. 1. p. 248-251, 2006.

[57] ORJUBIN, G. et al. On the FEM modal approach for a reverberation chamber analysis. IEEE Transactions on Electromagnetic Compatibility, v. 49, n. 1, p. 76-85, 2007.

[58] ORJUBIN, G. Maximum field inside a reverberation chamber modeled by the generalized extreme value distribution. IEEE Transactions on Electromagnetic Compatibility, v. 49, n. 1, p. 104-113, 2007.

[59] CLEGG, J.; et al. Optimization of stirrer designs in a reverberation chamber. IEEE Transactions on Electromagnetic Compatibility, v. 47, n. 4. p. 824-832, 2005.

[60] FREYER, G.J.; BÄCKSTRÖM, M. Comparison of anechoic and reverberation chamber coupling data as a function of directivity pattern - part II. In 
Proceedings of IEEE International Symposium on Electromagnetic Compatibility, Montreal, Canada, p. 286-291, 2001.

[61] HARIMA, K.; YAMANAKA, Y. Evaluation of E-field uniformity for radiated immunity testing in a reverberation chamber. In Proceedings of IEEE International Symposium on Electromagnetic Compatibility, Montreal, Canada, p. 768-770, 2001.

[62] HARIMA, K. Statistical characteristics of E-field distribution in a reverberation chamber, IEICE Transactions Communications, v. E88-B, n. 8, p. 3127-3132, 2005.

[63] WELLANDER, N.; LUNDÉN, O.; BÄCKSTRÖM, M. The maximum value distribution in a reverberation chamber. In Proceedings of IEEE International Symposium on Electromagnetic Compatibility, Montreal, Canada, v. 2, p. 751756, 2001.

[64] WELLANDER, N.; LUNDÉN, O.; BÄCKSTRÖM, M. Experimental investigation and mathematical modeling of design parameter for efficient stirrers in modestirred reverberation chambers. IEEE Transactions on Electromagnetic Compatibility, v. 49, n. 1, p. $94-103,2007$.

[65] DE LEO, R., PRIMIANI V. M., Radiated immunity tests: reverberation chamber versus anechoic chamber results. In Proceedings of IEEE Instrumentation and Measurement Technology Conference, Ottawa, Canada, p. 337-341, 2005.

[66] CERRI, G.; DE LEO, R.; PRIMIANI, V. P. Effetto del posizionamento della sorgente sulle distribuzioni del campo in uma camera riverberante. In Quaderni Della Societá Italiana Di Elettromagnetismo, v. 1, n. 2, p. 53-59, 2005.

[67] PIETTE, M.; MOESEN, K.; MONTEZUMA, S. Experimental field validation in a cubic reverberation chamber with mechanical mode stirring \& bistatic illumination. In Proceedings of Progress in Electromagnetic Research Symposium, Hangzhou, p. 424-427, 2005.

[68] HOLLOWAY, C. L.; et al. Requirements for an effective reverberation chamber: unloaded or loaded. IEEE Transactions on Electromagnetic Compatibility, v. 48, n. 1, p. 187-194, 2006.

[69] POUHÈ, D.; MÖNICH, G.; Figures of merit for field homogeneity in TEM waveguides. IEEE Transactions on Electromagnetic Compatibility, Vol. 49, n. 4, p. 792-804, 2007.

[70] HILL, D. A. Electronic mode stirring for reverberation chambers. In IEEE Transactions on Electromagnetic Compatibility, v. 36, n. 4, p. 294-299, 1994. 
[71] ARNAUT, L. R. Statistics of the quality factor of a rectangular reverberation chamber. IEEE Transactions on Electromagnetic Compatibility, v. 45, n. 1, p. 61-76, 2003.

[72] LALLECHERE, S.; BONNET, P; PALADIAN F. Modélisations tridimensionnelles hybrides de chambres réverbérantes $(\mathrm{CR})$. in Résumés de la 6éme Conférence Européenne sur Méthodes Numériques en Electromagnétisme Numeléc2008, Liège, p. 8-9, 2008.

[73] LALLECHERE, S.; GIRARD, S.; PALADIAN, F. Application d'un modèle théorique de chambre réverbérante à brassage de modes (CRBM) à l'analyse de résultats de mesures expérimentales normatives, in Résumés de la 6éme Conférence Européenne sur Méthodes Numériques en Electromagnétisme Numeléc2008, Liège, p. 126-127, 2008

[74] LEMOINE, C.; BESNIER, P.; DRISSI, M.; Proposition of tolerance requirements adapted for the calibration of a reverberation chamber, in Proceedings of 20th International Zurich Symposium on Electromagnetic Compatibility, Zurich, p. 41-44, 2009.

[75] ZHANG, B. et al. Field uniformity investigation of reverberation chamber at calibration stage, in Proceedings of 20th International Zurich Symposium on Electromagnetic Compatibility, Zurich, p. 45-48, 2009.

[76] POCAI, M. et al. Improving the performances of a reverberation chamber: a real case, in Proceedings of 20th International Zurich Symposium on EMC, Zurich, p. 53-56, 2009.

[77] MONEBHURRUN, V.; LETERTRE, T.; Total radiated power measurements of WiFi devices using a compact reverberation chamber, in Proceedings of 20th International Zurich Symposium on EMC, Zurich, p. 65-68, 2009.

[78] CERRI, G. et al. Array of Antennas Design for the Source Stirring Technique, in Proceedings of 20th International Zurich Symposium on EMC, Zurich, p. 105108, 2009.

[79] ANDERSON, M.; ORLENIUS, C.; FRANZÉN, M. Very fast measurements of effective polarization diversity gain in a reverberaion chamber. In Proceedings of the Second European Conference on Antennas and Propagation, EuCap2007, Edinburgh, UK, 2007.

[80] CONWAY, G. A.; SCANLON, W. G.; ORLENIUS, C.; WALKER, C. In situ measurement of UHF wearable antenna radiation efficiency using a reverberation chamber. In IEEE Antenas and wireless propagation letters, v. 7. p. $271-274,2008$.

[81] BALANIS, C.A. Advanced Engineering Electromagnetics, New York, John Wiley \& Sons, 1989. 
[82] DEMAREST, K.R. In BANSAL, R. Handbook of Engineering Electromagnetics. New York: Marcel Dekker. 2004. p. 227-253.

[83] WEISSHAAR, A. Transmission Lines. In BANSAL, R. Handbook of Engineering Electromagnetics. New York: Marcel Dekker. 2004. p. 185-226.

[84] MAGNUSSON, P. C. et al. Transmission Lines and Wave Propagation, 4th edition, USA: CRC Press, 2001.

[85] COLLIN, R. E. Foundations for Microwave Engineering, Tokyo: McGraw-Hill Kogakusha, 1966.

[86] JACKSON, J. D. Classical Electrodynamics, 3 ed., John Wiley \& Sons, EUA, 1999.

[87] BALANIS, C. A., Antenna Theory - Analysis and Design, 3 ed., John Wiley and Sons, New Jersey, 2005.

[88] POZAR, D.M.; Microwave Engineering, 2 ed., New York: Wiley, 1998.

[89] KENNEDY, G. Electronic Communication Systems, 2 ed., Mc-Graw Hill Kogakusha, Tokyo, 1977.

[90] RAMO, S., WHINNERY, J. R., VAN DUZER, T.; Fields and Waves in Communication Electronics, Tokyo: John Wiley and Sons, 1965.

[91] DAWSON, HATFIELD, ARNAUT, EULIG, Reverberation (Mode-Stirred) Chambers for Electromagnetic Compatibility \& 2007 The Institution of Engineering and Technology http://www.iee.org/oncomms/pn/emc/reverberation/index.cfm em 22NOV2007.

[92] BOX, G.E.P.; HUNTER, W. G.; HUNTER, J. S. Statistics for experimenters an introduction to design, data analysis, and model building, USA: John Wiley \& Sons, 1978.

[93] WEILAND, T. Time domain electromagnetic field computation with finite difference methods. International Journal of Numerical Modelling, v. 9, p. 295319, 1996.

[94] CST MICROWAVE STUDIO ${ }^{\circledR}$, Advanced Topics (www.cst.com).

[95] AVILA, S. L.; SARENI; B.; KRAHENBUHL, L.; A multi-niching multi-objective genetic algorithm for solving complex multimodal problems. In Proceedings of 9th International Workshop on Optimization and Inverse Problems in Electromagnetism - OIPE, Sorrento, 2006.

[96] AVILA S. L., CARPES, W. P. Jr.; GARCIA, J. S. Introduction to optimization procedures: a brief survey of methods. IEEE Multidisciplinary Engineering Education Magazine, v. 1, n. 2, p. 1-4, 2006. 
[97] HOLLAND J. R. Adaptation in natural and artificial systems: an introductory analysis with applications to biology, control, and artificial intelligence, Cambridge: MIT Press, 1992.

[98] BAZARAA, M. S.; SHERALI, H. D.; SHETTY, C. M. Nonlinear Programming Theory and Algorithms, John Wiley \& Sons, New York, 1993.

[99] COELLO COELLO C. A. List of references on evolutionary multiobjective optimization. [online]. http://www.lania.mx/ ccoello/EMOO, 2008.

[100]AVILA S. L. Algoritmos genéticos aplicados na otimização de antenas refletoras, Dissertação (Mestrado) - Universidade Federal de Santa Catarina UFSC, Florianópolis, 2002.

[101] AVILA S. L. Otimização multiobjetivo e análise de sensibilidade para concepção de dispositivos, Tese (Doutorado), Universidade Federal de Santa Catarina, Florianópolis, 2006.

[102] VASCONCELOS, J. A.; TAKAHASHI, R. H. C.; SALDANHA, R. R.; KRÄHENBÜHL, L. A multi-objective methodology for evaluating genetic operators. IEEE Transactions on Magnetics, v. 39, n. 3, p. 1321-1324, 2003.

[103]VASCONCELOS, J. A.; TAKAHASHI, R. H. C.; SALDANHA, R. R.; RAMIREZ J. A. Improvements in genetic algorithms. IEEE - Transactions on Magnetics, v. 37, n. 5, p. 3414-3417, 2001.

[104]WEILE, D. S.; MICHIELSSEN, E. Genetic algorithm optimization applied to electromagnetics: a review. IEEE Transactions on Antennas and Propagation, v. 45, n. $3,1997$.

[105]MAIO, I. A., A Primer on Scattering Parameter, Part I: Definition and Properties, in EMC Newletter - 2008 - www.emcs.org @310UT2008, pp.57-63.

[106]SADIKU, M. N. O. Deficiences in the way scattering parameters are taught, IEEE Transactions on Education, v. 46, n. 3, p. 399-404, 2003.

[107] GINZTON, E. L. Microwave Measurements, USA: McGraw-Hill, 1957.

[108] LAVERGUETTA, T. S. Modern Microwave Measurements and Techniques, Norwood, MA: Artech House, 1988.

[109]WEINZIERL, D. Estudo de câmaras de teste de compatibilidade eletromagnética (CEM) através do método de modelagem por linhas de transmissão (TLM), Tese (Doutorado), Universidade Federal de Santa Catarina, Florianópolis, 2004.

[110]AVILA, S. L.; SANTOS JR., M. A.; WEINZIERL, D.; KRÄHENBÜHL, L.; PERRUSSEL, R; VOLLAIRE, C.; SARTORI, C. A. F.; LEBENSZTAJN, L.; CARDOSO, J. R. Maximum working volume evaluation in a non-canonical 
reverberation chamber, In Proceedings of IEEE Conference on Electromagnetic Field Computation CEFC2008, Athenas, p. 314-314, 2008.

[111]AVILA, S. L.; SANTOS JR, M. A.; WEINZIERL, D.; KRAHENBUHL, L.; PERRUSSEL, R.; VOLLAIRE, C.; SARTORI, C. A. F.; LEBENSTAJN, L.; CARDOSO, J. R. Maximum working volume evaluation in a non-canonical reverberation chamber. IEEE Transactions on Magnetics, p. 1646-1649, 2009.

[112]WEINZIERL, D.; SANTOS JR, M. A.; PEROTONI, M. B.; SARTORI, C. A. F.; CARDOSO, J. R.; KOST, A. Statistical evaluation of non-canonical reverberation chambers. In Proceedings of International Microwave \& Optoelectronics Conference - IMOC2007, Salvador, p. 630-633, 2007.

[113]SANTOS JR. M. A.; AVILA, S. L.; WEINZIERL, D.; LEBENSZTAJN, L.; SARTORI, C. A. F. Optimization of reverberation chambers by applying working volume as figure of merit, In Proceedings of International Conference on Engineering Optimization EngOpt2008, Rio de Janeiro, 2008 [CD].

[114]AVILA, S. L.; SANTOS JR., M. A.; WEINZIERL, D.; SARTORI, C. A. F.; LEBENSZTAJN, L.; CARDOSO, J. R. Caracterização de câmaras reverberantes de modos misturados não-canônicas, in Anais do MOMAG2008 $\left(13^{\circ}\right.$ SBMO Simpósio Brasileiro de Microon das e Optoeletrônica e o $8^{\circ} \mathrm{CBMag}$ - Congresso Brasileiro de Eletromagnetismo), Florianópolis, v. único, p. 493-495, 2008.

[115]SANTOS JR., M. A.; ÁVILA S.; WEINZIERL, D.; KRÄHENBÜHL, L.; SARTORI, C. A. F.; CARDOSO, J. R. The working volume position on a non-canonical reverberation chamber, in Resumès de la 6ème Conférence Européenne sur les méthodes numériques en Electromagnétisme, Numelec2008, Liège, p. 122-123, 2008.

[116]SANTOS JR., M. A.; AVILA, S.; SARTORI, C. A. F.; WEINZIERL, D.; KRÄHENBÜHL, L.; LEBENSZTAJN, L.; CARDOSO, J. R. Conductor positions optimization of a transmission line excitation chamber, in Proceedings of International Compumag Society Conference COMPUMAG2009, Florianópolis, 2009. (no prelo).

[117]SANTOS JR., M. A.; VOYER, D.; SARTORI, C. A. F.; WEINZIERL, D.; PERRUSSEL, R.; VOLLAIRE, C.; KRÄHENBÜHL, L.; CARDOSO, J. R. Investigation of electronic stirring chamber phase-shifting excitation and load effects, in Proceedings of International Compumag Society Conference COMPUMAG2009, Florianópolis, 2009. (no prelo).

[118]SANTOS JR. M. A.; SARTORI, C. A. F.; WEINZIERL, D.; KRÄHENBÜHL, L.; CARDOSO, J. R. Transmission line excited chamber: experimental and numerical analysis, in Proceedings of International Conference on Electromagnetic Fields, Health and Environment EHE09, São Paulo, 2009. (no prelo). 
[119]VOYER, D., Chambre réverbérante, Rapport, École Centrale de LyonLaboratoire Ampére, Lyon, 2009, (relatório interno, não publicado). 


\section{APÊNDICE A PROTÓTIPO LMAG/CTMSP}

Os principais aspectos dimensionais, de posição de componentes aplicados no protótipo LMAG/CTMSP são mostrados na Figura 83.

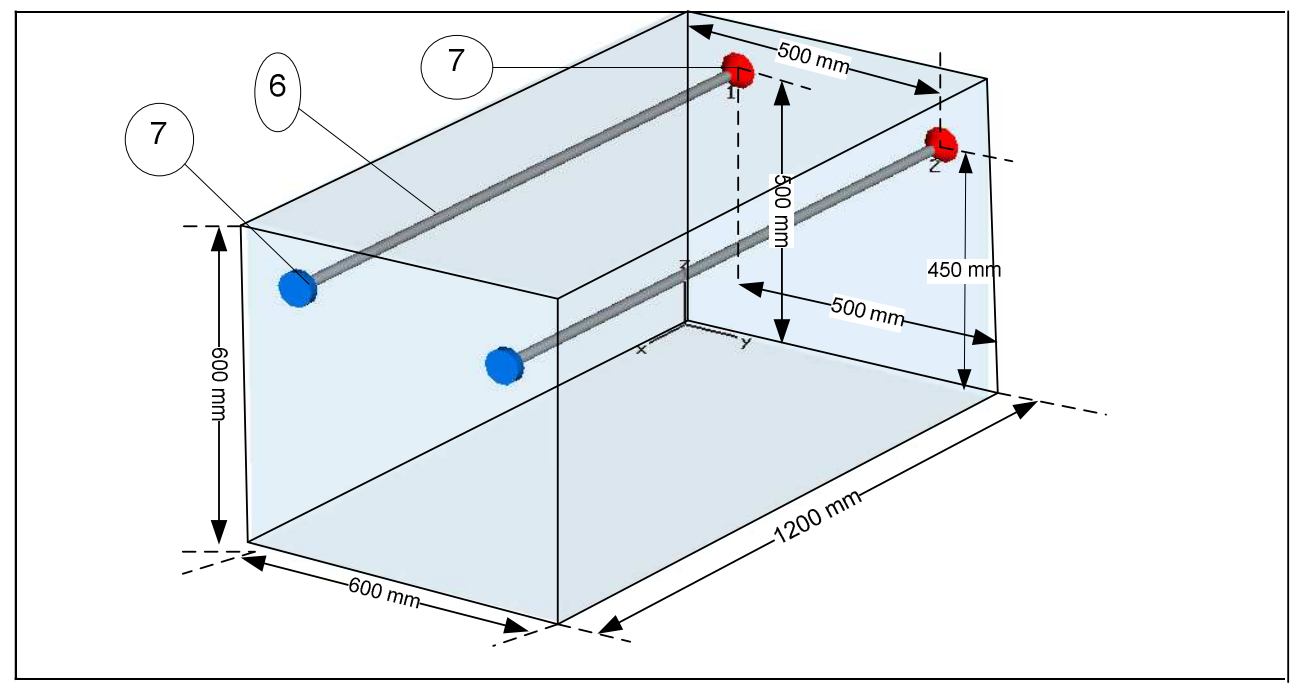

Figura 83 - Aspectos construtivos do protótipo.

A lista de materiais utilizados para a construção desta CELT encontra-se na

Tabela 6. Note-se que a numeração indicativa faz referência à lista de materiais, encontrada na Tabela 6.

A seguir, são citados alguns pontos que devem ser observados durante o projeto e construção de uma CELT.

a) Montagem Mecânica

$\mathrm{Na}$ construção da cavidade, foram utilizadas chapas de aço, com baixo teor de carbono $(<0,20 \%)$, e sem tratamento antioxidante. Com o objetivo de se obter uma maior resistência mecânica, utilizou-se chapas com 1,5 mm de espessura para a base e para as laterais, e de 2,0 $\mathrm{mm}$ de espessura para a parte superior. As chapas do piso e das laterais foram unidas por solda de prata contínua (interna e externa) utilizando-se maçarico de oxi-acetileno, de forma a se evitarem falhas. As 
paredes e a base são sustentadas por uma estrutura externa de cantoneiras, sendo unidas por pontos de solda de prata. A tampa da câmara, formada por três chapas (cada chapa com as medidas $0,45 \mathrm{~m} \times 0,7 \mathrm{~m} \times 1,5 \mathrm{~mm}$ ), foi fixada por meio de parafusos, diretamente nas cantoneiras da estrutura externa. Após isso, realizou-se uma pintura externa com tinta epóxi para proteção contra oxidação.

b) Fixação de conectores $\mathrm{N}$ : através de furos na chapa, de acordo com $\mathrm{o}$ posicionamento dos condutores e dimensões do conector;

c) Fixação dos condutores de excitação: através de solda de estanho;

d) Fixação de "feed-thru" para a passagem da fibra óptica do sensor de campo, através de furo na chapa; e

e) Verificação da continuidade elétrica: utilizando multímetro.

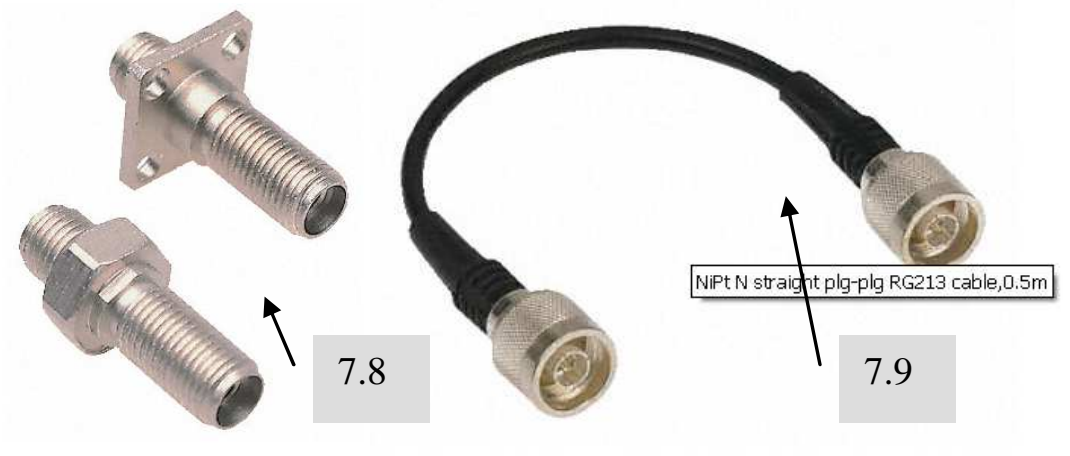

(a)

(b)

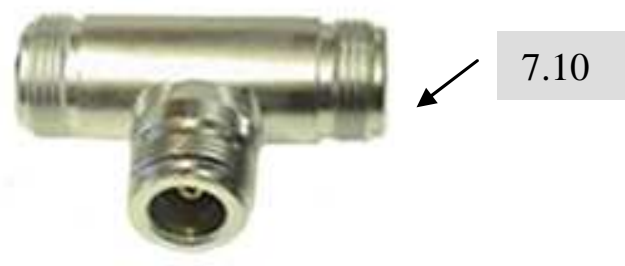

(c)

Figura 84 - (a) Conector de fibra ótica; (b) Cabo de conexão tipo N-macho/macho; (c) Adaptador tipo N (3 x fêmea). 
Tabela 6 - Lista de materiais utilizados para a construção da câmara analisada.

\begin{tabular}{|c|c|c|}
\hline Item & Descrição & Quantidade \\
\hline 7.01 & Chapa de aço AISI/SAE 1020 (1,5mm de espessura) & $2,88 \mathrm{~m}^{2}$ \\
\hline 7.02 & Chapa de aço AISI/SAE 1020 (2,0mm de espessura) & $0,72 \mathrm{~m}^{2}$ \\
\hline 7.03 & Cantoneiras de aço AISI/SAE 10201 1/4" × 1 1/4" × 1/8" & $9,6 \mathrm{~m}$ \\
\hline 7.04 & Parafusos cabeça sextavada M6 & 36 unid. \\
\hline 7.05 & Rodízios & 4 unid. \\
\hline 7.06 & Barra de cobre eletrolítico $\phi=2,5 \mathrm{~mm}^{2}$ & $2,4 \mathrm{~m}$ \\
\hline 7.07 & Conector tipo $\mathrm{N}$, montagem em chassis $50 \Omega$ & 4 unid. \\
\hline 7.08 & Conector de passagem de fibra ótica & 2 unid. \\
\hline 7.09 & Cabos coaxiais com terminais tipo N (macho-macho) & 2 unid. \\
\hline 7.10 & Acoplamento em T tipo $\mathrm{N}$ - 3xfêmea & 1 unid. \\
\hline
\end{tabular}




\section{APÊNDICE B CONFIGURAÇÃO E METODOLOGIA DE TESTES}

Nesta seção serão apresentadas e discutidas as configurações de testes e a metodologia empregada na execução dos testes. Observa-se que estas foram desenvolvidas considerando-se a disponibilidade de equipamentos e acessórios, e a capacidade técnica dos Laboratórios. Devido à especificidade dos equipamentos requeridos para a geração de sinais e a aliação experimental de campo, optou-se pela utilização de laboratórios externos especializados.

Desta forma, devido ao relacionamento pré-existente, disponibilidade de equipamentos e capacitação do grupo de técnicos, optou-se pela realização da análise de desempenho da CELT na seção de Compatibilidade Eletromagnética do Laboratório de Integração e Testes do Instituto de Pesquisas Espaciais (LIT-INPE), em São José dos Campos. Os demais ensaios, relacionados à caracterização da câmara e dos defasadores, foram desenvolvidos no Instituto de Energia Elétrica da Escola Politécnica da Universidade de São Paulo (IEE-EPUSP).

Os testes no LIT-INPE foram elaborados considerando as características daquele laboratório. Este apresenta uma reconhecida capacitação para realização de testes de CEM, utilizando procedimentos padronizados e uma ampla gama de equipamentos de geração de sinais, além de sensores adequados às medidas requeridas. Por outro lado, os testes de caracterização da câmara e dos defasadores têm um viés de pesquisa e desenvolvimento que são plenamente supridas pelo IEE-USP. Além destes aspectos, menciona-se a facilidade de acesso ao IEE-USP, já que se localiza próximo ao LMAG/PEA/EPUSP.

OBSERVAÇÃO:

Atenção especial foi dada para a caracterização de cargas utilizadas, pois considera-se um fator determinante para a consecução dos experimentos, de forma controlada e repetitiva. Desta forma, a utilização de cargas padrão $50 \Omega$, para se alcançar uma reprodutibilidade de resultados foi definida para os ensaios experimentais, de forma a caracterizar adequadamente a CELT, tanto com a utilização do VNA quanto com a utilização de antena isotrópica. 
Após essa primeira medida de caracterização, outras cargas e dispositivos puderam ser utilizados.

\section{B.1 Configuração de Teste}

\section{B.1.1 Medidas de campo E}

Para a execução dos testes no INPE foram utilizados os equipamentos e programas computacionais descritos na Tabela 7.

$\mathrm{Na}$ Figura 85, um diagrama esquemático geral da montagem de testes no INPE/LIT é apresentado. Note-se que a numeração dos itens é referida na Tabela 7. Para todos os equipamentos utilizados foi observada a validade de calibração, além da adequação aos requisitos de teste. Algumas fotos e detalhes dos equipamentos utilizados nos testes são mostradas da Figura 86 até Figura 90.

Na Figura 86 é mostrado uma parte do conjunto de testes utilizado, incluindo o gerador, amplificador, computador e o medidor de potência.

Na Figura 87 é mostrado o protótipo da CELT, montada e ligada através de cabos coaxiais ao acoplador direcional. O acoplador direcional, por sua vez, está ligado ao transdutor de potência. Na saída do acoplador direcional pode-se observar um "te", que distribui a potência injetada aos cabos que alimentam as linhas de transmissão. Na parte superior da câmara estão posicionadas as saídas dos cabos de fibra ótica, que transmitem as informações coletadas pelo sensor isotrópico (que se encontra dentro da câmara).

Na Figura 88 e Figura 89 são mostrados os equipamentos e configurações utilizados durante os testes no INPE/LIT. Na Figura 89 observa-se o detalhe dos resistores montados como carga.

Na Figura 88 é mostrada uma vista do sensor isotrópico posicionado dentro da CELT, ligado ao cabo de fibra ótica. Nota-se que o sensor está apoiado em um tubo de PVC que, por sua vez, é fixado à câmara por uma placa de isopor de $10 \mathrm{~mm}$. A 
placa de isopor foi perfurada nas posições indicadas na Figura 95, para repetição do posicionamento das medidas.

$\mathrm{Na}$ Figura 90 observa-se, em detalhe, as ligações efetuadas no acoplador direcional, com o "te" na saída e transdutor de potência na lateral.

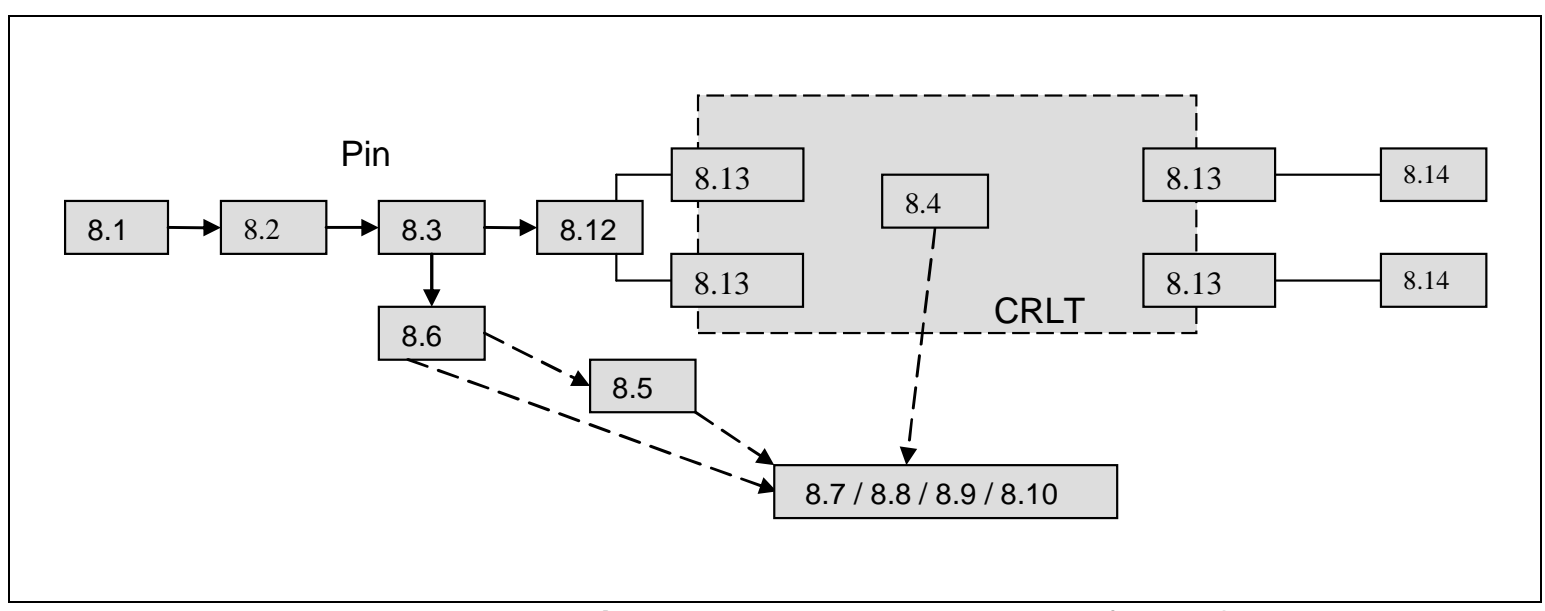

Figura 85 - Diagrama Esquemático: Montagem de Teste LIT/INPE (Lista de Material Tabela 7).

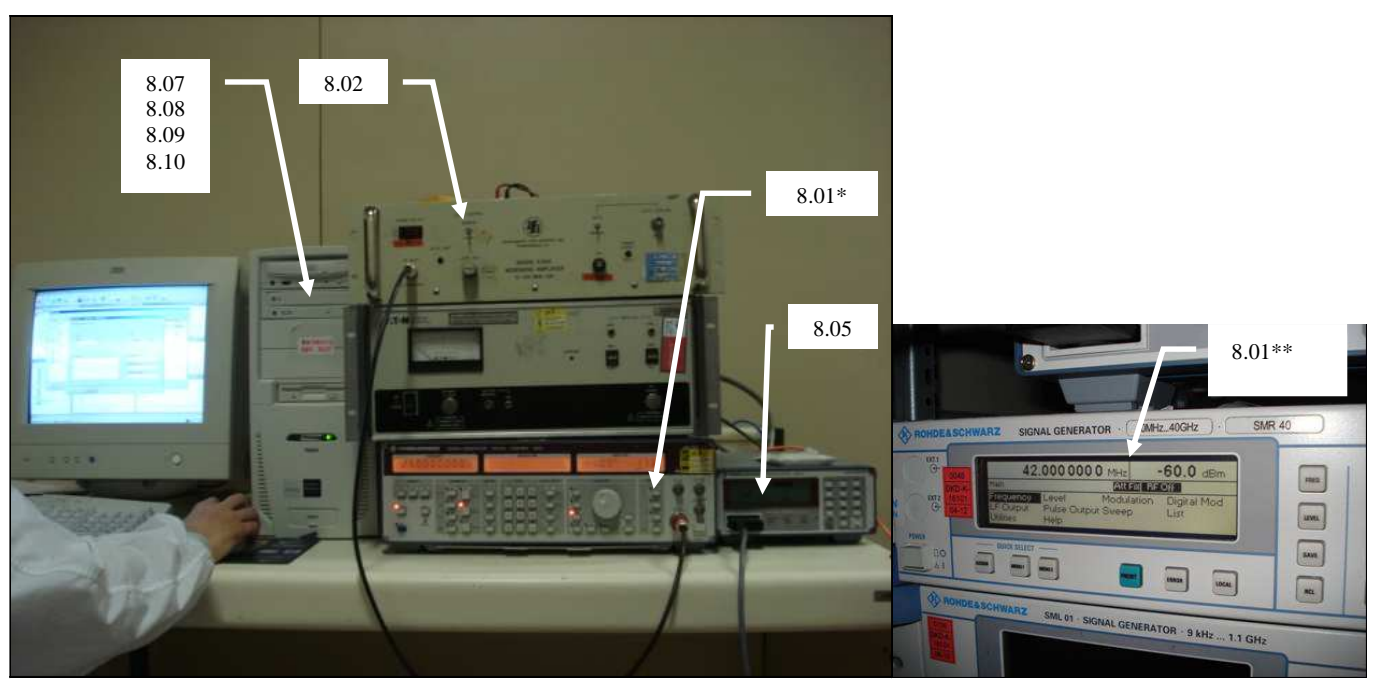

(a)

(b)

Figura 86 - Foto com equipamentos de teste INPE/LIT - (a)Gerador, Amplificador, Medidor de Potência, computador. (b)Gerador R\&S (2ª configuração). 


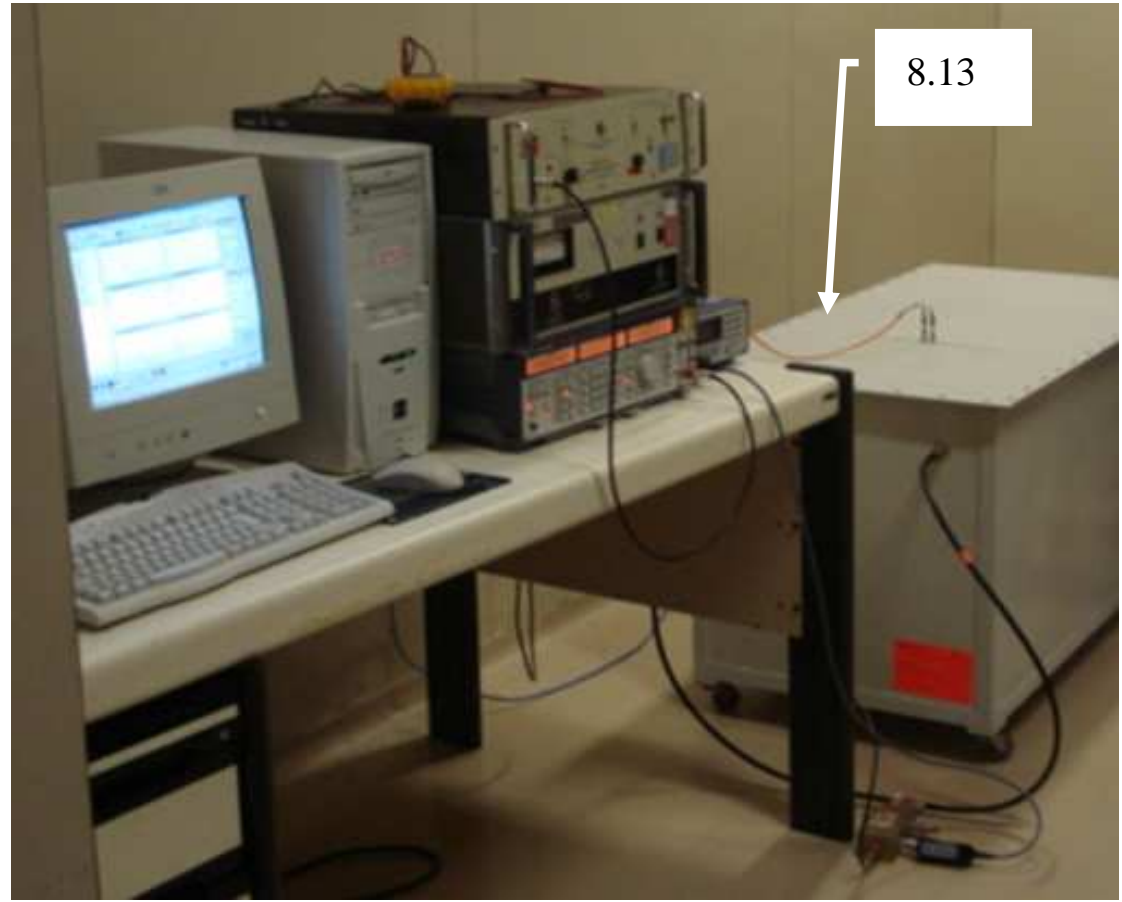

Figura 87 - CELT com "setup" de teste.

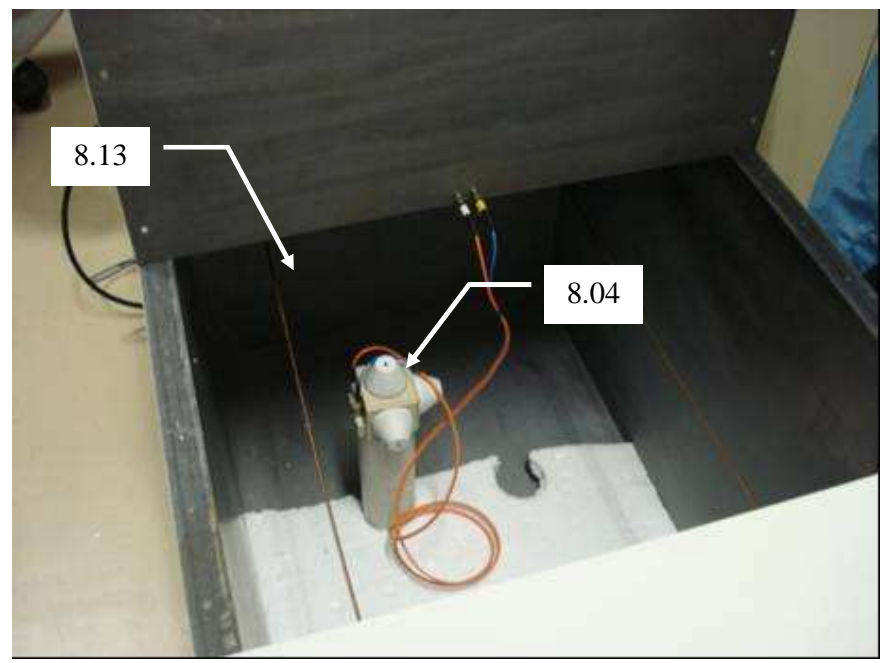

Figura 88 - Sensor de Campo E Holaday posicionado dentro da CELT, vista externa. 


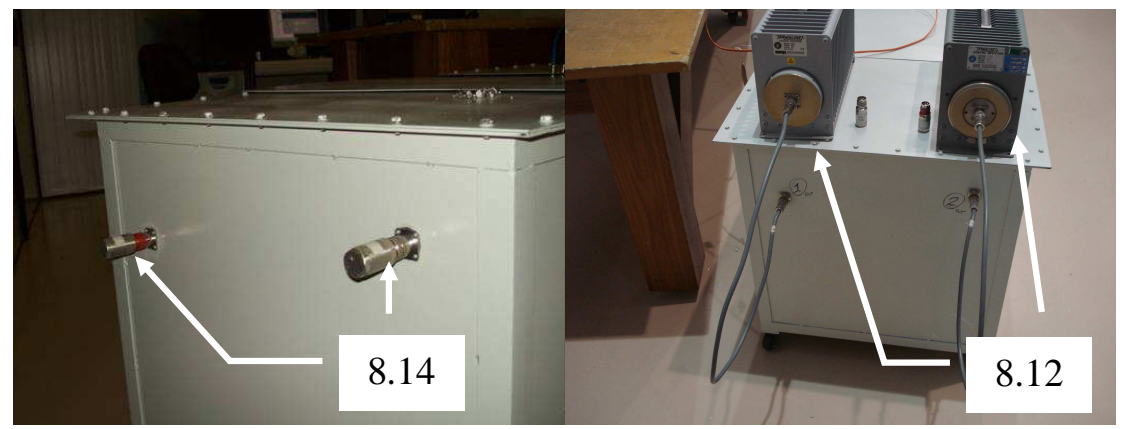

(a)

(b)

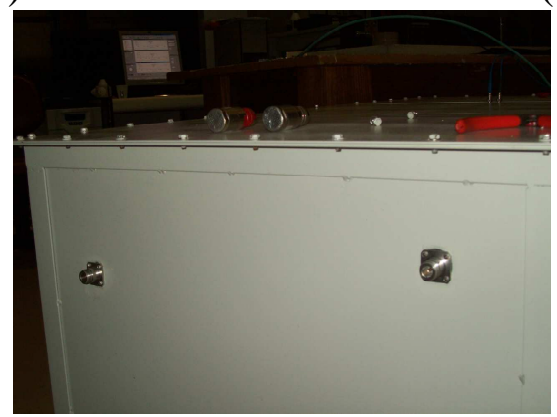

(c)

Figura 89 - Cargas aplicadas na CELT (a) tipo terminal $50 \Omega$; (b) tipo coaxial resistiva 50 $\Omega$; (c) carga aberta.

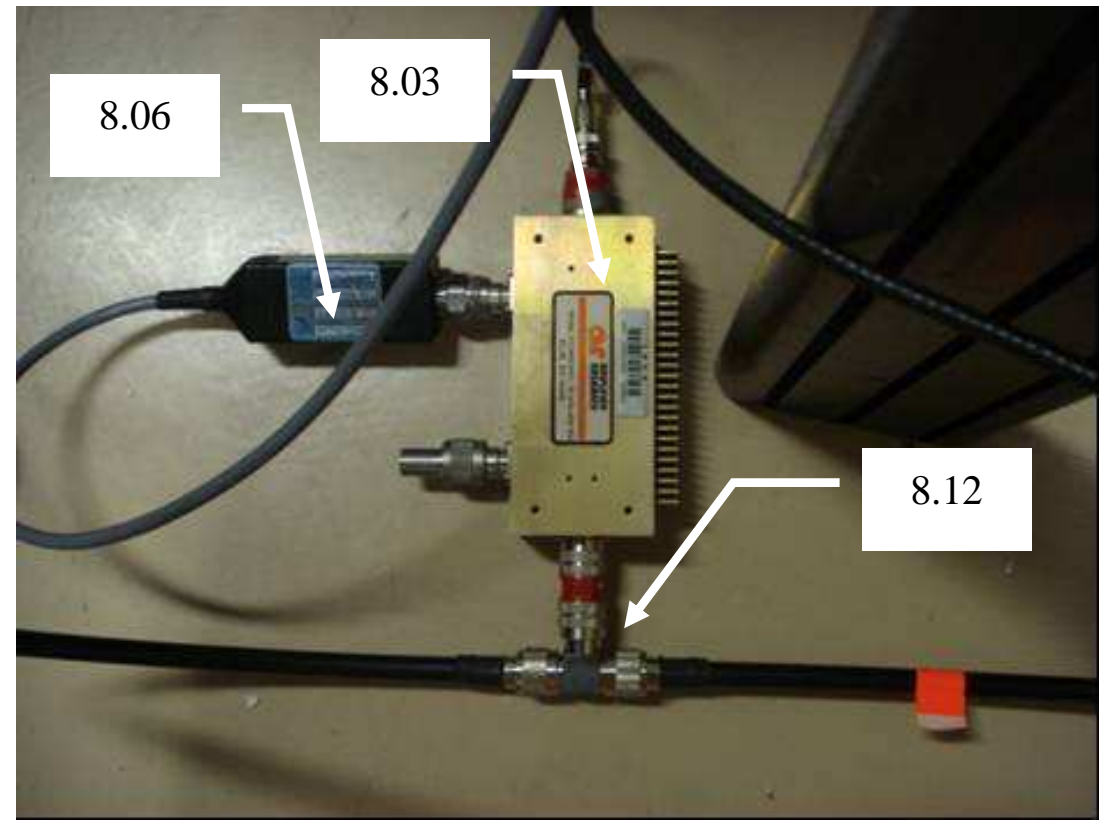

Figura 90 - Acoplador direcional AR, com transdutor de potência, saída para os dois cabos de alimentação das linhas de transmissão. 
Tabela 7 - Relação dos equipamentos: Testes - LIT/INPE.

\begin{tabular}{lcc}
\hline Item & Quantidade & Descrição \\
\hline $8.01^{*}$ & 01 & Gerador de Sinal Rohde \& Schwartz mod. SMG (100 \\
kHz-1000 MHz)
\end{tabular}




\section{B.1.2 Caracterização de componentes utilizando parâmetros S}

Para a execução do levantamento dos parâmetros S efetuado no IEE/USP, foi utilizado basicamente 0 analisador de redes vetorial (Vectorial Network Analyser VNA) Rohde \& Schwarz mod. ZVRE, mostrado na Figura 91. Um esquema simplificado da montagem de caracterização da CELT é mostrado na Figura 92, e os componentes e equipamentos utilizados nestes procedimentos são listados na Tabela 8.

Note-se que as medidas na câmara, quando se utilizou o Analisador Vetorial de Rede foram executadas sempre casando-se todas as portas não utilizadas com 50 $\Omega$, garantindo a homogeneidade de procedimentos de medição. Ou seja, todo a Linha de Transmissão que não estava sendo medida tinha os dois terminais (entrada e saída conectados com cargas $50 \Omega$ ).

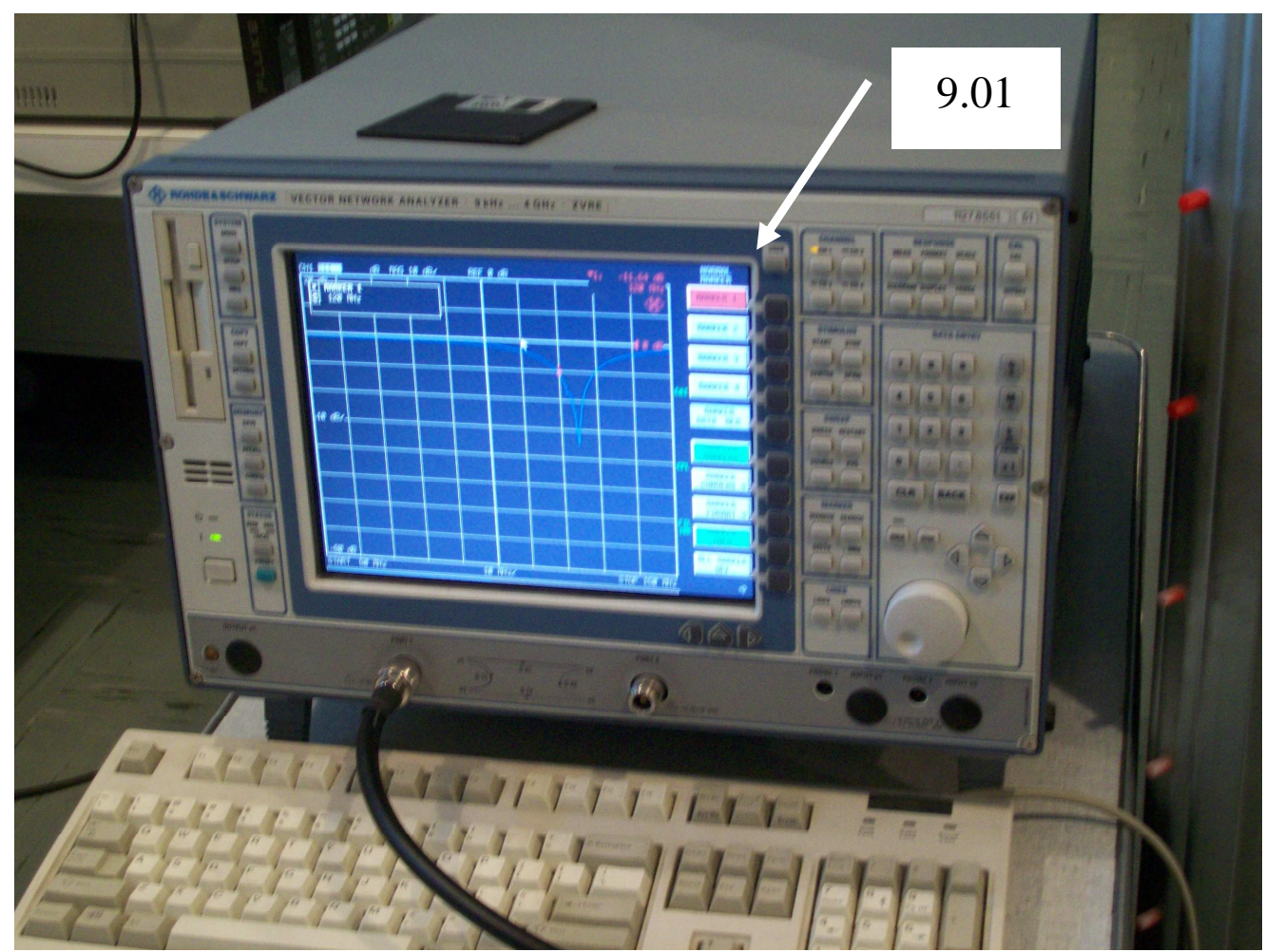

Figura 91 - Analisador Vetorial de Rede - Rohde \& Schwartz, modelo ZVRE.

Todas as cargas $50 \Omega$ (também as cargas padrão curto-circuito e circuito aberto) foram devidamente verificadas e o VNA foi calibrado para estas condições. As perdas do cabo de entrada também foram compensadas. 
Tabela 8 - Relação dos equipamentos: Teste - IEE/USP.

\begin{tabular}{|c|c|c|}
\hline Item & Quantidade & Descrição \\
\hline 9.01 & 01 & $\begin{array}{c}\text { Analisador Vetorial de Rede - Rohde \& Schwartz, modelo } \\
\text { ZVRE, faixa } 9 \mathrm{kHz}-4 \mathrm{GHz}\end{array}$ \\
\hline 9.02 & 02 & Cabos coaxiais com terminais tipo $\mathrm{N}-(\mathrm{MM})$ \\
\hline 9.03 & 01 & Câmara Excitada por Linhas de Transmissão (CELT) \\
\hline 9.04 & 01 & $\begin{array}{c}\text { Kit cargas de calibração tipo N (curto-circuito, aberto e } 50 \\
\Omega \text { ) - Rohde \& Schwartz }\end{array}$ \\
\hline $9.05 a$ & 02 & Defasador Pulsar® mod. SO-01-411 faixa $10 \mathrm{MHz}-20 \mathrm{MHz}$ \\
\hline $9.05 b$ & 01 & Defasador Pulsar® mod. SO-02-411 faixa $20 \mathrm{MHz}-40 \mathrm{MHz}$ \\
\hline $9.05 c$ & 01 & $\begin{array}{l}\text { Defasador Pulsar® mod. SO-05-411 faixa } 100 \mathrm{MHz}-190 \\
\qquad \mathrm{MHz}\end{array}$ \\
\hline $9.05 d$ & 01 & $\begin{array}{l}\text { Defasador Pulsarß mod. SO-06-411 faixa } 150 \mathrm{MHz}-280 \\
\qquad \mathrm{MHz}\end{array}$ \\
\hline 9.06 & 01 & Gerador de corrente contínua Tektronix mod. PS280 \\
\hline
\end{tabular}

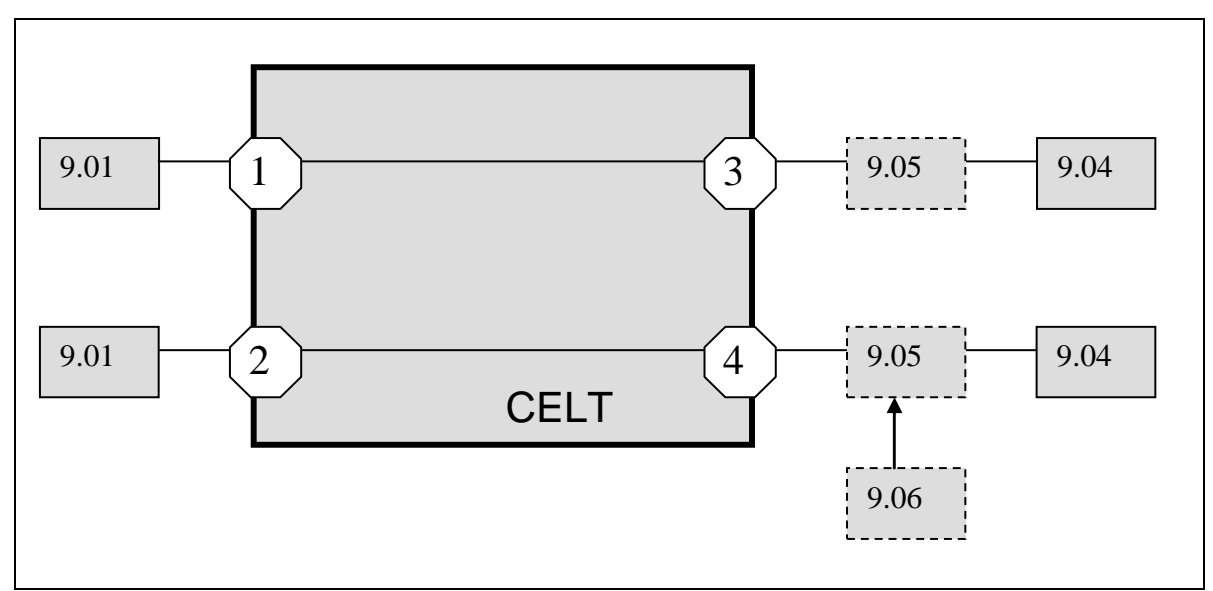

Figura 92 - Montagem de ensaio parâmetros S.

Alguns dos equipamentos e componentes utilizados são mostrados na Figura 93 e na Figura 94. 


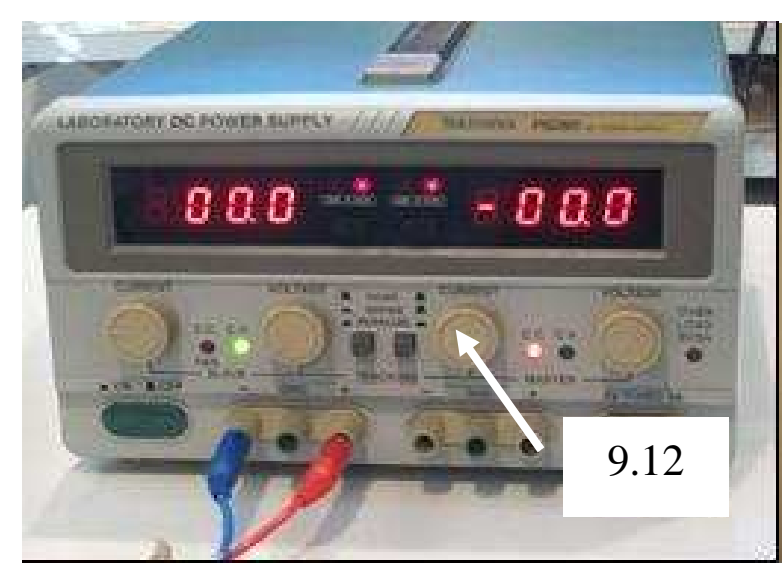

(a)

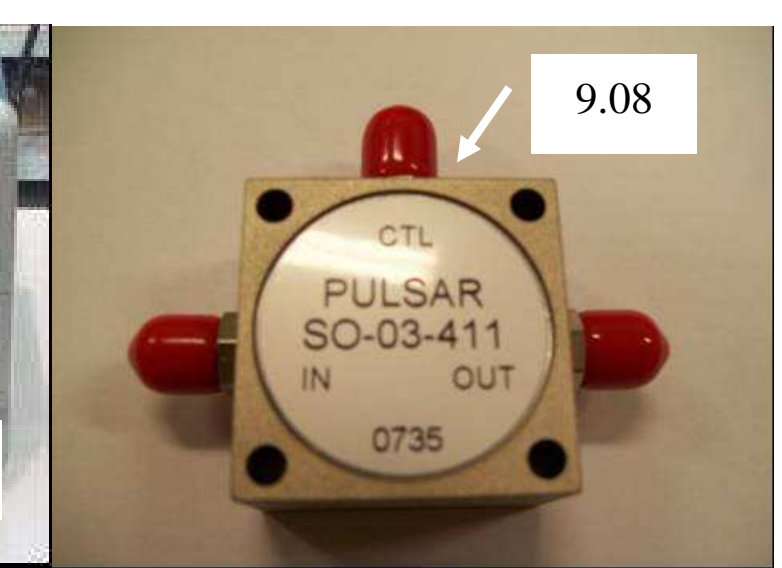

(b)

Figura 93 - (a) Gerador de potência de corrente contínua Tektronix mod. PS280 (b) Defasador Pulsar SO-03-411.

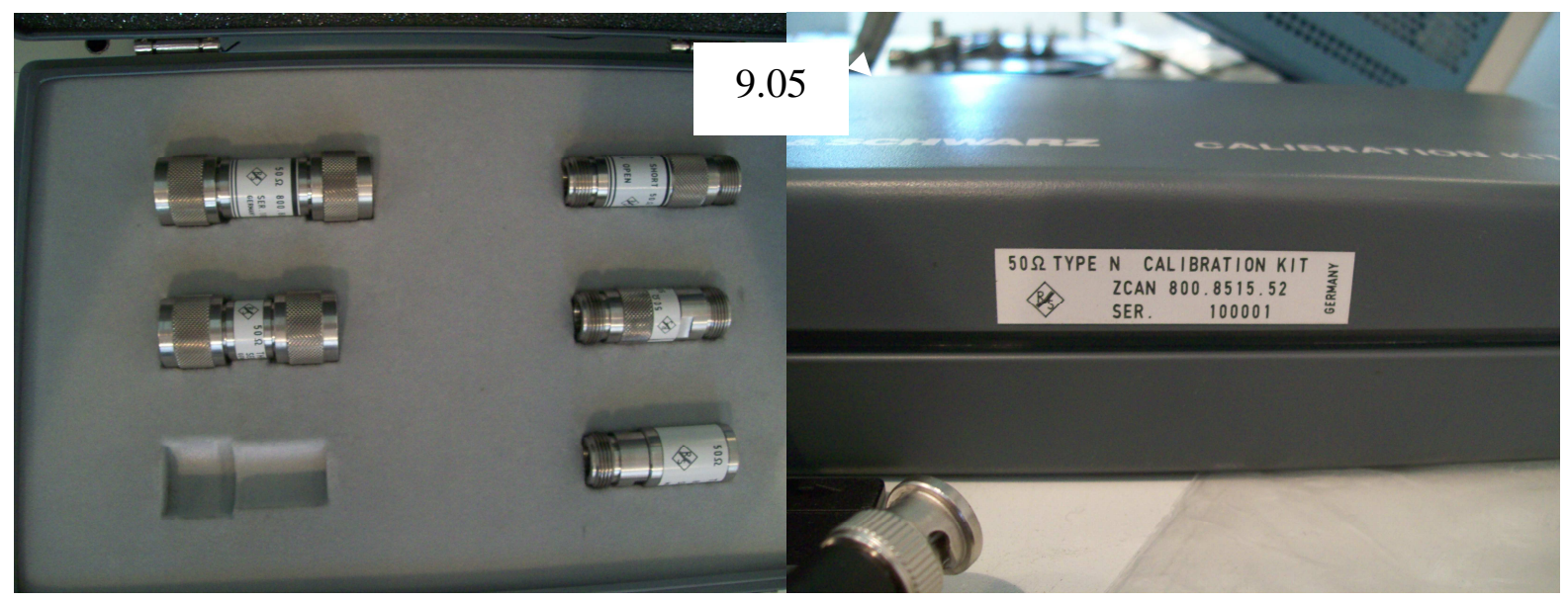

Figura 94 - Kit de cargas de calibração Rohde \& Schwartz.

\section{B.2 Procedimentos de ensaios}

Neste item apresenta-se a descrição dos procedimentos adotados nos ensaios da CELT.

\section{B.2.1 Medidas de Campo E}

Estes procedimentos visam avaliar o desempenho da CELT a partir dos valores de campo $E$ medidos em vários pontos e, permitir, assim, obter um mapeamento preliminar destes em relação à frequência e, simultaneamente, em relação ao espaço. Para analisar o comportamento da CELT face às configurações das cargas, duas configurações preliminares foram adotadas: $50 \Omega$ e aberta. 
Os pontos de medição considerados são apresentados na Figura 95, cujas coordenadas são as descritas na Tabela 9. A faixa de frequência considerada nos testes foi de $10 \mathrm{MHz}-250 \mathrm{MHz}$, assumindo-se o passo de frequência de $1,0 \mathrm{MHz}$, e tempo de aquisição ajustado em $1 \mathrm{~s}$.

a. Procedimentos no Ponto 1:

a.1. Medição do campo $E$ resultante com potência de excitação fixa $\left(P_{\text {in }}=10\right.$ [W]), injetada diretamente sobre o "T", e distribuída por este para as duas LTs. Esta medida foi feita com ambas as linhas de transmissão terminadas em carga de $50 \Omega$ cada e, também, com a carga em aberto;

a.2. Medição do campo $E$ resultante, com potência incidente fixa $\left(P_{\text {in }}=5[W]\right)$, somente, na linha de transmissão 1. Este procedimento foi feito em ambas as linhas de transmissão terminadas em carga de $50 \Omega$ e, também, com as cargas em aberto; e

a.3. Verificação do campo $E$ resultante com potência incidente fixa $\left(P_{\text {in }}=5[W]\right)$ somente na linha de transmissão 2. Este procedimento foi feito com as duas linhas de transmissão terminadas em carga de $50 \Omega$ cada e, também, com ambas as cargas em aberto.

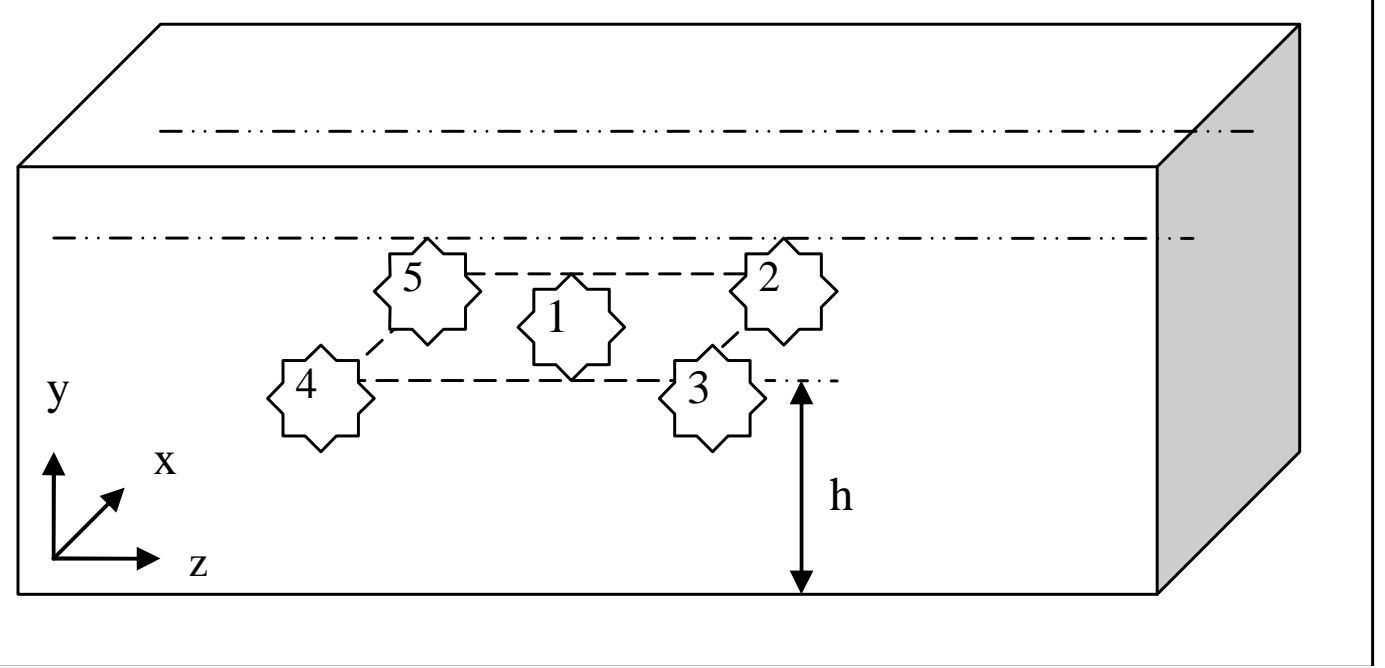

Figura 95 - Diagrama Esquemático da CELT - Pontos de medição, no plano correspondente $a$ altura $h$. 
Tabela 9 - Posições de medida

\begin{tabular}{cccc}
\hline $\begin{array}{c}\text { Posiçã } \\
0\end{array}$ & $x(m)$ & $y(m)$ & $z(m)$ \\
\hline 1 & 0,3 & 0,3 & 0,6 \\
\hline 2 & 0,4 & 0,3 & 0,8 \\
\hline 3 & 0,2 & 0,3 & 0,8 \\
\hline 4 & 0,2 & 0,3 & 0,4 \\
\hline 5 & 0,4 & 0,3 & 0,4 \\
\hline
\end{tabular}

OBS: Coordenadas conforme Figura 95.

b. Foram executadas medições no ponto 2, 3, 4 e 5 para avaliação do campo $E$ produzido com potência incidente fixa $\left(P_{\text {in }}=10[\mathrm{~W}]\right)$, com procedimentos e configurações similares aos utilizados na medição do ponto 1.

\section{B.2.2 Medidas de parâmetros S, Taxa de Onda Estacionária (TOE) e carta de Smith.}

O objetivo deste ensaio é caracterizar a CELT, em especial as reflexões na excitação (S11, S22), transmissão do sinal do ponto de entrada até a carga (S13, S31, S24, S42) e os acoplamentos entre as diversas entradas do sistema (S12, S21).

Um esquema simplificado da montagem experimental é mostrado na Figura 92.

Além disto, através do mesmo ensaio podem ser levantados outros parâmetros, como a Taxa de Onda Estacionária (TOE). Ainda, uma outra possibilidade é o levantamento da carta de Smith, o que permite verificar o comportamento das impedâncias do sistema, além de outros parâmetros e é muito utilizada em aplicações de microondas e linhas de transmissão [83], [88]. Estes dados foram levantados como subsídios e referência para futuros desenvolvimentos.

Em uma primeira abordagem, consideram-se como entradas do sistema os conectores $\mathrm{N}$ fixadas na parede da câmara, e como saídas os conectores das as cargas. Como já citado, verifica-se a reflexão em cada porta com excitação (S11 e S22), a transmissão entre as portas (S13, S31, S24, S41) das linhas de 
transmissão, e o nível de isolamento entre duas portas conectadas às diferentes linhas de transmissão (S12, S21).

Deste procedimento é determinada a matriz de espalhamento e os equipamentos necessários são descritos na Tabela 8.

Abaixo descreve-se o procedimento de testes:

a) O analisador de rede é ligado diretamente ao conector tipo $\mathrm{N}$, que é montado nas paredes da câmara. Todas as outras portas e antenas são conectadas a cargas padrão $50 \Omega$.

b) As medidas foram feitas utilizando-se um analisador de rede vetorial, para obtenção dos parâmetros de espalhamento (S). Todas as combinações de entradas e saídas são medidas, separadamente, enquanto as outras portas serão terminadas por cargas de $50 \Omega$. No mesmo procedimento podem ser levantados o TOE e a carta de Smith.

Em uma segunda abordagem, foram medidos somente os parâmetros S11 do sistema, quando se conecta um defasador no terminal da carga, variando-se a tensão de referência do defasador e para tensão, levanta-se uma curva de resposta de S11.

\section{B.2.3 Caracterização de defasadores}

Nesta seção é descrito o procedimento de caracterização dos defasadores.

A lista de equipamentos é a descrita na Tabela 8. As faixas de frequências e tensões de referência dos defasadores são mostrados na Tabela 10. Note-se que as tensões de alimentação dos defasadores devem ser observadas, anotando os valores de tensão. O procedimento aplicado é o seguinte:

- calibração do VNA, para utilização com cabos de conexão e com os adaptadores necessários;

- conectar os defasadores entre a porta 1 e a porta 2 do VNA;

- ajustar faixas de frequência de varredura para cada defasador; 
- variar as tensões de referência dos defasadores e gravar a resposta do dispositivo para cada tensão de referência.

Tabela 10 - Caracterização de defasadores

\begin{tabular}{ccc}
\hline Defasador & Frequência (MHz) & Tensão (Vcc) \\
\hline SO-01-411 & $10 \sim 20$ & $0 \sim 30$ (passo 3V) \\
\hline SO-02-411 & $20 \sim 40$ & $0 \sim 30$ (passo 3V) \\
\hline SO-05-411 & $100 \sim 190$ & $0 \sim 30$ (passo 3V) \\
\hline SO-06-411 & $150 \sim 280$ & $0 \sim 30$ (passo 3V) \\
\hline
\end{tabular}




\section{APÊNDICE C DEFASADORES PULSAR®}

Os defasadores são dispositivos utilizados em circuitos de altas freqüências para promover um atraso de fase em um sinal, com relação ao sinal injetado na entrada do dispositivo. Os defasadores Pulsar® da série SO possuem a característica de variar a a fase na saída de acordo com a variação da tensão de controle do dispositivo.

Um levantamento das características dos defasadores foi realizado de acordo com os procedimentos descritos no Anexo B.2.3. Assim, os defasadores foram conectados entre as portas 1 e 2 do VNA, para caracterizar a resposta em frequência e as impedâncias, os resultados são mostrados da Figura 96 até a Figura 99.

Estes resultados mostram que os defasadores adquiridos apresentam características de variação linear de ângulo entre a entrada e a saída, dentro da faixa de frequência para a qual foram projetados, além disso, observa que, para cada tensão injetada no conector de referência do defasador, corresponde uma curva de defasagens.

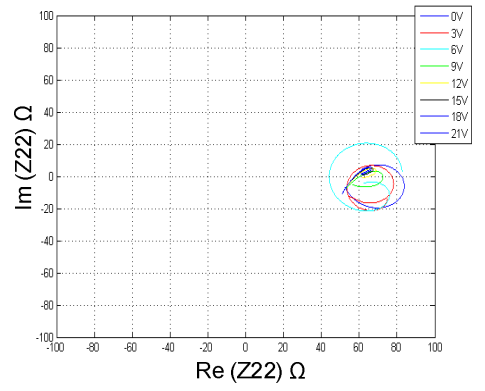

(a)

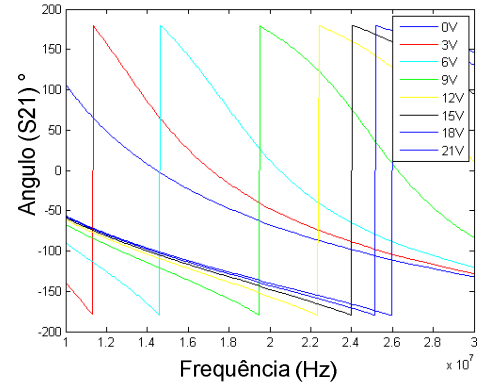

(b)

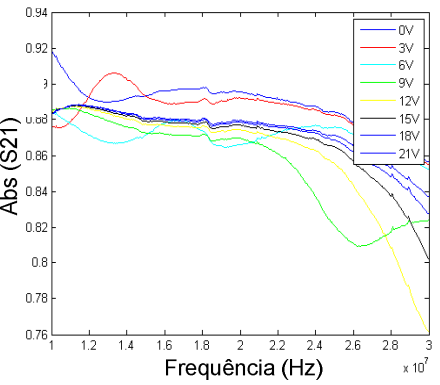

(c)

Figura 96 - Caracterização do Defasador 1 - 10MHz a $30 \mathrm{MHz}$ (a) Z real versus imaginário (b) Fase (S21) (c) Abs (S21). 


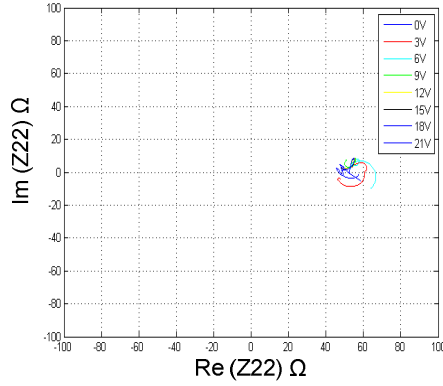

(a)

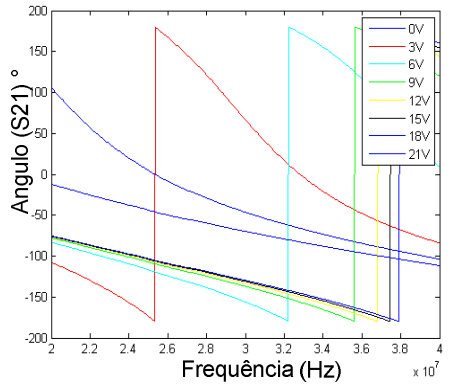

(b)

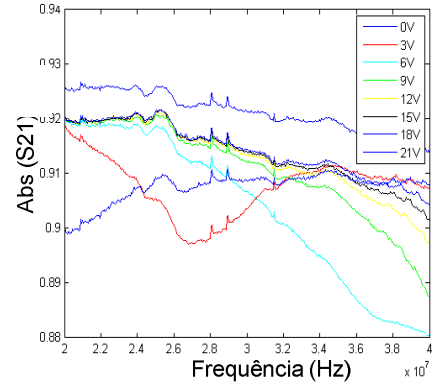

(c)

Figura 97 - Caracterização do Defasador 2 - 20MHz a $40 \mathrm{MHz}$ (a) Z real versus imaginário (b) Fase(S21) (c) Abs (S21).

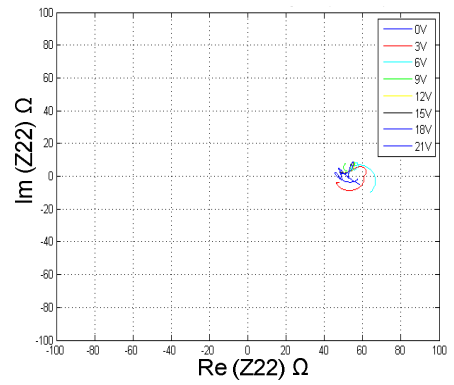

(a)

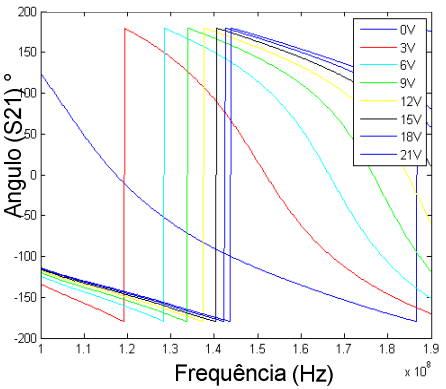

(b)

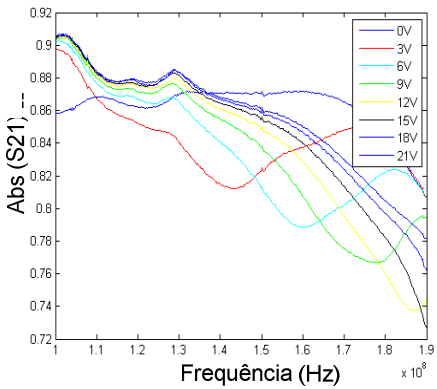

(c)

Figura 98 - Caracterização do Defasador 5 - 100MHz a 190MHz.(a) Z real versus imaginário (b) Fase (S21) (c) Abs (S21).

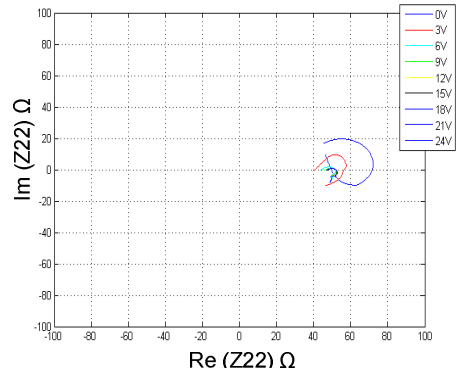

(a)

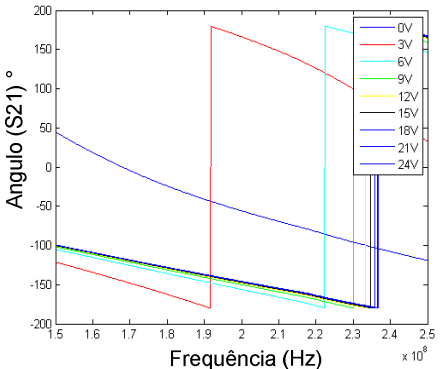

(b)

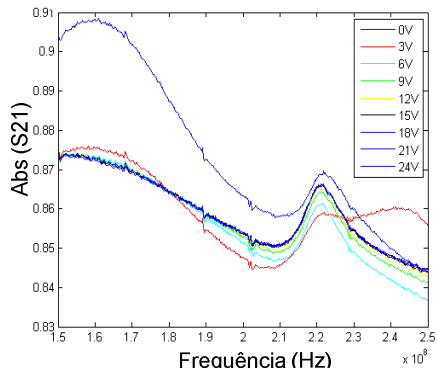

(c)

Figura 99 - Caracterização do Defasador 6 - 150MHz a 250MHz (a) Z real versus imaginário (b) Fase(S21) (c) Abs (S21). 


\section{APÊNDICE D ALGORITMOS DE CONTROLE DO CST-MWS}

O controle do CST-MWS $\AA$ a partir do Matlab $\AA$ mostrou-se uma ferramenta vital para o aumento da velocidade da análise dos resultados simulados das configurações e correspondente otimização da câmara. Este procedimento permite a mudança automática de parâmetros relacionados ao cálculo dos campos eletromagnéticos na câmara e a "exportação" dos dados resultantes. De posse desta ferramenta e dos diversos resultados disponíveis, pode-se pré-selecionar os dados desejados e compará-los com os resultados experimentais.

Uma priorização no método de trabalho foi estabelecida:

Primeiro, compreender como o Matlab e o CST interagem de forma consistente.

Segundo: "montar a câmara" no Matlab e recuperar os dados de campo, a partir do CST.

A exportação de dados do CST para um arquivo texto e posterior leitura deste pelo Matlab, através de comandos Activex do Matlab foi a melhor solução encontrada. Esta solução proporcionou robustez do processo de acesso, troca de parâmetros, solução e exportação de dados de campo E. Também possibilita a seleção do tamanho da malha de exportação, o que garante que as variáveis do Matlab não serão sobrecarregadas.

Os arquivos ASCII de campo E exportados têm o seguinte formato:

\begin{tabular}{|l|l|l|l|l|l|l|l|l|}
\hline$X(m)$ & $Y(m)$ & $Z(m)$ & ExRe & EyRe & EzRe & ExIm & Eylm & EzIm \\
& & & $(\mathrm{V} / \mathrm{m})$ & $(\mathrm{V} / \mathrm{m})$ & $(\mathrm{V} / \mathrm{m})$ & $(\mathrm{V} / \mathrm{m})$ & $(\mathrm{V} / \mathrm{m})$ & $(\mathrm{V} / \mathrm{m})$ \\
\hline
\end{tabular}




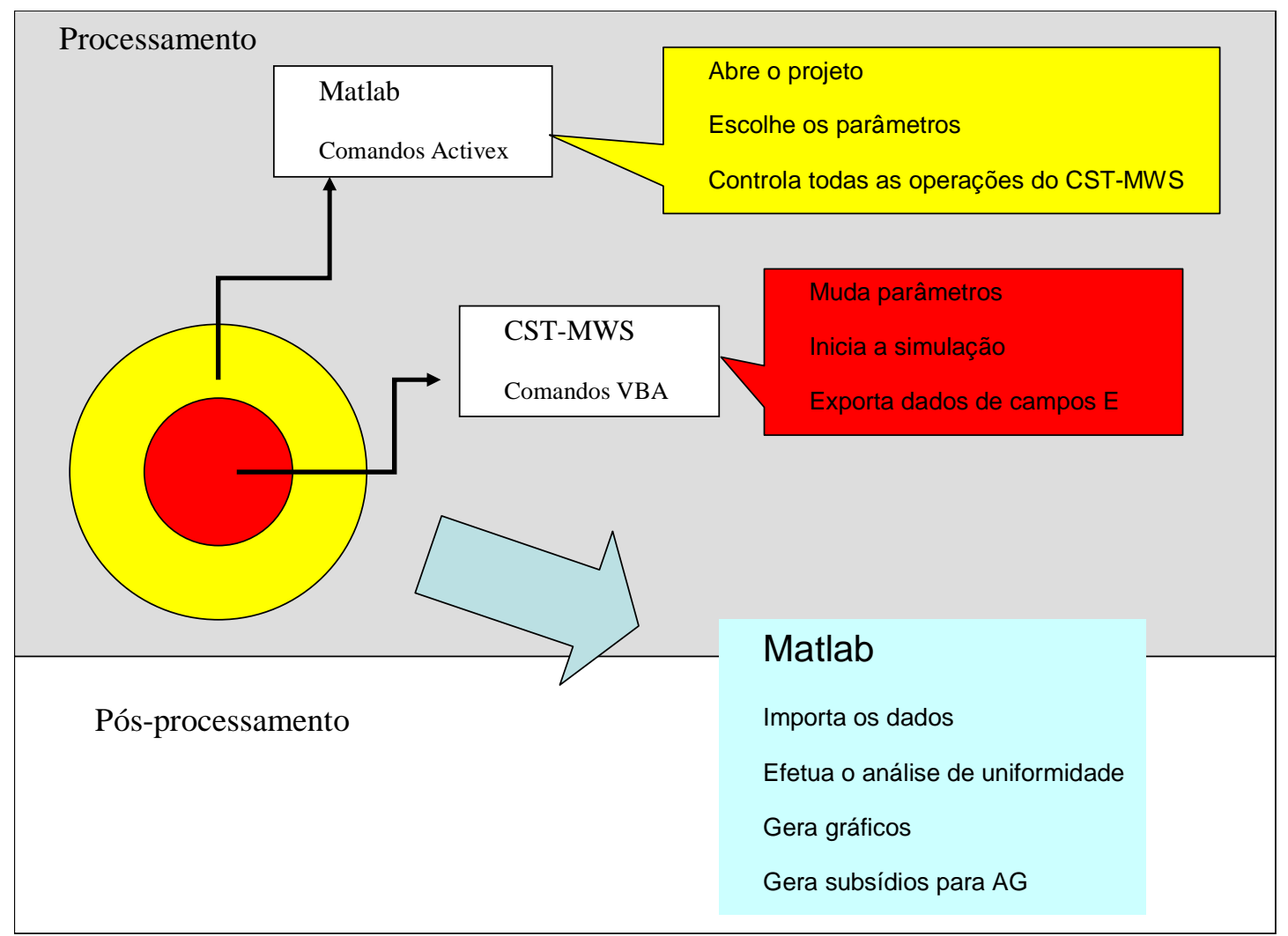

Figura 100 - Diagrama simplificado de controle do CST- MWS® pelo MatLab ${ }^{\circledR}$.

Um diagrama esquemático é apresentado na Figura 100 mostrando o procedimento adotado neste processo de simulação. Neste, o programa principal é o MatLab, que através dos comandos Activex é utilizado para controlar o CST-MWS. Desta forma, pode-se abrir o projeto CST correto, passar os valores dos parâmetros a serem calculados, iniciar as simulações, além de comandar ao CST-MWS para que exporte os dados da forma desejada.

A partir do momento em que os valores de campos eletromagnéticos foram calculados e exportados pelo CST, o Matlab inicia as rotinas de pós-processamento, importando os dados gerados e executando diversas operações, possibilitando a determinação e análise de índices estatísticos e das figuras de mérito.

Ainda, no ambiente Matlab, pode-se executar outras rotinas e códigos e interligá-las, tais como as rotinas de AG, às rotinas de controle do CST-MWS. 


\section{ANEXO A MÉTODO DAS INTEGRAÇÕES FINITAS}

O Método das Integrações Finitas (Finite Integration Technique - FIT) discretiza a forma integral das equações de Maxwell. As formas integrais são apresentadas nas equações (92) a (95) [93].

$$
\begin{gathered}
\oint_{\partial \mathrm{A}} \mathbf{E} \cdot \mathrm{d} \mathbf{s}=-\int_{\mathrm{A}} \frac{\partial \mathbf{B}}{\partial \mathrm{t}} \cdot \mathrm{d} \mathbf{A} \\
\oint_{\partial \mathrm{A}} \mathbf{H} \cdot \mathrm{d} \mathbf{s}=-\int_{\mathrm{A}}\left(\frac{\partial \mathbf{D}}{\partial \mathrm{t}}+\mathbf{J}\right) \cdot \mathrm{d} \mathbf{A} \\
\oint_{\partial \mathrm{V}} \mathbf{D} \cdot \mathrm{d} \mathbf{A}=\int_{\mathrm{V}} \rho \cdot \mathrm{dV} \\
\oint_{\partial \mathrm{V}} \mathbf{B} \cdot \mathrm{d} \mathbf{A}=0
\end{gathered}
$$

Para resolver estas equações numericamente, um domínio de cálculo finito deve ser definido englobando o problema considerado, que é dividido em um grande número de células. Na Figura 101 a tensão elétrica da malha (e) e o fluxo magnético de face (b) são posicionados na malha primária G. Somando-se a isso, fluxo dielétrico de face (d) e a tensão magnética de malha (h) são definidos na malha dual G'.
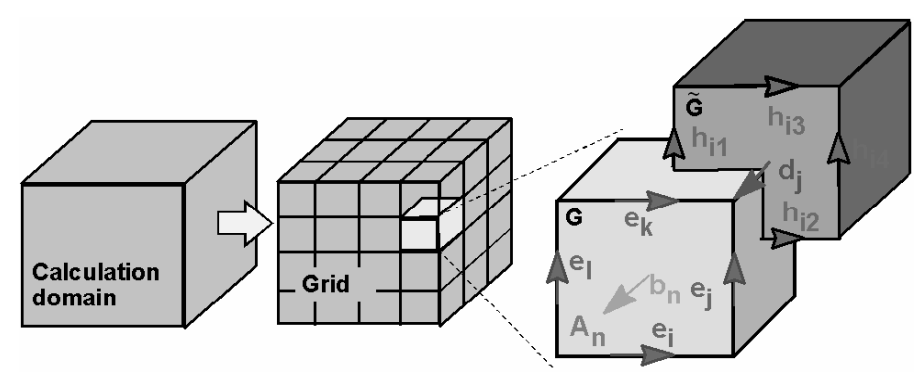

Figura 101 - Domínio de cálculo subdividido em células [93].

Considerando a equação (92), a integral fechada no lado esquerdo pode ser reescrita como a soma de quatro tensões de malha. Consequentemente, a derivada no tempo do fluxo magnético definido na face da célula primaria fechada representa 
o lado direito da equação, como mostrado na Figura 101. Este procedimento é repetido para todas as faces disponíveis nas células. Resume-se a regra de cálculo como uma formulação matricial, introduzindo a matriz topológica C como um equivalente discreto do operador rotacional analítico.

Aplicando este método a (93) na malha dual, a definição do operador dual rotacional $\tilde{C}$ discreto é necessário. Da mesma forma, a discretização das equações de divergentes remanescentes introduz os operadores divergentes $S$ e $\tilde{S}$, pertencendo às malhas primária e dual, respectivamente. $\mathrm{O}$ conjunto discretizado das equações de malha de Maxwell é dada por:

$$
\begin{gathered}
\mathbf{C e}=-\frac{\mathrm{d}}{\mathrm{dt}} \mathbf{b} \\
\tilde{\mathbf{C}} \mathbf{h}=\frac{\mathrm{d}}{\mathrm{dt}} \mathbf{d}+\mathbf{j} \\
\tilde{\mathbf{S}} \mathbf{d}=\mathbf{q} \\
\mathbf{S b}=0
\end{gathered}
$$

As relações dos materiais são resumidas nas matrizes correspondentes

$$
\begin{array}{cc}
\mathbf{D}=\varepsilon \mathbf{E} & \mathbf{d}=\mathbf{M}_{\mathcal{E}} \mathbf{e} \\
\mathbf{B}=\mu \mathbf{H} \Rightarrow \mathbf{b}=\mathbf{M}_{\mu} \mathbf{h} \\
\mathbf{J}=\sigma \mathbf{E}+\mathbf{J}_{S} & \mathbf{j}=\mathbf{M}_{\sigma} \mathbf{e}+\mathbf{j}_{\mathbf{S}}
\end{array}
$$

Em adição às malhas ortogonais hexaédricas, o FIT pode também ser aplicado aos tipos mais gerais de malha tais como as tetraédricas. Este conjunto de trabalho pode ser aplicado em ambos domínios, frequência e tempo, deixando ao usuário a escolha de qual situação é mais vantajosa dependendo do modelo. 


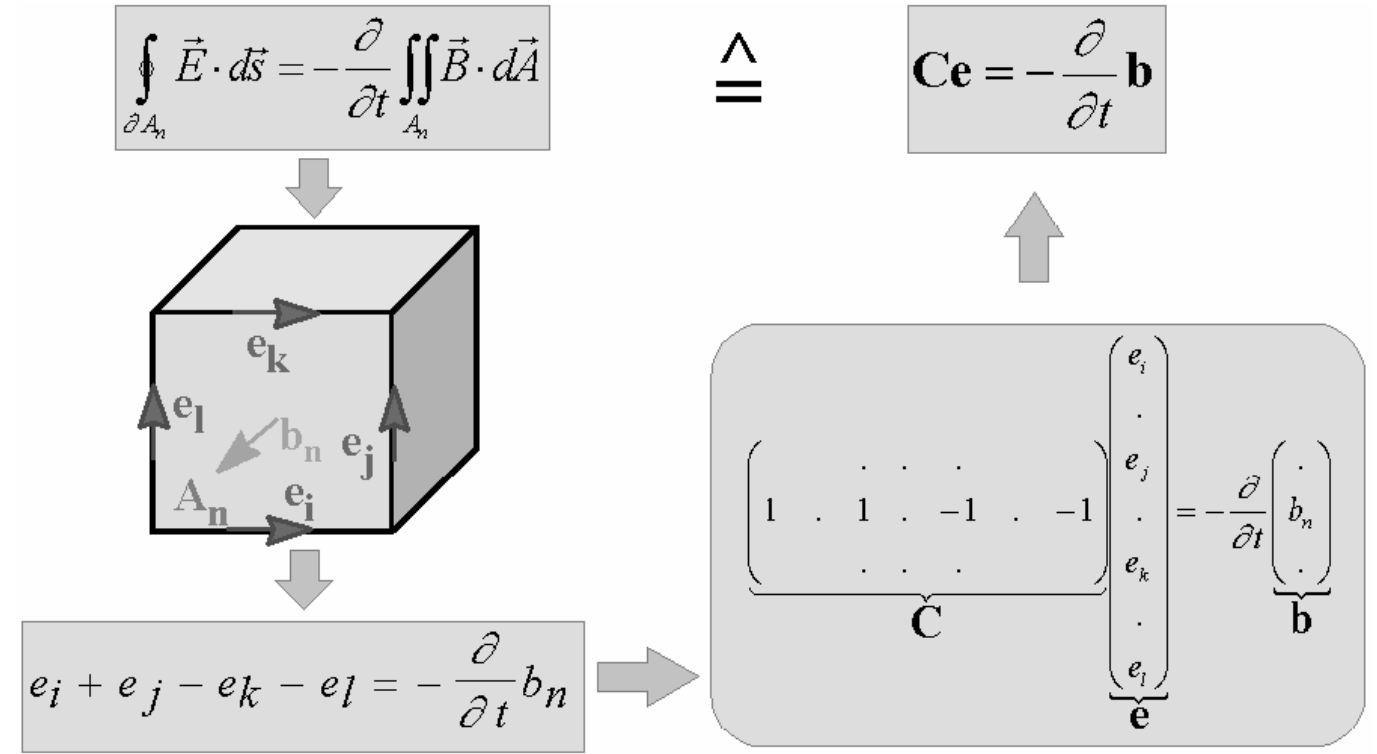

Figura 102 - Exemplo da formulação FIT aplicada a uma única célula, aqui aplicada à Lei de Faraday [93]. 


\section{ANEXO B ABORDAGEM SEMI-ANALÍTICA}

O estudo descrito nesta seção desenvolve uma abordagem semi-analítica do problema da câmara excitada por linhas de transmissão (CELT), como uma seção transversal de um guia de onda infinito preenchido com vácuo e possuindo linhas de transmissão infinitas e paralelas às paredes gerando campos TEM. Esta abordagem foi efetuada Voyer [119].

Na primeira parte, a expressão analítica do modo TEM é derivada a partir das equações de Maxwell. Em seguida, as propriedades da câmara são estudadas tratando-se o problema no plano transverso.

$\mathrm{Na}$ segunda parte, é efetuada uma análise numérica no plano transverso das propriedades intrínsecas de uma linha, seguida do efeito quando conecta-se outras linhas e efetua-se a variação das defasagens das excitações. Mostra-se que introduzir duas linhas TEM e "misturar" o campo, utilizando a defasagem não permite atingir os níveis de uniformidade recomendados nas normas. Por outro lado, mostra-se que, quando possuímos quatro linhas de transmissão, pode-se homogeneizar melhor o campo, e para isso, pode-se variar a fase e/ou a amplitude da excitação.

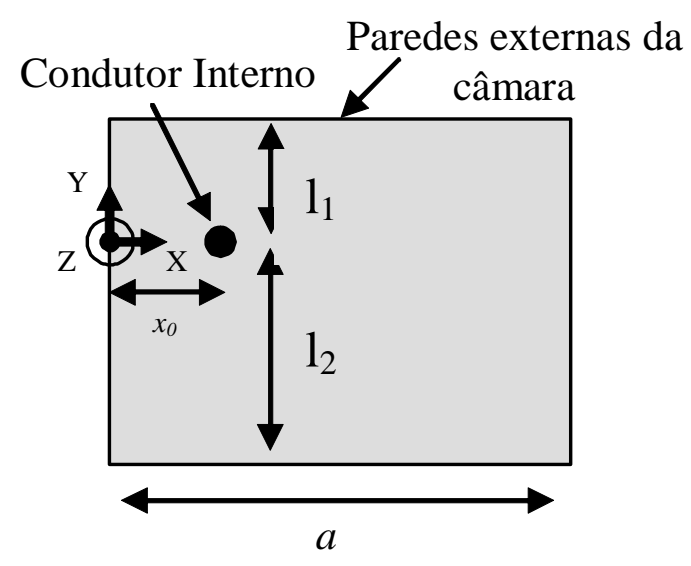

Figura 103 - Geometria no plano xy considerada pelo método analítico.

Inicialmente, supõe-se uma linha de transmissão, que tem geometria invariante na direção do eixo $\{\mathrm{Oz}\}$. O nosso interesse é sobre o modo TEM que é caracterizado pela mesma constante de propagação ko (vácuo). Resolve-se o 
problema analisando-se separadamente os domínios para $y>0$ (região 1) et $y<0$ (região 2).

\section{Região 1}

Para $y>0$, o campo magnético horizontal resultante da excitação do condutor externo é escrito sob a forma de uma série:

$$
H_{X 1}=\sum_{m=1}^{+\infty} \alpha_{1 m} H_{X 1 m}
$$

Com:

$$
H_{X 1 m}(x, y, z)=\sqrt{\frac{2}{a}} \operatorname{sen}\left(\frac{m \pi}{a} x\right)^{\cosh \left(\gamma_{m}\left(y-l_{1}\right)\right) / \cosh \left(\gamma_{m} l_{1}\right)^{e^{-j k_{0} z}}}
$$

Para determinar $\gamma_{m}$, aplica-se a equação de Helmholtz:

$$
\Delta H_{X 1 m}+k_{0}^{2} H_{X 1 m}=0
$$

Substituindo-se:

$$
\left(\left(-\frac{m \pi}{a}\right)^{2}+\gamma_{m}^{2}-k_{0}^{2}\right) H_{X 1 m}+k_{0}^{2} H_{X 1 m}=0=>\gamma_{m}=\frac{m \pi}{a}
$$

O coeficiente de normalização é tal que para $y=0$, tem-se

$$
H_{X 1 m}(x, 0)=\sqrt{\frac{2}{a}} \operatorname{sen}\left(\frac{m \pi}{a} x\right)=f_{m}(x)
$$


Onde, será inserida a dependência em $z:\left\{f_{m}\right.$ para $\left.m=1,2,3, \ldots\right\}$ constitui uma base ortonormal de funções $L_{2}$ que se anulam em $x=0$ e $x=a$.

Da mesma forma, tem-se:

$$
H_{Y 1}=\sum_{m=1}^{+\infty} \alpha_{2 m} H_{Y 1 m}
$$

Com

$$
H_{Y 1 m}(x, y, z)=A_{m} \cos \left(\frac{m \pi}{a} x\right) \operatorname{senh}\left(\frac{m \pi}{a}\left(y-l_{1}\right)\right)
$$

Para determinar $A_{m}$, utiliza-se do fato que, dentro de um meio homogêneo, temse na ausência de fontes magnéticas:

$$
\nabla \cdot \mathbf{H}=0
$$

Rescrevendo:

$$
\frac{\partial H_{X 1 m}}{\partial x}+\frac{\partial H_{Y 1 m}}{\partial x}=0
$$

Derivando:

$$
\left[\frac{\sqrt{\frac{2}{a}}}{\cosh \left(\frac{m \pi}{a} l_{1}\right)}+A_{m}\right] \frac{m \pi}{a} \cos \left(\frac{m \pi}{a} x\right) \cosh \left(\frac{m \pi}{a}\left(y-l_{1}\right)\right)=0
$$




$$
\Rightarrow A_{m}=-\frac{\sqrt{\frac{2}{a}}}{\cosh \left(\frac{m \pi}{a} l_{1}\right)}
$$

Então, o campo magnético é plenamente descrito. Para obtenção do campo elétrico, utiliza-se a equação seguinte, que relaciona o campo elétrico e o campo magnético.

$$
\begin{gathered}
\nabla \times \mathrm{E}=-j \omega \mu_{0} \mathbf{H} \\
-\frac{\partial E_{Y 1 m}}{\partial z}=-j \omega \mu_{0} H_{X 1 m} \text { e }+\frac{\partial E_{X 1 m}}{\partial z}=-j \omega \mu_{0} H_{Y 1 m} \\
E_{Y 1 m}=-\eta_{0} H_{X 1 m} \text { e } E_{X 1 m}=+\eta_{0} H_{Y 1 m}
\end{gathered}
$$

\section{Região 2}

Expandindo-se os campos em séries, tem-se:

$$
\begin{gathered}
H_{X 2}=\sum_{m=1}^{+\infty} \alpha_{2 m} H_{X 2 m} \\
H_{Y 1}=\sum_{m=1}^{+\infty} \alpha_{2 m} H_{Y 2 m} \\
E_{X 2}=+\eta_{0} \sum_{m=1}^{+\infty} \alpha_{2 m} H_{Y 2 m}
\end{gathered}
$$




$$
E_{Y 2}=-\eta_{0} \sum_{m=1}^{+\infty} \alpha_{2 m} H_{X 2 m}
$$

Para obter-se $H_{X 2 m}$ et $H_{Y 2 m}$, utiliza-se o mesmo procedimento anterior, somente trocando $l_{1}$ por $-l_{2}$.

\section{Resolução do problema completo (restrito a uma área)}

Em $y=0$, tem-se as condições de contorno seguintes:

$$
\begin{gathered}
J(x)=H_{X 2}(x, 0)-H_{X 1}(x, 0) \\
E_{X 1}(x, 0)-E_{X 2}(x, 0)=0
\end{gathered}
$$

Onde

$J(x)$ é a densidade de corrente dentro do condutor central.

Projetando-se a equação (121) sobre as funções da base $\left\{f_{m}\right.$ para $\left.m=1,2,3, \ldots\right\}$ :

$$
J_{m}=\left\langle J, f_{m}\right\rangle=\left\langle H_{X 2}-H_{X 1}, f_{m}\right\rangle=\alpha_{2 m}-\alpha_{1 m}
$$

Onde

$$
\langle u, v\rangle=\int_{0}^{a} u(x) v(x) d x
$$

Introduz-se, em seguida, a base $\left\{g_{m}\right.$ para $\left.m=1,2,3, \ldots\right\}$, tal que: 


$$
g_{m}=\sqrt{\frac{2}{a}} \cos \left(\frac{m \pi}{a} x\right)
$$

Projeta-se, então, a equação (121) sobre as funções da base $\left\{g_{m}\right.$ para $\left.m=1,2,3, \ldots\right\}$

$$
\left\langle E_{X 1}-E_{X 2}, g_{m}\right\rangle=\eta_{0} \alpha_{1 m} \tanh \left(\frac{m \pi}{a} l_{1}\right)+\eta_{0} \alpha_{2 m} \tanh \left(\frac{m \pi}{a} l_{2}\right)=0
$$

De onde vem:

$$
\begin{aligned}
& \alpha_{1 m}=-J_{m} \frac{\tanh \left(\frac{m \pi}{a} l_{2}\right)}{\tanh \left(\frac{m \pi}{a} l_{1}\right)+\tanh \left(\frac{m \pi}{a} l_{2}\right)} \\
& \alpha_{2 m}=+J_{m} \frac{\tanh \left(\frac{m \pi}{a} l_{1}\right)}{\tanh \left(\frac{m \pi}{a} l_{1}\right)+\tanh \left(\frac{m \pi}{a} l_{2}\right)}
\end{aligned}
$$

O campo elétrico é escrito explicitamente sob a forma:

- para $y>0$

$$
E_{X 1}=\frac{-\eta_{0} \sum_{m=1}^{+\infty} \alpha_{1 m} \sqrt{\frac{2}{a}} \operatorname{sen}\left(\frac{m \pi}{a} x\right)^{\cosh \left(\frac{m \pi}{a}\left(y-l_{1}\right)\right)}}{\cosh \left(\frac{m \pi}{a} l_{1}\right)}
$$




$$
E_{Y 1}=\frac{-\eta_{0} \sum_{m=1}^{+\infty} \alpha_{1 m} \sqrt{\frac{2}{a}} \cos \left(\frac{m \pi}{a} x\right)^{\operatorname{senh}\left(\frac{m \pi}{a}\left(y-l_{1}\right)\right)}}{\cosh \left(\frac{m \pi}{a} l_{1}\right)}
$$

- para $y<0$

$$
\begin{gathered}
E_{X 2}=\frac{-\eta_{0} \sum_{m=1}^{+\infty} \alpha_{2 m} \sqrt{\frac{2}{a}} \cos \left(\frac{m \pi}{a} x\right)^{\operatorname{senh}\left(\frac{m \pi}{a}\left(y+l_{2}\right)\right)}}{\cosh \left(\frac{m \pi}{a} l_{2}\right)} \\
E_{Y 2}=\frac{-\eta_{0} \sum_{m=1}^{+\infty} \alpha_{2 m} \sqrt{\frac{2}{a}} \operatorname{sen}\left(\frac{m \pi}{a} x\right)^{\cosh \left(\frac{m \pi}{a}\left(y+l_{2}\right)\right)}}{\cosh \left(\frac{m \pi}{a} l_{2}\right)}
\end{gathered}
$$

Ressalta-se que, por um lado, a solução não depende da frequência e que, por outro lado, que ela não faz aparecer singularidades ligada à eventuais ressonâncias (contrariamente à solução obtida no caso de mistura de modos [70]).

No caso ideal, o condutor central pode ser reduzido a um fio infinitamente fino, resultando em:

$$
J(x)=I_{0} \delta\left(x-x_{0}\right)
$$

De onde, deduz-se que:

$$
J_{m}=I_{0} \sqrt{\frac{2}{a}} \operatorname{sen}\left(\frac{m \pi}{a} x_{0}\right)
$$


No entanto, esta solução conduz a uma convergência lenta das séries no contexto dos cálculo numéricos do campo elétrico. Então, é preferível tomar-se uma chapa infinitamente fina de largura $b<<a$ para facilitar os cálculos e diminuir 0 tempo de convergência.

Assim, com

$$
J(x)=\mid \begin{array}{cc}
J_{0} & x \in\left[x_{0}, x_{0}+b\right] \\
0 & x \notin\left[x_{0}, x_{0}+b\right]
\end{array}
$$

Obtendo-se :

$$
J_{m}=J_{0} \sqrt{\frac{2}{a}} \frac{a}{m \pi}\left[\cos \left(\frac{m \pi}{a} x_{0}\right)-\cos \left(\frac{m \pi}{a}\left(x_{0}+b\right)\right)\right]
$$

Assim, aparece um termo em $1 / m$ que acelera a convergência das séries.

\section{B.1 Resultados Semi-analíticos}

Esta seção apresenta os resultados da análise numérica das expressões analíticas do campo E calculado no plano transverso (plano xy), aqui sumariamente reproduzidos, para uma, duas e finalmente quatro linhas de transmissão. Estes resultados são apresentados na Tabela 11 e foram utilizadas de ponto de partida para as comparações com as simulações numéricas tridimensionais desenvolvidas neste trabalho.

Considerando as dimensões da seção reta da câmara no plano xy ( $a=60 \mathrm{~cm}$ and $\left.l_{1}+l_{2}=60 \mathrm{~cm}\right)$, calculou-se várias configurações de câmaras, com uma, duas, três e quatro linhas de transmissão, aplicando-se a defasagem na excitação e também sem defasagem na excitação, incluindo outras estratégias de excitação, tais como excitar cada linha de transmissão somente $50 \%$ do tempo e outras. 
A área de trabalho foi definida como $0.15<x<0.45$ e $-0.45<y<-0.15$. O campo $\mathrm{E}$ médio $(\bar{E})$ e o desvio padrão $(\sigma)$ são calculados através das equações $(78)$ a $(80)$ para a abordagem determinística. Para a abordagem estatística as equações (82) a (81) são aplicadas. Os resultados da avaliação em bidimensionais, considerando a frequência $80 \mathrm{MHz}$, são apresentados na Tabela 11.

Tabela 11 - Resultados de desvios padrão para método semi-analítico

\begin{tabular}{|c|c|c|c|c|}
\hline Configuração & & $\begin{array}{l}\text { Des } \\
\text { (dB }\end{array}$ & & padrão \\
\hline $\begin{array}{l}\text { Quantidade } \\
\text { de Linhas de } \\
\text { Transmissão }\end{array}$ & Defasagem & $\overline{\hat{\sigma}_{x}}$ & $\hat{\sigma}_{y}$ & $\hat{\hat{\sigma}_{x, y}}$ \\
\hline 1 & ------ & 5.7 & 6.0 & 5.9 \\
\hline 2 & Não & 6.5 & 3.3 & 5.3 \\
\hline 2 & Sim & 6.4 & 2.0 & 5.0 \\
\hline 4 & Sim & 3.2 & 3.2 & 3.3 \\
\hline 4 & Aleatória & 2.8 & 2.6 & 2.8 \\
\hline
\end{tabular}

Portanto, nota-se nesta abordagem semi-analítica, que a melhor uniformidade seria atingida para uma configuração com quatro condutores excitados alternadamente com valores aleatórios (tanto de amplitude quanto de defasagens). Mas, ressalta-se que esta é uma avaliação preliminar, sem a consideração do eixo z, ou seja, trata-se de uma avaliação somente no plano xy. 